\title{
Illegal Residence and
}

Public Safety in

\section{the Netherlands}

ARJEN LEERKES 
Illegal Residence and Public Safety in the Netherlands 


\section{IMISCOE \\ International Migration, Integration and Social Cohesion}

The IMISCOE Network of Excellence unites over 500 researchers from European institutes specialising in studies of international migration, integration and social cohesion. The Network is funded by the Sixth Framework Programme of the European Commission on Research, Citizens and Governance in a Knowledge-Based Society. Since its foundation in 2004, IMISCOE has developed an integrated, multidisciplinary and globally comparative research project led by scholars from all branches of the economic and social sciences, the humanities and law. The Network both furthers existing studies and pioneers new research in migration as a discipline. Priority is also given to promoting innovative lines of inquiry key to European policymaking and governance.

The IMISCOE-Amsterdam University Press Series was created to make the Network's findings and results available to researchers, policymakers and practitioners, the media and other interested stakeholders. Highquality manuscripts authored by IMISCOE members and cooperating partners are published in one of four distinct series.

IMISCOE Research advances sound empirical and theoretical scholarship addressing themes within IMISCOE's mandated fields of study.

IMISCOE Reports disseminates Network papers and presentations of a time-sensitive nature in book form.

IMISCOE Dissertations presents select PhD monographs written by IMISCOE doctoral candidates.

IMISCOE Textbooks produces manuals, handbooks and other didactic tools for instructors and students of migration studies.

IMISCOE Policy Briefs and more information on the Network can be found at www.imiscoe.org. 


\section{Illegal Residence and Public Safety in the Netherlands}

Arjen Leerkes

IMISCOE Dissertations

AMSTERDAM UNIVERSITY PRESS 
Cover design: Studio Jan de Boer BNo, Amsterdam Layout: The DocWorkers, Almere

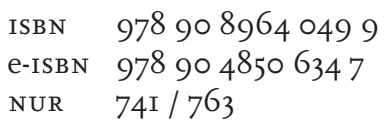

(C) Arjen Leerkes / Amsterdam University Press, Amsterdam 2009

All rights reserved. Without limiting the rights under copyright reserved above, no part of this book may be reproduced, stored in or introduced into a retrieval system, or transmitted, in any form or by any means (electronic, mechanical, photocopying, recording or otherwise) without the written permission of both the copyright owner and the author of the book. 


\section{Table of contents}

$\begin{array}{ll}\text { List of tables } & 7\end{array}$

List of figures 9

$\begin{array}{ll}\text { Preface and acknowledgements } & \text { II }\end{array}$

I Introduction $\quad$ I5

Brief outline of the research problem I5

Previous research and the contribution of the study I7

Specification of the research questions 22

The study's relevance for other countries $3 \mathrm{I}$

Definition of terms $\quad 33$

Ethical aspects $\quad 37$

Data sources $\quad 39$

Preview of the following chapters 40

PART 1 The ECOLOGy OF ILLEGAL RESIDENCE

2 Shadow places $\quad 45$

Introduction $\quad 45$

Opportunity structure: spatial aspects $\quad 46$

Research methods $\quad 48$

Results $\quad 50$

$\begin{array}{ll}\text { Concluding remarks } & 68\end{array}$

3 Against state rules against street rules? 73

$\begin{array}{ll}\text { Introduction } & 73\end{array}$

Theoretical starting points $\quad 75$

Data and analytical strategy 80

$\begin{array}{ll}\text { Quantitative findings } & 87\end{array}$

Illegal residence and neighbourhood safety in Bospolder-

$\begin{array}{lr}\text { Concluding remarks } & \text { I05 }\end{array}$ 


\section{PART 2 ILlegal RESIDENCE AND CRIME}

$4 \quad$ Embedded crimes? III

Introduction III

The differential opportunity structure $\quad$ II2

Data and research method II4

The 'quantity' of criminality $\quad$ II6

The 'quality' of criminality $\quad$ I20

Theoretical implications $\quad$ I23

$\begin{array}{ll}\text { Concluding remarks } & \text { I26 }\end{array}$

Coda $\quad$ I28

5 'I am just trying to live my life'

$\begin{array}{ll}\text { Introduction } & \text { I29 }\end{array}$

Previous findings and theory $\quad$ I30

Research method $\quad 132$

Respondent characteristics $\quad$ I36

Towards a typology of crime among illegal migrants $\quad$ I37

$\begin{array}{ll}\text { Criminal antecedents } & \text { I49 }\end{array}$

Theoretical interpretation $\quad$ I50

$\begin{array}{ll}\text { Concluding remarks } & \text { I54 }\end{array}$

6 The rise in crime $\quad$ I59

Introduction $\quad$ I59

Specification of the alternative hypotheses $\quad$ I6I

Data sources, research method and validity $\quad \mathrm{I}_{5}$

Testing the alternative hypotheses: results $\quad$ I70

$\begin{array}{ll}\text { Concluding remarks } & \text { I79 }\end{array}$

7 Conclusions and discussion $\quad$ I83

$\begin{array}{ll}\text { Theoretical conclusions } & \text { I83 }\end{array}$

Implications for policy $\quad 194$

$\begin{array}{ll}\text { Notes } & \text { 2OI }\end{array}$

References 213

Summary $23 \mathrm{I}$

Samenvatting (summary in Dutch) 239 


\section{List of tables}

Table 2.I Urban neighbourhoods with the highest absolute concentration of illegal residence

Table 2.2 Determinants of the relative concentration of illegal immigrants

Table 3.I Descriptive statistics

Table 3.2 Non-standardised effects of the rate of illegal residence on six measures of subjective safety

Table 3.3 Non-standardised effects on six measures of subjective neighbourhood safety: Full model IV

Table 3.4 Standardised effects of the rate of illegal residence on residents' within-neighbourhood victimisation rates

Table 3.5 Other standardised effects on residents' withinneighbourhood victimisation rates: Full model III

Table 3.6 Neighbourhood-related 'causes' of unsafe feelings and discomfort amongst IoI residents in BospolderTussendijken and De Schilderswijk

Table 3.7 Perceptions on illegal immigrants in BospolderTussendijken and De Schilderswijk by having contact with illegal immigrants

Table 4.I 'Legal' suspects by country of birth and the corresponding group population sizes as a whole (aged I8-24, I999 and 2000)

Table 4.2 Reasons for apprehension of illegal immigrants (aged I824, I998-200I)

Table 4.3 Correlation coefficients between crime rates among legal and illegal immigrants (aged i8-24) in eleven 'ethnic' groups; I999-2000 (legal immigrants) and I998-200I (illegal immigrants)

Table 4.4 Types of offences committed by 'legal' and 'illegal' crime suspects (aged I2-24); I999-2000 (legal immigrants) and I998-200 (illegal immigrants)

Table 5.I Respondent characteristics

Table 5.2 Overview of convictions and some pending cases per respondent 
Table 6.I Crime suspects among (non-EU) illegal migrants and legal migrants (I997-2003)

Table 6.2 Undesirable alien resolutions and (other) residence terminations, non-EU nationals (I997-2003)

Table 6.3 Crime suspects among (non-EU) illegal migrants after controlling for alternative hypotheses (I997-2003)

Table 6.4 Number of (non-EU) crime suspects with illegal residence status, apprehended at least once for a crime within three months of arrival (1997-2003)

Table 6.5 Total number of crime suspects in the Netherlands (I9972003) 


\section{List of figures}

Figure 2.I Spatial distribution of the illegal population across the Netherlands (absolute concentration)

Figure 2.2 Spatial distribution of the illegal population across the Netherlands (relative concentration)

Figure 2.3 Extent of residential segregation between the illegal population and (segments of) the regular population

Figure 2.4 Distribution of Turks across The Hague

Figure 2.5 Distribution of Moroccans across The Hague

Figure 2.6 Distribution of Eastern Europeans across The Hague

Figure 2.7 Predicted relative concentration in comparison with measured relative concentration

Figure 4.I Crime rate among legal immigrants compared to crime rate indicators for illegally residing countrymen aged I824; I999-2000 (legal immigrants), I998-200I (illegal immigrants)

Diagram 5.I A typology of crime among illegal immigrants: convictions and self-reported offences

Figure 6.I Relative developments in the estimated number of illegal migrants from Eastern Europe and other (non-EU) illegal migrants 



\section{Preface and acknowledgements}

Via a Master's thesis on socially responsible business and a report on illegal bingo in Amsterdam, I ended up in crime. Kees Schuyt, who supervised my Master's thesis, asked me to assist Marion van San with her study on 'crime and criminalisation of immigrant youth in Belgium'. I then conducted commercial policy research at Regioplan and tried to mend my ways by researching the transnational orientations of migrants as part of a project at the Erasmus University of Rotterdam. But, as it often goes in crime, I recidivated. During the Rotterdam project I wrote a $\mathrm{PhD}$ research proposal about illegal residence and crime in the Netherlands and Belgium. On the basis of that proposal I was accepted as a PhD candidate at the Amsterdam School for Social Science Research (ASSR) at the University of Amsterdam. Although that international comparison turned out to be unattainable, given time limitations, I believe my study gives a rich analysis of the Dutch situation - richer than I initially considered possible.

Eventually it grew into more than a study of crime. In this book I also go into other forms of rule transgression and observance that are important for public safety, particularly for its more subjective aspects such as fear of crime. Further, I became interested in the spatial component of my research problem: In what type of neighbourhoods do illegal migrants live, and why? To what extent and under what conditions does the presence of these migrants have positive or negative consequences for the safety and viability of the neighbourhoods concerned? Finally, I became interested in the possibility that migration and illegal residence might bring about new care arrangements for the poor in countries of destination like the Netherlands. At some point I wanted to bring that thought, which I have taken from Bram de Swaan, to the centre of my research topic. My supervisor, Godfried Engbersen, did not think this was a good idea, so I decided to serve it as a dessert in the section 'implications for policy' in the concluding chapter. (Researching is also negotiating.) I hope the study is of interest to a broad audience in the Netherlands and elsewhere. 
Doing a PhD is generally seen as a solo enterprise. In that respect I was pleasantly surprised. At the ASSR I met many other PhD students and within that research school smaller sub-schools continually emerged with whom I could swim along in various ways. I followed and organised courses with them, taught, formed reading and PhD groups and organised activities with them such as a conference about the municipal elections. With some of my PhD colleagues I regularly had a sandwich or a beer; with others I went skiing or shared activities like keeping fit or salsa dancing. I would like to thank the following people in particular for making the past few years more interesting and fun than they would otherwise have been: Floris Noordhoff, Josien de Klerk, Gerben Korthouwer, Ward Berenschot, Corina Hendriks, Eelke Heemskerk, Deasy Simandjuntak, Hester Houwing, Daniel Reijer, Peter van der Graaff, Sjoukje Botman, Christian Bröer, Justus Uitermark, Jill Alpes and Imrat Verhoeven. Furthermore, I would like to thank staff members José Komen, Hans Sonneveld, Miriam May, Teun Bijvoet, Anneke Dammers and Hermance Mettrop. During my research they made great efforts behind the scenes, to the benefit of the research, as did the women and men of the faculty library.

In my own research I sought out cooperation both inside and outside the ASSR. In recent years I have worked and written with the following people: Godfried Engbersen, Marion van San, Wim Bernasco, Erik Snel, Jan de Boom, Joanne van der Leun and Jack Burgers. My experience with them all was stimulating and I would like to warmly thank them.

I am grateful to IMISCOE for giving me the opportunity to publish this book in the IMISCOE-AUP Dissertation Series. Several other institutions and individuals have contributed to my study, financially or otherwise. I would like to express my gratitude in particular to the Ministry of Housing, the Ministry of Justice, the research programme Politie en Wetenschap ('Police and Science'), the Central Bureau for Statistics, the Dutch police forces, the Taakorganisatie Vreemdelingen Zorg ('TaskOrganisation Alien Care'), staff members of the Immigration and Naturalisation Service (particularly the research department INDIAC), the Aliens' Detention department at Tilburg prison, editorial staff and referees of the journals Urban Studies, The Netherlands' Journal of Social Sciences, Mens \& Maatschappij, Sociologie, Migrantenstudies, the municipalities of Rotterdam, The Hague and Amsterdam (Simon Bontekoning), researchers of the European IMISCOE network, 'my' sociology students at the University of Amsterdam, the Landelijk Ongedocumenteerden Steunpunt ('National Support Point for the Undocumented') (Rian Ederveen), residents of the Bospolder-Tussendijken neighbourhood in the city of Rotterdam and the De Schilderswijk neighbourhood in the city of The Hague and various employees of local housing corporations and neighbourhood centres. I would like to thank Johan Goudsblom for 
his comments regarding Chapters I and 7. Zoe Goldstein and Rowan Hewison corrected my English, for which I am grateful. Rowan also polished the manuscript before publication.

I would like to pause specifically to remember the migrants who have cooperated with this research, for which I am very grateful. They may have had little to gain from it. I have tried to describe their experiences and life stories conscientiously.

The fellow craftsman I have worked with most over the last few years, and from whom I have certainly learned most, is Godfried Engbersen. For a PhD student it must be a great privilege to receive a call from your supervisor on a Monday morning, checking whether you might be back from your holidays. Sometimes I had to reach a compromise, but there was always more than enough space for my own contribution. The cooperation was stimulating and pleasant, and if that did not happen to be the case on one occasion, we solved it very well. Many thanks.

The communis opinio wants us to keep work and private matters separate, but of course they have influenced each other, usually in a positive sense: when things were going well privately, they had a favourable effect on my work, and vice versa. And when they did not go so well, either privately or at work - or both - fortunately my dear friends, family (Ton, Ineke, Sander, thank you), music pals, sports pals and dance pals were there for me too.

Dear Tessa, three years ago we first danced with each other. That was no crime, it was love!

\section{Underlying publications}

This book is an edited version of the dissertation I defended at the University of Amsterdam in December 2007. It was assessed by a committee made up of Godfried Engbersen (Full Professor in Sociology at the Erasmus University Rotterdam), Catrien Bijleveld (Full Professor in Criminology at the Vrije University Amsterdam), Jack Burgers (Full Professor in Urban Sociology at the Erasmus University Rotterdam), JanWillem Duyvendak (Full Professor in Sociology at the University of Amsterdam), Sako Musterd (Full Professor in Human Geography at the University of Amsterdam), Jan Rath (Full Professor in Sociology and Migration Studies at the University of Amsterdam) and Bram de Swaan (Emeritus Professor in Sociology at the University of Amsterdam). In the summer of 2008 the manuscript was revised on the basis of very valuable feedback from the IMISCOE Editorial Committee.

Chapter 2 is a somewhat adapted version of A. Leerkes, G. Engbersen and M. Van San (2007) 'Shadow Places. Patterns of Spatial Concentration and Incorporation of Irregular Immigrants in the Netherlands', Urban Studies, 44 (8): I49I-I5I6. A Dutch version was published as A. 
Leerkes, G. Engbersen and M. Van San (2006) 'Schaduwplaatsen. Patronen van ruimtelijke concentratie en incorporatie van illegale migranten in Nederland', Mens \& Maatschappij, 8I (3): 223-25I.

Chapter 3 is an English adaptation of A. Leerkes and W. Bernasco (2007) 'Tegen de wetten van de staat, tegen de wetten van de straat? Illegaal verblijf en veiligheid in Nederlandse stadsbuurten', Sociologie, 3 (2): I68-204. A shorter and adapted version has been submitted to Urban Affairs.

Chapter 4 is a revised and somewhat more detailed version of A. Leerkes (2004) 'Embedded Crimes. On the overlapping patterns of delinquency among legal and illegal immigrants in the Netherlands', The Netherlands' Journal of Social Sciences, 40 (I): 3-23.

Chapter 5 is an English version of A. Leerkes (2007) "I am just trying to live my life." Statusdilemma's en criminaliteit bij illegale migranten met een asielachtergrond', Migrantenstudies, 23 (3): I80-206. A preliminary report, with less theory and more interview fragments, has been published as A. Leerkes (2006) 'Ik probeer alleen maar mijn leven te leven'. Uitgeprocedeerde asielzoekers en criminaliteit. Apeldoorn / The Hague: Politie en Wetenschap / Elsevier.

An adapted version of Chapter 6 has been submitted to Punishment a Society. 


\section{Introduction}

\section{Brief outline of the research problem}

Since the I970s the Netherlands and other Western ${ }^{\mathrm{I}}$ countries have increasingly implemented restrictive immigration policies for people from non-Western countries. At present such persons have to meet numerous conditions if they want to live in or merely visit Western countries. Many Western countries have developed policies intended to discourage such migrants from settling without government consent. The Netherlands seeks to accomplish this to a large degree by systematically excluding them from formal institutions such as the official labour market, social security and public housing (Engbersen \& Van der Leun 200I). Spain and Greece, which previously did not set out to make illegal residence unattractive (and frequently even legalised segments of their illegal population), have recently begun adopting or proposing additional restrictive measures (Anderson 2000; Kyle \& Siracusa 2005).

As a result, in recent decades the new social figure of the 'illegal migrant' has proliferated in the Western world. Although there were illegal migrants before the I970s, particularly in the United States (Ngai 2004), their number appears to have increased in spite of (and indeed owing to) current restrictive immigration politics (Doomernik 200I). Moreover, under the influence of these policies, illegal migrants have come to occupy a more clearly identifiable social position in comparison to legally residing inhabitants, including migrants with permission to remain. From a sociological perspective illegal migrants can increasingly be viewed as a class, a set of people with a more or less comparable social position (Lenski I994; Bourdieu I990: 59). In that capacity the phenomenon deserves specific social scientific study (cf. Engbersen I997).

The extent of illegal residence, while modest, is significant. In the Netherlands, a country of some 16 million registered inhabitants and I.6 million first-generation immigrants, approximately I per cent of the population was estimated to be illegal during the research period (I9972005) (Engbersen et al. 2002; Leerkes et al. 2004). ${ }^{2}$ Hence, about one in ten first-generation migrants appears to be illegal. The phenomenon is 
concentrated in certain agricultural areas and deprived urban neighbourhoods. In some urban neighbourhoods the figure is probably more like 6 to 8 per cent (Leerkes et al. 2004). It is assumed that the proportion may be greater in countries that have a larger informal economy than the Netherlands. Estimates of illegal residence in the United States range from 3.4 million (Espenshade I995) to 9 million (Martin 2004: 60), or I. 5 to 3.0 per cent of the total population, while in Italy, which only recently became a country of immigration, there are proportionally fewer immigrants than in the Netherlands though a greater percentage of them is illegal (Castles \& Miller 2003: 83). ${ }^{3}$ Substantial numbers of illegal migrants are also present in transit countries such as Turkey, Russia, Mexico and Malaysia (Schoenhardt 200I; Bade 2004).

Illegal migrants in the Netherlands originate from more than 200 countries. The largest groups are Turks, Moroccans, Algerians and Surinamese followed by a substantial number from Eastern and Central Europe, many of whom came to the Netherlands on tourist visas and overstayed, while others crossed the border illegally or became illegal migrants when they were refused refugee status (Burgers and Engbersen 1999; Staring 200I). Refused asylum seekers are estimated to constitute I5 per cent of the illegal population in the Netherlands (De Boom et al. 2006).

Social scientists have begun to wonder how such sizable groups can exist in contemporary societies despite the legal prohibition on their presence. Some obvious further questions bear upon the social consequences of illegal residence for the countries of destination. For example, what are the consequences for the labour market, economic development or public health? This study addresses the question of the extent to which the state's efforts to implement the social exclusion of in its view - unwanted migrants has consequences for public safety, with reference in particular to the neighbourhoods where illegal residence tends to become spatially concentrated.

There are two main reasons for taking up the relationship between illegal migration and public safety as a theme. First, the state's drive towards social exclusion makes it harder for unwanted migrants to migrate in a regular way. Migrants who nonetheless manage to settle have limited conventional livelihood opportunities, particularly in a country like the Netherlands with its policy of excluding such migrants from formal institutions. It is conceivable that this drive towards social exclusion encourages them to become involved in alternative and illegal means of migration and subsistence. Second, it might be assumed that the precarious social position of illegal migrants constitutes, at the same time, an impediment to rule transgression; might not the illegal residence status contribute to social pressure to comply with rules as much as possible, 
in order to minimise the chances of police contacts and, consequently, detention and expulsion?

Here, then, in a few brief sentences, one has the research problem, or issue, that this study tries to answer. The book encompasses five substudies, the results of which were initially reported in four separate articles and one - at the time of writing - unpublished paper. All five pieces have been edited for publication in this book, but their basic structure was preserved for reasons of time and efficiency. As a consequence, this introductory chapter, which discusses aspects that are often spread over several chapters, is longer than is the rule in social science dissertations. It elaborates on the research problem of the study in the light of previous research in the field and provides an explanation of immigration policy in the Netherlands, as well as a number of other characteristics of Dutch society that are required for a good understanding of the book. It also addresses the relevance of this study for other destination countries in Europe and North America, while some ethical aspects of studying illegal residence in relation to public safety are also discussed. The chapter ends with a brief explanation of why this dissertation was based on substudies and a brief outline of the five sub-studies and the data sources on which they were based. Chapter 8 summarises the main conclusions of the study as a whole.

\section{Previous research and the contribution of the study}

\section{Research on illegal migration and crime}

Research on the relationship between migration and crime has a long tradition in the social sciences, particularly in the United States (Thomas \& Znaniecki I9I8; Shaw \& McKay I942). Research is currently being carried out in several countries (Tonry I997; De Haan-Marshall I997; Waters I999; Van San \& Leerkes 200I). The taboo surrounding such research in social scientific circles after the Second World War was broken in the Netherlands during the I970s, although it has remained a sensitive topic. ${ }^{4}$

Dutch researchers have always focused on groups that the police and wider society associated with crime at that particular time..$^{5}$ Initially, this concerned mostly Indonesian youth from the Moluccas (Buikhuisen \& Timmermans 197I) and drug dealers of Creole Surinamese origin (Van Amersfoort \& Biervliet 1977). Attention later shifted to second-generation Moroccans and Antilleans (Van Gemert 1998; Van San 1998) and attention is now being paid to the latest migration flows, in particular from Africa and Central and Eastern Europe (Snel et al. 2000; Kromhout \& Van San 2003; De Boom, Engbersen \& Leerkes 2006). 
Almost all national and international criminological research pertains to migrant groups with legal residence. In the Netherlands, particularly, this has changed since the mid-I990s. In I995 an exploratory study was published (Engbersen, Van der Leun \& Willems 1995) in which researchers described the - to quote the study's subtitle - 'interweaving of illegality and crime', based on police data for Rotterdam. This publication was the prelude to an extensive and more encompassing study of the social position of illegal migrants in the Netherlands, paying special attention to the situation in Amsterdam, Rotterdam and Utrecht (Burgers \& Engbersen 1999; Engbersen 1999; Staring 200I; Engbersen et al. 2002; Van der Leun 2003). In this research programme crime remained a central topic, alongside other sociological themes such as labour, housing and health care.

Outside the Netherlands research on the relation between illegality and criminality was and remains scarce (exceptions are: Wolf I988; Scalia I996, 2002; McDonald 1997; Alt 1999; Van Meeteren, Van San \& Engbersen 2008), though in a number of studies the topic is addressed indirectly (Mahler 1995; Grabosky \& Smith 200I). ${ }^{6}$ Foreign research mostly focuses on illegal residence in connection with labour (see for instance Cornelius et al. 2004). Criminologists are mostly occupied with human smuggling and with victimisation within specific groups of illegal migrants after settlement, predominantly in connection with the trafficking of women (cf. Goodey 2003).

When I started this study in 2003 the interest in illegal residence within Dutch sociology had already led to some theory formation about the relationship between illegality and crime. On the one hand, it was assumed that illegal residence status curbs criminality (see Van der Leun 2003); illegal migrants were assumed to have greater reason to shun police contacts than legally resident inhabitants because of the risk of expulsion. There were, however, no concrete empirical indications for this 'deterrence thesis', except for the broad observation that a minority of all apprehended illegal migrants had police contacts because of crimes, while the ones who did were suspected of less serious crimes than criminally involved immigrants with legal residence status (Engbersen \& Van der Leun 2001: 58-59).

On the other hand, there were indications that such criminality as did occur was a response to the sometimes very marginal social position of specific groups of illegal migrants. Thus it was proposed that some of them commit 'survival crime', supposedly as a result of their failure to achieve an 'integrated career' (Engbersen \& Van der Leun I995: 254). This latter supposition was known as the 'marginalisation thesis'.

The researchers stressed that not all immigrants who lacked a residence permit had an equally marginal position. The observed patterns pointed to the existence of a 'differential opportunity structure' (cf. Clo- 
ward \& Ohlin 1960) with three dimensions, defined by the degree of access to: (i) formal institutions of the welfare state such as the formal labour market and social security, (ii) informal institutions like the informal economy and a network of family, friends and acquaintances in the Netherlands and (iii) criminal circuits. Involvement in crime would mostly develop in groups with little or no access to formal and informal institutions. Possible access to criminal institutions would bring a number of somewhat more organised offences, such as involvement in the drug trade, within the reach of illegal migrants.

These theoretical suppositions rested on three important empirical findings. First, substantial differences were observed according to nationality. In Rotterdam, no more than 4 per cent of illegal Turkish immigrants apprehended turned out to have come into contact with the police because of criminal activity. For Eastern Europeans, Algerians and Moroccans these percentages were 32, 54 and 65, respectively (Engbersen \& Van der Leun 1995). On the basis of the qualitative fieldwork, this variation was attributed to differences rooted in nationality with respect to social and particularly ethnic ties. In some publications these ties are referred to as 'relational embeddedness' or 'social capital'.

It became apparent that many illegal migrants from Turkey were supported by established Turkish migrant communities in the Netherlands. The established Turks increased access to formal institutions in informal ways, for instance, by lending out health insurance cards, as well as to informal institutions, for instance, by arranging informal work in Turkish shops. To a great extent, the illegal migration of Turks had the characteristics of directed chain migration; many newcomers turned out to know beforehand where they were going to reside and possibly where they would work (Staring 200I). Among groups receiving less support from established countrymen - such as asylum seekers who have exhausted all legal remedies as well as 'pioneers' from Eastern Europe there was a greater occurrence of improvised migration patterns; migration 'on the off chance'.

Among North African illegal migrants, crime turned out to be relatively high, even though there are many established Moroccans in the Netherlands. The researchers attributed this apparent discrepancy to the fragmented nature of the Moroccan migrant community, which they assumed diminished its potential as a source of social capital (cf. Van Gemert 1998). In addition, there turned out to be life chances in the lower echelons of the Rotterdam drug circuits for North African illegal migrants to the degree that they speak French: in the I99os there was a lively street trade in the harbour city for the benefit of French and Belgian 'drug tourists'. They were (and to a lesser degree still are) drawn by the favourable price-quality relationship of hard drugs. In the illegal economy too, the Netherlands is Europe's 'mainport' (Zaitch 2002). 
The second empirical observation was also gathered during fieldwork in Rotterdam (Burgers \& Engbersen 1999). The researchers interviewed I65 illegal migrants and observed that respondents with families and permanent residence in the Netherlands reported involvement in crime less frequently than did homeless illegal migrants who lacked kin in the Netherlands (Burgers \& Engbersen I999: 255).

The third empirical observation was based on police data concerning all illegal migrants apprehended in the Netherlands between I997 and 2000. While in 1997 suspicions of minor crimes - crimes punishable with less than four years of imprisonment ${ }^{7}-$ accounted for 18.5 per cent of apprehensions, this percentage had grown to 28.2 by 2000 (Engbersen et al. 2002). In the same period, the Dutch government made increasing efforts to make illegal residence unattractive (see below in the section on the rise of internal border control), tightening the exclusion from formal institutions of migrants without residence permits.

\section{Housing and spatial spreading}

In the I990s Burgers (1998), in particular, delved into the subject of the housing situation among illegal migrants. On the basis of fieldwork in Rotterdam and with the help of Mahler's (I995) insights for the US, Burgers pointed to the existence of 'parallel housing markets' in Dutch neighbourhoods, i.e. informal markets that show much similarity to the formal housing market. Rents in rent-controlled social housing in the Netherlands tend to be below market prices because of rental price regulation. This makes it easier for legal residents to offer cheap sublets of their apartments (or sections thereof) to family or acquaintances who happen to be illegal migrants, or to offer them free accommodation in the apartment altogether. At the same time, Burgers found a commercial, more private housing sector where illegal migrants could find higher priced accommodation.

Using police data, Van der Leun (2003: 7I) conducted an exploratory quantitative study of the spatial concentration of illegal residence in Rotterdam. The registered residential addresses of apprehended illegal migrants suggested a substantial over-representation in deprived neighbourhoods. It turned out that more than 60 per cent of the registered addresses were located in three areas, or boroughs, whereas only a third of the legal urban population lived in these three areas. Van der Leun explained this spatial concentration as reflecting the presence of legally resident immigrant families as well as the labour opportunities for migrants lacking a residence permit in these neighbourhoods. A number of international studies provided indications about the determinants of residential patterns among illegal migrants (Chavez I992; Miller I995; Bade 2003; Cornelius 2005). 


\section{The study's contribution}

Previous research had yielded new insights into the relationship between illegal residence and crime, but it had its limitations. To begin with, hardly any illegal migrants who had committed crimes had been spoken to; respondents in Rotterdam reported their own involvement in crime on the basis of a structured questionnaire, but they were not interviewed about the crimes they had committed. As a consequence, it was unclear how criminal illegal migrants had responded to the conditions they encountered in their country of destination, what they had been trying to achieve by their crimes and to what extent criminal careers developed only after settlement in the Netherlands. There was a clear lack of studies into the role of agency played by people within these groups. (This aspect is given more prominence in Chapter 5).

In this study, crime patterns among illegal migrants have been compared systematically for the first time to crime patterns in other social groups, including comparable migrant groups with legal residence (Chapter 4). This made it possible to discover whether previous research had overestimated the importance of illegal residence status in explaining crime patterns. Furthermore, additional theoretical insights from criminology were used, particularly from criminological studies of crime among legal migrants. For instance, more attention is paid here to cultural aspects of offending, as well as to the involvement of illegal migrants in criminal migration and cross-border crime, where the committing of crimes in the destination country, or at the border, is a motive for migration (see particularly Chapters 5 and 6 ). This study also pays more attention to illegal residence as a result rather than a determinant or condition of criminal involvement, for example, when the state withdraws the resident permit of an immigrant because he or she has been convicted of crimes (this aspect is given prominence in Chapter 6).

As has been said, qualitative sub-studies and exploratory research constituted the basis of existing scientific knowledge regarding the spatial distribution of illegal migrants and its determinants. This aspect was researched systematically for the first time in this study (Chapter 2). Further, building upon this spatial perspective, this study was the first to explore the consequences of the concentrated presence of illegal migrants in certain urban environments for local neighbourhood safety and what could be termed liveability (Chapter 3 ). Concerning the latter it should be mentioned that there was no research into the relationship between illegal residence and patterns of transgression of (or compliance with) unwritten social rules in public space, or into the more subjective aspects of safety among urban residents in neighbourhoods where illegal residence is concentrated, such as fear of crime.

In sum, this study intends to contribute to what Merton (I968) called 'theories of the middle range', i.e. theories that aim to bridge the gap 
between abstract theorising and empirical evidence. In particular, it intends to contribute to substantive theory on the terrain of migration, crime and public safety. It does so by: (I) critically testing and developing existing ideas about the relationship between restrictive immigration policies and crime involvement among migrants; (2) broadening the research from a focus on crime involvement among illegal migrants to an analysis of illegal residence in relation to objective and subjective notions of public safety; (3) examining the spatial aspects of illegal residence and public safety; and (4) paying more attention to illegal residence as a result rather than a determinant or condition of crime involvement (i.e. when the state withdraws a residence permit because of crimes committed by its holder).

\section{Specification of the research questions}

\section{International inequality and international migration}

International migration, in general, and illegal migration, in particular, involves substantial but relatively limited and selective groups. Although the unequal distribution of wealth and security - the World Bank (2006) estimates no fewer than two billion people in the world earn less than two dollars a day - creates a vast potential for international migration, there are several factors limiting the number of international migrants to a relatively modest fraction of 2 to 3 per cent of the global population (Castles \& Miller 2003: 5; Cornelius et al. 2004: 3). Even though international migrants are now thought to represent about io per cent of the population in Western countries (Cornelius et al. 2004: 3), the magnitude of international migration remains limited when compared, for instance, to domestic migration. ${ }^{8}$

The recent migration literature has identified various factors that limit the extent of international migration (see for instance Faist 2000; Massey et al. 2005). It is pointed out, for example, that long distance migration is relatively expensive and risky. The poorest people on the planet simply cannot afford international migration, although members of households sometimes pool their resources to facilitate the migration of a productive family member (Stark I995; Taylor I999). Social reasons also contribute to 'distance deterrence' (Molho I995); the chances of migration decrease with the distance to be travelled. On the one hand, distance deterrence arises because most people do not want to leave home (or at least not to go far from it) for very long; in many cases staying put increases the chances of social acceptance and integration within the family and society at large (Fischer, Martin \& Straubhaar 1997). On the other hand, those who want to leave cannot always establish themselves 
elsewhere, even if they have the money to travel. The social and cultural ties (family ties, economic ties, correspondences in language, etc.) between potential migrants and earlier immigrants who are established in their countries of destination facilitate migration. Admittedly, such ties are on the increase overall, but to the smallest degree of all for the poorest people on the planet. Hence, the poorest countries do not supply the most emigrants and most international migrants are not among the poorest; most tend to be the 'top dogs among the underdogs'. (This was probably less true for labour migrants who were recruited in Mediterranean countries during the I950s and I960s; it is also less the case for chain migrants.) $)^{9}$ Accordingly, the relationship between income and migration is not linear: migration initially increases when incomes in the country of origin rise, only to decrease after a certain point. In the migration literature this phenomenon is known as the 'migration hump' (Martin I993; Martin \& Taylor 200I).

The increased regulation of international migration contributes to the select nature of international migration even further (also see Carling 2002; Turner 2007). I will turn to this factor now, concentrating on the Dutch case and first giving a brief historical perspective.

\section{Background to Dutch immigration policy}

The Netherlands is a prosperous country that has attracted many migrants throughout the centuries. In large measure the country owes its Golden Age in the seventeenth century to newcomers, both poor migrant labourers and affluent aliens who often settled in the relatively tolerant Dutch cities for religious reasons. Nonetheless, the reception of newcomers was never entirely positive. In Amsterdam, well-to-do aliens, such as the French Huguenots, could count on favourable conditions of settlement (Lucassen \& Penninx I997), while newcomers who were unable to support themselves, or who caused trouble, were often sent away (De Swaan I988). Delinquent exiles risked having a cut in one of their cheeks so they could be identified more easily in the case of recidivism (Spierenburg 1995), and for a long time 'gypsies' were forbidden to reside in the Netherlands because they were considered thieves (Lucassen \& Penninx 1997).

When Dutch cities were forced to give up their leading world position to England and France and, somewhat later, the United States, immigration receded and a substantial emigration to the New World developed. This situation changed only in the second half of the twentieth century, when the Netherlands was becoming increasingly industrialised and the economy expanded considerably. ${ }^{\text {IO }}$ Migrant labourers were recruited in various economic sectors during the second half of the I950s and ig6os in particular, predominantly from countries around the Mediterranean 
(Italy, Spain, Portugal, the former Yugoslavia, Morocco and Turkey). This occurred in part with the help of the Dutch government. Unskilled employees were at that time very welcome, given the supply scarcity at the bottom of the labour market.

After the global oil crisis in 1973 more and more voices were heard arguing for a more restrictive immigration policy with regard to poorer countries. A reduction in the number of non-Western newcomers was then deemed necessary in order to protect the welfare state in the light of rising unemployment figures. Aside from this, some felt such a reduction was required to make possible the integration of those who had arrived in previous immigration flows that, as became increasingly recognised in the I980s, had led to the formation of permanent ethnic minorities (Bade 2004). ${ }^{\text {II }}$ More recently there has also been concern that continuing immigration, in particular from Arab countries, might conflict with established 'cultural' institutions and mores, such as equality between the sexes, gay rights and the separation between religion and the state (Fortuyn 200I).

In spite of the sometimes striking and revealing historical analogies with regard to migration control, there are also significant differences between contemporary immigration policy and previous forms of migration regulation. For instance, the selection of desired immigrants is now often made beforehand (Wray 2006). A further difference is that political elites could exert much more control over emigration in the past; many people were not free 'subjects', and could not simply leave if they wanted to (Torpey I999). ${ }^{\text {I2 }}$ Additionally, European unification took shape in the second half of the twentieth century and, as a consequence, Dutch immigration policy became more entangled with practices in other Western European states. As part of this same development, Dutch immigration policy became more liberal with respect to the settlement of EU citizens. Since I968 citizens of EU member states cannot, in principle, be refused entry to the Netherlands (Lucassen \& Penninx 1997). They are now entitled to look for a job without requiring a special work permit. Hence, in general Dutch (and EU) immigration policy should be qualified as selectively restrictive.

In the I980s and I990s several measures were taken in the Netherlands to curb migration from poorer countries. For instance, the Alien Labour Law, which regulates the employment of foreigners in the labour market, was passed in I995 and subsequently implemented. It stipulates that migrant labourers are entitled to a residence permit only if there is a shortage of employees from what are called EER countries, i.e. member states of the European Union, Norway, Iceland and Liechtenstein. Restrictive measures have been taken with respect to family formation and unification as well. Nowadays, since the modification of the Vreemdelingenbesluit 2000 (Aliens Resolution 2000), Dutch residents are required 
to have steady employment, must be at least 2I years old and need to earn at least $\mathrm{I} 20$ per cent of the minimum wage if they want to bring a foreign partner over. The asylum policy, too, has been sharpened several times. ${ }^{\mathrm{I3}}$

Tourists from countries with a visa obligation have to demonstrate sufficient means of support, or have to find a resident of the Netherlands or another Schengen country who has sufficient means to invite them. A tourist visa can be refused if there is any suspicion of an intention to settle illegally. The number of countries with a visa obligation has been augmented several times, with Surinam and Turkey (I980) and North African countries (I983) for instance. The visa policy with regard to what were at the time future member states of the European Union is again an exception to this rule. Since I994 the European Union has experienced three enlargements. As a result, the number of member states has more than doubled in twelve years. In two rounds, in 2004 and 2007, mostly relatively poor countries from Central and Eastern Europe were incorporated. As a prelude, the visa obligation for Poland was dropped in the early I990s, while for Bulgaria and Romania this occurred in $200 \mathrm{I}$.

\section{The rise of internal border control}

Because of diminishing control over external borders owing to European integration, and because a growing number of migrants ended up settling without government consent, the Netherlands has increasingly started to protect its 'internal borders'. Internal border control consists of a wide array of policy measures within state territory and can be contrasted with external border controls such as visa requirements and border policing (Broeders \& Engbersen 2007; Guiraudon \& Lahav 2007; Lahav \& Guiraudon 2000; Van der Leun 2006; Zolberg 2003).

For this study I find it useful to make an analytical distinction between two types of internal border control in particular, although they are sometimes difficult to separate in practice. I propose to call the first type of internal border control 'secondary territorial exclusion'. It is directed at tracing and expelling the 'residue' of those immigrants who are unwanted by the state, but who have circumvented the primary external border controls. (The term residue is also appropriate because, as was explained in the section on international inequality and migration, most potential migrants are immobile because of economic and other factors). I will call the second type of internal border control 'institutional exclusion', involving all measures aimed at systematically excluding illegal migrants from important institutions of the welfare state, such as the formal labour market, the housing market, health care and social security. It is the combination of external border control and both types of 
internal border control that determines, to a large extent, what it means, potentially, to have 'illegal residence status'.

During the I990s the Dutch government focused on intensifying the second type of internal border control. Policy in this area began with the advisory report of the Zeevalking Committee, which advised the government on illegal employment in I99I. In the same year the state blocked illegal migrants' access to the formal labour market by imposing sanctions on employers and by establishing a protective ring of documentary requirements around the formal labour market. It became impossible for illegal migrants to obtain a tax number and a social security number, which had serious repercussions for their labour market position (Van der Leun \& Kloosterman 2006; Broeders \& Engbersen 2007).

A few years later the state took steps to exclude illegal migrants from public services (welfare, social security, health care, education, public housing). In I998, the Linking Act came into force (Van der Leun 2003); from then on, only immigrants with residence permits could obtain social security and other social benefits. It also facilitated the exclusion of illegal migrants from all houses and apartments for which a housing permit is required. ${ }^{\mathrm{I}}$ The law is known as the Koppelingswet ('Linking Act') because it permits immigration service registration files, census bureau data, tax identification data and social security data to be cross-checked in order to verify the validity of a person's residence and work status.

The legislative changes to exclude illegal migrants from formal institutions were supported by major administrative operations. In I995 a central computerised database, known as the VAS (Vreemdelingen Administratie Systeem or 'Foreigner Administration System'), containing data on all foreigners residing in the Netherlands came into existence. Along with police units, several other government services - such as welfare departments - have access to the VAS so that they can determine whether their clients are lawfully residing in the Netherlands and are thus entitled to certain services or benefits. Housing corporations also have to check with the municipality whether their clients have a residence permit and are thus entitled to rent their apartments (this represents an interesting case of what Garland (200I: I24) has called 'responsibilisation strategies', in which state agencies prompt action by nonstate organisations and actors). The government has also increasingly allocated resources to enforce sanctions against employers who hire illegal migrants informally: between I997 and 2003 the annual budget of the Labour Inspectorate rose by 44 per cent. While the institutional exclusion of illegal migrants is not always enforced to the letter of the law because professionals sometimes resist such measures (Van der Leun 2003), there is no doubt that illegal migrants' access to the formal labour 
market, housing market, social security and health care was radically reduced over the course of the ig9os.

The Dutch government also took a number of measures to intensify the other type of internal border control, i.e. secondary territorial exclusion. In I994 the Wet op de Identificatieplicht ('Law on Identification Obligation') was introduced, which stipulated that people must be able to identify themselves in the case of crimes and misdemeanours, or whenever there is concrete suspicion of illegal residence as well as in a place of employment (the latter requirement also facilitated the institutional exclusion of illegal migrants from the labour market). Practices of secondary territorial exclusion were intensified around the turn of the century; for instance, after the implementation of the Aliens Act 2000, in April 200I a 'reasonable presumption of illegal residence' became sufficient grounds to demand identification, rather than a 'concrete suspicion'. After the turn of the century, the police also became more active in tracing illegal migrants in places other than at work. Particularly in the big cities, specialised teams were increasingly formed to arrest those illegal migrants heavily involved in crime (particularly in the Amsterdam area) and to target illegal 'doss houses', i.e. houses where between eight and twenty people, often illegal migrants, were renting a bed or a room (see Chapters 3 and 6).

Most recently, the Dutch state is trying to develop an effective policy of expulsion as a final step towards the general objective of a restrictive illegal immigrant policy (ACVZ 2002; Minderhoud 2004). In spite of this, no more than half of all apprehended illegal migrants are actually effectively repatriated (Engbersen et al. 2002; Van Kalmthout \& Van Leeuwen 2004). Expulsions fail in part because the illegal migrant cannot leave, because he or she is stateless or because the country of origin does not grant a laissez passer (travel document for return). It may also be that the migrant does not want to return because of a lack of prospects in his or her country of origin, migration debts and the like. Illegal migrants can also hamper expulsion by concealing their identity.

This raises the question of what consequences 'illegal stayers' - illegal migrants who do not leave or who come to the Netherlands in spite of an active policy of the discouragement of international migration, in general, and illegal residence, in particular, - experience from, and attach to, an immigration policy that, on the one hand, reduces residence opportunities and life chances for illegal migrants but on the other is unable to realise an effective policy of expulsion. Moreover, in studying this group, we should keep in mind that illegal migrants constitute a relatively small and privileged few out of a far greater number of potential international migrants who are less mobile. 


\section{A closed welfare state and a differentiated, open-market society}

While the Netherlands can be typified as being a relatively closed welfare state it is simultaneously a differentiated market society which contributes greatly to international flows of goods and people. As the latter features are essential for a clear understanding of this study, I will briefly describe and enumerate them in the following section.

First, the social structure in the Netherlands is marked by a high degree of economic, ethnic and cultural differentiation. The Dutch Centraal Bureau voor de Statistiek ('Bureau for Statistics' or CBS) finds it useful to distinguish more than a thousand economic sectors. These sectors provide labour opportunities in more than a hundred 'lower' and 'higher' categories of professions. Diversity according to ethnic background is also considerable. At present, almost one in five inhabitants (I9 per cent) was born abroad or has at least one parent who was born outside of the Netherlands. Approximately one in ten inhabitants has a foreign nationality, possibly in addition to Dutch nationality, and more than 6 per cent of the population was born in a non-Western country. There are 56 foreign nationalities whose representation in the population exceeds 4,000 persons (Blom et al. 2005).

Economic differentiation and ethnic heterogeneity are not unrelated. Partly because of its history as a trading nation and colonial power, the Netherlands participates intensively in a market society that increasingly spans the entire globe. Throughout its history the Netherlands has been characterised by involvement in a very extensive international traffic of goods, ideas and people. In 2005 the gross domestic product amounted to 505 billion euros. In the same year no less than 250 billion euros in goods and 68 billion euros in services were imported, including 139 billion from outside the European Union. Even more goods and services were exported and conveyed: 28I billion euros in goods and 74 billion euros in services (of which 98 billion went to non-EU countries). The 'openness' of the Netherlands is also indicated by the high number of holiday trips by the Dutch to foreign countries: residents of the Netherlands buy I4 million holidays in foreign countries each year, 2.I million of which are outside the European Union. ${ }^{15}$

In today's differentiated market societies individuals have a relatively large measure of personal freedom and responsibility (Beck \& BeckGernsheim 2002). The variety of possible lifestyles is considerable, even if many people still opt for 'the herd' (Duyvendak \& Hurenkamp 2004). Partner choice, for instance, is far less prescribed by the family and/or the community; to a great degree people can and indeed must make such choices individually (Shorter I975; Collins I988). At present, about one in three households consists of a single person - and in the cities in particular - there are very many singles. Some are widows or widowers, while others do not have a steady partner (at least not for the moment) 
for other reasons; many people engage in temporary relationships with partners to whom they may or may not be married and with whom they may or may not live (Bauman 2003). This is less the case for people with a more traditional, non-Western background and orientation. In these groups, tradition and family may determine the selection of a partner (Hooghiemstra 2003).

The Netherlands is a secular, democratic country. With the rise of liberalism and the ideal of the self-regulating market, the economic sphere has been uncoupled from the familial and political sphere to a great extent (cf. Polanyi I944). Employers can hire employees from the labour market that suit their needs; specific features of the employee, such as origin and sex, are now less relevant than before. In a democracy other institutions that structure social traffic - besides the market - exhibit considerable autonomy. The state even protects relative freedoms within civil society and family life with legislation. Accordingly, as members of parliament strive for arrangements that conflict with the agendas of certain segments of the social fabric or laws protecting these segments, the enforcement of their legal ideals will be more problematic and observance will be less complete.

The state itself is not a monolithic whole either. First, a distinction is made between the municipal, provincial and national governments and between the various departments contained therein - as well as the European Union at a supranational level. Second, the legislature, the executive and the judicial powers are separated, though interests that emerge in these spheres may sometimes clash. For instance, civil servants empowered to implement restrictive immigration policy may let their professional ideologies prevail (see Van der Leun 2003) ${ }^{16}$ Similarly, civil servants responsible for the economy sometimes set other priorities with regard to immigration policy from civil servants responsible for public order and safety (see Cornelius et al. 2004).

The simultaneously closed and open character of Dutch society creates ambivalence about migration flows. Among some parts of the social fabric, there is a demand for the knowledge and labour provided by aliens, or there are familial or affective ties that stretch beyond national borders - think of the migrant communities with family in the country of origin, or Dutch tourists with a holiday boyfriend or girlfriend. Parts of the population feel that the Netherlands should maintain its tradition of openness and tolerance, while precisely because of the increased dependence on foreigners, many others voice fears for their institutions and privileges (cf. Elias I939).

In the current epoch most states feel forced to open themselves to external influences, in the sphere of trade in particular. Among many of those who are already established, however, the desire to protect domestic institutions - the regulated labour market, social security, cultural 
achievements, public order - produces a simultaneous desire for social boundaries. In immigration policy the tension between inclusive and exclusive tendencies produces an inclination towards selectivity: there is a desire to keep the door open to desirable influences, while excluding influences seen as undesirable. Illegal migrants pre-eminently embody the paradox of this 'double movement' (cf. Polanyi I944). In a differentiated, open-market society residential and employment opportunities exist for various kinds of migrants in various social niches, while the craving for safety and closure in other parts of society prompts the state to classify these migrants as illegal.

\section{Effects of the restrictive immigration policy on public safety}

The restrictive immigration policy is in part aimed at preventing problems of public order and safety. The state can refuse, withdraw, or decline to renew a tourist visa or residence permit or declare a migrant an undesirable alien if the foreigner is believed to be or become a threat to public order (ACVZ 2005). These aspects of external and internal border control are less central in this study, but I will return to them in Chapter 6 particularly.

It may well be that a restrictive immigration policy also promotes public safety in a more indirect way by discouraging settlement by economically disadvantaged migrants. In many cities in developing countries the 'excess' domestic migration, which is often hard for governments to control, is coupled with considerable safety problems connected with the formation of dangerous slum areas. Such effects of restrictive immigration policy are outside the scope of this study.

Here I am primarily interested in the possible effects of restrictive immigration policy for those who do not receive permission to settle in the Netherlands but who settle nonetheless, either after entering the country illegally or by overstaying after a period of legal residence has ended as, for instance, a tourist or an asylum seeker. I want to know to what extent the behaviour of this group, insofar as it is relevant for public safety in the country of destination, can be explained by their specific relationship with the state in that country, in this case the Netherlands. My interest is primarily focused on illegal residence and, to a lesser extent, the migration processes preceding it. This brings us to the first central question: To what extent and under what conditions do residence and migration by illegal migrants have consequences for public safety in the Netherlands, and what influence does a restrictive immigration policy (particularly the 'illegal residence status') have on these consequences?

I examine this central question in part from a spatial perspective. Prior to this study, as we have seen, there were indications that illegal residence is concentrated in specific neighbourhoods. Further, a high 
percentage of street crime is committed close to where the offenders were living (cf. Kleemans I996). Subjective aspects of public safety have a clear spatial component as well (cf. Covington \& Taylor I99I). For these reasons we might expect that the answer to the first central question would in any case vary from municipality to municipality and, within these municipalities, from neighbourhood to neighbourhood. In addition, research on the spatial distribution of illegal migrants increases our insight into the social ties between illegal migrants and more established groups in society. One of the themes connecting the sub-studies is that these ties codetermine, albeit in complex ways, the extent to which the illegality of residence has consequences for public safety and in what ways. Hence, the ecology of illegal residence can be used as a window onto the sociology of illegal residence. This brings us to the second central question: To what extent and in what way is illegal residence spatially concentrated in the Netherlands, how can patterns of spatial concentration and incorporation be explained, and what are the consequences of the spatial concentration of illegal residence for neighbourhood safety?

\section{The study's relevance for other countries}

In recent decades other destination countries in Europe, as well as the United States and Australia, have witnessed a similar increase in restrictions aimed at limiting international mobility from poorer countries (see for instance Andreas \& Snyder 2000; Cornelius et al. 2004). For instance, since the ig8os the list of countries whose citizens required a visa to enter the EU has been expanded in almost all EU countries (Bigo $\&$ Guild 2005).

There are, however, significant international differences in the type of migration controls employed for these purposes. The Dutch case echoes current immigration control policies adopted by the Scandinavian countries, Germany and France, which have laid the emphasis on guarding the internal borders of the labour market and public provision (Cyrus \& Vogel 2003; Cornelius et al. 2004; Guiraudon \& Lahav 2007; Düvell 2006). The United States has focused more on controlling its external physical borders (Andreas \& Snyder 2000). These international differences arise in part from differences between forms of illegal migration. The most prevalent form of illegal migration in most European countries is legal entry (as a tourist, family visitor, or asylum seeker), followed by overstaying the allowed period specified by law or the entry visa. The illegal crossing of borders is much less prevalent in Europe than it is in the United States (OECD 2007: 48). A second factor concerns differences in formalised solidarity. Maintenance of comprehensive governmental forms of solidarity in the spheres of health care, social security, 
education and public housing, for the benefit of citizens and denizens, is assumed to imply the exclusion of unwelcome immigrants from the welfare state's social entitlements; the financial viability and legitimacy of such entitlements might be endangered if too many immigrants were to gain access to public provision too easily. This explains why countries with less internal solidarity, such as the United States and the countries of southern Europe, are more capable of incorporating illegal migrants into their societies and labour markets once they cross the border, and are more apt to introduce legalisation programmes in which illegal migrants who have worked for a number of years are eventually given resident status.

In spite of these international differences, there is an apparent tendency towards increased internal border controls, both in the EU and the US. This makes the Dutch case a strategic site for researching the effects of internal border controls - especially controls involving institutional exclusion.

The tendency towards tighter internal border controls in the EU is part of a larger tendency towards the harmonisation of migration policies: the I997 Amsterdam Treaty gave the European Commission a more prominent role in immigration, asylum and development policy (EMN 2007). So far, the European Commission primarily meets that responsibility by developing the 'external dimension' of immigration policy (Boswell 2003; Human Rights Watch 2005), which mainly includes the exportation of traditional instruments of migration control to the originating and transit countries (the latter being the countries migrants travel through on their way to the EU). Yet in May 2007 the European Commission issued a Proposal for a Council Directive providing for sanctions against employers of illegal third-country nationals (Carrera \& Guild 2007). It aims to establish a harmonised EU framework for imposing sanctions on employers for hiring illegal migrants. This proposal is part of the EU's increased efforts to develop migration policy at an EU level.

The United States has recently adopted similar internal border controls, along with stricter law enforcement. Over the past few years almost all American states have adopted measures aimed at: (I) curbing the employment of illegal migrants (via more severe employer sanctions and the denial of state contracts), (2) making it more difficult for illegal migrants to obtain state identification documents such as driving licenses, and (3) excluding illegal migrants from public benefits, mostly by denying them public assistance (cf. Jencks 2007; NCSL 2008).

The characterisation of the Netherlands as an open and differentiated market society is, to a large extent, also valid for other affluent countries in the West. For instance, due to the globalisation of social and economic life, the presence of various ethnic groups who maintain transnational 
relationships with all parts of the world is becoming increasingly common (Portes 1999; Snel, Engbersen \& Leerkes 2005). Furthermore, singles are proliferating around the Western world (Blok et al. 2000; Bauman 2003). Finally, in other destination countries there are often similar labour opportunities for illegal migrants in agriculture, construction, and in the expanding service sector (take-away restaurants, cleaning, baby-sitting) (see also Sassen I99I, I999; Ehrenreich 2002; Cornelius et al. 2004).

\section{Definition of terms}

In this introductory chapter I want to elaborate on a number of central terms. I will do this by first defining what I mean by the terms 'illegal migrant', 'objective safety', 'subjective safety', 'crime' and 'criminal illegal migrant'.

\section{Illegal migrant}

Illegal migrants are persons of foreign nationality, or no nationality, who reside illegally within the territory of a state, in this case the Kingdom of the Netherlands. The Dutch Bureau for Statistics (CBS) stipulates as an additional condition that residence in the Netherlands has lasted for at least three months. The latter stipulation mainly has technical research implications for the CBS, and is not significant here. ${ }^{17}$ This study pertains to people who have tried to settle in the Netherlands more or less permanently (immigrants) as well as to people who from the start have been counting on a temporary residence (pendulum migrants or transients). For this reason I use the term illegal migrant in this study in stead of the term illegal immigrant.

The predicate 'illegal' does not refer to a characteristic of a person, but rather describes a relationship between him or her and the state in a certain jurisdiction. Whether or not residence is considered illegal, and whether or not the state attaches consequences to illegal residence, largely depends on the state itself. In other words, illegal residence has the character of a social (or state) construct, over which the individual concerned has hardly any influence (cf. Gans I995). Illegal migrants can decide to settle illegally in a certain jurisdiction or attempt to stay for longer than the state permits - though persons who are victims of human trafficking or who are not taken back by their country of origin cannot decide for themselves even to that extent and can exert little influence on the legislative consequences associated with illegal residence status. ${ }^{\mathrm{I}}{ }^{\mathrm{T}}$ 
There is no agreement in the social sciences about what term should be used to refer to this category of migrants. The formal legal term is 'illegal aliens', though this term is rarely used. Most researchers prefer to replace the term alien by migrant or immigrant, and a considerable number prefer not to use the term 'illegal'. This has produced the neologisms 'undocumented migrant' and 'irregular migrant' in the social science literature (see for instance Chavez I992; Van Liempt 2007).

Unfortunately, none of the available terms is wholly unproblematic. I agree that the use of the terms illegal alien and illegal migrant may, at least in some contexts, express or imply an a priori criminalisation of the people concerned. At the same time, the terms undocumented migrant and irregular migrant are barely any more neutral. In my opinion, the use of such deliberate alternatives implies a critical stance towards restrictive immigration policy, and in any case the descriptive adequacy of the latter euphemisms is questionable. Firstly, the immigrants concerned are not necessarily undocumented. Many are in fact documented, for example, visa overstayers or rejected asylum seekers or those apprehended repeatedly because of illegal residence. Similarly, the adjective irregular is problematic since it suggests that illegal migration tends to be unstructured, while in fact it is often highly structured.

For this book I have in the end decided to use the term 'illegal migrant' in spite of its disadvantages. I would like to stress, however, that I only intend to use it as a short descriptive term for illegally residing migrant. In other words I use it only where I wish to indicate in a few words that a migrant's residence or stay in a jurisdiction is, at a specific time, illegal according to the ruling state in that jurisdiction. I do not mean to imply any particular position in regard to whether the presence of legal or illegal migrants in the Netherlands or elsewhere is a good or bad thing. Furthermore, I do not mean to essentialise the 'illegality' of the people concerned: my study shows that an illegal migrant may become a legal migrant over time and vice versa. An important reason for using the term illegal migrant is that it is comparable to other widely used terms in the social sciences and elsewhere, such as illegal drugs and illegal resistance. Whether or not the latter phenomena are to be condemned or praised is likewise a subjective matter that necessarily lies beyond the scope of empirical research. I realise that I could have used 'illegal alien' in a similar vein (cf. Ngai 2004), but I have decided it sounds too formal.

\section{Objective and subjective safety}

Safety has both objective and subjective facets. I define objective safety as the extent to which offences (felonies as well as misdemeanours) occur in the Netherlands. Safety increases as the number of offences de- 
creases. In the liberal tradition, a central task of the government is to help protect the individual's right to freedom. Criminal law is used to help protect people against aggression by third parties. Further, behaviour that conflicts with deeply felt social conventions is often made punishable even if there is no clear victim, one example being the prohibition on nudity in public spaces. Subjective safety pertains to the judgments people make about crime and nuisance in public space and whether they feel safe there (Vanderveen 2006).

I am primarily interested in objective aspects of safety, particularly in felonies. Felonies are offences that are strongly condemned by society and carry harsh prison sentences. Misdemeanours, i.e. lesser offences that are usually settled by a fine (but in the Netherlands are sometimes punishable by up to a year in prison), are of interest to me as well, particularly insofar as they occur in public or semi-public space. Hence, I am mainly interested in street crime and disorder. When illegal migrants work informally for a company, this does not, in my view, constitute a threat to public safety. Safety does have socio-economic aspects (see Wacquant 200I; Bauman 2004), but social security is not prominent in this study.

Illegal residence as such is not punishable in the Netherlands. An illegal migrant can be held in custody with a view to expulsion, but formally, from a legal perspective, this is not a punishment. Only in the case of repeated illegal residence, may the migrant, under certain conditions, be declared an ongewenst vreemdeling ('undesirable alien'). Repeated or continued residence is then regarded as a crime against the authorities (ACVZ 2005). ${ }^{\text {I9 }} \mathrm{I}$ do not treat illegal residence per se as an intrinsic threat to public safety, except in the case of an 'undesirable alien'.

Sociologically, offences differ from transgressions of informal norms because they can be sanctioned by society in specific ways. The state can use its monopoly on legitimate violence (Weber I947) in order to protect public safety or the legal order. Nonetheless, legal distinctions may be somewhat artificial in the context of studies in social science. Although it is not uncommon among criminologists, particularly those with a classical orientation, to rely on legal definitions, some criminological schools are reluctant to reduce the object of study to offences alone. Some criminologists point out that not all immoral behaviour is punishable, for example, certain forms of exploitation by corporations, and claim that the law sometimes merely serves to protect the interests of powerful groups in society. From such a critical perspective the restrictive immigration regime could perhaps be understood as state crime, and the legal notion of the 'illegal alien' as a form of symbolic violence (cf. Bourdieu I990: I27)! Life-course criminology often researches the violation of norms, or anti-social behaviour as such, and does not limit itself to actual criminality (see for instance Sampson and Laub 2005). 
My focus on felony crimes and misdemeanours is implied in my definition of my research project. It speaks for itself that a researcher interested in illegal residence and public safety should look at the violation of official norms. This focus also has a pragmatic basis. Felonies and misdemeanours are extensively registered by the police and other state organisations, and are measured in various surveys in the field of social science. By using a number of existing data sources I could make a larger scientific contribution, which in addition would be socially relevant. As we have seen, there has up to now been a relative lack of empirical information on illegal residence and public safety.

Nonetheless, I did not want to ignore the aforementioned criticisms altogether. While the emphasis in this book is on perpetratorship among illegal migrants in the sense of involvement in felonies and misdemeanours, I also look at subjective aspects of public safety. Far from all social rules in public space are legally sanctioned (Goffman I963, I971a); the legal order is merely part of the social order. Violations of informal rules, in particular, turn out to determine how people judge and experience safety in public space. I have therefore also taken an interest in the question of whether or not illegal migrants transgress or comply with unwritten rules in neighbourhood life, and to what extent the illegality of their residence contributes to this. I also point out that from a sociological perspective, offences often differ fundamentally in nature; for example, there are not always any individual victims. Further, I argue that the state has increasingly started to deploy its power of definition, and has mobilised criminal law in order to keep certain categories of aliens away from the Netherlands. The introduction of the Law on Identification is a case in point.

\section{Criminal illegal migrant}

Sometimes I use the term 'criminal illegal migrant' when I wish to denote in a few words that an illegal migrant has committed a crime (or is a crime suspect or convict). I do not mean thereby to essentialise the criminality of such migrants. I acknowledge that even offenders who commit many crimes do not commit crimes most of the time (cf. Collins 2008).

\section{Ethical aspects}

During my research I presented preliminary results at various scientific conferences and seminars. A number of times I was confronted with ethical questions. Some colleagues were concerned about my research on the determinants of the spatial concentration of illegal residence 
(Chapter 2): would this knowledge not encourage raids? One researcher even pointed out that the maps demonstrating the spatial distribution of illegal migrants, though increasing our insight into illegal residence, resembled the maps made in the Netherlands during the Second World War (printed in Scott I988), when Dutch civil servants made maps for the Nazis demonstrating the spatial distribution of Jews across Amsterdam. Other researchers voiced fears that my interest in crime and disorder among illegal migrants would promote their further stigmatisation and criminalisation. Outside of academia, the subject of my study is emotionally and politically charged. Some circles speak powerfully and engage in acts designed to protect illegal migrants (cf. Westerink 2005), while in other circles the negative aspects of both legal and illegal migration for the receiving society are emphasised and dramatised. ${ }^{20}$

On the whole, I am confident that my study is ethically responsible according to prevailing professional standards as described, for instance, by the American Sociological Association. In accordance with the standard of 'informed consent', all my respondents and informants were told about the purpose of the study, and their anonymity was guaranteed. Moreover, I have paid due attention to the need to report the findings in a balanced and responsible way. Four of the five sub-studies in this book had been published in peer-reviewed journals before I included them in this book.

I am, however, uncertain about the ethical soundness of two aspects of this study. I have no clear answer to either issue; I hope, therefore, that both will be debated by migration researchers and other social scientists. The first point concerns the question of whether the standard of informed consent is adequate in the light of increasing opportunities for linking separate quantitative data sources. New possibilities for research arise when data files are linked, as I have done. Sometimes these possibilities clearly transcend the purposes for which the separate data were initially gathered. For instance, while respondents to the Police Monitor (a survey on crime and neighbourhood safety, which is an important data source in Chapter 3) knew that they were cooperating with a scientific study, they could not have foreseen that these data would eventually be used in this book to explore the effects of illegal residence on neighbourhood safety. These possibilities only arose after the Police Monitor data had been linked to police apprehension data, which were in turn linked to data on neighbourhood characteristics. (I did ask the scientific department of the Dutch Ministry of Justice, which owns the Police Monitor data, for their permission to re-use the data for these purposes, but I realise that civil servants who assessed my request may have believed the state had an interest in that sub-study).

The second aspect pertains to the prescription by the American Sociological Association that research in the social sciences should 'respect 
people's rights'. This standard is problematic if people's rights and interests are clearly in conflict, as is inherently the case with a study on illegal residence. Some readers may feel that people in poorer countries have a right to settle in affluent countries without the consent of the governments in the countries of destination, given the present, highly stratified international order (cf. Düvell 2006). From a critical perspective it may also be argued that illegal migrants have a right not to be studied, because knowledge about illegal residence may contribute to more effective ways of excluding such migrants. However, such a position obviously ignores the right of the established population in destination countries to know about migration flows that influence their society and life chances. Measures to restrict immigration were introduced partly because of pressure, by labour unions for instance, to protect the welfare state, which benefits poorer native groups and promotes intranational social equality.

I sincerely hope that this study, building on previous social science research, has a fair chance of being used in productive ways. In the present social and political conditions, scientific knowledge about illegal migration may lead to their more effective exclusion, but it could also lead to increased incorporation of such migrants, for instance by easing the restrictions on legal migration. In the Netherlands, a legalisation programme was introduced in 2007 , granting residence permits to about 25,000 rejected asylum seekers. The political parties who proposed the programme were familiar with my work and other social science research on illegal residence in the Netherlands. ${ }^{2 \mathrm{I}}$ In addition, publishing findings and discussing them with researchers and students may also expose social myths that are persistent on both sides of the political spectrum. This would enlarge the space for a more nuanced discussion on the basis of verifiable assertions (Elias I978; Burgers I996). A further critical argument for conducting this research is that social science loses a lot of credibility - particularly when it aspires to be socially relevant - if it anxiously puts up with the fact that significant areas of social life are terra incognita.

Finally, I propose a shared moral responsibility, by which I mean that part of the moral responsibility lies with me as a researcher - for instance, I should not expose the respondents' identities or precise residential addresses and should not, in reporting findings, omit factors that I know are relevant - but another part lies with everybody who uses the findings, including journalists, policymakers and politicians. The latter should not willingly distort or selectively ignore my findings. 


\section{Data sources}

I was able to collect an unprecedented amount of interesting quantitative and qualitative data. These were mostly obtained during research activities for two contract studies as a result of a research proposal by my PhD supervisor (see points I, 2 and 4 below). These were a study by order of the Ministry of Housing and a study for the independent research programme Politie en Wetenschap ('Police and Science'), which is subsidised by the Ministry of Internal Affairs. Moreover, between 2003 and 2006 I gave seminars to sociology students at the University of Amsterdam. As part of these classes each student conducted an interview with a resident in a city neighbourhood with a relatively high percentage of illegal residents (see point 2 below). Further, various statistical data were gathered that were available in the Netherlands. The following is a concise list of the data on which this study is based:

I. At the end of 2003 , the 25 regional police forces in the Netherlands delivered anonymised data on all illegal migrants apprehended ${ }^{22}$ in the period from January I997 up to and including September 2003. This provided information at the individual level about the reason for, place and date of apprehension (or apprehensions) and, insofar as is known to the police, the date of arrival in the Netherlands, nationality, date of birth and sex.

2. Two urban neighbourhoods were selected where, according to police data, higher than normal concentrations of illegal residence could be found, one in Rotterdam and one in The Hague. In these neighbourhoods, a fellow researcher and I spoke with a total of twenty professionals. In addition, interviews were conducted with 70 illegal migrants from six countries and 45 accommodation providers. The latter interviews were done in the respondents' mother tongues by a team of trained interviewers with at least a higher vocational education. In the two neighbourhoods, the sociology students spoke to a total of IOI residents. The interviews were rehearsed in the seminars.

3. In 2005 I recorded the life stories of 26 male illegal migrants with an asylum background and a record of offences. Most respondents were interviewed twice for two hours each time. The records of offences were made available by the Ministry of Justice.

4. At my request, the Immigration and Naturalisation Service (IND) made data available on all immigrants declared undesirable aliens between 1997 and 2003 and/or who had lost their residence permit because of public order violations.

5. In the period 2003-2005 I gathered various statistical files and data on socio-economic neighbourhood characteristics, neighbourhood safety and neighbourhood crime. The main data sources were Kerncijfers wijken en buurten 1999 ('Core figures on districts and neigh- 
bourhoods I999') compiled by the Dutch Bureau for Statistics and the Politiemonitor Bevolking ('Police population monitor') for the years I997, I999, 200I and 2003.

6. In 2007 I interviewed two key informants who were involved in providing relief to illegal migrants in the form of accommodation. These were a policymaker for the Amsterdam municipality and a coordinator of a foundation subsidised by Dutch churches.

\section{Preview of the following chapters}

Five sub-studies were conducted with these data in order to answer the aforementioned research questions, and each sub-study constitutes a chapter in this book. There were two main reasons for basing this dissertation on sub-studies. Firstly, it allowed me to make the most efficient use of the data that were collected during the two commissioned studies (for the Ministry of Housing and the Police and Science programme) and to profit from the analyses that I had already carried out as part of these studies. Secondly, I wanted to create more opportunities to work with other researchers. By splitting the study into sub-studies, I could seek the cooperation of other researchers on aspects of my study. Three of the five sub-studies have been written in cooperation with four different co-authors. I am confident that the impact and quality of my scientific work have profited from this strategy (as has my job satisfaction), although it has also necessitated a more unconventional format for this dissertation.

I have primarily used the findings and limitations of the existing Dutch research as a point of departure, since science aspires to cumulative knowledge. In most sub-studies I incorporated additional theoretical insights. This was necessary because the sub-problems implied in the two central research questions extend over several disciplines, including sociology, social geography, criminology and social psychology. The theory I have used is explained in the relevant chapters, insofar as it has not been discussed in this introductory chapter. There I also go into research methods and the reliability and representativeness of the empirical data.

The following chapters can be read independently in combination with this introductory chapter. They have nonetheless been arranged in such a way that they build upon each other and form a coherent whole. Part I of this book - The ecology of illegal residence - starts with the substudy that looked into how illegal residence is spatially embedded in Dutch society. The empirical basis constituted the quantitative and qualitative data collected under I, 2 and 6 . The observed patterns are described and explained in Chapter 2: Shadow places. 
The second sub-study builds upon this ecological perspective. It explores the consequences of illegal residence for the safety and comfort of urban neighbourhoods. How safe and liveable are neighbourhoods where concentrations of illegal residence have been observed? Is there more or less crime than in other neighbourhoods? Do the residents feel more or less safe? To what extent can variations in neighbourhood safety be attributed to illegal residence? These questions were addressed based on the quantitative and qualitative data under I, 2 and 6. Chapter 3 describes the results: Against state rules, against street rules?

We will see in Chapter 3 that the effect of the presence of illegal migrants on neighbourhood safety depends, at least in part, on the extent to which the immigrants concerned are involved in crime (which is the case for only a minority of illegal migrants). For this reason, three substudies were conducted in order to enhance our understanding of the relationship between illegal residence and crime. These sub-studies constitute Part 2 of this book: Illegal residence and crime.

The third sub-study, i.e. the first sub-study of this book's second part, compared the patterns of criminality among illegal migrants to the patterns of criminality among legal migrants of the same age group and country of origin. It involved a comparison of migrants from eleven countries, aged from fourteen up to and including 24 years. To that end the data collected under I in the section on data sources were compared with police data on crime suspects with legal residence which have been published by other researchers (Kromhout \& Van San 2003). This is the subject of Chapter 4: Embedded crimes?

For the purpose of the fourth sub-study the experiences and stories of illegal migrants involved in crime were recorded and analysed qualitatively. How did the men become engaged in criminal activities? To what extent do the stories and records of offences collected during my fieldwork in the Tilburg Prison indicate that illegal residence status may have played a part in this outcome? How did the men deal with their situation? What crimes did they choose to commit and what crimes did they avoid? The results are described in Chapter 5: I am just trying to live $m y$ life.

The fifth sub-study analyses the background of the considerable rise in the number of crime suspects with illegal residence status in the Netherlands since the mid-I990s. On the basis of the quantitative data that was collected I looked into whether the marginalisation thesis which asserts that the increase is caused by the heightened marginalisation of illegal migrants under the influence of increased internal border control by means of institutional exclusion - holds up after statistically controlling for five alternative explanations: practices of reclassification by the state, criminal migration, developments in crime detection and registration, an increase in crime among legal migrants and, finally, de- 
mographic changes in the composition or size of the illegal population. The results can be found in Chapter 6: The rise in crime.

The main conclusions of the study as a whole are explained in Chapter 7, where a number of implications for policy are also discussed. 


\section{Part 1}

The ecology of illegal residence 



\section{Shadow places}

\section{Introduction}

Illegal residence appears to be unevenly spread across the Netherlands; an explorative study indicated that most illegal residents lived in the four large cities (Amsterdam, Rotterdam, The Hague and Utrecht) as well as a number of border and rural areas (Engbersen et al. 2002). It can therefore be assumed that illegal migrants make up a considerably larger part of the population in some places than the national average of I per cent locally probably up to about 6 to 8 per cent (Leerkes et al. 2004). Studies in other countries indicate a similar pattern: illegal residence is concentrated in specific urban and rural environments (Chavez I992; Miller I995; Bade 2003; Cornelius 2005).

There is as yet no systematic empirical information on the spatial distribution of illegal residence in the Netherlands and other Western countries on the level of municipalities and neighbourhoods. The research questions of this chapter are: To what extent, and in what way, is illegal residence spatially concentrated within the Netherlands and how can patterns of spatial concentration and incorporation be explained?

Unlike in previous studies, the spatial distribution of illegal residence will be described in quantitative terms in this chapter. The central determinants of illegal migrants' residential pattern will also be operationalised, i.e. defined in measurable 'terms' and tested quantitatively. Statistical results will be interpreted and illustrated with data from two ethnographical neighbourhood studies. Such a triangular approach is innovative in this research field.

This sub-study focuses on illegal residence in urban environments, as most illegal migrants live in big cities; fieldwork was conducted in two urban neighbourhoods in the cities of Rotterdam and The Hague, the second- and third-largest cities in the Netherlands.

First, the central theoretical concepts and assumptions of this study are presented and then the data sources and research methods will be explained. I briefly describe the spatial distribution of the illegal population across Dutch municipalities and provinces. The determinants of the 
spatial patterns of illegal residence in urban environments are analysed subsequently, followed by an outline of the implications of the findings for other Western destination countries, projected into the near future.

\section{Opportunity structure: spatial aspects}

There is an abundant international literature on the spatial concentration of migrant groups with legal residence. The American literature, which includes work by researchers from the Chicago School who were the first to write about processes of spatial distribution among migrant groups, is particularly rich (see, among others, Park, Burgess \& McKenzie I925; Massey \& Denton I993; Jargowsky I997). A comparable literature is emerging in Europe, a continent increasingly confronted by similar processes of spatial and economic segregation, spatial mobility and the emergence of 'residential enclaves' (Van der Wouden \& Bruine 200I; Musterd \& Deurloo 2002; Van Kempen \& Idamir 2003; Musterd 2004).

Various studies provide indications of the crucial factors of the spatial settlement pattern of illegal migrants. The first of these is the degree of embeddedness in transnational social networks. For this incorporation process, one can use the term 'social capital' as operationalised by Portes (I998) to refer to the ability of illegal migrants to mobilise various resources (money, work, housing, information, documents and also possible marriage partners) from their ethnic and family networks. Social capital determines to a large degree the residential opportunities available to illegal migrants (Mahler I995; Engbersen 200I; Grzymala-Kazlowska 2005; Engbersen, Van San \& Leerkes 2006). The social capital that illegal migrants can mobilise varies both between and within ethnic groups. Not every immigrant has access to a network of fellow migrants. Dutch studies show that Turkish, Moroccan and Surinamese groups (and, to a lesser extent, African groups) can often fall back on established migrant communities (Burgers \& Engbersen I999). Lack of social capital is found particularly among rejected asylum seekers who come from new immigration countries, but strongly marginalised illegal migrants, who cannot depend on established migrant communities, can also be found in other groups. If they do not find a job, they will have to fend for themselves in most cases.

Labour opportunities constitute a second residential factor. Various authors assume that there is increasing room for low-skilled jobs (formal and informal) at the bottom of the labour market in large cities (Sassen I99I; Miller I995; Bonacich \& Appelbaum 2000). In this part of the economy, remnants of industrial activities (such as textile sweatshops) remain and there is low-wage labour in all kinds of enterprises in the 
personal service industries (cleaning, security, catering, care for children and the elderly, home improvement). Furthermore, a sizeable ethnic economy has evolved in many large cities where informal labour by illegal compatriots is a relatively common phenomenon. By keeping labour costs low these businesses hope to achieve economic success. There is also considerable demand for illegal labour in agriculture and horticulture (Cornelius 2005). Illegal migrants are very important for this sector in Western Europe (see Cornelius et al. 2004).

A third relevant factor is the presence of cheap and accessible accommodation. The local housing market in some city districts is favourable to illegal migrants, since many private landlords are willing to rent out flats, rooms or beds to them. Building on Mahler's views (Mahler I995), Burgers (I998) noted the existence of 'parallel housing markets' in Dutch city districts - i.e. informal markets that are broadly similar to the formal housing market. He points to two parallels. On the one hand, there is social housing in the Netherlands, with its rent ceilings, which makes it possible for illegal migrants to live-in with compatriots free of charge or in exchange for a modest rent. On the other hand, there is a private housing market that is harder to control by the government. Illegal migrants have access to this private market if they can afford to pay higher rents. There are now a number of hybrid forms in which legal migrants sublet or re-let their council houses to illegal migrants (Leerkes et al. 2004). Offering accommodation to illegal migrants can be a welcome source of income for legal migrants (and also for established illegal ones). Those who have been in the Netherlands for a longer period of time can start a career as a landlord, linking the formal and informal housing markets. Due to governmental regulations, rents - particularly in the social sector - are often lower than market prices. This makes informal sub tenancy lucrative. A previous study indicated that the active dispersal policy implemented in the case of asylum seekers has had some effect on the distribution of illegal migrants (see Leerkes et al. 2004) though these effects were limited. First, most illegal migrants do not have an asylum history and are therefore not subjected to a policy of dispersal. Secondly, failed asylum seekers often appear to leave rural and small town areas and head for the big cities.

The three factors that constitute the opportunity structure of illegal residence - social capital, labour and housing - are often connected. People who have much social capital often have easier access to labour and housing (Engbersen 200I). Others are more dependent on commercial intermediaries, shadowy temporary employment agencies and landlords, for obtaining work and housing. Various ethnographic studies conducted in Dutch cities and in cities such as New York, Athens, London, Berlin and Brussels make clear that the dimensions of the opportunity structure for illegal migrants have a clear spatial component (Mahler 
I995; Romaniszyn 1996; Burgers \& Engbersen I999; Alt 2003; Grzymala-Kazlowska 2005). Opportunities for illegal residence in cities are limited to certain urban environments. It is the spatial proximity of labour, social networks and housing that seems to determine why illegal migrants live and work in particular city regions.

A new insight yielded up by this sub-study is that the presence of poor singles contributes to the opportunity structure of illegal residence. These single households represent a fourth, independent dimension in this opportunity structure. This dimension has a clear spatial component as well.

\section{Research methods}

This sub-study is based on the registered home addresses of all illegal migrants apprehended in the Netherlands between I January I997 and I October 2003 . The data have been provided by the 25 Dutch police forces and are taken from the Vreemdelingen Administratie Systeem, VAS, a national database in which all known aliens are registered. For each municipality and neighbourhood (postcode area, i.e. an area that contains on average roughly 2,000 households and 5,000 individuals), the number of addresses were counted where, according to police data, illegal migrants were living. This measure, which was called absolute concentration, gives an indication of the local density of the illegal population. It was linked to a database containing information on various demographic and socioeconomic characteristics of the neighbourhood and the share of private homeownership in them. This database with neighbourhood characteristics was compiled by the Dutch Bureau for Statistics (CBS) and is called Kerncijfers Wijken en Buurten I999. The data on private homeownership were supplied by the Ministry of Housing and are taken from the research Geomarktprofiel 1998. As a measure of the relative number of illegal migrants, hereinafter called relative concentration, the absolute concentration of illegal migrants was multiplied by I,০o० and divided by the number of legal local residents. Next, the socioeconomic characteristics of the neighbourhoods where illegal residence is common were identified. By means of multiple regression analysis, the relative concentration of illegal migrants was predicted on the basis of such neighbourhood characteristics.

The fieldwork was conducted in Bospolder-Tussendijken in Rotterdam and De Schilderswijk in The Hague in 2003. These neighbourhoods were selected because police data indicated that illegal residence occurs regularly there. Both neighbourhoods are part of multicultural districts populated by many non-Western immigrants. Sixty-five per cent of the residents of Bospolder-Tussendijken are immigrants, including many 
Turks, Moroccans, Cape Verdeans and Surinamese. De Schilderswijk comprised 85 per cent immigrants, including many Turks, Surinamese, Moroccans and Antilleans. Twenty key informants were interviewed by my fellow researcher Dr. Marion van San and myself. These professionals regularly came into contact with illegal migrants and could often indicate why, and how, illegal migrants reside there. They were employees of the alien police, the municipal authority and housing associations, as well as community and social care workers. The interviews were conducted with the help of a short topic list.

In addition, 65 illegal migrants from Morocco, Turkey, Bulgaria, Somalia, India and Pakistan were interviewed, as well as 45 providers of accommodation (Dutch, Moroccan, Turkish, Surinamese and Somali). In addition, five mixed couples, of whom one partner was staying in the Netherlands illegally, were interviewed. The interviews with illegal migrants and providers of accommodation were carried out by a team of interviewers who were selected according to their ethnic background so that the interviews could be held in the respondent's mother tongue. All had some form of higher education, useful interviewing skills and experience with the research groups concerned. They personally recruited respondents with the help of key informants (police, social workers, etc.), or searched for respondents in cafes, teahouses, mosques or in the street. Respondents were asked to bring the interviewer into contact with other illegal migrants or with their accommodation providers. The interviewers made use of a questionnaire with open and closed questions. Illegal migrants who took part in the research were given a financial incentive.

\section{Limitations}

This sub-study has some limitations. First, the quantitative data primarily give a picture of the illegal population that ran some risk of being apprehended. Although the number of apprehensions, I07,322, was substantial, it was impossible to determine the extent to which the home addresses of apprehended illegal migrants constituted a correct representation of the home addresses of all illegal migrants who lived in the Netherlands between 1997 and 2003. In a number of apprehensions no home address was registered and sometimes the stated home address proved to be the address where the person was apprehended or the address of a police station or detention centre. Most of these complications could be solved by checking and cleaning up the database. ${ }^{\mathrm{I}}$ Registrations without home address, for example, often involved illegal migrants who were apprehended at the border and therefore had not yet taken up residence in the Netherlands. The addresses of police stations and detention centres could be identified. In addition, it was examined how often the 
police had recorded the place of apprehension as the home address while the arrested person was actually living somewhere else. It is not likely that this happened very often. When the address was not registered, the place of apprehension could sometimes be used as an indication of the home address (such as in the case of house raids). Bias as a result of incomplete or inaccurate registration of home addresses may therefore be said to be limited.

Local police priorities naturally influence the number of local apprehensions. At the end of this sub-study's research period (1997-2003) raids became more frequent in Amsterdam, Rotterdam and The Hague, as well as in some rural concentration areas. Employers were increasingly subjected to checks by the labour inspectorate. Most illegal migrants, however, are still apprehended in the course of regular police work - i.e. as crime suspects or because of minor offences such as driving too fast or dodging public transport fares (Van der Leun 2003). This is probably the reason why no indications were found for substantial geographical differences in the risk of arrest. $^{2}$

Although the results of the neighbourhood studies cannot be generalised as such, 'qualitative completeness' was aimed at (Hammersley \& Atkinson 1995; Lofland \& Lofland 1995). Additional respondents were searched until no more new types of accommodation were found, and a complete picture appeared to have been formed of the reasons why illegal migrants resided in these neighbourhoods. The limitations of the separate research methods and sources were met as far as possible by triangulation. The information provided by the professionals, landlords and illegal migrants could be compared. The information obtained from the people involved was compared with the quantitative results. This reinforced confidence in the validity of the findings.

\section{Results}

The distribution of illegal residence across Dutch provinces and municipalities

Illegal residence is not merely an urban phenomenon, for the greatest relative concentrations were found in both the most and least densely populated areas. There are illegal migrants in rural areas in the north of the province of North Holland (A), and in the provinces of Brabant (B) and Groningen (C) (see Figures 2.I and 2.2). In rural areas illegal residence is primarily connected with the demand for seasonal workers in the horticultural and agricultural sectors (De Bakker 200I). The registered addresses suggest that the presence of centres for asylum seekers, Chinese restaurants and brothels are also important, albeit to a lesser extent. The increased level of illegal residence in the south of the pro- 
vince of Limburg (D) is, in part, due to drug tourism from bordering EU member states. Many illegal migrants there have French, Belgian or German nationality and have usually lost the right of residence in the Netherlands since they were declared undesirable aliens after causing nuisance related to drugs. Finally, a substantial proportion of illegal residence occurs in municipalities with detention and deportation centres for illegal migrants and rejected asylum seekers - for example, in Zevenaar (north of B), Ter Apel (near C) and Rijsbergen (near D). Apprehended illegal migrants often stay in these institutions for months and often more than once (Van Kalmthout \& Van Leeuwen 2004; see also the conclusion of this book).

Figure 2.1 Spatial distribution of the illegal population across the Netherlands (absolute concentration)

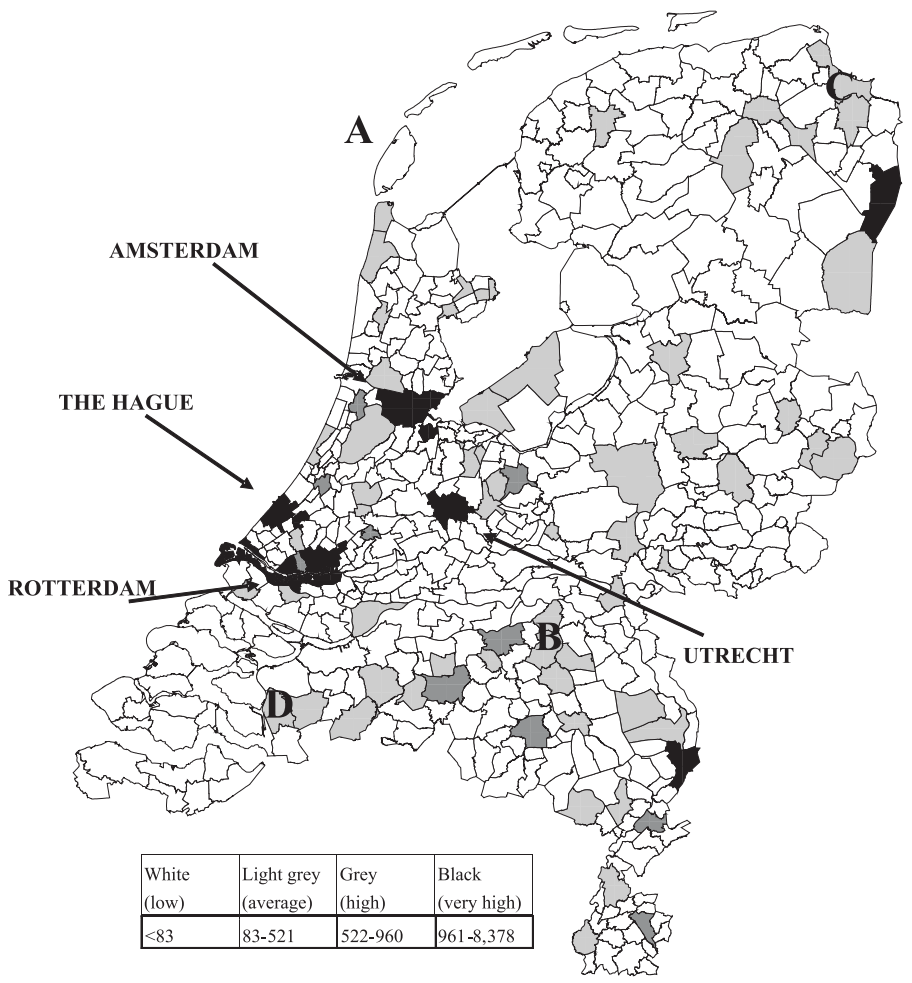

Sources: Dutch Bureau for Statistics; Vreemdelingen Administratie Systeem 1997October 2003

The description that follows is limited to illegal residence in urban environments, not in detention. In addition, the focus is on illegal residence 
by non-Western third-country nationals (i.e. people from outside the EU who are not nationals of states in North America or Oceania).

Figure 2.2 Spatial distribution of the illegal population across the Netherlands (relative concentration)

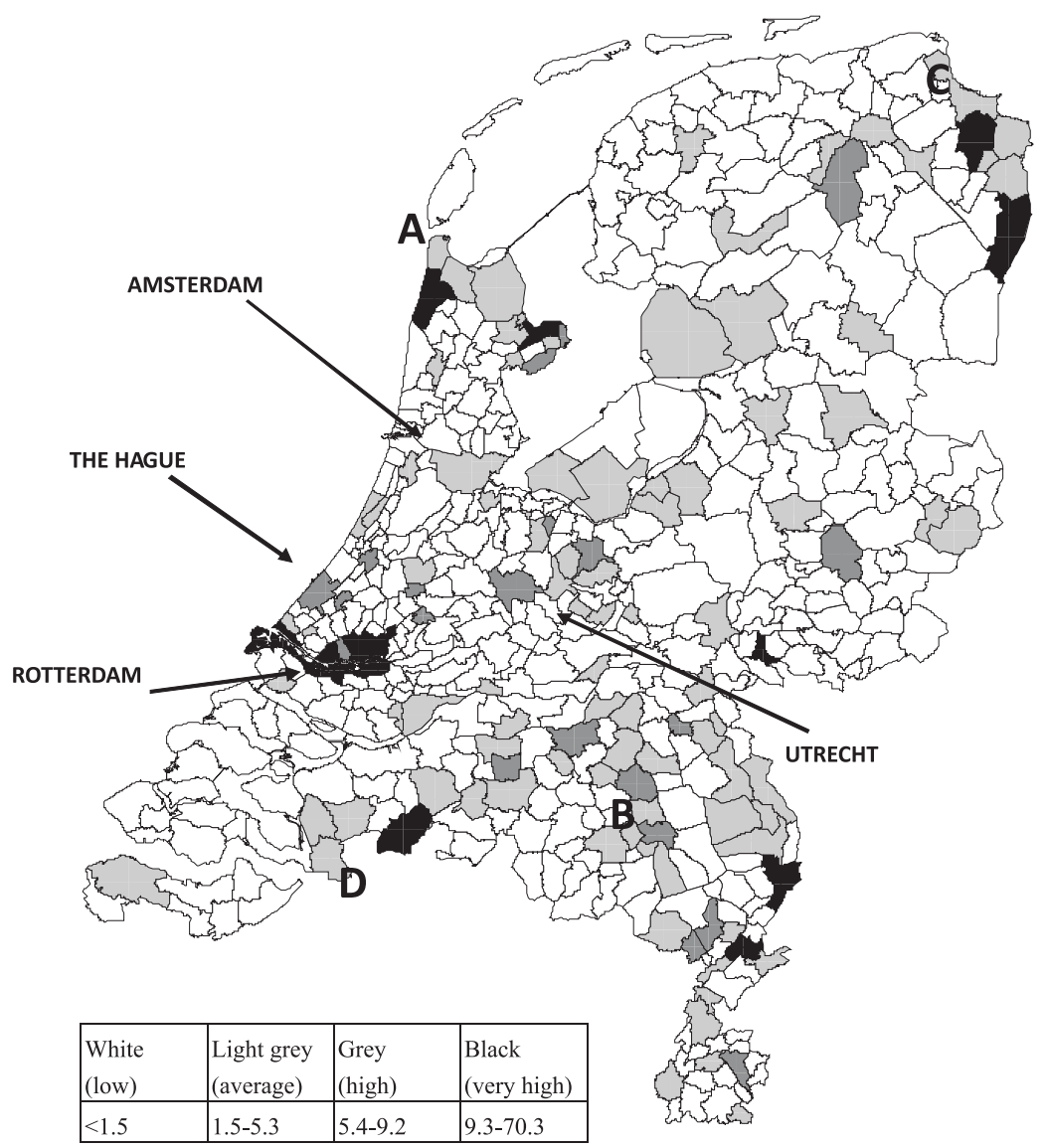

Sources: Dutch Bureau for Statistics; Vreemdelingen Administratie Systeem 1997October 2003

The spatial incorporation of illegal residence in urban environments

It is common practice to use segregation indexes (S) to measure the extent to which two groups are spatially segregated from one another. (Strictly speaking, the term 'dissimilarity index' should be used when two groups do not constitute the total population.) The index indicates the percentage of the group that should move in order to bring about a 
complete mutual mixing. The higher the index, the lower the extent of mixing and the stronger the degree of residential segregation. The results are calculated at the level of postcode areas and should be interpreted with some caution, since postcode areas differ somewhat in size. Figure 2.3 shows the extent to which the illegal and legal populations are spatially segregated. Three curves can be distinguished which respectively, from top to bottom, indicate the mixing with the Dutch native population $(S=52)$, the total urban population $(S=48)$ and the non-Western immigrant population ${ }^{3}(\mathrm{~S}=33)$. What becomes clear is that, compared with ethnic minority groups, Dutch natives less often have illegal migrants as neighbours. Approximately 60 per cent of the illegal migrants live in city districts that house $\mathrm{I} 3$ per cent of all Dutch natives, 4I per cent of all non-Western immigrants and I7 per cent of the total legal urban population. Furthermore, 80 per cent of the illegal urban population lives in districts that house 3I per cent of the native population, 6I per cent of the legal non-Western immigrants and 35 per cent of the total urban population (see the dotted lines in the figure).

Figure 2.3 Extent of residential segregation between the illegal population and (segments of) the regular population ${ }^{3}$

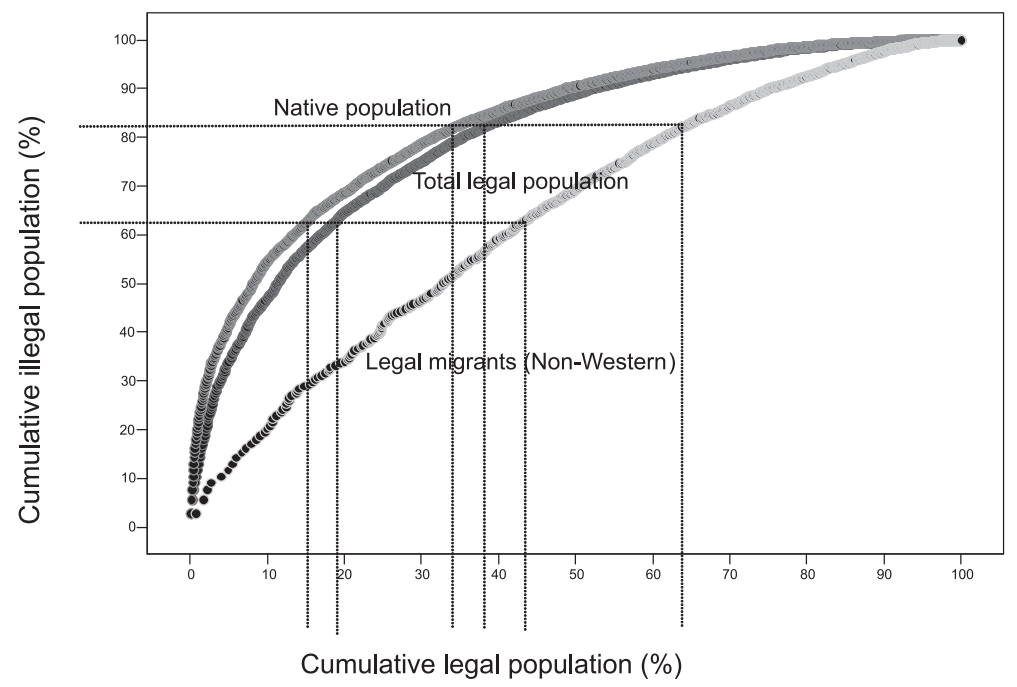

Sources: Dutch Bureau for Statistics; Vreemdelingen Administratie Systeem 1997October 2003

As expected, the illegal population is selectively incorporated in the urban landscape. Whereas some city districts house relatively large numbers of illegal migrants, most neighbourhoods house none or only a few. This observation implies that illegal migrants usually constitute a much 


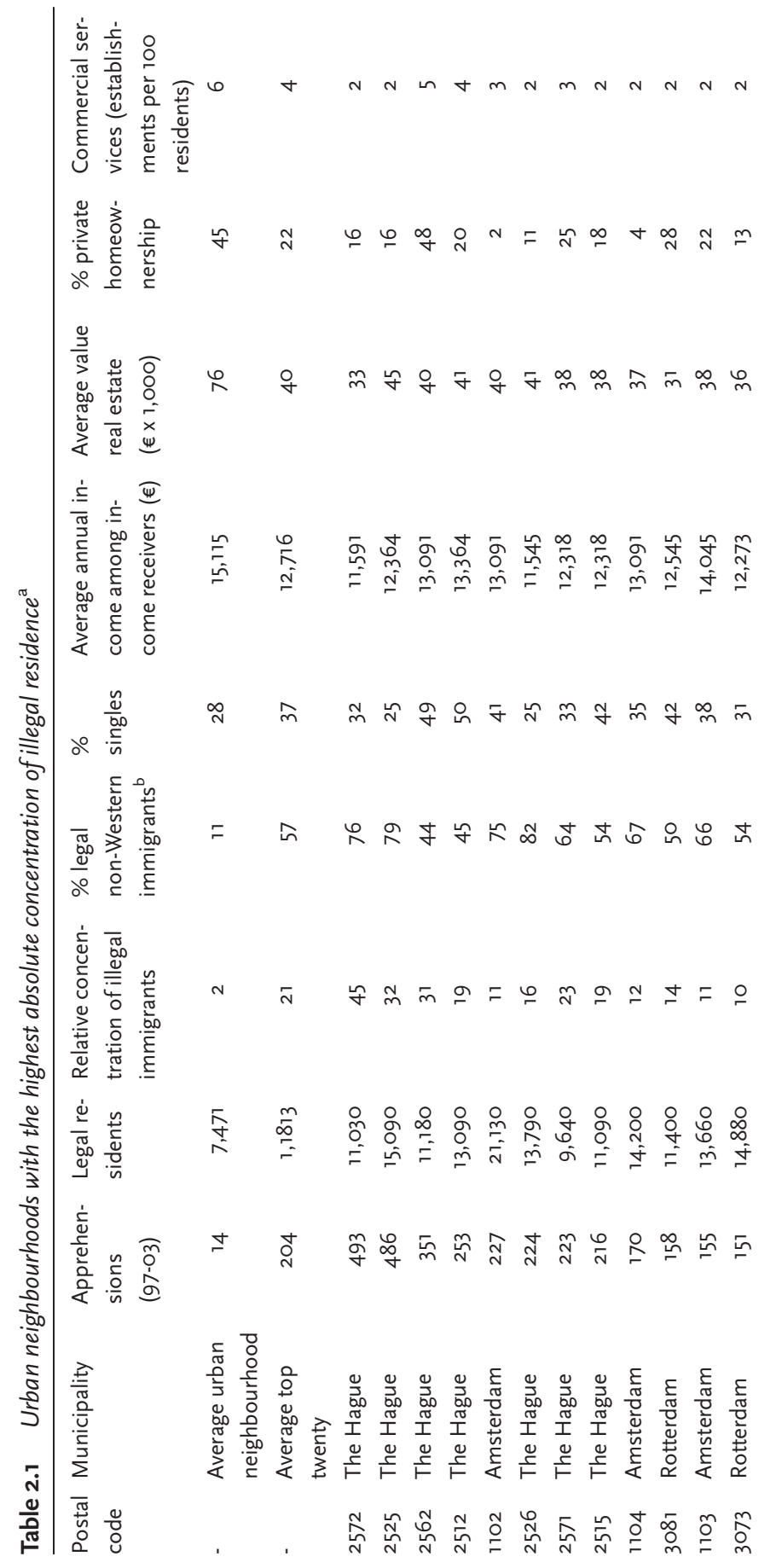




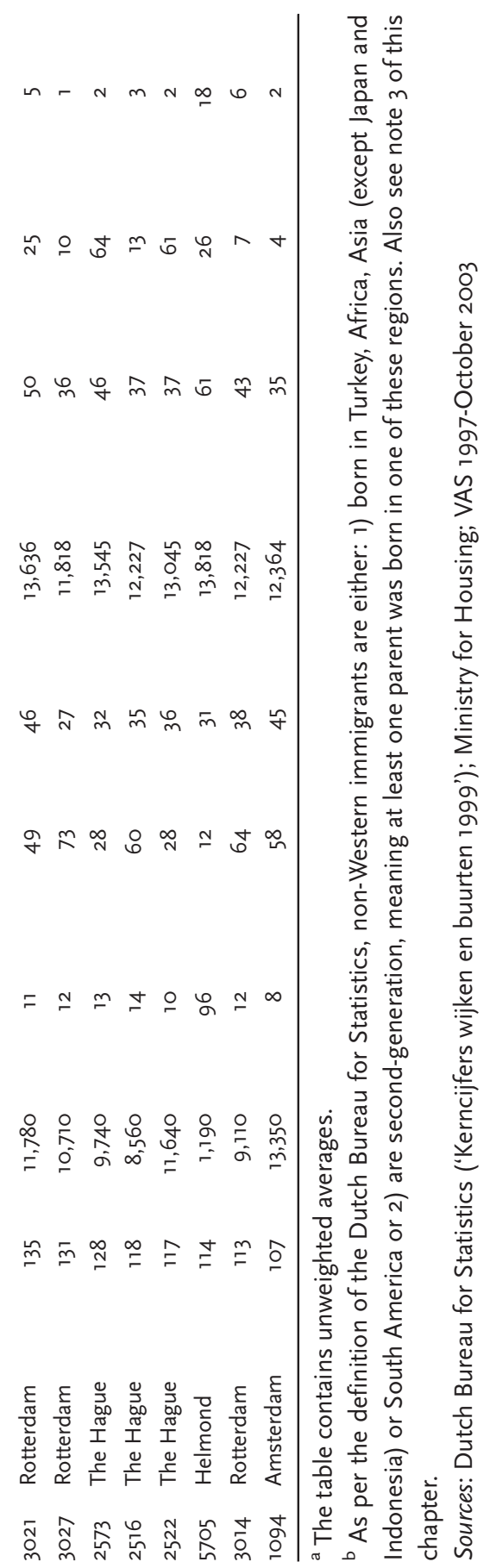




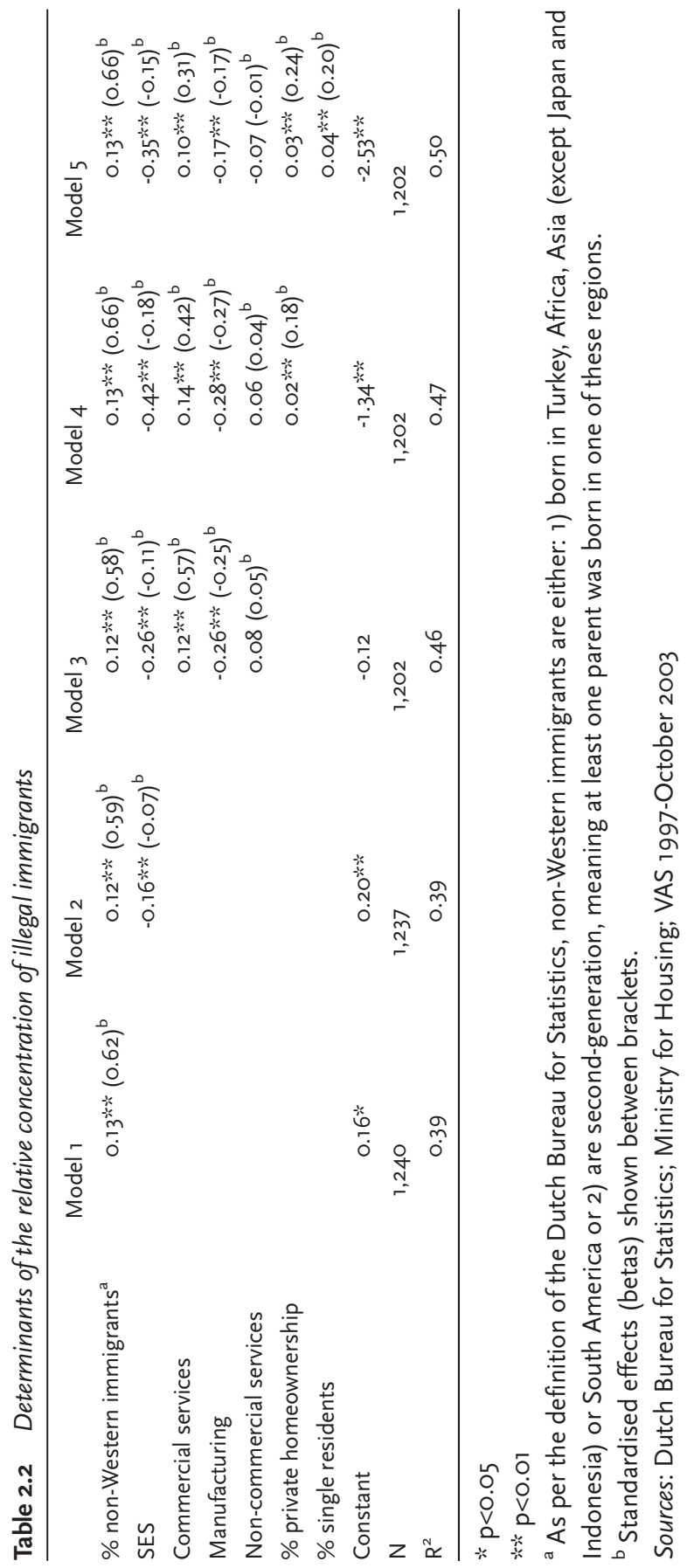


smaller proportion of the local population than the estimated national average of I per cent and sometimes substantially higher - probably up to about 6 or 8 per cent (see Leerkes et al. 2004).

The question is how the selective spatial incorporation of illegal migrants can be explained. Table 2.I gives a ranking of twenty neighbourhoods that house the most illegal migrants. The table contains only a few Amsterdam and Rotterdam neighbourhoods, but this is mainly because the local police record the home addresses of illegal migrants less often than in other cities. The police in The Hague, by contrast, record them quite accurately. In The Hague ( 48 per cent) the percentage of registered residential addresses is twice as high as in Amsterdam (24 per cent) and Rotterdam (2I per cent). Nationally, this figure is 30 per cent. If police registration had been better, the Amsterdam and Rotterdam neighbourhoods would have been featuring prominently in this top twenty list (see Leerkes et al. 2004).

The characteristics of the neighbourhoods provide an initial confirmation of the theoretical expectations. Illegal migrants are often housed in poor immigrant districts; the average proportion of non-Western immigrants for the twenty districts is 57 per cent versus in per cent for the city as a whole.

Table 2.2 contains five linear regression models. ${ }^{4}$ The models show that differences between neighbourhoods as to the rate of illegal residence depend on neighbourhood differences in the concentration of legal non-Western immigrants, socioeconomic status, the size and form of the neighbourhood economy, the share of private homeownership and the concentration of single-person households. The first four models test the extent to which the spatial distribution of the illegal population corresponds with our initial theoretical assumptions. The independent variables are indicators of the extent to which neighbourhoods contain non-Western migrant communities (percentage of non-Western immigrants), economic opportunities (the relative number of establishments engaging in commercial services, manufacturing and non-commercial services) and housing opportunities (socioeconomic status of the neighbourhood and percentage of private homeownership). It was examined whether the fourth model could be improved with additional independent variables. The percentage of single people did indeed have an additional effect (fifth model). ${ }^{5}$

In what follows, the quantitative results in Table 2.2 are discussed and interpreted with findings that are of a qualitative nature.

\section{The presence of non-Western migrant communities}

Two statistical observations suggest that legal immigration tends to bring about illegal chain migration. First of all, as Table 2.2 shows, the 
effect of the proportion of immigrants in the neighbourhoods on the rate of illegal residence hardly decreases when other neighbourhood characteristics are incorporated into the model. A second indication is the settlement pattern of illegal migrants from countries for which there are large established ethnic groups, such as Turkey, Morocco and Surinam. This pattern can be quite well illustrated with the help of a number of maps of The Hague (see Figures 2.4 and 2.5). It turns out, for example, that a relatively large number of illegal Turks live in the districts where legal Turks live and that illegal Moroccans usually end up in the districts with many legally resident Moroccans. This effect is somewhat stronger for the Turks than for the Moroccans, which has to do with the stronger social cohesion and networks of trust among Turkish immigrants (Engbersen 200I; Staring 200I).

Figure 2.4 Distribution of Turks across The Hague
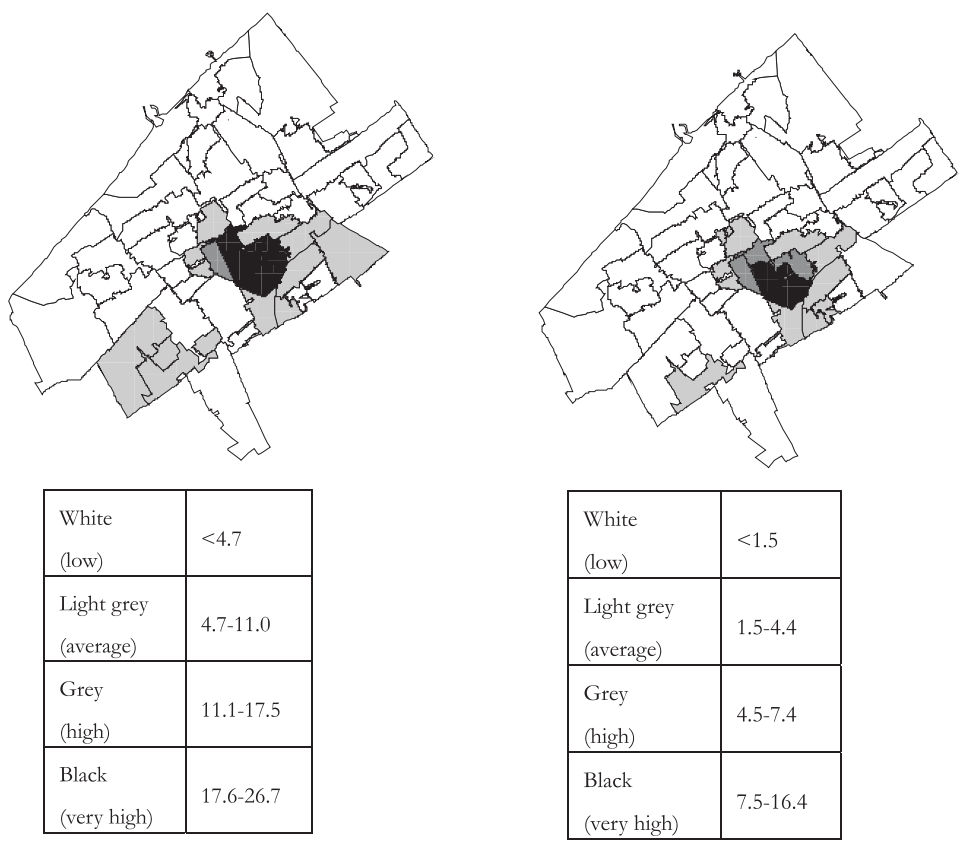

Left: First- and second-generation legal Turks (\% of total population)

Right: Illegal Turks (relative concentration)

Sources: Dutch Bureau for Statistics; Vreemdelingen Administratie Systeem 1997-

October 2003

The fieldwork suggests that such causal connections can be direct and indirect. First, it turns out that many respondents live in these neighbourhoods because family or acquaintances, who usually took care of 
them after they arrived, live nearby. These established immigrants often help illegal newcomers in their primary network to find a room or flat in the neighbourhood. The indirect relations are mainly found among illegal migrants who have no family members in the Netherlands. It turned out that some had come to Europe with the help of human smugglers and/or had gone through asylum procedures to no effect, often elsewhere in the Netherlands.

Figure 2.5 Distribution of Moroccans across The Hague
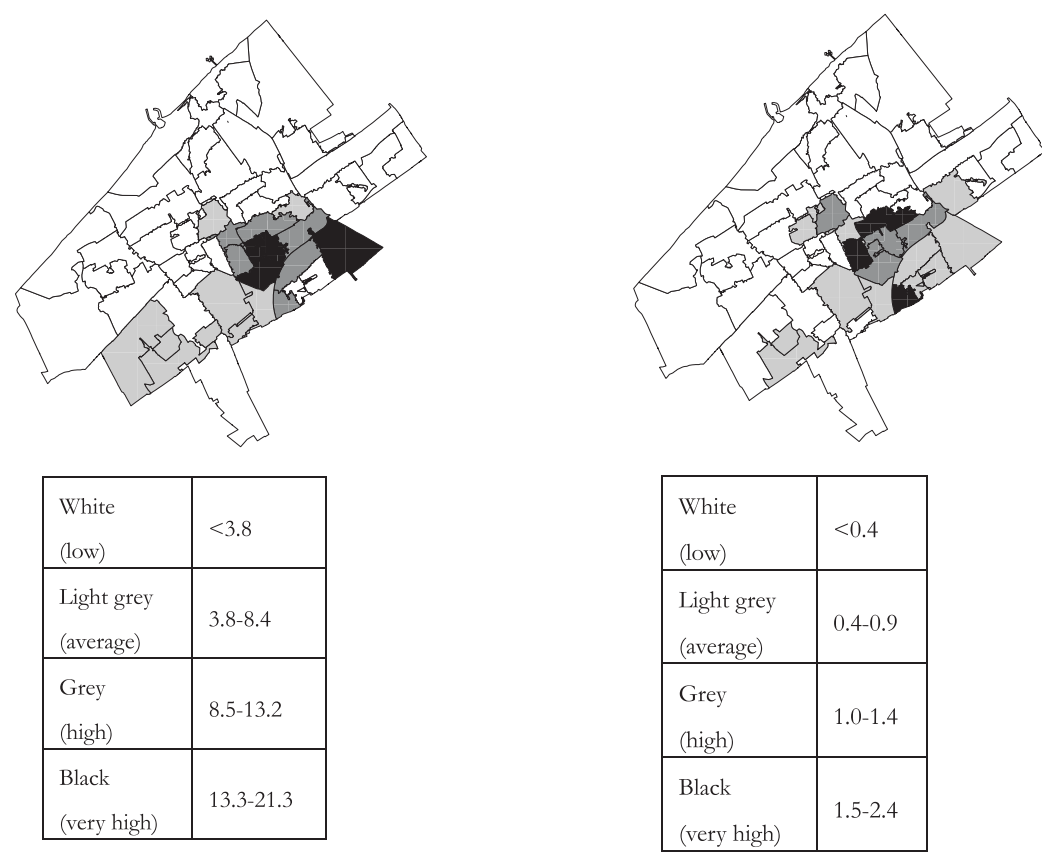

\begin{tabular}{|l|l|}
\hline $\begin{array}{l}\text { White } \\
\text { (low) }\end{array}$ & $<0.4$ \\
\hline $\begin{array}{l}\text { Light grey } \\
\text { (average) }\end{array}$ & $0.4-0.9$ \\
\hline $\begin{array}{l}\text { Grey } \\
\text { (high) }\end{array}$ & $1.0-1.4$ \\
\hline $\begin{array}{l}\text { Black } \\
\text { (very high) }\end{array}$ & $1.5-2.4$ \\
\hline
\end{tabular}

Left: First- and second-generation legal Moroccans (\% of total population)

Right: Illegal Moroccans (relative concentration)

Sources: Dutch Bureau for Statistics; Vreemdelingen Administratie Systeem 1997-

October 2003

They told us they preferred neighbourhoods with some ethnic variety and where many people speak their language or dialect, making them inconspicuous. In addition, they hope to benefit from the ethnic infrastructure established by previous immigration flows: mosques (to pray and meet people, and where free food is sometimes served during Ramadan), ethnic shops (where they can buy products from the country of origin and can sometimes get a job) and coffee houses (to spend the day cheaply and come into contact with people). The tendency to seek accommodation near places where compatriots live - 'ethnic self-segrega- 
tion' (see Stepick et al. 2003) - is well documented for legal migrants (Musterd et al. I998; Van der Wouden \& Bruijne 200I). That the presence of legal compatriots tempts illegal migrants to live in relatively homogeneous 'urban villages' (Gans I962/I982) is aptly illustrated by the following excerpt from an interview.

I went to live in Bospolder-Tussendijken because my brother lived here and because there are many Moroccans with a valid residence permit in this neighbourhood who help me with all kinds of things when I need them. This neighbourhood mainly has a social function for me. I meet a lot of people with whom I make appointments and chat about all and sundry'. (illegal Moroccan)

Certain groups of illegal migrants do not take up residence in deprived immigrant neighbourhoods because they have family members or compatriots who live there, but rather because of the, in comparison to other neighbourhoods, favourable supply of housing. This becomes more evident when the effect of neighbourhood socioeconomic status is included in the analysis.

\section{The socioeconomic status of the neighbourhoods}

Illegal residence is associated with low income in two ways. First, lowskilled potential immigrants have little chance of obtaining a legal residence permit because the Dutch government has strongly discouraged low-skilled labour migration for some time now (Van der Leun 2003). Secondly, it is practically impossible to earn a high income without a residence permit, because it precludes a work permit. It is therefore understandable that illegal migrants often end up at the bottom of the housing market.

Table 2.2 indicates that the socioeconomic status of the neighbourhoods yields an independent negative effect on the degree of illegal residence. ${ }^{6}$ Two additional maps of The Hague confirm this observation (Figure 2.6). Illegal Eastern Europeans usually live in neighbourhoods where many illegal Turks and Moroccans reside (near A) and are thus not spatially embedded in a legal Eastern European community. The few legal Eastern Europeans in The Hague (staff of embassies and international organisations) live primarily in the more upmarket city districts (near B).

In the neighbourhoods where the fieldwork took place, an informal commercial housing sector has emerged. This informal sector is particularly important to illegal migrants who cannot fall back on the support of family or friends in the Netherlands. Both in Rotterdam and in The Hague, landlords of mainly Dutch, Turkish or Hindu-Surinamese origin 
offer accommodation to indigent people, in general, and illegal migrants, in particular. They rent out floors, rooms and beds. Premises where ten to 30 people can rent a bunk bed are called 'sleeping houses' by the local residents. It usually concerns rundown houses. In the commercial circuit, the price for a bed turns out to be about 150-250 euros and the price for a flat is 600-700 euros. This is clearly more than the amount paid by illegal migrants who live-in with their family or acquaintances, usually for free, or sublet a flat from a friend or family member (I50-400 euros).

Figure 2.6 Distribution of Eastern Europeans across The Hague
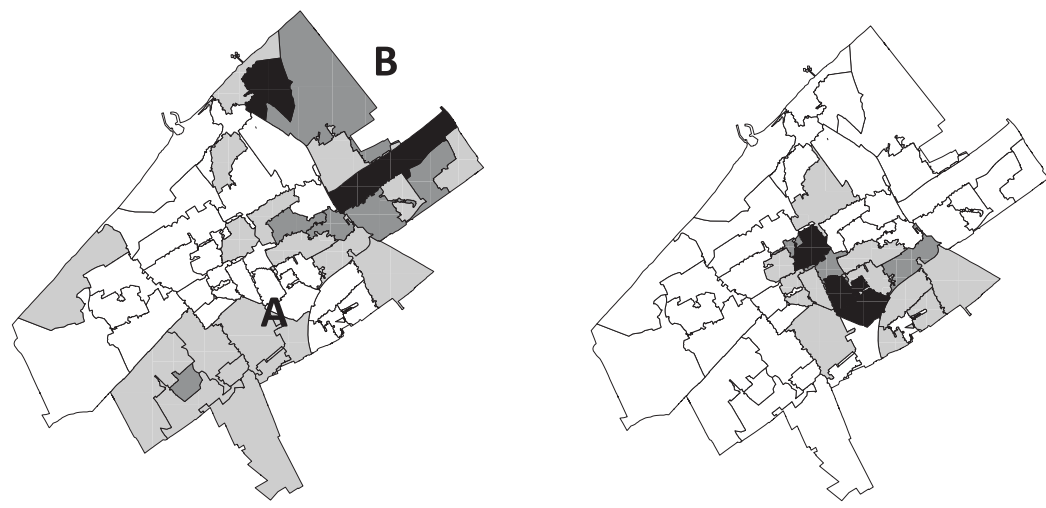

\begin{tabular}{|l|l|}
\hline $\begin{array}{l}\text { White } \\
\text { (low) }\end{array}$ & $<1.0$ \\
\hline $\begin{array}{l}\text { Light grey } \\
\text { (average) }\end{array}$ & $1.0-1.3$ \\
\hline $\begin{array}{l}\text { Grey } \\
\text { (high) }\end{array}$ & $1.4-1.6$ \\
\hline $\begin{array}{l}\text { Black } \\
\text { (very high) }\end{array}$ & $1.7-1.9$ \\
\hline
\end{tabular}

\begin{tabular}{|l|l|}
\hline $\begin{array}{l}\text { White } \\
\text { (low) }\end{array}$ & $<2.3$ \\
\hline $\begin{array}{l}\text { Light grey } \\
\text { (average) }\end{array}$ & $2.3-5.8$ \\
\hline $\begin{array}{l}\text { Grey } \\
\text { (high) }\end{array}$ & $5.9-9.3$ \\
\hline $\begin{array}{l}\text { Black } \\
\text { (very high) }\end{array}$ & $9.4-14.1$ \\
\hline
\end{tabular}

Left: First- and second-generation legal Eastern Europeans (\% of total population) Right: Illegal Eastern Europeans (relative concentration)

Sources: Dutch Bureau for Statistics; Vreemdelingen Administratie Systeem 1997October 2003

Although illegal migrants from Eastern Europe often live in rural horticultural areas, some were also found in Bospolder-Tussendijken and, in rather larger numbers, in De Schilderswijk. They were mainly Bulgarians. The men usually spent the night in sleeping houses and were 
picked up by minivans in De Schilderswijk and taken to the greenhouses in the nearby Westland area every workday (Engbersen et al. 2006). The men slept in sleeping houses because of their relatively modest incomes, but also because of the absence of established family members and compatriots in the neighbourhood. A lack of economic capital drives this group to deprived neighbourhoods, while a lack of social capital makes them dependent on the commercial circuit within these neighbourhoods, though the men also stayed in these houses more or less by choice. The Bulgarians, for instance, told us that they had come to the Netherlands first of all to earn money for their families. These labour migrants, or 'birds of passage' (Piore I979), aim for a temporary stay in the Netherlands and hope to save as much money as possible. They are therefore willing to make concessions as to how they are housed. This phenomenon has also been observed among legally resident labour migrants. In the nineteenth century, there were 'migrant hostels' for country folk who had moved to town (De Regt I984; De Swaan I988) and many Mediterranean guest workers, who came to the Netherlands in the twentieth century, lived initially in similar simple guesthouses (Bovenkerk et al. I985; Bolt \& Van Kempen 2002). It may well be, however, that the present-day sleeping houses are more overcrowded and rundown than in the past, because illegal migrants are more prone to exploitation. They probably have fewer alternative housing opportunities than legal migrants had in the past and, moreover, have no rights if they complain about the quality of their housing. The importance of cheap rooming houses and 'flophouses' ('flop' was slang for bed in the I920s) is also documented by scholars from the early Chicago School (see Anderson I923/I967 and Zorbaugh I929).

\section{Economic activity}

The compiled database enables us to examine to what extent illegal residence correlates with the neighbourhood economy. It was found that there is indeed an elevated concentration of illegal residence in neighbourhoods that contain more businesses in the commercial service industry. Activity in semi-governmental institutions (ministries, schools, hospitals, etc.) does not influence the number of illegal migrants. The latter observation is fairly unremarkable. After all, if semi-governmental institutions do offer illegal migrants chances of work, it will be merely indirectly, for example, through cleaning agencies located elsewhere.

These observations suggest that illegal migrants more often work in service industries than in manufacturing - at least in their immediate living environment. There are several explanations for this selective labour pattern. First of all it is common knowledge that illegal migrants often perform jobs with little social prestige, which do not appeal to the 
established working population (Visser \& Van Zevensbergen 200I; Engbersen et al. 2002). Whereas low-skilled industrial labour has been largely automated and transferred to low-wage countries over recent decades, such cost savings were often impossible in the more labourintensive service industries. Small and medium-sized enterprises, including most ethnic shops, often depend on cheap and informal labour in order to make their business pay (Stepick I989). Over recent decades in the personal service industry in the Netherlands many new migrant enterprises have emerged that often have access to illegal migrants in their personal networks, at least more so than Dutch industrial entrepreneurs (Kloosterman, Van der Leun \& Rath i998; Van Tillaart 200I). According to some professionals, some illegal migrants travel to the Netherlands on tourist visas as labour migrants, to find jobs in ethnic shops or small family businesses with the help of family and friends. Finally, the risk of getting caught may differ per sector. Industrial enterprises are generally larger than service companies. Checking small firms for illegal workers may be inefficient.

The place of residence and place of work of illegal migrants are linked in several ways. Several respondents told us that they took up residence in the neighbourhood after they had found work there by asking around (Engbersen et al. 2006). Others were unemployed for a while and stayed in the neighbourhood after they ultimately found work there. For specific groups of illegal migrants the place of residence and place of work are actually one and the same: they sleep at their workplace. Police data suggest this occurs primarily in businesses that cannot provide illegal workers with suitable accommodation in the immediate vicinity, such as Chinese restaurants, which are often located outside migrant districts in the Netherlands, and brothels in inner cities or rural areas. However, some professionals told us that these practices sometimes take place in migrant neighbourhoods as well. According to these informants, such housing practices may indicate human trafficking and exploitation (see also Van der Leun \& Vervoorn 2004).

Economic activity may promote illegal residence, but the reverse may also be the case: the presence of illegal migrants sometimes promotes specific types of economic activity. In particular, in De Schilderswijk, many small semi-legal and shady employment agencies have been recently established to recruit illegal migrants (Zuidam \& Grijpstra 2004). The companies that make use of their services, such as the Dutch horticulture greenhouses in the nearby Westland, are often located elsewhere. In this way the clients can profit from illegal migrant labour in spite of government regulations and increased checks on illegal labour. The companies themselves do not risk the increased fines, as the employees are formally employed by the employment agencies. 
The effects of the neighbourhood economy on the concentration of illegal residence demonstrate the surplus value of multiple regression analyses. The twenty districts with the most illegal migrants are characterised by a low number of businesses in the commercial service sector (see Table 2.I). It appears that the elevated rate of illegal residence in these concentration areas is brought about mostly by the remaining dimensions of the opportunity structure of illegal residence, such as the presence of ethnic minorities. Hence, it is likely that the rate of illegal residence there would increase further if more small businesses were set up. After all, it would then become more attractive to have a family member come over illegally, as it is more certain that the follow-up migrant will be able to earn his or her own living and will thus not constitute a financial burden.

\section{Private homeownership}

The presence of private rental accommodation - indicated in Table 2.2 by the percentage of private homeownership, since geographical data on private renting were not available - exerts an independent effect on the degree of illegal residence as well. On average, more illegal migrants turn out to live in deprived neighbourhoods with many immigrants and private homeownership than in comparable neighbourhoods where most of the housing stock is in the hands of housing associations, as is the case in most concentration areas.

It can be assumed that it is easier to house illegal migrants in privately owned houses than in houses that belong to housing associations (Burgers I998). There are two reasons for this. First, illegal migrants can no longer be the main tenants of houses owned by associations. The implementation of the Koppelingswet, the I998 law that made it possible to limit the access of illegal migrants to public services, means that housing associations are now obliged to check the residence status of potential tenants in the population register (see Van der Leun 2003). Private landlords do not have this obligation, so illegal migrants can rent in the private sector, whereas they have only indirect access to housing association houses as either informal sub-tenants or housemates. Secondly, private premises can more easily be made suitable for occupation by a larger number of people than intended (see Botman \& Van Kempen 200I). It turns out that some landlords set up partition walls in their houses in order to rent out as many small rooms or beds as possible. A small number of landlords in districts such as Bospolder-Tussendijken and De Schilderswijk own hundreds of houses. In addition, there are many small private landlords who rent out one or two houses to migrants who lack residence permits. 
The positive effect of private homeownership is revealed using multiple regression analyses. In the twenty concentration neighbourhoods (see Table 2.I), most houses are owned by housing associations. It seems that most illegal migrants follow the residential pattern of the legal, nonWestern immigrants with whom they live as housemates or subtenants. At present most non-Western immigrants live in housing association homes (Van der Wouden \& Bruijne 200I). So the rate of illegal residence would probably rise somewhat in these concentration areas, and in the Netherlands in general, if established non-Western immigrants lived in the vicinity of privately owned homes to a greater extent.

\section{Singles}

Personal relations between single people and illegal migrants have so far not been given much attention in the literature though previous research has documented that illegal migrants sometimes enter into relationships with legal residents in order to obtain residence permits (Staring I998; Engbersen 200I). Furthermore, Burgers (I998) pointed to the reciprocal character of some relationships, which he often encountered among illegal prostitutes or ex-prostitutes.

The presence of single people indeed appears to increase the rate of illegal residence even though it was suspected initially that the correlation was spurious. Illegal migrants as well as singles are overrepresented in poorer urban environments; like illegal migrants, many singles have lower incomes than people with families or those who cohabit. And indeed, the effect of the percentage of singles on the concentration of illegal residence decreases when the percentage of non-Western immigrants and the socioeconomic status of the neighbourhood are controlled for. Still, the effect of the percentage of singles does not disappear. ${ }^{7}$ The positive correlation between the rate of illegal residence and the percentage of singles therefore cannot be attributed entirely to the fact that, as a rule, illegal migrants happen to live in neighbourhoods with many singles and that the districts involved usually have a lower socioeconomic status.

The neighbourhood studies confirm that there are differing connections between singles and illegal migrants. First of all, singles appear to have an increased probability of subletting or partial subletting. The Dutch rent rebate system enables people with comparatively low incomes to rent relatively large houses, parts of which can be sublet to third parties. Furthermore, there is also the possibility that someone who initially lived together with a partner continues to rent the house after separation and sublets parts thereof. According to some professionals, local residents sometimes rent a self-contained dwelling in order to become eligible for higher unemployment benefits, whereas they do 
not actually live there but re-let the dwelling to third parties. Some local residents supposedly see renting a housing association house as a welcome opportunity to increase the family income. The formal tenant moves in with his or her partner or relatives and sublets the housing association flat to a third party at a higher price. Informal subletting of social housing can be rather profitable, as the official rent of these subsidised houses is lower than the market value (after deduction of the rent rebate).

Besides subletting practices, there is also the matter of relationships between singles and illegal migrants. Several professionals mentioned that some legal residents have illegal partners. In their view, heterosexual singles are at the very least providing accommodation for illegal migrants of the opposite sex. These residents are quite often older men who offer illegal young women a roof over their heads. They may well be indigent single men with relatively few chances on the primary dating market. An employee of a housing association in The Hague told us that he encountered several cases each month involving residents officially registered as singles - legal immigrants as well as Dutch natives - who had their partners come over illegally or who felt obliged to let their partners reside illegally in the Netherlands after a residence permit had expired, for instance because they could not prove that they would be able to support their partner. In the Netherlands the criteria for having a partner come over from outside the EU have recently become more restrictive (Chapter I, also see Snel et al. 2005). Furthermore, the local alien police regularly receive calls from people who claim to have ended their relationships and indicate that their partners are now probably residing illegally somewhere in the Netherlands, perhaps somewhere else in the postcode area.

\section{Determinants in combination and interaction}

So far, we have seen that the spread of the illegal population is related to the distribution of non-Western ethnic minorities, the distribution of low-income and high-income households, the distribution of certain types of economic activity, the distribution of privately owned cheap housing and the distribution of poor single people. In other words: the patterns of spatial incorporation of illegal migrants parallel the more comprehensive allocation patterns among legal migrants, economic activity and single households, as well as elaborating on them. And yet the socioeconomic nature of the forces that determine the spatial incorporation of illegal migrants does not, as such, provide sufficient explanation for the high degree of spatial concentration of the illegal population. Illegal residence is concentrated in a limited number of environments primarily because the opportunity structure of illegal residence is itself spa- 
tially concentrated. The dimensions of this structure exhibit the strongest development in the cities (with the exception of private homeownership, which occurs relatively often outside the cities). In the cities the separate dimensions are spatially concentrated in specific residential areas. After all, legal ethnic groups are not evenly spread across all city districts. And houses for indigent households, relevant types of economic activity and indigent singles are also spatially concentrated.

Secondly, the determinants of illegal residence are often concentrated in the same neighbourhoods. High concentrations of non-Western immigrants and single people are after all characteristic of city districts with a low socioeconomic status. Furthermore, economic activity in the personal service industry is clustered in urban areas, although within these areas it is quite evenly distributed. Private homeownership is, at least in the Netherlands, concentrated in districts where the other dimensions of the opportunity structure of illegal residence are relatively weakly developed. Private homeownership is more often found outside the cities and, within the city, it is scarcer in poor districts than in affluent districts. This condition is in principle favourable for deconcentration of illegal residence. It might be the case that illegal residence in privately owned houses also occurs in the more well-to-do districts (see Mahler I995). However, it is unlikely that this variant, in which a high rent is paid by a large number of illegal migrants, occurs very often in the Netherlands (see note 6).

Thirdly, there are interactions between the determinants. The statistical analyses assumed that each neighbourhood characteristic had a separate effect and was independent of the other neighbourhood characteristics. This division into independent factors does not do full justice to the complex mutual dependencies in social reality (see Elias I978). For example, the cohabitation of a single person and an illegal migrant presupposes mutual contact. The opportunities for that depend, among other things, on the extent to which single people and illegal migrants fall back on the same neighbourhoods. Some respondents met their partner in the neighbourhood.

Said is a 29-year-old Moroccan man from Rabat who came to the Netherlands on a student visa in I998. Family members who already lived in the Netherlands were willing to receive him. At first he lived with his uncle. Since 2000 Said has lived in the Netherlands without a residence permit. He had discontinued his education and therefore his temporary residence permit was withdrawn. Shortly thereafter, Said met Marieke in a café in the neighbourhood where they both lived. Marieke is a Dutch woman aged 28, who works as a receptionist for a small company. They fell in love and after a year Said moved in with Marieke. As Said is unemployed, Marieke pays for their costs 
of living. They intend to get married before long. According to them, it is a marriage of love, but they also intend to marry because they believe that Said will not have to worry about his residence permit any longer.

Furthermore, opportunities for illegal residence sometimes occur only when illegal migrants have family in the neighbourhood, more particularly family who have connections with employers. An example of such a complex interaction effect is the settlement of illegal Bulgarians in the Randstad, the urban agglomeration of Western Holland. They belong to a Turkish-speaking minority group in the east of Bulgaria. Particularly in the recent past, many Turkish agricultural labourers worked in the greenhouses of the horticultural area called Westland (Braam I994). An informal process of 'ethnic succession' can currently be observed, in which some upwardly mobile Turks serve as a 'middleman minority' (see Bonacich 1973) between the Dutch employers in the horticultural sector and the Bulgarian newcomers. The settlement pattern of these labour migrants presupposes the combined spatial proximity of established Turkish immigrants, Dutch horticulturists and cheap private houses in districts where such newcomers are inconspicuous.

There is a fourth reason for the spatial concentration of illegal residence. After some time, 'shadow institutions' (Scott 1985) or 'bastard institutions' (Hughes I95I/I994) begin to develop in the concentration districts, catering specifically for illegal residents in the neighbourhood. These institutions are sometimes legal, and sometimes illegal. They involve Dutch volunteers who teach languages in community centres, unqualified 'doctors' who provide medical advice and pharmaceuticals in coffee houses, quasi-legal agencies that provide advice on how to obtain a residential permit, temporary employment agencies that take care of the required documents and jobs and so on. These informal institutions have developed as a result of the 'favourable' climate for illegal migrants to establish themselves, but are now an additional element of it. Although it is difficult to demonstrate such complex effects using regression analyses, our statistical findings also suggest that the rate of illegal residence is in part the result of the extent to which the independent variables reinforce each other. Note that the trend line in Figure 2.7 - in which the number of registered home addresses of illegal migrants per I, ০०० legal residents, the indicator for the relative concentration of illegal migrants, is compared with the predicted relative concentration of illegal migrants on the basis of the neighbourhood characteristics (fifth regression model; each circle in the figure represents an urban neighbourhood) - is not linear, but exponential. This suggests that in concentration areas the actual degree of illegal residence is somewhat greater than would be predicted on the basis of the sum of the effects of the 
separate independent variables. (Note also that Figure 2.7 shows some unexplained variance; it turns out, however, that the empirical anomalies can be accounted for; they do not contradict our theoretical approach.) ${ }^{8}$

Figure 2.7 Predicted relative concentration in comparison with measured relative concentration

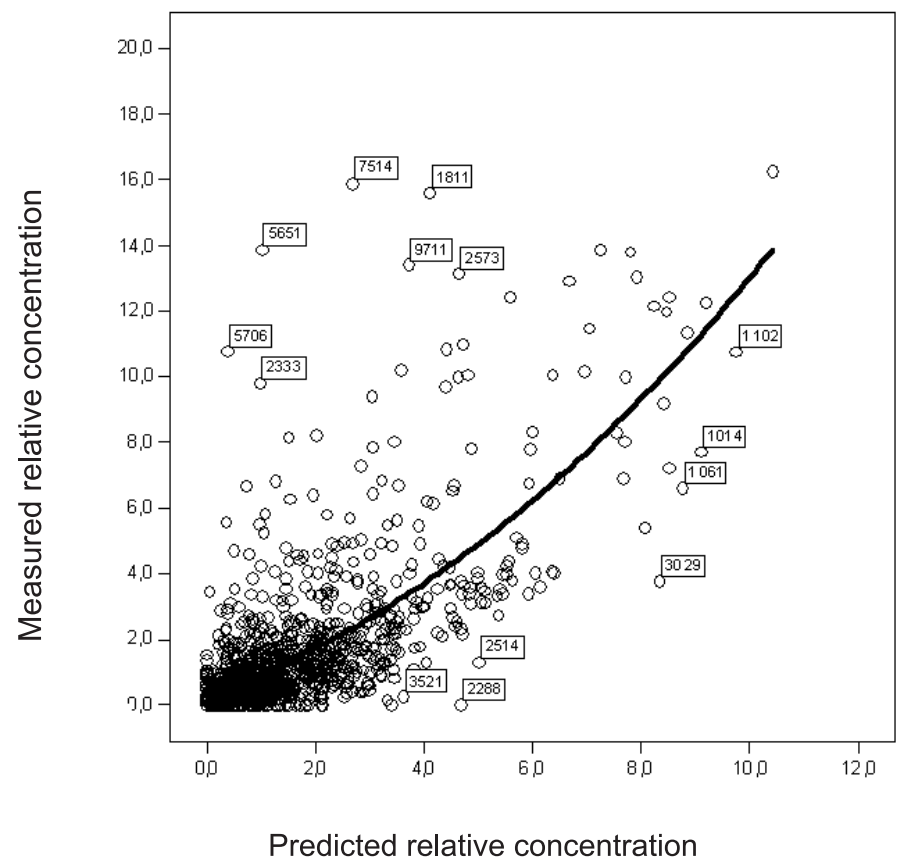

Sources: Dutch Bureau for Statistics; Vreemdelingen Administratie Systeem 1997October 2003

\section{Concluding remarks}

On a theoretical and empirical basis it is plausible that the number of illegal residents in neighbourhoods is determined by the scale on which legal non-Western immigrants, specific economic activities, cheap housing opportunities and single people are present in neighbourhoods - as well as by the extent to which these dimensions of the spatial opportunity structure for illegal residence are coupled with one another in certain urban neighbourhoods. Not only do the aforementioned neighbourhood characteristics facilitate illegal residence, they also generate a demand for it. Many illegal migrants satisfy economic and other needs 
of family members, friends, partners and employers. Seen from this perspective, illegal immigration cannot be qualified as undesirable. It encompasses all types of migration that also have legal counterparts, such as chain migration, labour migration, family-forming migration and asylum migration. The foregoing warrants five hypotheses on the spatial distribution and concentration of illegal migrants in other Western immigration countries (see Cornelius et al. 2004).

First, there must be sizeable groups of illegal migrants in other immigration countries as well. After all, most Western countries have had a migration surplus for several decades, which led to the settlement of a large number of ethnic minority groups. We have seen that there are direct and indirect causal relations between legal and illegal immigration. The other dimensions of the opportunity structure of illegal residence are also largely present in other immigration countries.

Secondly, it is likely that illegal residence is also spatially concentrated in other immigration countries. In Western societies - since industrialisation in particular - the social classes exist in relative isolation and the spheres of living, labour and consumption have become more segregated (Lofland I998; De Swaan I988; Jargowsky I997). Western countries have also always known ethnic segregation (Lofland i998). The spatial incorporation of illegal migrants follows such class- and ethnicityrelated separations among the legal population and builds on them.

Thirdly, the rate of illegal residence will differ by country. Although it is hard to say exactly what the combination of factors will be in other countries, one can observe that the dimensions of the spatial opportunity structure are not equally well developed everywhere. For example, there are national differences in the size of the post-industrial service sectors (Musterd \& Van Kempen 2000). And whereas almost 50 per cent of the households in some northern European cities consist of singles although an increasing proportion of these singles are in the final phase of life - married couples with children are still dominant in southern Europe (Musterd \& Van Kempen 2000). Countries such as Japan and Greece have only recently become immigration countries.

Fourthly, country-specific variation in the composition of the illegal population can be expected. The ethnic background of minority groups is closely related to the European colonial past (Sassen I999). This explains, for example, why many illegal Latin Americans live in Spain and Portugal while the illegal migrants in France and England are predominantly of African and Asian origin. The extent to which the bottom of the housing market is subsidised also differs, as does the degree of private homeownership. For example, in Belgium and France, a large part of the housing stock is in the hands of private owners (Musterd \& Van Kempen 2000). The presence of private homeownership is particularly favourable for the illegal 'forerunners' without supportive social networks. 
They can rent directly from landlords, some of whom have adjusted their houses specially for the purpose of leasing to illegal migrants. Illegal newcomers are then less dependent on the goodwill of their extended families, friends or acquaintances for accommodation. Social democratic and corporatist welfare states such as the Netherlands, Germany and the Scandinavian countries actually offer rather favourable housing conditions for illegal follow-up migration. Newcomers with established family or friends also benefit from this decommodification of the housing market, as sub-tenants paying a 'friendly price' or as housemates (see Burgers I998). The official main tenants, who pay rather low housing costs, will of course be more readily inclined to re-let their houses or parts thereof to an illegal acquaintance or family member at a low price. They can also afford to have an illegal newcomer stay for free more easily.

Fifthly, national differences in the extent of the spatial concentration of the illegal population may also be expected, although it probably is a spatially concentrated phenomenon everywhere. The extent of spatial concentration depends on the degree of socioeconomic and ethnic segregation among the legal population. The Netherlands has a progressive tax system and pursues an egalitarian income policy on the housing market as well, with all kinds of rent rebates and building subsidies. These policies temper residential segregation according to income and also promote, albeit indirectly and in unforeseen ways, a certain dispersion of the illegal population across a somewhat larger number of neighbourhoods. In countries such as the US and Belgium, where the state pursues a less progressive income policy through the housing market, illegal residence will be less evenly distributed across the urban landscape than in the Netherlands.

The social and economic opportunities for illegal residence and the willingness and necessity to make use of it will not disappear in the foreseeable future. Many developing countries will be facing an increase in the number of potential emigrants as a result of continuous population growth and limited economic prospects (Bauman 2004; OECD 2005). On the demand side, there are also developments that promote both legal and illegal immigration. For example, as a result of the globalisation of social and economic life in an increasing number of Western countries, more ethnic groups will maintain transnational relationships (Portes I999; Snel et al. 2005). Yet this is certainly not the only determinant of illegal residence that has found a strong foothold in society. Paid personal services currently constitute one of the largest growth sectors in Western countries. Furthermore, due to the implementation of neo-liberal privatisation policies, an increasing proportion of the housing stock is passing into private hands (see O'Loughlin \& Friedrichs 1996; Thorns 2002). Finally, in Western city districts, more and more singles yearn for a partner in life (Blok et al. 2000; Bauman 2003). 
It goes without saying that the uneven global distribution of life opportunities in a time of intensified globalisation is a root cause of migration from poor countries to the Western world. Although emigration to a rich Western country remains a pipe dream for most people in poor countries, many will continue to try their luck in countries such as the Netherlands. This sub-study shows that, although illegal migrants are excluded by law from national territories and formal institutions, illegal residence has become quite firmly embedded in the social and economic structures of advanced societies. 


\section{Against state rules against street rules?}

\section{Introduction}

The previous chapter demonstrated how and why most illegal migrants live in deprived urban neighbourhoods. This spatial concentration of illegal residence in specific urban environments leads to questions that have not been extensively dealt with in the literature on illegal immigration or in the literature on neighbourhood safety. Several studies have analysed how illegal migrants are incorporated into their countries of settlement (see for instance Mahler I995; Engbersen I996; Burgers I998; Alt 1999; Ehrenreich 2002) and a handful of studies have focused on the criminal involvement of illegal migrants (Scalia I996, 2002; McDonald 1997; Alt 1999, Engbersen \& Van der Leun 200I; Zaitch 2002; Van Meeteren, Van San \& Engbersen 2008), but no other study has ever explored the consequences of concentrated illegal residence for neighbourhood safety.

How safe are neighbourhoods where concentrations of illegal migrants live? Is there more crime, or less? Do people feel more unsafe, or less so? What is the impact of the presence of illegal migrants, and what is the influence of the illegal residence status on these effects? These are the main research questions in this second sub-study.

There are two central reasons for raising these questions. Firstly, it is plausible that the presence of illegal migrants will impact neighbourhood crime and safety, though perhaps in complex and differential ways. It can be hypothesised that illegal migrants are likely to shun police contacts more than legal residents do, which may have a deterrent effect on offending. I mentioned in Chapter I that other researchers have dubbed this assumed effect 'the deterrence thesis'; I also argued there that it seems to be related to internal border control by means of secondary territorial exclusion. Conversely, a number of illegal migrants appear to commit property crimes under the influence of having illegal residence status; in the Netherlands, particularly, having illegal residence status increasingly bars people from most legal means of satisfying conventional needs (Engbersen, Van San \& Leerkes 2006; see also 
Chapters 5 and 6.) This second hypothesised effect is known as the marginalisation thesis; in Chapter I I argued that the effect appears to be related to internal border control by means of institutional exclusion.

Similarly, illegal residence status and the various forms of border control that, to a large extent, define it, may influence the degree of compliance with other formal and informal social rules that are known to be important for neighbourhood safety, particularly subjective safety, such as hanging around in public spaces or treating passers-by with subtle aggression.

The second reason for conducting this explorative sub-study is Shaw and McKay's (1942) classic, often replicated finding that street crime is much more prevalent in poor, ethnically mixed neighbourhoods with high residential mobility rates - the sort of neighbourhoods where, as we have seen in the previous chapter, illegal migrants tend to settle than in rich, ethnically homogeneous, meaning mostly white, stable neighbourhoods. This also raises the question whether illegal residence constitutes, in a more indirect way, an additional burden for the safety of the poor and ethnically mixed neighbourhoods in the large cities. Even if it would turn out that illegal migrants tend to comply with social rules that are important for neighbourhood safety, their presence may erode safety to the extent that illegal residence weakens neighbourhood organisation even further. Illegal migrants are understandably less likely to report social disorder to the police or to correct deviant behaviour by legal residents in informal ways.

Traditionally, the social sciences have focused on objective aspects of safety. How many residents commit crimes? How prevalent are crimes in a neighbourhood? More recently researchers have also become interested in perceived safety, especially since research showed that perceived safety and fear of crime are only to a limited extent determined by objective crime rates. This scientific interest has social relevance: fear of crime and more diffuse feelings of social discomfort and annoyance may harm the quality of social life, as they make people withdraw from public space (Hale i996).

This second sub-study tries to answer the aforementioned research questions with data from a diverse array of sources. Beside police records, social surveys and administrative data, qualitative fieldwork data were used that were collected in two urban areas that have high rates of illegal residence.

The quantitative data are analysed first in order to assess whether, and how, the rate of illegal residence is associated with indicators of objective and subjective neighbourhood safety. Subsequently it is examined whether the qualitative findings confirm the quantitative findings, and whether the fieldwork provides additional information about the social mechanisms that may produce the established statistical associations. In 
this way I hope to contribute to the integration of quantitative and qualitative perspectives in the literature on public safety (for the desirability of this integration, see Hale I996; Ditton \& Farrall 2000).

\section{Theoretical starting points}

\section{Illegal residence}

As mentioned in Chapter I, illegal migrants in the Netherlands come from over a hundred countries. The largest groups are Turks, Moroccans, Algerians and Surinamese, generally chain migrants with settled family in Holland. In the course of the I990s the numbers and proportions of Eastern Europeans, mostly labour migrants, and rejected asylum seekers have risen.

To understand the actual implications of having illegal residence status we have to consider the opportunity structure for illegal residence as a whole, i.e. more than simply the laws on immigration and illegal residence. The previous chapter demonstrated that illegal immigration is incorporated into Dutch society in several ways, even though the migrants concerned are increasingly excluded by the state. Differences in social incorporation correspond to differences in life chances. Established immigrants from some countries, for example, Turkey, have formed closely knit social networks in the Netherlands. Illegal newcomers from these countries can usually count on support from settled family members, other relatives, or people who are from the same town or region in the country of origin. Examples of assistance are temporary inclusion in the family, borrowing of health insurance cards and finding a partner or a house. Minorities with a strong tradition of ethnic entrepreneurship such as the Chinese and Turks also provide work opportunities in ethnic niches. Those who happen to possess less social capital (Bourdieu I983; Portes I998), such as illegal pioneers or chain migrants from relatively fragmented ethnic groups like the Moroccans, have to rely on their own resources to a greater degree. Previous research suggests that they may more readily become involved in crime for this reason (Engbersen \& Van der Leun 200I).

Eastern European immigrants do not usually have ties with established countrymen in the Netherlands. They often work for Dutch entrepreneurs, in horticulture for example. Some occupy sought-after jobs, albeit in the informal economy - think of the illegal plumber - but most do work that is not highly esteemed by the legal population (De Bakker 200I). The geographical proximity of Eastern Europe and the smaller political distance to the European Union (the migration laws with respect to future member states of the European Union are relatively liber- 
al), make these circular migrants particularly attractive as seasonal workers in Dutch horticulture.

The research period on which this sub-study focuses (I997-2003) predates the inclusion of countries like Poland and Bulgaria into the EU. With an eye to this expansion, however, Bulgarians were allowed to visit Schengen countries, including the Netherlands, without visas since 200I (Van Gestel 2006) as have Poles since the early I990s, though as tourists they were not allowed to work. Those who stayed longer than three months - which many did - could be arrested for illegal residence. These spatial and political conditions have had, and still have, the unintended side-effect of small groups of Eastern European 'tourists' travelling to Western Europe with intent to commit crimes, mostly burglary, car theft or pick-pocketing (Van Tilburg \& Lammers 2004; see also Chapter 6). In comparison to most other illegal migrants, Eastern Europeans from non-EU countries have lower costs, monetary and otherwise, when they settle illegally, or when they return to the Netherlands in the case of forced repatriation. Most illegal migrants have to bridge larger geographical distances and must penetrate borders that are far less porous. Such differences in migration costs and motives influence behavioural opportunities and preferences in the Netherlands.

\section{Crime and perceived safety in urban neighbourhoods}

Safety has objective and subjective components. Objective safety pertains to victimisation i.e. the measurable recorded experience of becoming a victim of a criminal act. Subjective safety concerns the assessment by residents of the local crime and nuisance rate, and the extent to which they feel safe, particularly in their own neighbourhoods (Vanderveen 2006).

There is no one-to-one relationship between objective and subjective safety. People who live in comparable objective circumstances with regard to crime, or who have become victims of a particular crime, usually do not feel safe to the same degree (Hale I996). It turns out, for instance, that vulnerable residents are often more frightened than people who consider themselves relatively invulnerable. This is the primary reason why women, the elderly and singles tend to feel less safe than men, young adults and cohabitants (Killias I990). A further reason for the weak connection between objective and subjective safety is that fearful people reduce their chances of victimisation by avoiding risky situations more than the more daring (Mesch 2000).

It is not only - nor even primarily - the crime rate that determines subjective safety; other signs of disorder are more important (Taylor \& Hale I986; Lewis \& Salem I986; Markowitz et al. 200I). Examples of the latter are groups hanging around in public places and begging, being 
noisy, addressing strangers or showing symptoms of alcohol or drug use. Since Goffman's work (1963, I971a) we know that people expect from each other - and of themselves - that certain unwritten rules be observed in public space. Transgressions can produce fear and unease. Besides this, Goffman showed that the absence of shared behavioural expectations - in sociology also known as anomie - can cause feelings of risk and discomfort. Hence, norm violations on top of a lack of shared norms as regards 'what is appropriate' in public space, may contribute to a fear of crime. Signs of disorder that are, strictly speaking, physical such as rubbish in the street, graffiti, vandalised pay phones and bus shelters - may cause anxiety in many residents, and may eventually increase crime rates as more people withdraw from public space (Kelling $\&$ Wilson I992).

Shaw and McKay's (1942) ecological studies demonstrated that a large share of street crime and disorder occurs in socially disorganised neighbourhoods: poor neighbourhoods with unstable residential populations as well as much ethnic and cultural diversity (see for more recent studies in this tradition Sampson \& Groves I989; Xu, Fiedler \& Flaming 2005). Such conditions complicate the establishing of contacts between residents; many social relations are temporary (Bellair 1997; Sampson, Raudenbush \& Earls 1997). Consensus about respectable or acceptable norms is therefore more difficult to achieve and the willingness on the part of residents to protect and defend each other, each other's property or shared interests, for example, by correcting each other's children, diminishes. Social disorganisation also hampers the efforts of specialised agents of social control, like the police, to help preserve public order (Bursik \& Grasmick I993; Velez 200I). As a result, there is less resistance to anti-social behaviour, including crimes, committed by residents and offenders from other areas. Groups that do not live up to widely shared social standards - such as bohemians, petty criminals and homeless people - often prefer disorganised areas and/or are successfully barred from the better-organised neighbourhoods.

\section{Stereotypes}

In order to understand subjective neighbourhood safety, in particular, it is necessary to pay attention to stereotypes about the, in a sociological sense, assumed statuses of residents in a neighbourhood. Unlike villagers, most city dwellers are strangers to one another. In public space people need to employ fast and shallow assessments of others in order to orientate themselves in social traffic; in everyday life, city dwellers depend heavily on stereotypes, such as ethnic or sex stereotypes (Hamilton \& Trolier I986). Such stereotypes are usually not based on experiences with the particular stranger involved, but drawn from experiences with, 
or stories about comparable persons from similar social categories. Visual characteristics in particular, such as care for external appearances, projected attitude, external care, clothing, or skin colour activate these stereotypes.

In the United States young black men are strongly associated with criminality. Because of this stereotype local residents tend to overestimate the scale of neighbourhood crime in proportion to the degree to which the number of local black youths increases, especially if they themselves are white (Chiricos, Hogan \& Gertz I997; Quillian \& Pager 200I). In Europe, too, minorities - particularly non-Western ones - are traditionally associated with crime and disorder (see for example Van Heek I936; Angel-Ajani 2003). Such stereotypes tend to exaggerate group differences (Elias \& Scotson I965; Van San \& Leerkes 200I).

This raises the question of whether residents see illegal migrants as a separate social type and, if so, to what extent they associate this type with rule violation. Because illegal residence status is first of all an administrative feature that is not directly visible from the outside, it may well be that other stereotypes that are associated with illegal migrants are activated in public space, for example, the stereotypes about non-Western newcomers. We must therefore take into account perceptions of parallel statuses among illegal migrants (see the next section). I will go into these issues, which are hard to answer with the available statistical data, when I report the qualitative findings.

\section{The status-set of illegal migrants and legal residents}

Sociologists use the term status to describe positions in the social structure to which specific behavioural expectations, or roles, are attached. The strong or hierarchical variant of the concept refers to the position of an individual or group in a social hierarchy, which is based on the relative degree of access to economic, political and cultural resources and social esteem.

Most adults have a 'status-set' (Merton I957): they must combine several, sometimes conflicting, statuses and roles. For instance, a woman who holds a managerial position has a different role and level of social prestige as a manager than as a mother. This also applies to illegal migrants. They have to deal with the illegal residence status and at the same time with their role as a man or woman and, depending on the circumstances, as an employee, a partner, a kinsman or a drug addict.

Engbersen (1996) has argued that the illegal residence status is a master status (Hughes I945) that overshadows parallel statuses. While it is obvious that immigration statuses influence life chances greatly, at least in a highly bureaucratised country like the Netherlands, it is questionable whether illegal residence status has much direct weight in subjec- 
tive neighbourhood safety. It may be that local residents do not see illegal migrants in their midst, but rather the more visible parallel statuses, like foreigners, men, or poor. Thus, whereas the master status may dominate illegal migrants' behaviour, it may be that the environment reacts primarily to parallel statuses.

Certain statuses, like the status of being poor are causally linked to the condition of being categorised as an illegal migrant. Relatively poor migrants from non-Western countries have a relatively small chance of obtaining a residence permit and, hence, a vanishingly small chance to earn a high income, particularly in a country like the Netherlands. But an illegal residence status is much less causally related to other statuses (such as gender and age) if at all. Migrants as such tend to be young men because older people and women are less mobile; illegal migrants - who are, on average age, 30 years old - are no exception (see Van der Leun 2003). We must therefore take into consideration whether possible effects on subjective neighbourhood safety are closely connected with illegal migrants as illegal migrants, when illegal residence might be seen as an intrinsic threat or sign of disorder, with parallel statuses that may be caused in part by residence status (for example, the status of drug addict), or with statuses that many of them have but are nonetheless quite independent of these immigrants living in illegal residence (the status of newcomer or male).

Finally, it is important to think about statuses in relational terms (Bourdieu \& Wacquant I992). From the perspective of subjective neighbourhood safety the statuses of illegal migrants obtain most of their significance in relation to the statuses of established groups. Status anxiety constitutes a striking example of a relational effect. Because of changes in the power balance, for instance as a new group makes its entry, an established group may feel threatened in its social privileges. This perceived threat is stronger the less certain the superior status claim of the threatened group (Schwartz I967; Johansson I987; De Botton 2004). Sometimes a status group feels threatened in its social prestige, even though the power balance on which this claim rests is not immediately at stake. This is because social esteem may, in part, spill over into the social and physical environment (prestige contagion, Benoit-Smullyan I944). Where some observers attribute feelings of insecurity to signs of disorder and dilapidation, a social status perspective might attribute them partly to status anxiety: many people do not want to be lumped together with those whom they consider inferior.

Stereotypes about the status-sets of illegal migrants should also be understood in relation to the statuses of established groups. For instance, Anderson (I999) has shown that in the United States the stereotypical fear of black youngsters is amplified by their low social prestige in comparison to other social groups. Traditionally, the black middle class can 
claim more prestige than the white lower class, but is of lower standing in the social hierarchy than the white middle class (Warner I936). Anderson's study suggests ethnicity is still a significant separate dimension of social stratification in the US, next to, and in interplay with, class differences (cf. Berreman 1960; Shibutani \& Kwan 1972; Anthias 1990). Status anxiety has also been described in Dutch cities, in relation to both class differences (De Swaan I988; Wuertz I990) and ethnic differences (Bovenkerk, Bruin \& Wouters I985). For this reason I explored the question as to what extent the arrival of illegal newcomers produces status anxiety among at least parts of the settled population. Illegal migrants are among the lowest socioeconomic strata in the country of settlement and most originate from poor non-Western countries. They may have low prestige and may be seen as intensifying the status competition for life chances, such as labour and access to housing.

\section{Data and analytical strategy}

\section{Quantitative sources}

The quantitative analyses apply to the residents of 596 residential neighbourhoods in the police regions that cover the metropolitan areas of the four largest cities in the Netherlands: Amsterdam, Rotterdam, The Hague and Utrecht. In line with previous research in the Netherlands (Van Wilsem, Wittebrood \& De Graaf 2006; Goudriaan, Wittebrood \& Nieuwbeerta 2006), a neighbourhood is defined in terms of a postcode area. Such areas contain on average roughly 2,000 households and 5,000 individuals.

The Dutch Bureau for Statistics (CBS) provides demographic, social and economic statistics data on these neighbourhoods on a regular basis. Data on homeownership were made available by the Ministry of Housing.

Three variables were chosen to measure the level of social disorganisation in the neighbourhoods: the percentage of single-person households, the percentage of homeownership and the percentage of legal non-Western ethnic minorities. In the literature it is not uncommon to use such established determinants, or at least correlates, of social disorganisation to measure the extent of social disorganisation, rather than measuring social disorganisation directly (see for example Wei et al. 2005). The percentage of legal non-Western ethnic minorities was chosen because in the Netherlands it correlates very strongly with more complex and theoretically superior measures of ethnic heterogeneity that take into account the mix of specific ethnic groups (Bernasco \& Luykx 2003: 988-989). 
Estimates of illegal residence in the neighbourhoods were derived from the VAS, a police database dedicated to the registration of foreigners living in the Netherlands, including all apprehended illegal migrants. The rate of illegal residence is indicated by the number per I,००० legal residents of registered residential addresses of illegal migrants who have been apprehended by the police somewhere in the Netherlands between January I997 and October 2003. The number of individuals involved in this sub-study is quite substantial: I0,497 apprehensions with a registered residential address in the 596 neighbourhoods. The records were provided by the 25 Dutch regional police departments. The VAS mainly contains data on illegal migrants who have risked apprehension for some reason. Therefore the system is unlikely to be completely representative for all illegal migrants. We have seen, however, that good results could be obtained using these data; it demonstrated statistical patterns that confirmed theoretical expectations on the basis of qualitative research conducted in the Netherlands and elsewhere (see Chapter 2).

In the Netherlands the aliens police have the primary responsibility for the supervision of illegal migrants. This department has an important role in detecting illegal residence and illegal labour though most illegal migrants are apprehended during routine policing activities. During the research period specific raids became more frequent in Amsterdam, Rotterdam and The Hague, as well as in some rural concentration areas. These raids mainly targeted the overcrowded illegal sleeping houses that were already mentioned in Chapter I. Employers were also increasingly subjected to checks by the labour inspectorate. As a result, far from all apprehensions are related to crimes or misdemeanours; this is only the case for slightly more than half of apprehended illegal migrants. In 2003 eight per cent concerned misdemeanours like urinating in public and fare-dodging; 43 per cent concerned crimes, mainly property crimes, identity fraud and drug dealing, as well as some violence (Leerkes et al. 2004; 24-25).

Because the likelihood of apprehension increases with the degree of criminal involvement, criminal illegal migrants are likely to be overrepresented in the police data. For this sub-study this selectivity is, however, partially compensated for by a lower likelihood of criminal illegal migrants having a registered residential address: it turns out that relatively few criminal illegal migrants have a residential address that has been registered by the police. ${ }^{\text {I }}$ Although the number of targeted crackdowns on illegal labour and illegal residence has increased in the cities of Amsterdam, Rotterdam and The Hague (Boekhoorn, Speller \& Kruijssen 2004; Van Gestel 2006; see also Chapter 6), large geographic differences in the likelihood of apprehension were not found.

Assessments of neighbourhood safety were taken from the Police Monitor, a comprehensive biannual national survey on criminal victimisation, 
fear of crime, local physical and social disorder and satisfaction with police services. To improve the reliability of the assessments the surveys for the years 1997, I999, 200I and 2003 were taken together. In the 596 neighbourhoods 78,927 respondents were interviewed over these four years. Unfortunately, ethnic minorities are under-represented, in part because the survey is administered in the Dutch language only (Schoen, Defize \& Bakker 2000). The participation of illegal migrants in the survey is possible, but unlikely for this and similar reasons.

Vulnerability is indicated by the following characteristics of the respondents in the Police Monitor: being female, being middle-aged or older, membership of an ethnic minority (Covington \& Taylor I99I), unemployment, low educational attainment and being part of a small household. The survey measures the number of victimisations of specific types of offences during the past twelve months. For every offence except residential burglary respondents were asked to report whether the offence took place in their own neighbourhood or elsewhere. For the analyses reported here, only victimisation in the respondent's neighbourhood is used (see Table 3.I for descriptive statistics per offence type).

The criminal victimisation variable that is used in the analysis of subjective safety is a factor score of two measures: 'number of incidents of criminal victimisation during past year' and 'number of types of incidents of criminal victimisation during past year'. ${ }^{2}$ The 'neighbourhood victimisation rate' refers to the average number of victimisations of any type, experienced by other neighbourhood members participating in the survey. It is thus an aggregated neighbourhood level variable.

The PM survey contains various items that tap subjective aspects of public safety in residential neighbourhoods. Some specifically apply to fear of crime, while others refer to annoyances such as noise nuisance, or signs of physical deterioration or neglect. Using factor analysis, the items were reduced to six dimensions that can be meaningfully interpreted. The six dimensions of subjective safety are listed below. ${ }^{3}$

- Feeling unsafe. Included items are 'Do you ever feel unsafe?', 'Do you ever avoid certain places because they are unsafe?', 'Do you ever refuse to open the front door because it is unsafe?', 'Do you ever leave things at home for fear of being robbed?', 'Do you ever take an alternative route to avoid going through unsafe places?'

- Perceived magnitude of property crimes. Included items are 'How often does this occur in your neighbourhood?' for each of the following: bicycle theft, theft from cars, theft of cars, burglary

- Perceived magnitude of physical deterioration. Included items are 'How often does this occur in your neighbourhood?' for each of the following: litter and dog droppings on street, vandalism, graffiti.

- Perceived magnitude of social deterioration. Included items are 'How often does this occur in your neighbourhood?' for each of the follow- 
ing: people who are drunk, people who annoy others, people who make threats, violent crimes, drug crimes.

- Perceived magnitude of nuisances. Included items are 'How often does this occur in your neighbourhood?' for each of the following: noise nuisance (except traffic noise), juveniles hanging around, nuisance behaviour by immediate neighbours.

- Perceived magnitude of traffic nuisances. Included items are 'How often does this occur in your neighbourhood?' for each of the following: aggressive behaviour in traffic, loud traffic noise, speeding and traffic accidents.

The following strategy is used for the quantitative analyses. First, I will assess the extent to which there is a bivariate relationship between the degree of illegal residence and aspects of subjective neighbourhood safety. Subsequently, I assess whether these associations persist when, in addition to the degree of illegal residence, measures of social disorganisation and other determinants of neighbourhood safety are entered in a multivariate model. If the degree of illegal residence affects neighbourhood safety when these risk factors are included in the model, there is some circumstantial evidence that it could be a causal factor in neighbourhood safety. If no association remains, the association between the degree of illegal residence and neighbourhood safety is likely to be spurious, and possibly caused by the fact that immigrants often have few other choices than to live in neighbourhoods already disorganised and unsafe to begin with. I repeat this strategy with regards to objective neighbourhood safety.

In order to model the six dimensions of subjective neighbourhood safety, I employ hierarchical linear models, a methodology that takes into account that variables are measured at different hierarchical levels, such as the individual or household and the neighbourhood level. In order to model objective neighbourhood safety ordinary least squares regression was used. In the latter analyses the percentage of juveniles in the neighbourhoods is controlled for as a rough proxy for the concentration of potential offenders engaged in street crimes in the area (e.g. Gottfredson and Hirschi I990). This control is unnecessary when modelling subjective safety, as these models already include more precise measures of victimisation and neighbourhood crime.

Victimisation surveys such as the PM supplement police records by providing insight in the 'dark number' of crimes not reported to the police, and because they tap subjective aspects of public safety (Goudriaan 2006; Levitas \& Guy I996). But they do have their drawbacks. Minor offences may still be underreported, because respondents have forgotten them, or do not view the events as offences and sexual offences and domestic violence are also likely to be underreported because respondents 
are unwilling or unable to talk about these experiences. Crimes against businesses and organisations (shoplifting, commercial burglary, fraud) and the more consensual crimes (prostitution, drug dealing) are not touched upon in population surveys, although the latter may be reported under the heading of subjectively perceived nuisance and social deterioration. Davies, Francis and Jupp (2003) provide a comprehensive overview of the restrictions that apply to victimisation surveys.

Table 3.1a Descriptive statistics ( $N=78,927$ respondents; $N=596$ neighbourhoods)

\begin{tabular}{|c|c|c|c|c|}
\hline & Min. & Max. & Average & St. dev. \\
\hline \multicolumn{5}{|l|}{ Independent variables: } \\
\hline \multicolumn{5}{|l|}{ Individual level } \\
\hline Sex $($ male $=1)$ & O & 1 & 0.47 & 0.5 \\
\hline Age (years) & 15 & 98 & 48.5 & 18.1 \\
\hline Dutch by origin (self-categorisation) & o & 1 & 0.89 & 0.31 \\
\hline Education $^{\mathrm{a}}$ & 1 & 7 & 4.3 & 1.9 \\
\hline Employment (employed >15 hours/week) & ० & 1 & 0.5 & 0.5 \\
\hline Household size & 1 & 15 & 2.3 & 1.3 \\
\hline Criminal victimisation (scale) & -0.68 & 28.0 & 0.0 & 1.0 \\
\hline \multicolumn{5}{|l|}{ Neighbourhood level } \\
\hline Rate of illegal residence (number per 1,0oo) & o & 130 & 2.5 & 4.7 \\
\hline Neighbourhood victimisation rate (number per 100) & o & 6.3 & 0.75 & 0.4 \\
\hline$\%$ singles & 6 & 79 & $29 \cdot 9$ & 14.0 \\
\hline$\%$ private homeownership & o & 100 & 39.7 & 22.1 \\
\hline$\%$ non-Western migrants (first- and second-generation) ${ }^{b}$ & 1 & 82 & $17 \cdot 4$ & 17.5 \\
\hline$\%$ residents aged $14-25$ & 3 & 30 & 12.1 & 2.9 \\
\hline
\end{tabular}

${ }^{a}$ Includes primary education, lower vocational training, secondary general training, intermediary vocational training, grammar/high school, higher vocational training and university.

${ }^{b}$ See note 3 in Chapter 2.

Sources: Dutch Bureau for Statistics; Politiemonitor Bevolking 1997-2003; VAS 1997-

October 2003; Geomarktprofiel 1998

\section{Qualitative sources}

Fieldwork was carried out in 2003 in the Bospolder-Tussendijken neighbourhood in Rotterdam and the De Schilderswijk neighbourhood in The Hague. Both neighbourhoods house many first- or second-generation non-Western immigrants. The value of real estate is typically low. Many Dutch citizens who could afford to have moved to the suburbs. The neighbourhoods also have a sizeable student population.

In Bospolder-Tussendijken 65 per cent of the population is of nonDutch origin, mostly Turkish, Moroccan, Cape Verdean or Surinamese. 
Table 3.16 Descriptive statistics ( $N=78,927$ respondents; $N=596$ neighbourhoods)

\begin{tabular}{|c|c|c|c|c|}
\hline & Min. & Max. & Average & St. dev. \\
\hline \multicolumn{5}{|l|}{ Dependent variables: } \\
\hline \multicolumn{5}{|l|}{ Individual level } \\
\hline Feeling unsafe (scale) & -12.5 & 18.1 & 0.0 & 10 \\
\hline Property crimes (scale) & -17.4 & 11.2 & 0.0 & 10 \\
\hline Physical deterioration (scale) & -17.9 & 13.2 & 0.0 & 10 \\
\hline Social deterioration (scale) & -8.4 & 23.6 & 0.0 & 10 \\
\hline Nuisances (scale) & -10.1 & 20.3 & 0.0 & 10 \\
\hline Traffic nuisances (scale) & $-14 \cdot 4$ & 13.2 & 0.0 & 10 \\
\hline \multicolumn{5}{|l|}{ Neighbourhood level ${ }^{c}$} \\
\hline Total victimisation rate ( number per 100) & o & 588 & 95.7 & 62.5 \\
\hline Theft, including: & o & 200 & 34 & 24.8 \\
\hline Bicycle theft & o & 200 & 6 & 5.7 \\
\hline Car theft & o & 12.5 & 1.1 & 1.5 \\
\hline Theft from car & o & 200 & 10.6 & 11.6 \\
\hline Burglary (including attempt) & O & 143.5 & 10.7 & 8.4 \\
\hline Robbery & o & 2.6 & 0.2 & 0.4 \\
\hline Pickpocketing & ० & 20 & 1.0 & 1.2 \\
\hline Other theft & o & 100 & 4.5 & 4.5 \\
\hline Vandalism, including: & o & 208.9 & 39.8 & 25.8 \\
\hline Purposeful car damage & O & 180.3 & 31.2 & 20 \\
\hline Other vandalism & o & 80.1 & 8.6 & 9 \\
\hline Violence, including: & o & 166.7 & 4.3 & 7.1 \\
\hline Threatening with violence & O & 166.7 & 3.8 & 6.5 \\
\hline Assault & O & 37.6 & 0.5 & 1.9 \\
\hline Traffic crimes, including: & o & 344.8 & 17.6 & 20.4 \\
\hline Leaving place of accident & o & $33 \cdot 3$ & 2.5 & 3.7 \\
\hline Collision & O & 100 & 13 & 14.4 \\
\hline Other crimes & o & 326.7 & 2 & 11.7 \\
\hline
\end{tabular}

${ }^{\mathrm{c}}$ In OLS regression neighbourhoods are weighted proportionally to the number of residents.

Sources: Dutch Bureau for Statistics; Politiemonitor Bevolking 1997-2003; VAS 1997October 2003; Geomarktprofiel 1998

In De Schilderswijk, 85 per cent of the population is of non-Dutch origin, mostly Turkish, Surinamese, Moroccan and Netherlands-Antillean. The neighbourhoods were selected because police data indicated that illegal residence is a common phenomenon in both. On top of that, they appear to represent two faces of illegal residence. In Bospolder-Tussendijken a relatively large percentage of known illegal migrants are arrested because of crimes, while in De Schilderswijk the reason for apprehension is mostly illegal residence and illegal labour. 
Twenty professionals were interviewed who could provide a view as to whether, how and why the presence of illegal migrants impacts neighbourhood safety and liveability. They included police officers some of whom were from the aliens police, representatives of municipalities and housing corporations and neighbourhood social workers. Further, a team of trained interviewers conducted interviews with 70 illegal migrants from six different countries of origin and 45 landlords who provided accommodation to illegal migrants. The study, which was subsidised by the Ministry of Housing, initially focused on the local housing situation; illegal migrants were not asked to report on victimisation or safety issues, but on issues of housing and reasons for settling in the neighbourhood (for a more comprehensive description, see Leerkes et al. 2004). The results of these interviews did, however, provide very useful information about the ways in which illegal migrants are embedded in the two neighbourhoods.

In addition, IOI sociology students from the University of Amsterdam each interviewed a resident about social relations in the neighbourhood, in general, and feeling safe or unsafe in the neighbourhood, in particular. These interviews contained some directed questions on illegal residence that were posed later during the interview, in order to allow spontaneous answers and associations to emerge during the first phase. These interviews took place until March 2006, in part after the fieldwork was finished. To increase sample variation the students, who typically worked in pairs, were to interview a male and a female, a younger and an older, a native and a non-native resident; the combination of characteristics was not prescribed. The students recruited respondents by ringing doorbells or buttonholing people on the street. Students were free to choose either neighbourhood. Most interviews, 66, took place in De Schilderswijk in The Hague. Interviews were held with 43 Dutch (23 male, 20 female), 25 Turkish (twenty male, five female), nineteen Moroccan (thirteen male, six female), five Surinamese (three males), two Netherlands Antillean (one male, one female) and seven residents from various other ethnic groups (three male, four female). About half the sample was 30-55 years of age, one-third was above 55 and one-fifth was below 30. In line with the demographic structure of the neighbourhoods, the older respondents were mostly Dutch, while the younger generations were predominantly of foreign origin.

The findings of the fieldwork should not be generalised to urban neighbourhoods, because both neighbourhoods were selected precisely because of the concentration and overrepresentation of illegal residence. It is likely that the social mechanisms of inclusion and exclusion are more pronounced and observable in the selected neighbourhoods than they are elsewhere. Furthermore, the qualitative results were entirely dependent on the views of residents and professionals in the neighbour- 
hoods and not based on direct observations. Illegal residence may have various effects on the neighbourhood without the respondents being aware of it. And the opposite is true as well: respondents might blame or commend illegal migrants for certain phenomena, without the immigrants playing any substantive role in them. The quantitative analyses have the advantage that effects of illegal residence are derived indirectly from the registered level of illegal residence in the neighbourhood, and do not depend on whether the residents are consciousness of possible effects.

As in the previous chapter, the stories of illegal migrants, residents and professionals could nonetheless be compared with each other and with the quantitative findings. This triangulation provides additional validity, contributing to a plausible description and explanation of the relations between illegal residence and neighbourhood safety. The criterion for plausibility is that interpretations are consistent with theory and supported by the empirical findings (Merton i948).

\section{Quantitative findings}

\section{Illegal residence and perceived risk in the neighbourhood}

The analysis starts with an exploration of the relationship between illegal residence and subjective neighbourhood safety. Table 3.2 shows the effects of the rate of illegal residence on six dimensions of perceived risk, for five regression models that are increasingly comprehensive in terms of the number of independent variables included. Table 3.2 shows only the effects of the rate of illegal residence. Table 3.3 displays additional information for model IV, the most comprehensive model.

Model I summarises the bivariate relations between the rate of illegal residence and insecurity. It shows that perceived risk increases along with any increase in the level of illegal residence, a conclusion that holds for all six aspects of perceived safety. Illegal migrants are overrepresented in neighbourhoods where residents feel less comfortable and safe.

Should these lower levels of subjective safety be attributed to the presence of illegal migrants, to individual characteristics of residents, to other neighbourhood characteristics or to all these factors simultaneously? The second model (II) assesses whether the differences in vulnerability explain neighbourhood differences in subjective safety. If that were the case, vulnerable social groups would be overrepresented in neighbourhoods with high levels of illegal residence. Yet a comparison between models I and II shows that the effect of illegal residence on subjective safety does not diminish when the individual characteristics 
indicating vulnerability are taken into consideration. It seems that residents of neighbourhoods with high levels of illegal residence are not individually predisposed to feel particularly unsafe. This is in line with the observation that in fact the demographic structure of the neighbourhoods with the highest levels of illegal residence does not indicate vulnerability, since young males turn out to be overrepresented in such neighbourhoods. For example, neighbourhoods where the concentration of illegal residence is at least one standard deviation above the mean have fewer people over the age of 65 (8.7 per cent against I4.2 in other urban neighbourhoods) and more males (5I.4 per cent against 48.7 per cent elsewhere).

Table 3.2 Non-standardised effects of the rate of illegal residence on six measures of subjective safety ( $N=78,927$ respondents; $N=596$ neighbourhoods) ${ }^{a}$

\begin{tabular}{lllllll}
\hline Model & $\begin{array}{l}\text { Feeling } \\
\text { unsafe }\end{array}$ & $\begin{array}{l}\text { Property } \\
\text { crime }\end{array}$ & $\begin{array}{l}\text { Physical } \\
\text { deterioration }\end{array}$ & $\begin{array}{l}\text { Social } \\
\text { deterioration }\end{array}$ & Nuisances & $\begin{array}{l}\text { Traffic } \\
\text { nuisances }\end{array}$ \\
I & $0.193 * * *$ & $0.166 * * *$ & $0.179 * * *$ & $0.298 * * *$ & $0.183 * * *$ & $0.197 * * *$ \\
II & $0.192 * * *$ & $0.167 * * *$ & $0.179 * * *$ & $0.299 * * *$ & $0.183 * * *$ & $0.188 * * *$ \\
IIIa & $0.079 * * *$ & $0.098 * * *$ & $0.083 * * *$ & $0.206 * * *$ & $0.092 * * *$ & $0.132 * * *$ \\
IIIb & $-0.040 *$ & -0.023 & -0.030 & 0.002 & -0.026 & 0.015 \\
IV & $-0.042 *$ & -0.023 & -0.028 & 0.002 & -0.031 & 0.014 \\
\hline
\end{tabular}

$* \mathrm{p}<0.10$

$* * \mathrm{p}<0.05$

**** $p<0.01$

${ }^{a}$ Linear hierarchical regression models; all other effects not shown.

Sources: Dutch Bureau for Statistics; Politiemonitor Bevolking 1997-2003; VAS (1997-October 2003); Geomarktprofiel 1998

Possibly the causes of the lower levels of safety should be sought in neighbourhood characteristics. In model III our indicators for social disorganisation are added. Because the rate of illegal residence tends to be relatively closely associated with the percentage of non-Western legal immigrants in a neighbourhood, a distinction is made between, on the one hand, demographic and economic indicators (percentage of singles and percentage of private home ownership in model IIIa) and, on the other hand, an ethnic-cultural indicator (percentage of legal non-Western immigrants in model IIIb).

The outcomes of model IIIa show that the effect of the rate of illegal residence on subjective safety decreases substantially when indicators for social disorganisation are taken into account. It decreases to about half the initial size when neighbourhood differences in the percentage of single-person households and private home ownership are added to the model. When the percentage of legal non-Western immigrants is in- 
cluded too (model IIIb), the effect of the rate of illegal residence disappears completely, for all six dimensions of subjective neighbourhood safety. Indeed, for one dimension, unsafe feelings, a small negative effect is found.

Table 3.3 Non-standardised effects on six measures of subjective neighbourhood safety: Full model IV ( $N=78,927$ respondents; $N=596$ neighbourhoods)

\begin{tabular}{|c|c|c|c|c|c|c|}
\hline $\begin{array}{l}\text { Independent } \\
\text { variables }\end{array}$ & $\begin{array}{l}\text { Feeling } \\
\text { unsafe }\end{array}$ & $\begin{array}{l}\text { Property } \\
\text { crime }\end{array}$ & $\begin{array}{l}\text { Physical } \\
\text { deterioration }\end{array}$ & $\begin{array}{l}\text { Social } \\
\text { deterioration }\end{array}$ & Nuisances & $\begin{array}{l}\text { Traffic } \\
\text { nuisances }\end{array}$ \\
\hline \multicolumn{7}{|l|}{ Individual level: } \\
\hline Male & -0.024 & $-0.168 * *$ & -0.085 & 0.036 & -0.109 & 0.023 \\
\hline Age & 0.004 & $0.005^{*}$ & $-0.005 *$ & 0.000 & 0.001 & 0.001 \\
\hline Native Dutch & 0.087 & 0.006 & 0.183 & $0.195^{*}$ & 0.214 & $0.335^{* * * *}$ \\
\hline Education & 0.036 & $0.054 * *$ & -0.002 & 0.006 & $0.049 * *$ & 0.024 \\
\hline Employed & 0.019 & 0.088 & 0.009 & 0.033 & 0.130 & -0.033 \\
\hline Household size & -0.029 & 0.050 & 0.001 & 0.045 & 0.009 & 0.050 \\
\hline Victimisation & $0.076 * *$ & $-0.207^{* * * *}$ & $-0.117^{* * * *}$ & -0.022 & -0.011 & $-0.217^{* * * *}$ \\
\hline \multicolumn{7}{|l|}{ Neighbourhood level: } \\
\hline$\%$ singles & $0.082 * * *$ & $0.055^{* * * *}$ & $0.026 * *$ & $0.090 * * *$ & $0.023 * * *$ & $0.066 * * * *$ \\
\hline$\%$ homeowners & $-0.021 * * *$ & $0.021^{* * * *}$ & $-0.034^{* * * *}$ & -0.002 & $-0.030 * * * *$ & $0.021 * k *$ \\
\hline $\begin{array}{l}\% \text { non-Western } \\
\text { immigrants }^{a}\end{array}$ & $0.066 * * *$ & $0.070 * * *$ & $0.072 * * *$ & $0.140 * * *$ & $0.059 * * *$ & $0.059 * * *$ \\
\hline Victimisation rate & $0.627 * *$ & $2.783^{*} * * *$ & $2.459 * * *$ & $2.756 * *$ & $1.853^{* * * *}$ & $1.315 * * * *$ \\
\hline Rate illegal residence & $-0.042 *$ & -0.023 & -0.028 & 0.002 & -0.031 & 0.014 \\
\hline
\end{tabular}

$* \mathrm{p}<0.10$

$* * \mathrm{p}<0.05$

**** $\mathrm{p}<0.01$

${ }^{a}$ As per the definition of the Dutch Bureau for Statistics, non-Western immigrants are either: 1) born in Turkey, Africa, Asia (except Japan and Indonesia) or South America or 2) are second-generation, meaning at least one parent was born in one of these regions. Also see note 3 of Chapter 2.

Sources: Dutch Bureau for Statistics; Politiemonitor Bevolking 1997-2003; VAS 1997-October 2003; Geomarktprofiel 1998

The final version of the model (model IV) introduces individual and neighbourhood level variables of victimisation. It turns out that both the amount of individual victimisation and the level of criminal victimisation reported by other neighbourhood residents decrease subjective safety on most of the six dimensions distinguished (Table 3.3). The inclusion of the victimisation variables, however, has no further consequences for the effects of the rate of illegal residence on subjective neighbourhood safety. 
Table 3.4 Standardised effects of the rate of illegal residence on residents' withinneighbourhood victimisation rates ( $N=78,927$ respondents; $N=596$ neighbourhoods) ${ }^{a}$

\begin{tabular}{|c|c|c|c|c|}
\hline Dependent variables & Model I & Model Ila & Model IIb & Model III \\
\hline Total victimisation rate & $0.525 * * * *$ & $0.342^{* * * * *}$ & $0.133^{*-k * *}$ & $0.128 * * *$ \\
\hline Theft, including: & $0.554^{* * * * *}$ & $0.384 * * * *$ & $0.179 * * * *$ & $0.174 * * * *$ \\
\hline Bicycle theft & $0.406 * * * *$ & $0.210 * * *$ & $0.070 * *$ & $0.064 *$ \\
\hline Car theft & $0.507^{* * * *}$ & $0.407^{* * * *}$ & $0.266 * * *$ & $0.264^{* * * *}$ \\
\hline Theft from car & $0.608 * * * *$ & $0.455^{* * * * x}$ & $0.190 * \cdots * x$ & $0.186 * * * *$ \\
\hline Burglary (including attempt) & $0.282 * * *$ & $0.240 * * * *$ & $0.203 * * *$ & $0.198 * * * *$ \\
\hline Robbery & $0.325 * k *$ & $0.181 * * * *$ & -0.007 & -0.007 \\
\hline Pickpocketing & $0.301 * * *$ & $0.151 * * * *$ & $0.117^{* * *}$ & $0.116 * *$ \\
\hline Other theft & $0.173^{* * * *}$ & 0.041 & -0.087 & -0.092 \\
\hline Vandalism, including: & $0.488 * \cdots * *$ & $0.320 * * * *$ & $0.102 * *$ & $0.091 \%$ \\
\hline Purposeful car damage & $0.509 * k * k$ & $0.348 * * *$ & $0.111 * * *$ & $0.101 * *$ \\
\hline Other vandalism & $0.266 * * *$ & $0.143^{* * * *}$ & 0.044 & 0.037 \\
\hline Violence, including: & $0.228 * \cdots *$ & $0.122 * * *$ & 0.052 & 0.049 \\
\hline Threaten with violence & $0.223 * k * *$ & $0.117^{* * * * k}$ & 0.063 & 0.061 \\
\hline Assault ${ }^{\mathrm{b}}$ & $0.196 * x *$ & $0.099 * *$ & -0.022 & -0.024 \\
\hline Traffic crimes, including: & $0.242^{* * * *}$ & $0.135^{* * x * k}$ & 0.044 & 0.048 \\
\hline Leaving place of accident & $0.319 * k * k$ & $0.238 * 2 * *$ & $0.102 * k$ & $0.103 *$ \\
\hline Collision & $0.239 * k * k$ & $0.142^{* * * *}$ & 0.008 & 0.014 \\
\hline Other crimes & 0.028 & -0.014 & 0.035 & 0.035 \\
\hline \multicolumn{5}{|l|}{$* p<0.10$} \\
\hline \multicolumn{5}{|l|}{$* * p<0.05$} \\
\hline \multicolumn{5}{|l|}{$* * * x<0.01$} \\
\hline \multicolumn{5}{|c|}{ a Based on OLS regression analyses; all other effects not shown. } \\
\hline \multicolumn{5}{|c|}{$\begin{array}{l}\text { because the distribution of assault victimisation across neighbourhoods is very } \\
\text { skewed, a square root transformation was applied in order to approximate the } \\
\text { normal distribution. }\end{array}$} \\
\hline \multicolumn{5}{|c|}{ Sources: Dutch Bureau for Statistics; Politiemonitor Bevolking 1997-2003; VAS 1997- } \\
\hline \multicolumn{5}{|c|}{ October 2003; Geomarktprofiel 1998} \\
\hline
\end{tabular}

\section{Illegal residence and criminal victimisation in the neighbourhood}

This section focuses on the relation between illegal residence and objective neighbourhood safety. It discusses the results of ordinary least squares regression models of neighbourhood characteristics on the within-the-neighbourhood rate of victimisation of various types of crime.

Tables 3.4 and 3.5 follow the same structure as Tables 3.2 and 3.3, but have been transposed. Table 3.4 shows the effects of the rate of illegal residence on victimisation rates for various types of crime. It does so for four different models, each more comprehensive than the one before. 
The complete outcomes of model III, including the estimated coefficients of all independent variables, are presented in Table 3.5.

Table 3.5 Other standardised effects on residents' within-neighbourhood victimisation rates: Full model III ( $N=78,927$ respondents; $N=596$ neighbourhoods)

\begin{tabular}{|c|c|c|c|c|c|c|}
\hline Dependent variables & $\begin{array}{l}\text { \% non- } \\
\text { Western } \\
\text { migrants }\end{array}$ & $\begin{array}{l}\% \\
\text { singles }\end{array}$ & $\begin{array}{l}\% \\
\text { home } \\
\text { owners }\end{array}$ & $\begin{array}{l}\% \\
\text { aged } \\
15-24\end{array}$ & $\begin{array}{l}\% \\
\text { illegal } \\
\text { residence }\end{array}$ & $R^{2}$ \\
\hline Total victimisation rate & $0.337^{* * * *}$ & $0.505^{* k * k}$ & 0.032 & $0.069 * *$ & $0.128 * * * *$ & 0.615 \\
\hline Theft, including: & $0.328 * * * *$ & $0.566 * * *$ & $0.113^{* * * *}$ & $0.072 * *$ & $0.174^{* * * * k}$ & 0.659 \\
\hline Bicycle theft & $0.211 * * * *$ & $0.719 * * *$ & $0.098 * *$ & $0.073^{* * * *}$ & $0.064^{*}$ & 0.667 \\
\hline Car theft & $0.238 * \cdots *$ & $0.131 * k *$ & 0.069 & 0.026 & $0.264 * k *$ & 0.339 \\
\hline Theft from car & $0.446 * * *$ & $0.465^{* * * *}$ & 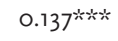 & $0.054 *$ & $0.186 * \cdots *$ & 0.654 \\
\hline Burglary (including attempt) & 0.033 & $0.257^{* * * *}$ & 0.097 & 0.063 & $0.198 * * *$ & 0.137 \\
\hline Robbery & $0.345^{* \ldots * k}$ & $0.308 * * *$ & -0.010 & -0.012 & -0.007 & 0.286 \\
\hline Pickpocketing & 0.058 & $0.492 * * *$ & -0.025 & 0.007 & $0.116 * *$ & 0.338 \\
\hline Other theft & $0.212 * k *$ & $0.350 * * * *$ & -0.003 & 0.037 & -0.092 & 0.195 \\
\hline Vandalism, including: & $0.319 * * *$ & 0.429 knt & 0.015 & $0.132 * * *$ & $0.091 * *$ & 0.529 \\
\hline Purposeful car damage & $0.353^{* * * k}$ & $0.375^{* * * * *}$ & 0.011 & $0.133^{* * * *}$ & $0.101 * *$ & 0.521 \\
\hline Other vandalism & $0.131 *$ & $0.395^{* * * k}$ & 0.017 & $0.083^{* * *}$ & 0.037 & 0.249 \\
\hline Violence, including: & 0.105 & $0.185^{* * * k}$ & $-0.105 \%$ & 0.038 & 0.049 & 0.134 \\
\hline Threaten with violence & 0.086 & $0.193 * * *$ & $-0.111 *$ & 0.019 & 0.061 & 0.131 \\
\hline Assault ${ }^{\mathrm{a}}$ & $0.186 * *$ & $0.113^{k-k}$ & -0.096 & 0.050 & -0.024 & 0.112 \\
\hline Traffic crimes, including: & $0.194^{* * *}$ & $0.252 * \cdots *$ & -0.022 & -0.054 & 0.048 & 0.155 \\
\hline Leaving place of accident & 0.251 冰火 & $0.229 * k *$ & 0.066 & -0.012 & $0.103^{*}$ & 0.173 \\
\hline Collision & $0.285^{* k * k}$ & $0.242 * * *$ & 0.040 & $-0.079 *$ & 0.014 & 0.148 \\
\hline Other crimes & -0.091 & 0.070 & -0.108 & 0.006 & 0.035 & 0.015 \\
\hline
\end{tabular}

Sources: Dutch Bureau for Statistics; Politiemonitor Bevolking 1997-2003; VAS 1997October 2003; Geomarktprofiel 1998

The rate of illegal residence correlates positively with all measured types of victimisation except 'other crimes' (see model I in Table 3.4). Evidently, the presence of illegal migrants tends to be a feature of neighbourhoods with elevated victimisation levels. Should high crime rates be attributed to the presence of illegal migrants in these neighbourhoods? We obviously cannot tell without adding controls for factors known to be related to neighbourhood crime.

As in the previous section, on subjective aspects of safety, the effects of the rate of illegal residence decline substantially when the percentage of single-person households and the percentage of homeownership are entered in the model (model IIa). The effects decline further when the percentage of legal non-Western immigrants is included as an additional 
indicator of social disorganisation (model IIb). Yet unlike the results for the subjective aspects of safety, the effects do not completely disappear for all types of crime. The rate of property offences, in particular, still turns out to correlate with the rate of illegal residence. Adding the percentage of juveniles (model III) reduces the effects of the rate of illegal residence somewhat further for most types of crime.

Thus although most of the association between the relative number of illegal migrants and objective neighbourhood safety is accounted for by aspects of social disorganisation, the rate of illegal residence still appears to have a modest independent effect on victimisation of most property crimes. Further, the effect reduction differs substantially across crime categories (compare models I and III in Table 3.4). It turns out that the reduction for vandalism (8I per cent), other crime (80 per cent) and violent crime (79 per cent) is larger than for property crime (69 per cent). These disparities may suggest that the presence of illegal migrants has some impact on property crimes, but hardly on violence against persons and objects.

Interestingly a similar pattern can be observed within crime categories: it turns out that the effect reduction is stronger for 'other vandalism' (86 per cent) than for 'car vandalism' (80 per cent - car vandalism is distinguished as a separate crime type because it sometimes concerns attempted thefts from cars, and thus represents property crime). Furthermore, it is stronger for 'robbery' (> Ioo per cent) than for pickpocketing (6I per cent).

These figures do not necessarily imply, of course, that illegal residents are responsible for the elevated property crime rates in the neighbourhoods where they life. The effects may also point at unmeasured causal factors that are correlated, causally or otherwise, with illegal residence. Possibly the rate of illegal residence is correlated with elements of social disorganisation that have not been adequately measured with the indicators used here. Such a correlation could have differing causes. It may be that the rate of illegal residence increases social disorganisation beyond levels indicated by the indicators that have been used in this sub-study (percentage of singles, legal non-Western migrants and private homeownership). This concern was, in fact, the second reason to conduct this sub-study. Yet it could also be that unmeasured elements of social disorganisation are not a consequence of illegal residence but are related to illegal residence for other reasons. Perhaps high rates of social disorganisation in a neigbourhood facilitate the local level of illegal residence because of reduced social control.

It is nonetheless remarkable that these quantitative findings confirm what is generally found about the involvement of illegal migrants in crime; for this reason I am inclined to attribute the observed patterns to offending by criminal illegal migrants. Chapter 4 shows that compared 
to legal persons of the same age and ethnic background, illegal migrants are more likely to be involved in instrumental offences such as theft and less likely to be involved in expressive offences such as assaults. Similar patterns have been found for the United States (Wolf I988; McDonald I997) and Belgium (Van Meeteren, Van San \& Engbersen 2008). In Chapter 5 we will see that many instrumental offences among illegal migrants appear to be aimed at meeting certain minimum living standards - standards that are perceived as elementary by the offenders and the social networks of which they are, or used to be, a part - under the prevailing restrictive conditions. This usually concerns theft, working with somebody else's papers in the formal economy or drug dealing (these two offences are not measured by the Police Monitor because there is usually no clear individual victim.) Further, a significant part of the illegal population consists of foreign criminals who travel to the Netherlands and other Western countries in order to commit crimes. They also tend to commit property crimes (see Chapter 6).

An additional reason to attribute the positive effect of illegal residence on property crimes to criminal illegal migrants is that we would expect to find similar effects on violence and vandalism under the hypothesis that the rate of illegal residence is merely associated with criminogenic factors that have not been adequately controlled for in this sub-study, such as unmeasured social disorganisation.

The findings in Table 3.4 also appear to indicate that illegal residence is associated with covert offences rather than with overt offences: as has been said, the effect reduction turned out to be stronger for robbery than for pickpocketing. Covert offences do not require overt physical contact with a victim and are therefore more unlikely to lead to police contacts. This preference for covert offences has some logic for illegal offenders. It can be assumed that most illegal migrants will seek to minimise the chances of police arrest in order to minimise the risk of expulsion.

Yet the fear of being expelled need not always inhibit crime, but may in fact promote certain crimes. Note that the effect reduction of the crime of 'causing traffic accident and leaving scene' (68 per cent) is lower than that of 'causing traffic accident' (94 per cent). Although this does not constitute direct evidence of the involvement of illegal migrants in traffic accidents, it is fairly probable that fear of contact with the police leads illegal migrants to flee the scene after a traffic accident. Many illegal migrants do not have the resources to own or access a car, but those who do are not allowed to carry a Dutch driver's license, will inevitably be uninsured, and risk repatriation if the police find them. 


\section{Illegal residence and neighbourhood safety in Bospolder- Tussendijken and De Schilderswijk}

The fieldwork focused on illegal residence in relation to subjective neighbourhood safety, but also provides some additional insights on illegal residence in relation to objective neighbourhood safety. The results of our fieldwork help us interpret and comment on three main aspects of the quantitative findings discussed. First, they make transparent the reasons why the presence of illegal migrants appears to have only modest effects on neighbourhood safety, particularly in its subjective dimension but also in its objective dimensions. Second, they show that the consequences for neighbourhood safety of the presence of illegal migrants are not unequivocal, and help explain why. They bring us closer to a solution of the paradoxical finding that the rate of illegal residence appears to increase the risk of property crime victimisation somewhat, but does not decrease subjective safety; it even appears to increase subjective safety somewhat. Third, the fieldwork results refine the statistical results: they illuminate how the effects of the rate of illegal residence on neighbourhood safety may vary across the types of illegal migrants and the types of legal residents involved. In this section, in particular, I will make heuristic use of the concepts of informal social rules, anomie, stereotyping and status-sets, which were introduced in the section 'theoretical starting points'.

\section{Why aren't the effects stronger?}

Even in neighbourhoods with percentages of illegal residence as high as in Bospolder-Tussendijken and De Schilderswijk, residents and professionals attribute unsafe feelings and discomfort primarily to phenomena other than illegal residence. Table 3.6 presents the reasons most often reported spontaneously (i.e., before specific questions about illegal residence had been asked). The three 'causes' reported most often are: 'junkies' (marginalised, problematic drug and alcohol users), 'youths hanging around' (mostly boys, aged twelve to 25, often second- or thirdgeneration Moroccans and Antilleans, who gather on certain street corners) and 'sexually obtrusive men' (men approaching women with sexual propositions). Only two residents attribute their unsafe feelings explicitly to illegal migrants. One Turkish girl and one Moroccan girl were annoyed because youths sometimes approach minority girls on the street or in schoolyards in order to make contact with potential partners who could help them obtain a residence permit.

In order to understand why the degree of illegal residence has limited effects on neighbourhood safety, and in order to stipulate the conditions under which stronger effects are to be expected, it is helpful to describe 
why residents feel unsafe in connection with these three social categories.

The fear of drug addicts, youths hanging around and obtrusive men is primarily due to their alleged involvement in norm violations, including crime. It turns out that drug addicts are often associated with robbery and pickpocketing, because they are assumed to be in need of money to buy drugs. Youths hanging around are associated with physical assault, robbery, threatening behaviour and sexual crimes. They are feared in particular because they operate in groups, and may therefore join forces. Women, in particular, feel unsafe because of the behaviour of sexually obtrusive men, who are sometimes suspected of being potential rapists and murderers. Although most respondents have never been victimised by drug addicts, groups of youths, or obtrusive men, many report unpleasant encounters with them, because they violate informal street rules quite frequently and openly.

Residents tend to interpret violations of informal rules as symptoms of underlying deviant identities, and consequently as omens of more serious dangers. The interviews suggest that at least three important informal rules are broken, although this street etiquette is rarely defined explicitly. Firstly, all three categories (drug addicts, youth groups and obtrusive men) fail to comply with the rule of civil inattention (Goffman I963). This rule dictates that participants in social traffic are expected to show co-participants that they have been noticed, but if the co-participant is a stranger, to do so only subtly. One ought to leave strangers in peace. Youth groups and obtrusive men often fail to do so. Marginalised drug addicts violate this rule when they ask passers-by for money or food.

Table 3.6 Neighbourhood-related 'causes' of unsafe feelings and discomfort amongst 101 residents in Bospolder-Tussendijken and De Schilderswijk

\begin{tabular}{lc}
\hline & $N$ \\
Drug users, dealers, alcoholics & 18 \\
Youth hanging around (especially of Moroccan or Antillean origin) & 15 \\
Men sexually harassing women, stalkers & 9 \\
Criminals in the streets & 5 \\
Dominant presence of a 'hostile' ethnic group (including 'skinheads') & 5 \\
Violent victimisation (assault and robbery in public space) & 3 \\
People behaving incoherently & 3 \\
Appearance of properties (boarded windows, windows with curtains closed) & 2 \\
'Illegals' & 2 \\
Unknown languages being spoken in the street & 2 \\
Shouting people in the street ('they might as well be strangling someone') & 1 \\
\hline
\end{tabular}

The second street law is the prescription that one must not appropriate too much public space ('privatizing public space', Lofland I973). Margin- 
alised drug users do not live up to this standard, since they live in the streets most of the time. But this rule is violated predominantly by youths who define their turf in public space at 'hang-out spots' (Clay I973). They announce their territorial claims to outsiders by producing noise, and may treat passers-by with verbal aggression.

The third rule prescribes the right dose of situational involvement (Goffman I963). A participant (like the noisy street youth) must show neither too much involvement nor too little. This stipulation explains why many residents feel unsafe when people use drugs or alcohol in public, or appear to be confused. They are too much in their own world, and therefore insufficiently conscious of the socially accepted definition of the situation. They are both unreachable and unpredictable, and therefore susceptible to transgressing other street rules or the law.

Fear of drug addicts, particularly, is connected to a fear of social degradation. Their behaviour and proximity makes residents feel ashamed of their own neighbourhood. The same is true, to a lesser extent, of the nuisance behaviour displayed by minority youth groups and obtrusive men. These fears prevail among native Dutch residents, as well as residents from well-established ethnic minorities like the Hindu-Surinamese. Ethnic groups of relatively high esteem fear being lumped together with groups of low esteem, since they share the same living environment and sometimes other characteristics as well. The downwardly mobile, including certain segments of the local native Dutch, tend to have a comparable income. The social climbers, such as those from the minority middle class, have in many respects comparable a physical appearance. The higher status groups tend to evade the lowerstatus groups in order to mark the social distinction, for instance, by giving these lower-status groups a wide berth or, eventually, by moving to a 'better' neighbourhood. (Recall that the Police Monitor item 'Do you ever take an alternative route to avoid going through unsafe places?' was included in the factor 'feeling unsafe'.)

Six reasons were found why residents do not associate illegal migrants with neighbourhood safety more frequently. The first reason is that illegal residence status is invisible. Residents cannot determine whether a stranger has a residence permit or not. It may be that residents think of the illegal residence status as an intrinsic threat or sign of disorder. These opinions are, however, hardly activated in public space because illegal residence may, at most, be assumed from certain presumed signs. When asked for signs, residents primarily point to dosshouses, usually in run-down blocks, where clients rent a room or bed (compare the flophouses in hobohemia as described by Anderson I923). These premises usually house between ten and 30 people, usually including illegal migrants. Residents also mention having witnessed police crackdowns aimed at tacking overcrowding. From time to time the police close down 
dosshouses because of nuisance or danger. Sometimes the aliens police check whether local employers are employing illegal migrants. Other signs are less frequently mentioned by residents: languages unusual in the neighbourhood, behaviour (supposedly, illegal migrants are 'timid', especially in the presence of police), their old-fashioned clothing, and Eastern European car plates (some illegal migrants drive to the Netherlands by car or van).

Due to the limited visibility of illegal residence, some members of the most-feared social categories (drug addicts, youth group members and obtrusive men) may in fact be illegal migrants, and their illegal residence status may have contributed to their deviancy. This is one of the reasons why the reported quantitative analysis is of importance: the presence of illegal migrants may influence neighbourhood safety even if local residents are unaware of it. We will see that having illegal residence status may indeed give rise to problematic drug use in some groups (see Chapter 5). Sometimes it is also, to a more limited extent, associated with behaviour that is typical for obtrusive men. However, it has hardly any relation to the phenomenon of street youths.

The second reason is the limited number of illegal migrants. It is unlikely that even in neighbourhoods like Bospolder-Tussendijken and De Schilderswijk they account for more than 8 per cent of the population (Leerkes et al. 2004). Therefore the presence of illegal migrants rarely dominates activities and social relations in the neighbourhood. The modest proportion also ensures that illegal migrants do not pose a great psychological threat. As can be seen from the listing of residents' images of illegal migrants documented in Table 3.7, most residents are indifferent or ambivalent about illegal residence in their neighbourhood. Some people support illegal migrants, for example, by providing language classes as volunteers, even though they do not have other ties to the beneficiaries. Illegal residence only became a prominent issue in De Schilderswijk when the relative number of illegal Bulgarians suddenly grew strongly after visa requirements were eased, and became very visible at some sites (See also Van Gestel 2006).

The third reason is the usefulness of illegal migrants for local residents. It turns out that a lenient attitude towards illegal migrants, and the willingness to provide support, is not facilitated by their modest number alone; sometimes the legal population depends on illegal migrants. Numerous residents, for instance, profit economically from their presence. Local shopkeepers profit from their capacity for work and the additional clientele they represent. Private individuals exploit dosshouses or sublet parts of their apartments. Furthermore, it turns out that there are affective ties between legal and illegal migrants. The illegal migrants who were interviewed - especially those from countries from which previous migration flows originated - often had legal close rela- 
tives or a partner in the neighbourhood. It is not uncommon (even among the native Dutch) for men or women to bring a foreign partner to the Netherlands illegally, whereas others live with an illegal partner whom they have met in Holland. An unintended consequence of the restrictive immigration policy seems to be that to some degree family reunion and family formation now occurs in clandestine ways (see also Staring 200I).

Table 3.7 Perceptions on illegal immigrants in Bospolder-Tussendijken and De Schilderswijk by having contact with illegal immigrants

\begin{tabular}{|c|c|c|c|c|c|c|}
\hline Images* of illegal immigrants & \multicolumn{3}{|c|}{$\begin{array}{l}\text { Bospolder- } \\
\text { Tussendijken }\end{array}$} & \multicolumn{3}{|c|}{ De Schilderswijk } \\
\hline \multirow[t]{2}{*}{ They ... } & \multicolumn{3}{|c|}{ Contact } & \multicolumn{3}{|c|}{ Contact } \\
\hline & Yes & No & Total & Yes & No & Total \\
\hline 'have come here to work' & 9 & 4 & 13 & 22 & 8 & 30 \\
\hline 'keep more quiet' & 3 & 5 & 8 & 13 & 13 & 26 \\
\hline ‘are people like you and me' & 5 & 3 & 8 & 11 & 8 & 19 \\
\hline 'commit crimes/are into crime' & 9 & 3 & 12 & 5 & 6 & 11 \\
\hline 'are being exploited/are pitiful' & 3 & 1 & 4 & 4 & 4 & 8 \\
\hline ‘oust/displace legal residents' & 2 & 4 & 6 & 3 & 3 & 6 \\
\hline ‘are nicer/more tidy’ & 2 & 3 & 5 & 7 & $\mathrm{O}$ & 7 \\
\hline 'are illegal for a suspicious reason' & 1 & 1 & 2 & o & 4 & 4 \\
\hline ‘harass women’ & 1 & 1 & 2 & 1 & 2 & 3 \\
\hline 'cause nuisance by overcrowding' & 1 & 1 & 2 & 1 & 2 & 3 \\
\hline 'cause serious nuisance' & 2 & o & 2 & 1 & 2 & 3 \\
\hline 'tarnish good name of neighbourhood/group' & 2 & 3 & 5 & ○ & O & ० \\
\hline 'live in unsafe buildings' & o & 1 & 1 & 4 & o & 4 \\
\hline 'use drugs' & ० & 3 & 3 & 1 & O & 1 \\
\hline 'carry infectious diseases' & 1 & o & 1 & o & 1 & 1 \\
\hline Total & 41 & 33 & 74 & 73 & 53 & 126 \\
\hline
\end{tabular}

"Multiple images per respondent possible

The fourth reason is that illegal immigration does not increase anomie substantially. Most illegal migrants rent a room or apartment for extended periods of time, or live-in with legal residents (see Engbersen et al. 2006). The ethnic and cultural diversity also hardly increases because of illegal settlement, at least in the selected neighbourhoods: concentration neighbourhoods tend to have very diverse populations, quite apart from the effects of illegal immigration flows. And many illegal migrants are from countries that have been a source of legal flows for some time now, or are culturally not very distant from them. Nonetheless, some evidence was found that anomie increases in the vicinity of dosshouses, 
also called turnover houses by the local residents because of their unstable populations.

Fifth: the tolerant attitude towards illegal residence is, in part, compatible with a neighbourhood culture that puts up with light norm violations. It turns out that many respondents feel secure and at home there in spite of elevated local crime rates. The interviewing students often marvelled at the increased insensitivity to small norm violations which this seems to require. It seems many local residents have become accustomed to the prevailing circumstances, and those who did not have moved. In these ways the neighbourhood conditions form and select residents who are not so easily annoyed by behaviour that is uncivilised and antisocial according to upper and middle class Western standards (see also Elias I939). This is a matter of degree; we have seen that the residents definitely value certain informal and criminal laws.

The sixth reason is that illegal status does not have unequivocal consequences for rule transgression (according to the opinion and experience of residents and professionals). This also mitigates the resulting effect. This final reason is explained in the next section.

\section{Why is the effect not unequivocal?}

It was found that the opinions on illegal residents are ambivalent and conflicting (Table 3.7). On the one hand, many residents have the impression that an illegal residence status promotes law-abiding behaviour. By implication, illegal migrants are assumed to live quieter lives than people who are more certain of their civil rights. On the other hand, respondents (often the same ones) suppose that illegal migrants might become involved in crime because they are not allowed to work and are excluded from unemployment benefits.

While these perceptions are partially based on assumptions and stories in the media (which in turn appear to be influenced by sociological research in the Netherlands, providing an interesting case of what Giddens called the double hermeneutic), they are in several ways in keeping with the available figures. It turns out, for instance, that the residents in Rotterdam associate illegal residence with crime more frequently than the respondents in The Hague (Table 3.7). The relative number of illegal migrants who have been arrested because of crimes is indeed higher in Bospolder-Tussendijken than in De Schilderswijk. The professionals attribute this neighbourhood difference to the problem of unoccupied dwellings and persistent drug tourism that used to plague the Rotterdam area. Especially during the I990s criminal illegal migrants who spoke French travelled to Rotterdam in the wake of flows of drug consumers, mostly French citizens. These users were attracted by the favourable price and quality of the drugs available - as a trading nation, the Nether- 
lands is an important country of import and redistribution of drugs and, for them, Rotterdam was conveniently located in the south of the country, a few hours driving time from France. Some North African illegal migrants who initially came to the Netherlands for other reasons found work in this black economy as well (Van der Leun 2003). The opinions on the effects of an illegal residence status are also in keeping with our own statistical findings: we have seen that the rate of illegal residence has differing effects on crime rates, depending on the type of crime. Victimisation from covert property offences, in particular, tends to rise in connection with the rate of illegal residence (drug trade remains largely undocumented in the PM data)

Although most residents are not personally acquainted with criminal illegal migrants, the police officers maintain that criminal careers may indeed develop amongst illegal residents, especially in cases of drug addiction. Substance dependency usually corresponds with homelessness and/or is preceded by a career as a clean street merchant (see also Chapter 5). The police also point to the phenomenon of criminal migration (see Chapter 6): on a limited scale, transnational banditry takes place, mostly involving Eastern Europeans (for example, car theft). Both residents and professionals report activities by illegal sex entrepreneurs and Eastern European prostitutes.

A larger number of respondents know illegal migrants who do not commit crimes. They know - and the professionals confirm this - that these people are generally very careful as a result of their precarious social position, in order to prevent expulsion. A Moroccan girl mentioned how three of her illegal acquaintances kill most of their time in their rooms or at a Moroccan café, hoping one day to marry. Unemployment among Moroccan illegal migrants is quite high, since there are relatively few Moroccan businesses in the Netherlands (see Burgers \& Engbersen I999). A Dutch woman remembers that she never had such quiet neighbours as when there were illegal migrants on the apartment in the apartment above hers. 'It sometimes seemed as if they crept along their ceiling.'

Some comments are in order about the assumption that illegal migrants' fear of repatriation always favours the safety of the local residents. According to the professionals some illegal migrants are apt to leave the curtains closed so they cannot be seen. Observing unopened curtains during the day is sometimes interpreted as an informal norm violation that makes some neighbours and passers-by feel unsafe (see Table 3.6). The assertion that illegal migrants live quietly should not be exaggerated either. Eventually illegal newcomers find out that in the Netherlands one rarely has to show an ID to the police, as long as one remains within the law (see also Staring 200I). In addition, the police do not always take great pains to repatriate illegal migrants. Random raids 
are prohibited. A community police officer in Rotterdam acknowledged that there have been illegal migrants in the neighbourhood for years. 'We don't do anything about it as long as they don't cause trouble.' Refugees, in particular, and migrants with strong social ties in the Netherlands such as family members or a partner, try to avoid expulsion. This tendency is stronger among migrants who believe they will have few opportunities to return. An official of the immigration service explained that from time to time illegal Eastern Europeans turn themselves in voluntarily because they want to be transported back free of charge. Because the geographical distance to their country of origin is smaller, and because of their status as future citizens of EU-member countries, Eastern Europeans could take more liberties about being openly visible in the neighbourhoods than other migrants who lack a residence permit. They were sometimes associated with types of nuisance that are quite atypical for illegal migrants. A square in The Hague was known locally as the Bulgarenplein ('Bulgarians Square') for a while because every day hundreds of Bulgarian men used to gather in front of a Turkish café. The café served as a meeting point and illegal temp agency for horticultural labour in a nearby area. Eventually the police intervened because of complaints, mostly by and on behalf of women (see also Van Gestel 2006). The 'technically unexpellable' are a second exception; typically they have been put in Aliens' Detention at least once, but later released because they concealed their identity, or because their country of origin did not cooperate with repatriation. My field work in the Aliens' Detention facility suggests that seriously marginalised illegal migrants sometimes prefer a temporary stay in detention to life on the street (see also Chapter 7).

In general, however, illegal migrants are more likely to comply with state rules, precisely because they are not supposed to be in the Netherlands. The weak cannot take the same liberties to violate rules overtly as the more powerful, legal residents (cf. Scott I990; Collins 2008). The fieldwork suggests that illegal migrants break formal state rules in a reserved, secretive and selective way (there was already some evidence for this), and exhibit the same patterns of compliance with unwritten street codes. Violation of street etiquette may even provoke state action, especially in cases of escalation. Usually these rules are transgressed, if at all, selectively, such as by illegal boys who approach potential marriage partners. The exception here is the minority of illegal migrants who are addicted to alcohol or drugs and have become homeless: they may break more than one type of social rule.

We have now come closer to solving the paradox that the rate of illegal residence does not worsen subjective neighbourhood safety, even though it appears to increase the number of property crimes. First, the residents are relatively inured to minor norm violations; they do not very easily feel unsafe, and may also be less likely to answer in the PM survey 
that much offending takes place in their area, even though this may well be the case according to objective criteria. Second, illegal migrants do not appear to violate unwritten street rules with high frequency, while such overt deviant behaviour is a substantial factor in perceived neighbourhood safety in spite of the increased tolerance for norm violations that is typical for concentration neighbourhoods. Third, illegal offenders are not very often involved in violence, while the association between criminal victimisation and subjective safety tends to pertain to violent crimes (Miceli, Roccato \& Rosato 2004; Moore \& Shepherd 2006).

\section{Does it apply to all illegal newcomers in relation to all established residents?}

We have seen that the presence of illegal migrants does not, in itself, have serious and unequivocal consequences for neighbourhood safety. The consequences depend on the degree to which legal residents believe that illegal migrants contribute to norm violations, anomie and status anxiety. Having an illegal residence status is anything but decisive in these respects, partly because this status has different consequences for different groups; the effects of the presence of illegal migrants on neighbourhood safety vary across categories of illegal migrants. This section briefly lists the main variants that pose a threat for nearly all residents, and variants that are a threat to almost anybody. Subsequently two examples are noted that demonstrate how specific illegal newcomers can be a threat to specific strata.

The contribution of an illegal migrant to neighbourhood safety corresponds strongly with his or her position at three levels. The first is the degree of criminality. Illegal migrants who work or who are supported by family or friends are clearly less threatening than illegal migrants who commit crimes or display antisocial behaviour. The latter are usually the most underprivileged illegal migrants, as well as some circular migrants, including transnational criminals (for instance, thieves from Eastern Europe who expand their work terrain) who pose a threat to the social order and, often threaten neighbourhood prestige.

The second is the degree of incorporation into regular institutions. Illegal migrants who live-in with family or friends are less threatening than illegal migrants who are housed in improvised and deviant ways, who sleep in dosshouses, in vans or on the streets. According to the professionals, unconnected illegal migrants also tend to invest less in social relationships, and are usually less informed about neighbourhood rules like waste collection times. Likewise illegal migrants who work informally, for instance in bakeries, are less threatening than illegal migrants who perform black economy functions like the drug trade.

The third is the degree to which the established mistake newcomers for members of a dangerous established groups. Initially, it was as- 
sumed that many established residents might fear illegal migrants in more or less categorical ways for being relatively underprivileged nonWestern foreigners. This is not the case. Most residents of BospolderTussendijken and De Schilderswijk are of modest foreign origin themselves. They do not share the negative ideas about ethnic minorities that are prevalent among quite a few elderly Hollanders in the same neighbourhoods, even though they realise that there is a connection in Dutch society between ethnic origin and social status. Furthermore, it turns out that most residents, including native Dutch youngsters and middle-aged individuals, have gradually become more familiar with the multi-ethnic character of the neighbourhoods One Dutch man said: 'Yes, I had to accustom myself to it, it does look different, you know. But they are not so different after all, believe me on that one.'

Most residents, it seems, have become streetwise in this respect too; they are quite capable of making distinctions, both between and within ethnic groups. For instance, higher and lower groups are distinguished. In particular, the groups of low esteem - and among them boys and young men, especially - are associated with crime and disorderly behaviour. Also, according to most residents, there are elements in all groups who contribute to society in positive ways. Interestingly, many respondents are critical about certain aspects of the multi-ethnic composition, while other aspects are seen as the most positive aspects of the neighbourhood. The contributions to economic vitality and diversity (stores, restaurants) are praised in particular. This implies that negative stereotypes about visible parallel statuses will be activated mainly with regard to specific groups of illegal migrants. Presently, young Moroccan and Antillean males tend to be feared. Illegal newcomers from North Africa and Sub-Saharan Africa risk being equated with them (in so far as their clothing is not 'old-fashioned'). However, this does not apply, for instance, to illegal Asian and female immigrants. It is of little significance in this respect that North African illegal migrants do not have an interest in copying the behaviour of the delinquent boys.

Sometimes the established differ strongly in the degree to which they consider a specific variant of illegal residence a threat. Such relational effects reveal themselves, for example, in the evaluation of illegal males and - partly in connection to their presence - the arrival of sex entrepreneurs. Admittedly, the chances of finding a partner increase for some women as these men become established. Nevertheless, the arrival of the men implies a higher risk of unwanted sexual approaches. According to one professional, Turkish women worry particularly about Bulgarian sex entrepreneurs, since the prostitutes they bring to the Netherlands not only service Bulgarian illegal workers but also other men, including Dutch Turks. Many prostitutes are from an underprivileged 
part of Bulgaria in which Turkish is spoken, so they can approach Turkish men quite easily.

The second example also pertains to the relation between established Turks and Bulgarian illegal migrants. In it, several variants of status anxiety come together. For instance, poorly educated Turks often fear losing out in the economic competition with Bulgarians, who are suspected of working below the usual labour price. Traditionally, i.e. since the early I970s, many Turks worked in horticulture near The Hague (Braam I994) and it turns out that some Turks fear that the arrival of criminal Bulgarians will darken the name of the neighbourhood, in general, and the reputation of Turks, in particular. Outsiders cannot readily distinguish between Turkish Bulgarians and Turks. The following edited fragment from an interview with a Turkish Rotterdam resident shows how different forms of status anxiety can occur simultaneously, and how they can promote unsafe feelings:

Respondent: 'If the Bulgarians weren't here, we'd work and live better.'

Interviewer: 'Do you think they take your jobs?'

R: 'Yes, of course. First I worked for, say, ten euros per hour. Then three, four people could work there. But now those people work for 2.50 euros and they get the work.'

I: 'Do you feel unsafe because of the illegals?'

R: 'Yes, also for the reason that they do wrong things.'

I: 'What kind of wrong things?' [interviewer's field note: Here he gesticulated that I had to turn off the recorder; subsequently, he told me about trafficking of women by illegal migrants.]

R: 'In my view those illegals must leave.'

\section{I: 'Why?'}

R: 'Because they do bad things. And now we have less work. We live here. This country is our country. This city is our city. We want to feel safe in the street. Our children go to school here. We want our children to feel safe here. I'm scared when I open the door for my children to play in the street.' 


\section{Concluding remarks}

This chapter has demonstrated that illegal migrants are overrepresented in relatively unsafe neighbourhoods, where considerable street crime occurs and where residents feel relatively unsafe. Yet when individual and neighbourhood variables that are known to determine neighbourhood safety are kept constant, the effect of the rate of illegal residence on neighbourhood safety diminishes. Is not associated with subjective neighbourhood safety and liveability any longer; it was even found that the rate of illegal residence may, if all other things are equal, somewhat decrease unsafe feelings among local residents. It turns out that indicators of social disorganisation explain to a great degree the reduced perceived safety in neighbourhoods where illegal migrants are concentrated.

Similar results were found with regards to the relationship between illegal residence and objective neighbourhood safety. Yet a robust positive relation remained between the rate of illegal residence and covert property crime rates in particular.

For several reasons, the opportunity structure for illegal residence is concentrated in disorganised urban neighbourhoods that house a disproportionate segment of non-Western minority groups and - though the effect is less pronounced - poor singles (Chapter 2). Illegal migrants and other poor newcomers find openings in unsafe neighbourhoods because many households with more social and financial resources tend to move out of these neighbourhoods when they can. Therefore, the concentration of illegal residence is to a great degree not a cause but a consequence of decreased safety: illegal residence does not generate neighbourhood differences in safety; neighbourhood differences in safety generate differences in the concentration of illegal residence.

The fieldwork suggests six reasons why the presence of illegal migrants does not endanger neighbourhood safety much: (I) illegal residence status is barely determinable by strangers; (2) the relative number of illegal migrants is, at least in the Netherlands, quite modest even in concentration neighbourhoods; (3) there are economic and affective ties between legal and illegal residents; (4) the presence of illegal migrants does not increase anomie substantially; (5) the legal residents of the neighbourhoods are relatively tolerant of minor norm violations; (6) having illegal residence status has differential consequences for norm violations and crime.

There were two main reasons for exploring the relationship between the concentration of illegal migrants in neighbourhoods and neighbourhood safety. First, it was supposed that illegal residence status may, under certain conditions, exacerbate the violation of social rules, for instance in the form of property crime. This sub-study found some evidence that such an effect may indeed exist: we have seen that the rate 
of illegal residence increases property crimes, particularly covert property crimes, when other factors are held constant. Of course we do not know with certainty whether these elevated crime rates should be attributed to illegal offenders or to criminogenic factors that are correlated with the rate of illegal residence, such as unmeasured social disorganisation. The second reason for conducting this explorative study was that it can be assumed that illegal residence may promote a further decline of social organisation, and therefore of safety. Yet, on the basis of this explorative study, we cannot rule out the possibility that concentration areas contain many legal residents who commit such property crimes and/or that these areas are attractive to non-resident thieves because of reduced social control. Future studies could examine how many legal offenders reside and/or offend in neighbourhoods with elevated levels of illegal residence, as well as whether they tend to commit additional property offences rather than other types of crime.

Although additional research is clearly needed, the qualitative data suggest that the presence of illegal migrants does not necessarily produce a substantial decline in social organisation, since it often concerns informal chain migration. This finding is valid under the circumstances found in Bospolder-Tussendijken and De Schilderswijk. When the percentage of illegal migrants exceeds a certain limit, or when substantial vagrant groups become part of the illegal population - which occurred in the Rotterdam crack houses for a while - we can assume that there is a higher chance of negative effects on social organisation and, therefore, on neighbourhood safety.

The safety of illegal migrants deserves more research as well. This sub-study at least suggests that we should worry about their safety. They often live in unsafe districts. Many of them are young men and women. Admittedly, young men do not feel unsafe so quickly, but they do have an elevated risk of victimisation depending on their lifestyle - think of the illegal men who start to sell drugs as a form of subsistence crime (see Chapter 5). Young illegal women may have a higher risk of sexual abuse. Because filing a charge with the police is more risky for illegal migrants than for citizens or legal denizens, they may be ideal crime victims.

The state determines whether people's stay in a country is legal or illegal. In a highly bureaucratised country like the Netherlands it also influences substantially the behavioural options people in its jurisdiction have. Internal border control does not appear to have unequivocal consequences for neighbourhood safety and liveability. Institutional exclusion as an instrument of internal border control may, for some groups, contribute to involvement in property crimes and possibly increases the risk of problematic drug use (Chapter 5). Restrictive immigration policies also occasion the formation of 'bastard institutions' (Hughes I95I) like the false documents circuit. On the other hand, the risk of secondary 
territorial exclusion, in particular, appears to push most illegal migrants away from violence and into complying with most informal street rules. When in public space, most of them are pressured to behave like model citizens. Precisely because illegal residence is, by definition, a violation of immigration law, most illegal migrants cannot get away so easily with the overt violation of other state and street laws. That is far from bad news for neighbourhood safety and liveability, at least as it is perceived by the established population.

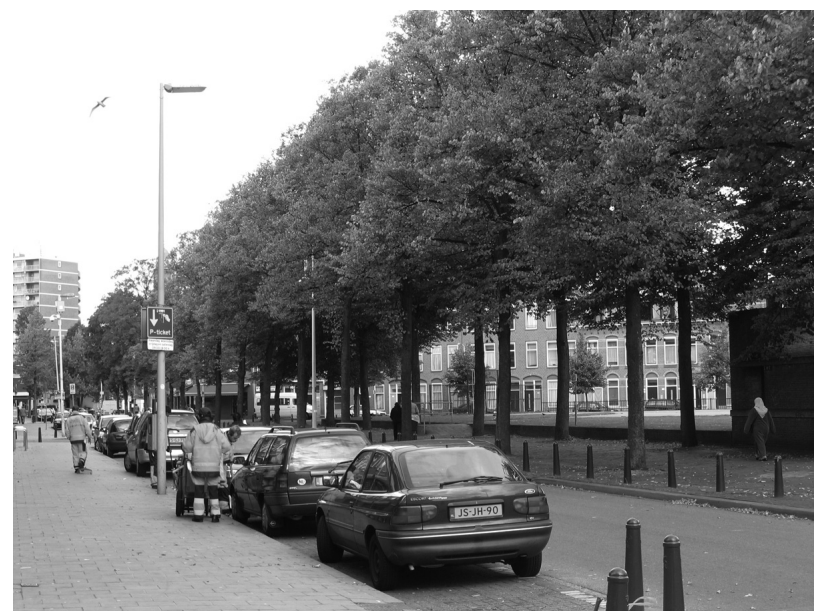

Sanitation department at work at Bulgarenplein ('Bulgarians square') in De Schilderswijk

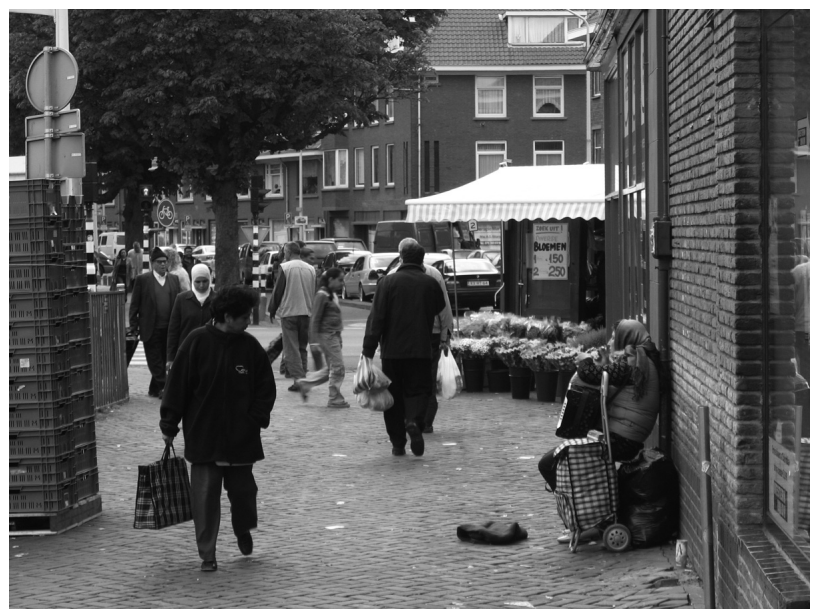

Eastern European musician performing at the entrance of Haagse Markt ('The Hague market') near De Schilderswijk 


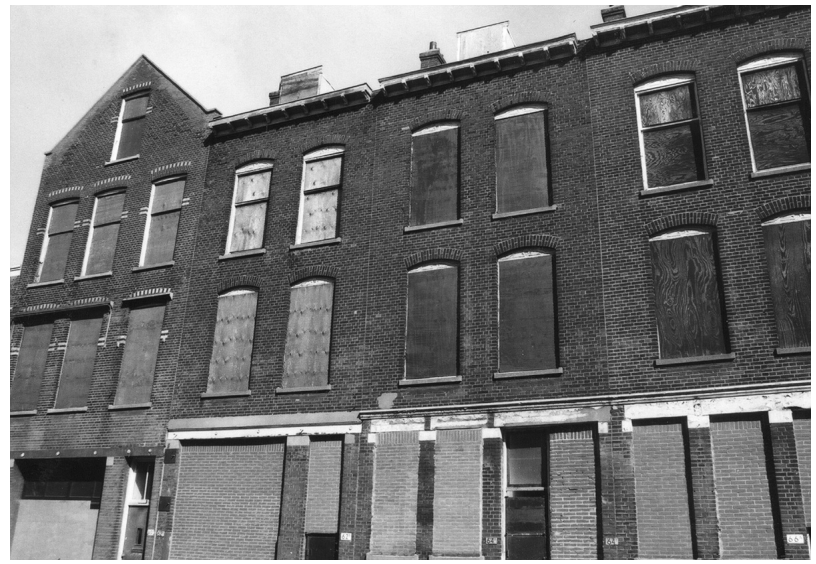

Vacant houses closed with bricks in Bospolder-Tussendijken

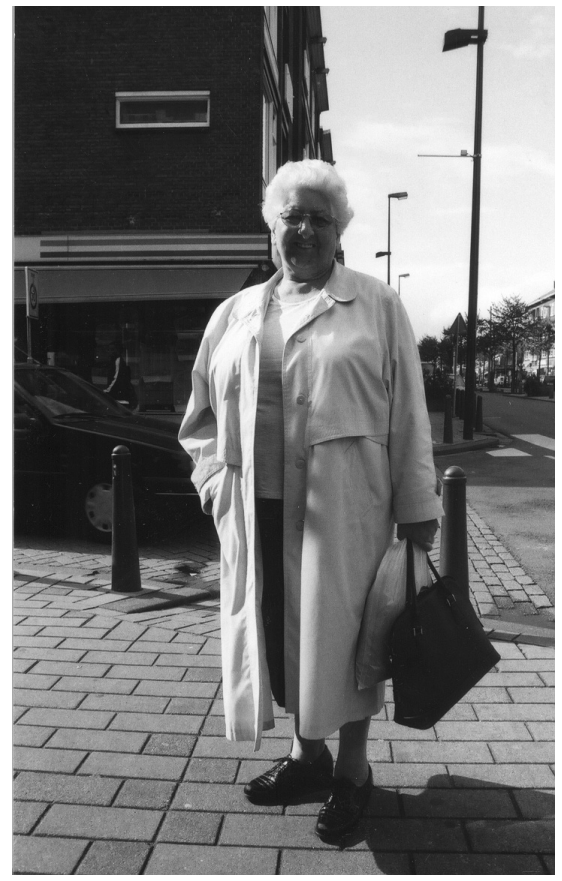

Dutch woman in Bospolder-Tussendijken 


\section{Part 2}

\section{Illegal residence and crime}





\section{Embedded crimes?}

\section{Introduction}

It appears that many, though not all, immigrant groups from poorer countries are over-represented in street crime in the Netherlands (Junger I990; Werdmölder I997; Van San I998; Bovenkerk 200I). The same is true for other Western countries as well (cf. De Haen-Marschall I997; Tonry I997; Waters I999). The available studies also indicate that migrants from specific countries commit, to some degree, specific types of crimes.

Engbersen et al. have paid ample attention to the life strategies of illegal migrants in the Netherlands (Engbersen, Van der Leun \& Willems I995; Engbersen \& Van der Leun I995; Burgers \& Engbersen I999; Engbersen et al. I999; Engbersen \& Van der Leun 200I; Engbersen et al 2002). One of their key findings was that there are large variations in the extent to which illegal migrants from different countries of origin come into contact with the police through criminal activity. Furthermore, the researchers found indications that the prevalence of crime among illegal migrants appears to have risen since 1997 (Engbersen et al. 2002). Although the latter increase will be analysed in Chapter 6, this chapter will propose an alternative hypothesis to explain this increase.

A swift comparison of the results of the research on crime among legal and illegal migrants suggests that there are similarities as well as differences in the extent to which legal and illegal migrants from a particular country of origin come into contact with the police as suspects for certain types of crime. Such similarities and dissimilarities, however, have not been examined systematically, and have been for the greater part neglected in explaining illegal migrants' criminality patterns, as well as the crime patterns among legal migrants.

The aim of this third sub-study is to reduce this gap through a systematic comparison of the crime rates among eleven groups of legal migrants with indicators of the crime rates among illegal migrants of comparable age and country of origin. It also examines to what degree legal migrants commit similar offences to those of their illegal compatriots. 
Firstly, I will briefly repeat how crime involvement among illegal migrants was understood when I started this study. In the next section, the origin of the data and the research method is explained. Thereafter the empirical results are presented and some concerns about the validity of the data are discussed. Then the findings are related to some individual examples of criminal illegal migrants who are reported in the literature. Finally, the theoretical implications of the evidence are addressed.

\section{The differential opportunity structure}

Engbersen and Van der Leun (I995, 200I) found systematic differences in the extent to which illegal migrants of differing nationalities come into contact with the police as suspects in connection with criminal offences. Suspicion of involvement in criminal offences accounted for 32 per cent of the apprehended Eastern Europeans, 54 per cent of the Algerians and 65 per cent of the Moroccans. Illegal Turks had only a 4 per cent chance of being apprehended as suspected criminals. For a good understanding of this sub-study it is useful to repeat briefly how Engbersen and Van der Leun explained these differences.

Inspired by Cloward and Ohlin's (i960) theory of delinquent subcultures, which aimed to integrate Mertonian strain theory with Sutherland's theory of differential association, these differences were explained using the notion of the differential opportunity structure. Engbersen and Van der Leun reasoned that, depending on their ethnic group, illegal migrants have differential access to (I) formal institutions of the welfare state such as the labour market, education, unemployment benefits, housing and health care, (2) informal institutions such as the network of family and friends and the informal economy and (3) criminal institutions, or circuits. The latter idea particularly departs from Mertonian strain theory, because it assumes that crime cannot be understood purely by examining the degree of access to conventional ways to satisfy needs which are regarded as legitimate in mainstream society. It is argued that crime is not always possible, even if there is motivation; illegal opportunity structures should be taken into consideration as well.

The Dutch state gradually implemented the institutional exclusion of illegal migrants as an instrument of internal border control so that, unlike many categories of legal migrants, illegal migrants now have fewer opportunities to work and cannot receive state scholarships, profit from unemployment benefits, or rent houses or apartments for which a housing permit is required. Although unemployment is high among many legal non-Western immigrant groups, legal migrants are not as systematically and legally excluded from life chances as are illegal migrants. ${ }^{\mathrm{I}}$ The increased institutional exclusion of illegal migrants appears to have 
had a statistically positive effect on the involvement in crime among illegal migrants. This rise will be analysed in Chapter 6. In this chapter I will formulate an hypothesis aside from marginalisation to account for this rise.

If state policies dealing with illegal residence are held constant then illegal migrants' survival chances are assumed to vary in direct relation to the level of embeddedness or social capital of the illegal migrant and the immigrant communities in the Netherlands on which the illegal newcomer depends. Social capital, defined as the capacity of individuals to mobilise certain resources from an established immigrant community or a social network of which they are a part (Bourdieu I983; Coleman I990; Portes I995), can provide illegal fellow countrymen with ample access to the second dimension of the opportunity structure, such as the informal ethnic economy, provided illegal migrants have social contacts with members of the ethnic community and are able to receive their support (Staring \& Engbersen 200I). Legal migrants may also provide illegal migrants with some indirect access to the first dimension of the opportunity structure by lending or renting out health insurance cards or fiscal numbers (cf. Engbersen et al. I999). For these reasons, it has been asserted that criminality by illegal migrants is caused by societal marginalisation as a result of their illegal residence status, particularly when a lack of access to formal institutions is aggravated by a lack of social capital: 'This study made very clear that illegal migrants with little social capital commit crimes in order to survive' (Engbersen 200r: 245). While illegal Turks are quasi-integrated in the Turkish community, illegal Moroccans are more at risk of committing survival crime - this term will concern us in the next chapter - because they 'often have to manage on their own' (Engbersen \& Van der Leun 2001: 63).

Hence, the tendency in most publications to understand illegal migrants' involvement in crime in a negative way, i.e. as a last option. Engbersen and Van der Leun have, however, asserted that the chances of illegal migrants becoming engaged in crime may, in part, be linked with features of criminal circuits. They found that North African illegal migrants made the best employees to occupy the lower echelons of the sale of hard drugs to French drug tourists who travelled to Rotterdam to buy and consume hard drugs, since many North Africans speak French (Van der Leun 2002). But this is more a question of differences in human capital than differences in social capital. The role of immigrant communities in providing access to criminal circuits has hardly been taken into consideration so far. ${ }^{2}$

It was difficult to develop precise hypotheses from the marginalisation thesis that could be tested using the evidence collected for this sub-study. The data pertained to the group level and could not be taken as direct indicators of the amount of social capital available to individual illegal 
migrants. It will, however, become clear why the following analyses indicate that the current explanation must, in two ways, be incomplete: (I) there is not always a negative relation between social capital and criminality and (2) an adequate understanding of crime involvement among illegal migrants requires that additional factors are taken into consideration besides the illegal residence status i.e. the consequences of the policies with respect to immigrants who are considered illegal by the state, interacting with social capital in the country of destination. The importance of illegal residence status in explaining patterns of crime involvement among illegal migrants appears to have been overestimated in previous studies.

\section{Data and research method}

The data on legal migrants were taken from the HKS, a database in which the Dutch police register suspects. The HKS system contains all official reports by the police, which describe offences (type of offence, date, place) as well as features of the suspects (date of birth, sex, nationality, country of birth). The data on apprehensions of illegal migrants were taken from the Vreemdelingen Administratie Systeem (VAS), the database also used in Chapters 2, 3 and 6. It is designed to register all foreigners who require explicit permission from the Dutch authorities to enter and/or to reside in the Netherlands. All apprehended illegal migrants - apprehended by the regular police or by specialised divisions such as the aliens police - are documented in this system too. It is often the VAS that determines whether a foreigner can be apprehended as an illegal alien in the first place, because prior to their apprehension, illegal migrants are either not registered, are already listed as illegal migrants because of previous apprehensions or are known as formerly legal foreigners with expired residence permits. Possible additional grounds for apprehension besides illegal residence, such as working without a permit, using public transport without paying the fare, drug offences and theft are filed in the VAS. These registrations of possible offences and misdemeanours are excerpts from official reports filed in the HKS.

The data were initially gathered for two separate studies: (I) research on delinquency among young immigrants aged twelve to 25 from relatively recently arrived groups of legal migrants (Kromhout \& Van San 2003) and (2) research on illegal migrants of all ages (Leerkes et al. 2004). For this study a secondary analysis of the former dataset was combined with a primary analysis of the latter. Since the first research was limited to young immigrants, and comparable research on older legal migrants is not available in the Netherlands, the emphasis in this sub-study had to be on young immigrants. Investigation was limited to 
eleven non-Western immigrant communities that are relatively large in the Netherlands: Morocco, Turkey, Surinam, the former Soviet Union, the former Yugoslavia, China, Somalia, Iran, Iraq and Afghanistan (see Table 4.I). ${ }^{3}$

Table 4.1 'Legal' suspects by country of birth and the corresponding group population sizes as a whole (aged 18-24 years, 1999 and 2000)

\begin{tabular}{|c|c|c|c|c|c|c|c|}
\hline & $\begin{array}{l}\text { Suspects } \\
1999\end{array}$ & $\begin{array}{l}\text { Suspects } \\
2000\end{array}$ & $\begin{array}{l}\text { Population } \\
1999\end{array}$ & $\begin{array}{l}\text { Population } \\
2000\end{array}$ & $\begin{array}{l}\text { Average } \\
\text { crime rate } \\
1999 / 2000\end{array}$ & $\begin{array}{l}\text { Adjusted } \\
\text { crime } \\
\text { rate (A) }\end{array}$ & $\begin{array}{l}\text { Adjusted } \\
\text { crime } \\
\text { rate (B) }\end{array}$ \\
\hline Morocco & 2,360 & 2,030 & 24,855 & 23,548 & 9.1 & 8.7 & 8.9 \\
\hline Turkey & 749 & 580 & 22,450 & 19,980 & 3.1 & 2.9 & 3.0 \\
\hline Surinam & 1,049 & 942 & 16,550 & 14,565 & 6.4 & 6.2 & 6.3 \\
\hline Yugoslavia & 508 & 428 & 4,698 & 5,090 & 9.6 & 8.1 & 9.0 \\
\hline Somalia & 340 & 293 & 3,535 & 3,680 & 8.8 & 8.5 & 8.7 \\
\hline Iraq & 187 & 218 & 3,015 & 3,373 & 6.4 & 5.8 & 6.1 \\
\hline China & 44 & 59 & 2,533 & 3,098 & 1.8 & 1.0 & 1.4 \\
\hline Afghanistan & 67 & 78 & 2,143 & 2,860 & 2.9 & 2.6 & 2.8 \\
\hline Soviet Union & 191 & 274 & 1,910 & 2,423 & 10.7 & 6.7 & 8.6 \\
\hline Iran & 119 & 147 & 1,700 & 2,110 & 7.0 & 6.4 & 6.7 \\
\hline Ethiopia & 70 & 55 & 1,018 & 1,043 & 6.1 & 5.8 & 5.9 \\
\hline
\end{tabular}

Sources: Kromhout and Van San 2003; VAS 1999-2000

Residence status is not documented in the HKS. Accordingly, legal migrants cannot be distinguished from illegal migrants in this system. Therefore, Kromhout and Van San, who were interested in legal migrants only, estimated the number of suspects with residence permits by eliminating from their analyses all foreign-born suspects who told the police they did not reside in the Netherlands. As the complete dataset on illegal migrants was placed at my disposal, I was able to eliminate illegal migrants from the analyses of Kromhout and Van San with greater precision. First, using the VAS data, I calculated per country of birth the total number of illegal migrants who were apprehended for offences and were between eighteen and 25 years old. These numbers were subtracted from the number of legal suspects reported by Kromhout and Van San (data adjustment A). In this way, the maximum distortion in their figures could be corrected for. Next I calculated per country of birth the number of illegal migrants who were in the required age category, were apprehended for offences, and had told the police their residential addresses in the Netherlands (data adjustment B). The best correction of Kromhout and Van San's overestimation of the number of suspects with residence permits probably lies between the two adjustments. ${ }^{4}$ 
Table 4.2 Reasons for apprehension of illegal immigrants (aged 18-24, 1998-2001)

\begin{tabular}{lcccc}
\hline & $\begin{array}{c}\text { Total number } \\
\text { apprehensions }\end{array}$ & $\begin{array}{c}\text { Apprehensions } \\
\text { for offences }\end{array}$ & $\begin{array}{c}\text { Apprehensions } \\
\text { for other reasons }\end{array}$ & $\begin{array}{c}\text { \% apprehensions } \\
\text { for offences }\end{array}$ \\
Morocco & 3,008 & 1,065 & 1,943 & 35.4 \\
Turkey & 1,216 & 197 & 1,019 & 16.2 \\
Surinam & 223 & 131 & 92 & 58.7 \\
Yugoslavia & 816 & 325 & 491 & 39.8 \\
Somalia & 138 & 47 & 91 & 34.1 \\
Iraq & 224 & 67 & 157 & 29.9 \\
China & 423 & 88 & 335 & 20.8 \\
Afghanistan & 90 & 28 & 62 & 31.1 \\
Soviet Union & 1,281 & 427 & 854 & 33.3 \\
Iran & 105 & 51 & 54 & 48.6 \\
Ethiopia & 22 & 14 & 8 & 63.6 \\
\hline
\end{tabular}

Sources: VAS 1998-2001

\section{The 'quantity' of criminality}

The data in Table 4.I, which were taken from Kromhout and Van San, are ordered according to the size of the population of offenders and nonoffenders in the age group eighteen to 25 . For methodological reasons the age group twelve to eighteen is excluded here. ${ }^{5}$ In the right-hand columns indicators for the crime rate are shown per country of birth. The crime rate is defined as the percentage of a population registered in the course of a year as suspected of at least one criminal offence. The average crime rate is the average of the crime rates for 1999 and $2000 .^{6}$ Table 4.I demonstrates that the crime rate varies with national origin. Whereas the crime rate approaches io per cent for countries such as Morocco, the former Yugoslavia, Somalia and the former Soviet Union, it is 3 per cent or less for Turkey, Afghanistan and China. The data adjustments are particularly significant for the former Soviet Union (the average crime rate fell from I0.7 to 6.7 and 8.6) and, to a lesser extent, the former Yugoslavia (the average crime rate dropped from 9.6 to 8.I and 9.0).

The figures indicate that delinquency is quite widespread among youngsters in some immigrant communities, especially since the data relate to the total population in the age category concerned, male and female. ${ }^{7}$ A crime rate of to per cent for the total population between eighteen and 25 years of age may sometimes imply that approximately one-fifth of the male population is annually registered as a crime suspect (cf. Van San \& Leerkes 200I). Table 4.2 shows the number of apprehen- 
sions of illegal migrants from the selected eleven countries of origin. In order to reduce the influence of random variation - the number of illegal migrants aged between eighteen and 25 was quite small for some nationalities - a somewhat longer period of time was used (I998-200I). ${ }^{8}$ For instance, 3,008 apprehensions of illegal Moroccans took place in these four years. ${ }^{9}$ About 35 per cent of these were related to crimes, ${ }^{\mathrm{IO}}$ while for Turkey, this figure was only I6.2 per cent. The remaining apprehensions concerned illegal labour, using public transport without paying the fare, illegal occupation of apartments, etc. In the Netherlands, these offences do not fall within the criminal law.

The total number of illegal migrants per country of birth is unknown. Only the total number of such immigrants, regardless of their country of origin, has been estimated in previous studies. It is therefore impossible to calculate precise crime rates per country of birth, as we did for legal migrants. Instead, the percentage of apprehensions for offences was used as an indicator of the prevalence of crime (see also Engbersen \& Van der Leun I995, 200I). This crude measure suggests that crime is much more prevalent among illegal migrants from Ethiopia, Surinam, Iran, Yugoslavia and Morocco, than among illegal Chinese, Turks and Iraqis. The former Soviet Union, Afghanistan and Somalia occupy an intermediate position.

Figure 4.1 Crime rate among legal immigrants compared to crime rate indicators for illegally residing countrymen aged 18-24; 1999-2000 (legal immigrants), 1998-2001 (illegal immigrants)

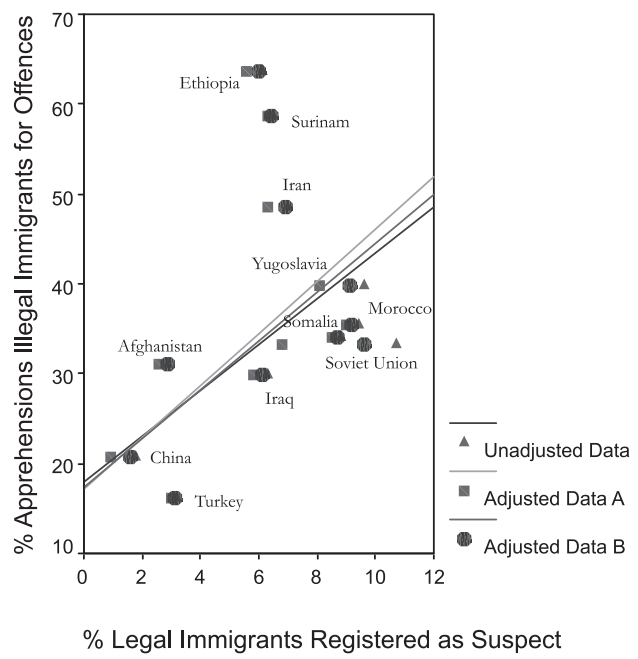

Sources: Kromhout and Van San 2003; Vreemdelingen Administratie Systeeem 
Unfortunately, in the absence of precise crime rates, it was impossible to determine whether, compared to legal migrants, illegal migrants are more likely, less likely, or equally likely to come into contact with the police because of criminal offences. Yet, what we can establish in Figure 4.I, which plots indicators of the crime rates for the researched groups, is that the crime rate for legal migrants can be used to predict the percentage of apprehensions of illegal compatriots on the grounds of criminal offences (and vice versa). With residence status held constant, Ethiopian, Surinamese, Iranian and Yugoslavian immigrants are two to three times more likely to be registered as suspects of criminal offences than are immigrants from China, Turkey and Afghanistan. Table 4.3 confirms that the correlation coefficient between the two measures is positive. It varies between 0.34 (unweighted) and 0.74 (when the data are weighted according to the relative size of the immigrant groups).

Table 4.3 Correlation coefficients between crime rates among legal and illegal immigrants (aged 18-24) in eleven 'ethnic' groups; 1999-2000 (legal immigrants) and 1998-2001 (illegal immigrants)

\begin{tabular}{lll}
\hline & Unweighted & Weighted \\
Unadjusted data & $0.34(p<0.31)$ & $0.57(p<0.14)$ \\
Adjusted data A & $0.42(p<0.20)$ & $0.74(p<0.11)$ \\
Adjusted data B & $0.37(p<0.27)$ & $0.67(p<0.13)$ \\
Without Surinam & & \\
Unadjusted data & $0.39(p<0.27)$ & $0.78(p<0.01)$ \\
Adjusted data A & $0.44(p<0.20)$ & $0.76(p<0.01)$ \\
Adjusted data B & $0.42(p<0.23)$ & $0.78(p<0.01)$ \\
Without false documents & & \\
Unadjusted data & $0.53(p<0.09)$ & $0.40(p<0.22)$ \\
Adjusted data A & $0.58(p<0.06)$ & $0.43(p<0.19)$ \\
Adjusted data B & $0.55(p<0.08)$ & $0.41(p<0.21)$ \\
Without Surinam and false documents & & \\
Unadjusted data & $0.79(p<0.01)$ & $0.92(p<0.00)$ \\
Adjusted data A & $0.77(p<0.01)$ & $0.88(p<0.00)$ \\
Adjusted data B & $0.78(p<0.01)$ & $0.93(p<0.00)$ \\
\hline
\end{tabular}

* The data are weighted according to the relative size of the immigrant community $(N=11 ; N=10$ without Surinam).

Sources: Kromhout and Van San 2003; VAS 1998-2001

\section{Some remarks on the validity of the association}

The validity of the statistical association in Figure 4.I can be questioned on a number of grounds. Firstly, it may be argued that the connection is merely the result of Kromhout and Van San's inability to eliminate illegal migrants from their analyses with certainty. The association may be 
the result of auto-correlation in as far as both datasets include illegal migrants. The data adjustments, however, do not support such an argument, as the correlation becomes somewhat stronger when the corrections for the possible inclusion of illegal migrants in Kromhout and Van San's data are taken into account (Table 4.3). In particular, the score for the former Soviet Union becomes more in agreement with the general trend.

A second objection could be that police data are always incomplete and selective (cf. Brown i988; Levitas et al. I996). Self-report surveys show that the actual prevalence of crime is much higher than official police figures tell us. This problem of the 'dark figure' is intensified by its non-randomness: some offences do not interest the police, some offences are more easily discovered than others, et cetera.

Researchers in the field of ethnicity and crime tend to agree that while police data represent a somewhat biased image of the 'true' crime rates among ethnic groups (Bovenkerk, De Haan \& Yesilgöz I99I; De Haan \& Bovenkerk I993), selectivity of police data probably amplifies, but does not cause, ethnic differences regarding crime (cf. Van San \& Leerkes 200I). Admittedly, low status groups may be policed and punished to a higher degree than high status groups (Black I978), but in our case, all the data pertain to immigrants from relatively poor countries; no comparison is made with the dominant, native population or with high status immigrant groups from Western countries. In any case, no good alternative to police data is available. ${ }^{\text {II }}$

For the sake of argument, it could nonetheless be assumed that police data do not at all reflect the extent to which immigrants are involved in crime. The scores for Turkish and Chinese immigrants may be low merely because the offences committed by members of these groups do not interest the police, or happen to have a relatively low chance of discovery. In Figure 4.I, two exceptions or outliers can be observed: among illegal Ethiopians and Surinamese, the percentage of apprehensions for offences is higher than would be expected based on the crime rates for their legal compatriots. Interestingly, selectivity by the police probably explains the deviant score for Surinam (the deviant score for Ethiopia will be addressed later). Many Surinamese speak Dutch as a first or second language and are often considered Surinamese Dutch. Therefore, Surinamese people are probably less likely to be apprehended for illegal residence than illegal migrants from other countries. If we could control for this bias, the position of Surinam would be more in accordance with the general trend, because its score would shift vertically, i.e. towards the trend line. Indeed, the positive association in Figure 4.I becomes stronger when Surinam is left out of consideration (Table 4.3).

For the rest, it is unlikely that the association is caused merely by police selectivity. If we assume, for instance, that the figures are biased 
because the eleven immigrant communities are policed differently, the connection remains unexplained, since every point in the figure relates to immigrants from the same ethnic group. If the police paid more attention to some ethnic groups than others, the prevalence of crime among legal Turks, for example, might be underestimated to a greater extent than the crime rate for legal Moroccans. But in that case, the percentage of illegal Turkish immigrants apprehended for an offence would probably be underestimated as well, as compared to the score for illegal Moroccans. For similar reasons, it is impossible to account for the connection by hypothesizing that ethnic groups are involved in offences with differing chances of being caught. Again, the score for a particular group of legal migrants would be biased in the same way as the score for the corresponding group of illegal migrants: some countries of origin would move up diagonally along both axes, while others would move down a little, leaving the connection unchanged.

The association also remains unaltered if it is assumed that illegal migrants are invariably involved in crimes with a lower or higher chance of discovery than their legal counterparts: all scores would shift horizontally to the right or to the left, or vertically up or down. Such shifts would not alter the connection.

Moreover, the hypothesis of police selectivity cannot explain why legal and illegal migrants tend to commit, to a considerable degree, specific types of crime depending on their country of origin. This is the subject of the next section.

\section{The 'quality' of criminality}

Across all ethnic groups, most offenders are engaged in petty crimes such as theft. Less prevalent crimes such as rape and homicide add relatively little to the total number of registered offences. Such distributions are independent of the ethnicity of offenders. Next to such universal similarities, several examples of criminal specialisation have been observed. For example, suspects of Turkish descent are often apprehended for violence in the Netherlands. This crime pattern is, in part, connected with the tradition of honour vengeance in some parts of Turkey (cf. Bovenkerk \& Junger-Tas 2000). Turks are also known to have substantial involvement in heroin trafficking to Western Europe (Bovenkerk \& Yeşilgöz I998). Suspects from South America are frequently apprehended for cocaine trafficking (ISEO 2002). Offenders from Eastern Europe are apprehended for theft and burglary more often than offenders from other countries, but rarely for drug trafficking (Snel et al. 2000; Van San, Snel \& Boers 2002). Moroccan offenders are disproportionately engaged in theft with violence (ISEO 2002) and marijuana trafficking (Van 
Gemert I998). Suspects from several African countries have a much higher chance of being apprehended for fraud than suspects from other countries (Van San \& Leerkes 200I).

Table 4.4 Types of offences committed by 'legal' and 'illegal' crime suspects (aged 12-24); 1999-2000 (legal immigrants) and 1998-2001 (illegal immigrants)

\begin{tabular}{|c|c|c|c|c|c|c|c|c|c|c|}
\hline & $\mathrm{N}$ & $\begin{array}{l}\text { Sexual } \\
\text { offences } \\
\text { with } \\
\text { violence }\end{array}$ & $\begin{array}{l}\text { Sexual } \\
\text { offences } \\
\text { without } \\
\text { violence }\end{array}$ & Violence & $\begin{array}{l}\text { Theft } \\
\text { with } \\
\text { violence }\end{array}$ & $\begin{array}{l}\text { Theft } \\
\text { without } \\
\text { violence }\end{array}$ & Vandalism & $\begin{array}{l}\text { Traffic } \\
\text { offences }\end{array}$ & Drugs & $\begin{array}{l}\text { Other } \\
\text { offences }\end{array}$ \\
\hline Former Yugoslavia & 1,469 & 0.8 & o & 9.9 & 2.6 & 63.7 & 11.4 & 4.9 & 0.9 & 5.9 \\
\hline Cramer's V $=0.30$ & 372 & 0.8 & o & 4.6 & 1.1 & 53 & 4.3 & 7.3 & 5.9 & 23.1 \\
\hline Somalia & 1,258 & 0.6 & 1 & 15.4 & 6 & 51.9 & 14.2 & 2.9 & 0.8 & 7.1 \\
\hline Cramer's V $=0.34$ & 53 & o & 1.9 & 7.5 & 7.5 & 17 & 5.7 & 3.8 & 1.9 & 54.7 \\
\hline Iraq & 672 & 2.7 & 1 & 25.1 & 6 & 37.6 & 18 & 2.2 & 0.7 & 6.5 \\
\hline Cramer's V $=0.42$ & 77 & O & o & 7.8 & 2.6 & 28.6 & 5.2 & 6.5 & 9.1 & 40.3 \\
\hline China & 126 & o & o & 24.6 & 7.1 & 38.9 & 5.6 & 10.3 & 0.8 & 12.7 \\
\hline Cramer's V $=0.49$ & 123 & O & o & 16.3 & 3.3 & 16.3 & 0.8 & 5.7 & o & 57.7 \\
\hline Afghanistan & 191 & 5.8 & 4.2 & 23 & 1 & 33.5 & 17.3 & $7 \cdot 3$ & o & 7.9 \\
\hline Cramer's V $=0.74$ & 26 & o & o & 3.8 & o & o & o & ० & o & 96.2 \\
\hline Former Soviet Union & 1,126 & 0.2 & o & 4.5 & 2.9 & 74.3 & 4.5 & 3.4 & 3.9 & 6.2 \\
\hline Cramer's V $=0.25$ & 477 & 1.7 & o & 4.2 & 2.5 & 60.6 & 1.5 & 8.6 & 2.3 & 18.7 \\
\hline Iran & 504 & 1.2 & 0.6 & 18.7 & 6.7 & 39.5 & 19 & 4.6 & 2.8 & 6.9 \\
\hline Cramer's V $=0.54$ & 58 & o & o & 5.2 & o & 13.8 & 3.4 & 10.3 & 3.4 & 63.8 \\
\hline Ethiopia/Eritrea & 205 & 1.5 & 0.5 & 13.7 & 12.7 & 38.5 & 14.1 & $7 \cdot 3$ & 1 & 10.7 \\
\hline Cramer's V $=0.49$ & 16 & o & o & o & o & 18.8 & o & o & 6.3 & 75 \\
\hline Total legal immigrants & 5,551 & 1.1 & 0.6 & 13.6 & 4.6 & $55 \cdot 3$ & 12.3 & 4.1 & 1.6 & 6.8 \\
\hline Total illegal immigrants & 1,202 & 1 & 0.1 & 5.9 & 2.2 & 45.6 & 2.8 & $7 \cdot 3$ & 3.7 & 31.6 \\
\hline $\begin{array}{l}\text { Total illegal immigrants } \\
\text { (aged 12-17) }\end{array}$ & 162 & o & o & 5.6 & 4.3 & 46.3 & 3.1 & 4.3 & 3.7 & 32.7 \\
\hline $\begin{array}{l}\text { Total illegal immigrants } \\
\text { (aged 18-24) }\end{array}$ & 1,040 & 1.1 & 0.1 & 6 & 1.8 & $45 \cdot 5$ & 2.7 & 7.8 & 3.7 & 31.4 \\
\hline \multicolumn{11}{|c|}{ Nationalities for which 'quality' of delinquency is not specified by Kromhout and Van San: } \\
\hline Morocco & 1,253 & 1.1 & 0.2 & 4.7 & 3.7 & 19.9 & 4.4 & 7.6 & 22.7 & 35.8 \\
\hline Turkey & 241 & 1.7 & 0.4 & 13.3 & 1.7 & 15.8 & 5.4 & 17 & 18.7 & 26.1 \\
\hline Surinam & 135 & 0 & 0 & 5.2 & 5.2 & 17 & 2.2 & 3 & 56.3 & 11.1 \\
\hline
\end{tabular}

Sources: Kromhout and Van San 2003: 69; VAS 1998-2001

Table 4.4 specifies the types of crimes of which legal and illegal migrants are suspected. For each country of origin the first row represents crime suspects who are staying in the country legally, while the second row represents suspects without legal residence status. It lacks data on legal Moroccans, Turks and Surinamese, as Kromhout and Van San did not specify the offences for these groups. Their research mainly focused on delinquency among immigrant groups that are new to the Netherlands. Also, Kromhout and Van San reported offences for the age category 
twelve to 25 years old as a whole, and did not present separate data for suspects aged eighteen to 25. Therefore, Table 4.4 shows the apprehension reason for all suspects aged twelve to 25 , even if for methodological reasons it would have been preferable to restrict investigation to suspects aged eighteen to $25 .^{\text {I2 }}$

The data in Table 4.4 are in agreement with the literature: the selected ethnic groups differ significantly, but not enormously, with regard to the types of offences their delinquent members commit. For legal offenders (Cramer's $V=0.14 / p<0.00 / c a l c u l a t e d$ using eight ethnic groups), the association between country of origin and offence committed is somewhat weaker than for illegal offenders (Cramer's V=0.20; $\mathrm{p}<0.00 /$ calculated using eleven ethnic groups), but this difference is not substantial and may be due to the absence of data on legal offenders from Morocco, Turkey and Surinam. A comparison of the way legal offenders as a whole are distributed among the nine categories of offences with the corresponding distribution for illegal offenders yielded Cramer's V=0.33 $(\mathrm{p}<\mathrm{O} . \mathrm{OI})$. This figure indicates that there is a modest but significant association between residence status and type of offence committed. ${ }^{\mathrm{I} 3}$

Legal and illegal migrants' offences can also be compared in a more qualitative way. Regardless of ethnicity and residence status, the main reason for apprehending offenders is 'theft without violence', whereas sexual offences and 'theft with violence' are relatively rare. Secondly, whatever their residence status, Eastern European offenders (from the former Yugoslavia and the former Soviet Union) have a higher than average chance of being apprehended for 'theft without violence': the police have, respectively, a 63.7 chance and a 74.4 per cent chance of apprehending a legal Yugoslavian or Russian suspected of 'theft without violence', while the overall chance of apprehension on these grounds is only 55.3 per cent. For comparable illegal offenders, these figures are 53.0 per cent and 60.6 per cent compared to 45.6 per cent. Thirdly, more than I3 per cent of apprehensions of Turkish illegal offenders concern violence, whereas for people from other countries this proportion is only 5 or 6 per cent. Fourthly, more than 50 per cent of apprehensions of illegal Surinamese delinquents concern drugs.

There are also significant differences. The first that strikes the eye is the lower occurrence of violence among illegal offenders - both against persons and goods. When Morocco, Turkey and Surinam are left out of consideration - Kromhout and Van San did not publish separate data on these groups - the rate of these crimes among illegal offenders is only 5.9 per cent and 2.8 per cent, compared to I3.6 per cent and I2.3 per cent for legal offenders. Similarly, whereas the ratio of the number of suspects of theft without violence compared to theft with violence is I2:I for legal offenders, this ratio is 21:1 for illegal offenders. 
The second difference is the elevated share of the category 'other offences' among offenders who lack a residence permit (3I.6 per cent for illegal migrants versus 6.8 per cent for legal migrants) probably due to the inclusion of 'false documents' in this category. About 87 per cent of apprehensions of illegal migrants within the category 'other offences' concerns this form of fraud (figure not presented in table).

Separate analyses per country of origin reveal that the extent to which the quality of crime among illegal migrants resembles the crime involvement among their legal counterparts differs somewhat per ethnic group: Cramer's V varies from 0.25 for the former Soviet Union to 0.74 for Afghanistan. ${ }^{14}$ This differing extent of resemblance appears to be coupled with the differing size of the category 'other offences' per ethnic group. Note that the latter category is especially large for illegal suspects from Ethiopia, Iran and Afghanistan. These are precisely the three nationalities in Figure 4.I (next to Surinam) for which the crime rate for illegal migrants is higher than would be expected based on the crime rate amongst their legal compatriots. When apprehensions for false documents were excluded from the analyses, the connection in Figure 4.I became even stronger, especially when Surinam was also left out of consideration. ${ }^{15}$

\section{Theoretical implications}

\section{Similarities}

There are two ways to account for the observation that the patterns of crime among legal and illegal migrants resemble one another: (I) we can look for common explanatory variables and (2) we can hypothesise that the involvement in crime among legal migrants has a criminogenic effect on illegal migrants and/or vice versa.

As an example of the first strategy, we could speculate that marginalisation gives rise to crime among illegal migrants as well as among legal migrants. This seems a valid argument since many poor newcomers initially have to put up with a relatively marginal social position in the country of destination, which is amplified in some groups by a lack of social capital in their ethnic networks. For legal migrants the marginal social position is then not the result of having illegal residence status, i.e. of formalised social exclusion that is organised and legitimised by the state. Rather, it is the outcome of other causes and processes of social exclusion, such as social exclusion because of poor education or because of ethnic discrimination in the labour market; one could argue that having illegal residence status prevents such informal mechanisms of exclusion from having an effect, for exclusion is already brought about by the 
state. For instance, Sansone (I992), who researched the 'survival strategies' of Afro-Surinamese in Amsterdam, understood the involvement of these legal migrants in the street trade in drugs as a reaction to conditions of social marginality coupled with a lack of social capital. He also observed that even if the involvement of these migrants in the lower and relatively non-organised echelons of the drug trade was quite high at the time, only a few men managed to rise in the criminal hierarchy. Sansone argues that the extended but weak social networks of these Afro-Surinamese migrants impeded their success as businessmen in the formal economy and in the illegal economy as well.

Yet this strategy still leaves unresolved the question of why criminality tends to take the form of burglary among migrants from one country, while violent honour vengeance is overrepresented among migrants from another country. Precisely because there is ethnic diversity in crime, many researchers in the field of crime and ethnicity believe that several explanatory variables should be taken into consideration (cf. De Haen-Marshall I997; Tonry 1997; Kromhout \& Van San 2003). A review of the literature shows that different forms of ethnic criminality require different explanations. For example, whereas many offences are connected with high levels of unemployment and social exclusion, other forms of crime only become possible when an ethnic group possesses an extensive institutional infrastructure. In the latter circumstances criminal compatriots have more opportunities to use companies to cover up certain criminal activities such as the wholesale trade of drugs (cf. Zaitch 2002), or to extort money from entrepreneurs. In addition, some ethnic groups may have access in their country of origin, or diasporas, to criminal resources such as guns and drugs, which are not so easily obtained by members of other ethnic groups (Bovenkerk 200I).

Next to such structural factors, cultural aspects, even if they usually interact with structural factors and are sometimes hard to distinguish from them, also appear to play a role. For instance, ethnographers such as Bovenkerk (I994: 59) and Van Gemert (1998) have stressed that in comparable structural conditions, ethnic groups tend to develop different strategies - including different criminal strategies. Van San (I998, 2002) also demonstrated the relevance of cultural aspects in crime patterns. She found that delinquent as well as non-delinquent youths from Curacao, as well as their mothers, although to a lesser degree, tended to justify certain crimes that are relatively common among immigrants who originate from the lower classes of that Caribbean island, particularly stabbing in the case of certain insults or threats.

Given that crime patterns among illegal migrants reflect the criminal involvement of legal compatriots, and given that a multitude of variables are usually used to explain the differential involvement of legal migrants in crime, offending by illegal migrants must be influenced by such addi- 
tional variables as well, either directly (strategy I) or indirectly (strategy 2). Hence, criminality cannot be understood only as a uniform reaction to strong marginalisation that is the outcome of social exclusion by the state in combination with a lack of social capital.

So far, few criminal illegal migrants have been interviewed. Some respondents confirm the marginalisation thesis. For example, in a nonrandom sample of $\mathrm{i} 65$ illegal migrants, involvement in crime was associated with features indicating a marginal existence in the Netherlands. The twenty criminally involved migrants lacked relatives in the Netherlands more often than did the non-delinquent migrants, and they were also more often homeless (see Burgers \& Engbersen I999: 255). Among illegal migrants there may indeed be a negative empirical correlation between social capital and crime. However, the ethnographic literature has also reported examples of criminal illegal migrants who were embedded in ethnic communities to a considerable extent. These suggest that social capital gained as a result of ethnic incorporation does not necessarily reduce crime.

The latter examples can be divided into two ideal types. Both illustrate the possibility of co-offending by illegal migrants and their legal counterparts (strategy 2). The first type pertains to criminal illegal migrants who cater to the economic demands of parts of their ethnic communities, albeit in ways that violate criminal law. This includes bicycle thieves and illegal migrants who work in informal restaurants where they sell some marijuana on the side (see Engbersen et al. I999: 187/8). The consumers of these goods are residents (often compatriots) of poor urban neighbourhoods where such illegal migrants reside and operate. A certain degree of embeddedness in the local immigrant community is a necessary condition for supplying goods such as cheap bicycles and marijuana.

Examples such as these are reminiscent of Mahler's (I995) study of immigrant life in poor neighbourhoods in the United States. She refers to the activities of 'claveros' who obtain calling codes by 'surfing' callers who use call cards at public phones, and who then sell these codes to other (legal and illegal) immigrants who use them for international phone calls: 'They risk being caught in this line of business, but they risk never meeting their goals if they pursue a straight and narrow trajectory in the mainstream economy' (Mahler I995: I52). ${ }^{16}$ Although not all immigrants make use of such illegal services, we could assert that such crimes are functional for some members of these ethnic communities, given their socio-economic circumstances. Such offences are so closely connected with these communities that it could even be argued they are a feature of them.

The second type of embedded crimes concerns illegal offenders who seize criminal opportunities as a result of contacts with criminal compa- 
triots who reside in the Netherlands with residence permits. In that case, crime involvement appears to develop via processes of differential association (Sutherland I937). Examples include an illegal migrant who was recruited in Morocco by a Dutch-Moroccan owner of a coffee shop in which marijuana is sold (reported by Engbersen et al. I999: 219), and illegal migrants from Colombia who were offered the opportunity by their countrymen to make money in the cocaine business (Zaitch 2002: 232). In such instances, crime among illegal migrants is promoted by social ties to criminal legal migrants: the involvement in crime could not have taken place, at least not in the same form, without criminal social capital, in this case contacts with criminal countrymen who live in the Netherlands with residence permits. Social capital predominantly implies an increase in the number of behavioural options, chiefly noncriminal but also criminal (cf. Portes i998).

\section{Accounting for the dissimilarities}

The observation that patterns of crime among legal and illegal migrants are not completely identical needs to be accounted for as well. It is plausible that the relatively low use of violence by illegal offenders, including theft with violence, as well as their elevated use of false documents, is a consequence of their precarious legal position in comparison with legal migrants: secondary territorial exclusion is more of a threat for the former than for the latter. ${ }^{17}$ Illegal migrants face more difficulties in establishing themselves in the Netherlands, and for many illegal migrants, deportation is a real risk given the state's endeavour to implement secondary territorial exclusion, even though many apprehended illegal migrants are not deported. ${ }^{\mathrm{I} 8}$ As a result, criminality by illegal migrants, if it occurs, appears to be more prudent and is primarily aimed at obtaining income - it is 'instrumental' rather than 'expressive' (cf. Radcliffe-Brown I952: I43; Van San I998; Blok 200I).

The use of false documents appears to be most widespread among illegal quartermasters from ethnic groups that are relatively new to the Netherlands (Ethiopians, Iranians and Afghans). These forms of offending primarily appear to be a response to restrictive migration policy by means of external border control. Illegal migrants from relatively settled ethnic groups (from Turkey, Morocco and Surinam) do not require false documents to the same extent, since it is often easier for them to reside in the Netherlands by invitation, if only temporarily (Staring 200I). ${ }^{\text {I9 }}$ This can indeed be understood as a form of social capital in the country of destination. 


\section{Concluding remarks}

This sub-study has demonstrated that both the quantity and the quality of criminality among illegal migrants are associated with the involvement in crime among legal migrants of comparable age and country of origin. Still, these patterns are not completely interchangeable: illegal offenders make use of false documents more often than legal offenders do, and they appear to be engaged less frequently in theft with violence and vandalism.

On the basis of the available data, differences in opinion about the interpretation of the evidence are still possible, and additional research is needed, especially ethnographic research on the individual level, and on immigrants older than 24. For instance, the offences committed by legal and illegal migrants and the motives for committing these offences are not necessarily identical, even where their crime patterns resemble each other. It could be, for instance, that legal and illegal migrants who steal tend to take different types of goods, and for different reasons. It could also be argued that illegal migrants have an interest in participating in criminal activities that are not especially risky, e.g. acting as lookout during a burglary, while legal co-offenders, by contrast, may compel illegal migrants to carry out the more risky activities, e.g. breaking and entering. Interviews would have to be conducted and judicial dossiers examined in order to determine the extent to which this is the case.

Nevertheless, given the similarity in crime patterns and given that several variables besides, or in interaction with, societal marginalisation are commonly used to explain offending patterns among legal migrants, it is probable that similar variables, and interaction effects between these variables, also influence illegal migrants' crime involvement. Cultural aspects, and differences in the availability of criminal resources in the country of origin in particular, should also be taken into consideration. Moreover, we should be aware that there is no hard and fast negative connection between social capital and criminality, even if empirically the association may indeed be negative. Several offences require some measure of social capital.

In this study, the two types of embedded crime identified illustrate that incorporation in ethnic communities can give access to criminal institutions or circuits: (I) criminal activities that are, arguably, functional for segments of poor immigrant communities of which criminal illegal migrants are a part and in which they are to some extent embedded, and (2) criminal activities by illegal migrants who are incited to commit crimes by compatriots who reside legally in the Netherlands. Being embedded in an ethnic community can apparently be connected with all three dimensions of the differential opportunity structure, i.e. the formal, the informal and the criminal institutions or circuits. 
It seems that incorporation into ethnic communities does not have an unequivocal effect on illegal migrants' involvement in crime; such incorporation may only reduce the likelihood of illegal migrants embarking on criminal careers in the Netherlands insofar as the crime rate in the ethnic community is low. The likelihood of illegal migrants engaging in criminal careers in the Netherlands, and the types of offences such offenders may commit, vary with the involvement in crime of their legal compatriots. This is an important observation, since involvement in crime appears to be relatively widespread in some ethnic groups, especially among young males.

There are, as has been mentioned, empirical indications that illegal migrants are increasingly engaging in various forms of crime in the Netherlands. This study suggests that such growth may not be purely a consequence of the exclusionist migration policies of recent years. The increase could be also due to a heightened prevalence of crime among legal migrants, on whom - for their own chances of survival - illegal migrants may come to depend. This issue will be taken up in Chapter 6 . But first we will examine the life histories of a group of illegal migrants who were held in Aliens' Detention after having committed a crime in the Netherlands.

\section{Coda}

In this sub-study, the percentage of apprehensions for crimes has been used as a proxy for the prevalence of crime among illegal migrants. As a consequence, the analyses do not reveal whether the crime rate for illegal migrants is higher or lower than for comparable legal migrants. Nonetheless, it is possible to calculate a more conventional crime rate for the total illegal population of non-European origin, using Cruijf and Van der Heijden's 2004 estimations of the total size of the non-European illegal population in the Netherlands. This is done in Chapter 6 .

Finally, the extent to which having illegal residence status tends to depress involvement in violence may even be underestimated somewhat on the basis of this sub-study; the VAS data include a number of formerly legal migrants who have lost their residence permits because of criminal activities in the Netherlands. Convictions for serious crimes often with a violent component - are overrepresented as a reason for ending residence rights (see also Chapter 6). At the time (in 2004), I lacked the proper data to include this aspect in the analysis. 


\section{5 'I am just trying to live my life'}

\section{Introduction}

Asylum migration to Western Europe increased sharply toward the end of the twentieth century, particularly after the fall of the Iron Curtain. Because of this and other factors, the willingness to admit refugees declined in the Western world (Schuster 2000). In the period I995-2005 approximately 50 to 70 per cent of asylum requests were rejected in the Netherlands (De Boom, Engbersen \& Leerkes 2006). Moreover, those who are recognised as refugees increasingly receive temporary residence permits (Doornbos \& Groenendijk 200I).

Asylum seekers who have exhausted all legal remedies lose their right to stay in the Netherlands four weeks after the final rejection of their asylum request. ${ }^{\mathrm{I}}$ Persons who do not leave can be forcibly expelled. There are a number of reasons why many of them do not leave, or are able to delay their departure for a long period (see Engbersen et al. 2002; Van Kalmthout \& Van Leeuwen 2004). ${ }^{2}$ As a consequence, a sizeable group of illegal migrants with an asylum background existed in the Netherlands during the period of study. In 2005 it stood at between I7,500 and 30,000 people, Io to 20 per cent of the estimated total illegal population of the Netherlands that year (De Boom, Engbersen \& Leerkes 2006).

This chapter deals with three questions that have not been adequately covered in the previous literature on illegal residence and crime, using illegal migrants with a history as asylum seekers as a strategic research group. First, it was unclear whether survival crime is a suitable term. Before I conducted this study only a few criminal illegal migrants had been interviewed. It was therefore impossible to draw any firm conclusions about what illegal migrants are trying to accomplish by committing crime, and whether their motives can be covered by a single term. Second, we do not know the degree of importance of the choices that criminal illegal migrants make. Previous studies assumed that the opportunity structures to which an illegal migrant may or may not have access determine whether or not he or she will be involved in crime. 
This kind of explanation, while important, risks being too mechanical. It neglects the question of how illegal migrants who commit crimes deal with such opportunities and what their own contributions to the outcome are. The third question that requires further study is whether the criminality began in the Netherlands or earlier in their lives. At a time when criminology increasingly searches for causes of criminality in early youth and adolescence (Gottfredson \& Hirschi I990; Samson \& Laub I993, 2005), little is known about criminal antecedents among illegal migrants.

Theoretically, illegal migrants with backgrounds as asylum seekers run an elevated risk of involvement in survival crime. Asylum migrants are often pioneers who cannot rely on well-established co-ethnics when they find themselves illegal residents. They therefore constitute a strategic research group to test and refine the theories that have been proposed so far. To this end the life stories of 26 male illegal migrants with an asylum background and a record of offences were recorded at the Aliens' Detention unit in Tilburg. Three research questions underlie this research, which was part of a more comprehensive study on asylum migration and crime in the Netherlands (De Boom et al. 2006; Althoff et al. 2006; Leerkes 2006).

- What were the men trying to accomplish with crime and what kinds of offences did they choose for these purposes and what kinds of offences did they not choose?

- How did their illegal residence status influence the men's choices, specifically with regard to the development of crime?

- To what extent had they come into contact with the police in their countries of origin?

\section{Previous findings and theory}

De Haan (1993) introduced the term 'survival crime' in the Dutch research on illegal residence. Survival crime is assumed to be a reaction to extremely difficult living conditions (see also Sansone I992). It is a way of dealing with constant problems of livelihood and personal safety. The term therefore is primarily used to refer to offending by illegal migrants with very limited life chances. Internationally, the term is sometimes also used in research on homeless people (for instance, Pain \& Francis 2004). The idea that illegal migrants commit crimes in order to survive is also mentioned briefly in Wolf (I988).

Before I started to conduct research in this field there were three empirical indications for a negative connection between conventional life chances and survival crime. First, there were considerable differences 
between ethnic groups. The previous chapter showed that Turkish and Chinese newcomers, who are often supported by tight-knit ethnic communities that are characterised by high levels of entrepreneurship in the Netherlands, are less often suspected of crimes than North Africans, who primarily depend on Moroccan migrant communities that, as Dutch research shows, tend to be fragmented. As a result, Moroccan illegal migrants have to fall back on their own resources to a greater extent. Second, in a group of 165 illegal migrants, involvement in crime was reported more often by respondents who were homeless and/or did not have kin in the Netherlands than by respondents who did have a fixed domicile and family in the country (Burgers \& Engbersen I999). Third, the number of crime suspects with an illegal residence status rose markedly between 1997 and 2003, a period in which internal border controls in the form of institutional exclusion of illegal migrants increased considerably in the Netherlands (this rise will be analysed in Chapter 6).

At the same time it has been suggested that illegal residence status can curb rule violation (Van der Leun 2003). Such migrants can be assumed to avoid police contacts as an adaptation to the state's endeavours to achieve secondary territorial exclusion: the risk of detention and expulsion that unwanted migrants face after they have managed to circumvent the primary external border controls. In Chapters 3 and 4 , a number of additional empirical indications have already been given for this deterrence thesis. For instance, the effect appears to reveal itself in the relatively low involvement of illegal migrants in the expressive crimes of violent assault and vandalism. Compared to instrumental offences in which the offence is primarily a means to a particular end, such as identity fraud, violent assault and vandalism with their strong expressive component are more often an end in themselves (see Van San I998; Cohn \& Rotton 2003).

The previous chapter also demonstrated that there are significant ethnic differences in the types of crimes in which illegal migrants may be involved. Initially this diversity was mainly explained by group differences in the degree of access to criminal circuits in the Netherlands. For example, Engbersen and Van der Leun have shown that illegal migrants who spoke French turned out to be relatively well equipped to assist with the sale of hard drugs to French drug tourists who travelled to Rotterdam to buy and use these drugs. In the previous chapter I argued, elaborating on this insight, that illegal newcomers have higher chances of criminal embeddedness as they encounter more offenders in their social networks, if a particular type of crime is relatively common among countrymen with legal status, for example (see also Kehla I999; Zaitch 2002). In that case social ties to legal and criminal inhabitants enable involvement in somewhat more integrated and organised forms of crime, and 
do not necessarily function as a buffer against offending (cf. Weerman I998). Because of a combination of factors, since the I980s ethnic North Africans have increasingly left their mark on the street trade in hard drugs in the Netherlands. ${ }^{3}$ It seems likely that illegal newcomers from North Africa can join this black economy more easily than illegal migrants from other countries of origin.

A number of criminologists who have done research on legal migrants have attributed ethnic diversity in criminality, in part, to cultural or subcultural factors, although doing so was a taboo in academia for a long time (see Van Gemert 1998). Today we still do not know whether or how such factors may impact the degree and form of criminality among illegal migrants. An exploration of the role of such cultural factors is one of the purposes of this sub-study.

Finally, we do not know much about criminal antecedents among illegal migrants in the countries of origin. Van der Leun (2003) interviewed a few North African drug runners and found indications that their offending had begun in the Netherlands. However, in his ethnographic research on cocaine trade among Colombians, Zaitch (2002) found indications for continued criminal careers. Both types of offenders were reported by Wolf (I988) in his explorative study in the San Diego area.

\section{Research method}

The vast majority of crime suspects are men. This holds true for crime suspects among asylum seekers (De Haan \& Althoff 2002) and among illegal migrants (Engbersen et al. 2002). Women were therefore excluded from this study. The limited size of the interview group also played a part in this selection, along with practical considerations: the Tilburg prison is an institution for men.

The fieldwork on which this chapter is based was carried out in the Aliens' Detention unit of Tilburg prison in 2005. Initially all IIo detainees with an asylum background and a record of offences were approached by letters in English, French, Arabic, Russian and Serbo-Croat. The records of offences the men had committed were made available by a department of the Ministry of Justice. In return for engaging in an interview the respondents were offered a ten-euro phone card.

Because only five men responded, a more informal approach was chosen which included a role for the clergymen of the institution (imams, Catholic priests and Protestant ministers). An imam recruited three men who had not responded to the letter. In addition, I was given the opportunity to introduce myself during two Islamic and two ecumenical Christian services. Such services are well attended. ${ }^{4}$ The willingness to cooperate with the research was high; 86 men registered. A further selection 
was made of 30 people who actually had an asylum history and a record of offences. Ultimately, the target number of 25 could only just be reached, since several of the men were expelled from the Netherlands before the interviews could take place.

Most respondents were interviewed twice. An interpreter was present with eight respondents. ${ }^{5}$ The remainder were sufficiently fluent in Dutch or English. Many men had, or had had, a Dutch partner and/or had taken language courses during the asylum procedure. The Africans who were from former English colonies generally spoke English as a first or second language. The interviews took place in rooms in the visitors' wing that are ordinarily used for meetings between detainees and lawyers or representatives of external state organisations. The individual interviews, which were semi-structured, lasted for between one-and-ahalf and two hours. Twenty respondents permitted me to record the interviews.

The interviews were sometimes quite emotional, especially for the respondents but in some cases for me as well. Several men were dejected, angry, stressed or fearful, although there was also regular laughter. I often tried to break the ice with a joke. In other ways as well, I tried to put the men at ease. The record of offences was put on the table ('Did you know this? This is what they say...'). To reassure the men once more that this was a matter of scientific research, I put two books on the table about illegal residence in the Netherlands (Engbersen et al. I999; Leerkes et al. 2004). It seemed to me that most respondents appreciated the opportunity to tell their story in a setting where no moral judgements or important decisions would be made about them.

\section{Validity}

The life-course approach has a number of methodological drawbacks (Giele \& Elder I998). The same is true of prison interviews (see Kroese $\&$ Staring I993). People tend to rearrange their experiences, and they do not remember everything. Questions about deviant behaviour can stimulate socially desirable answers. Respondents may fear that talking about unsolved crimes will lead to additional punishment. One respondent indeed ended his cooperation after the first interview because he did not want to take the risk that I was a policeman after all. Others were less worried on that score. Some men even confessed to incidents for which they had not been convicted. It is probable that strategic responses may have occurred with regard to migration motives in particular. The interviewees were no longer in the asylum procedure, but many had not given up all hope that they would eventually be recognised as refugees. Political motives may have been feigned or exaggerated. I suspect that the risk of strategic response with regard to offending was lower as all 
respondents knew that I had their police and court records in front of me. The hope of being granted a residence permit may have promoted a conventional presentation of self - within the limits set by the record of offences - but may also have led to greater openness. An institution psychologist informed me that one respondent had gone on the rampage after the interviews because he had hoped - in spite of information to the contrary - that he would obtain a residence permit in this way and that that was one of the reasons he had granted full cooperation.

Table 5.1 Respondent characteristics

\begin{tabular}{|c|c|c|c|c|c|}
\hline & Country & Age & Interviews & Language & Interpreter? \\
\hline \multicolumn{6}{|c|}{ North Africa } \\
\hline$A$ & Algeria & 22 & 1 & Dutch & No \\
\hline$B$ & Algeria & 35 & 2 & Arabic & Yes \\
\hline$C$ & Algeria & 37 & 2 & Arabic & Yes \\
\hline \multicolumn{6}{|c|}{ Other Africa } \\
\hline$D$ & Sierra Leone & 19 & 2 & English & No \\
\hline$E$ & Sierra Leone & 20 & 3 & Dutch & No \\
\hline $\mathrm{F}$ & Sierra Leone & 22 & 1 & English & No \\
\hline G & Sierra Leone & 23 & 1 & English & No \\
\hline $\mathrm{H}$ & Sierra Leone & 25 & 1 & English & No \\
\hline I & Zaire/Congo & 29 & 2 & French & Yes \\
\hline$J$ & Zaire/Congo & 32 & 2 & English & No \\
\hline K & Zaire/Congo & 37 & 3 & English & No \\
\hline $\mathrm{L}$ & Liberia & 29 & 2 & English & No \\
\hline M & Liberia & 36 & 2 & English & No \\
\hline $\mathrm{N}$ & Angola & 20 & 2 & Dutch/English & No \\
\hline $\mathrm{O}$ & (South) Mauritania & 22 & 2 & Dutch & No \\
\hline$P$ & (South) Sudan & 24 & 2 & English & No \\
\hline \multicolumn{6}{|c|}{ Eastern Europe (including former Soviet Union) } \\
\hline Q & Former Soviet Union & 22 & 2 & English & No \\
\hline $\mathrm{R}$ & Former Soviet Union & 29 & 2 & Dutch & No \\
\hline$S$ & Former Soviet Union & 33 & 2 & Russian & Yes \\
\hline $\mathrm{T}$ & Former Soviet Union & 36 & 2 & Russian & Yes \\
\hline $\mathrm{U}$ & Former Soviet Union & 44 & 2 & Dutch & No \\
\hline V & Georgia & 20 & 2 & Russian & Yes \\
\hline W & Former Yugoslavia & 25 & 2 & Serbo-Croatian & Yes \\
\hline \multicolumn{6}{|c|}{ Other Asia } \\
\hline $\mathrm{x}$ & Lebanon & 23 & 1 & Dutch/Arabic & Yes \\
\hline Y & Afghanistan & 29 & 2 & Dutch & No \\
\hline Z & Iran & 42 & 1 & Dutch & No \\
\hline
\end{tabular}


Table 5.2 Overview of convictions and some pending cases per respondent

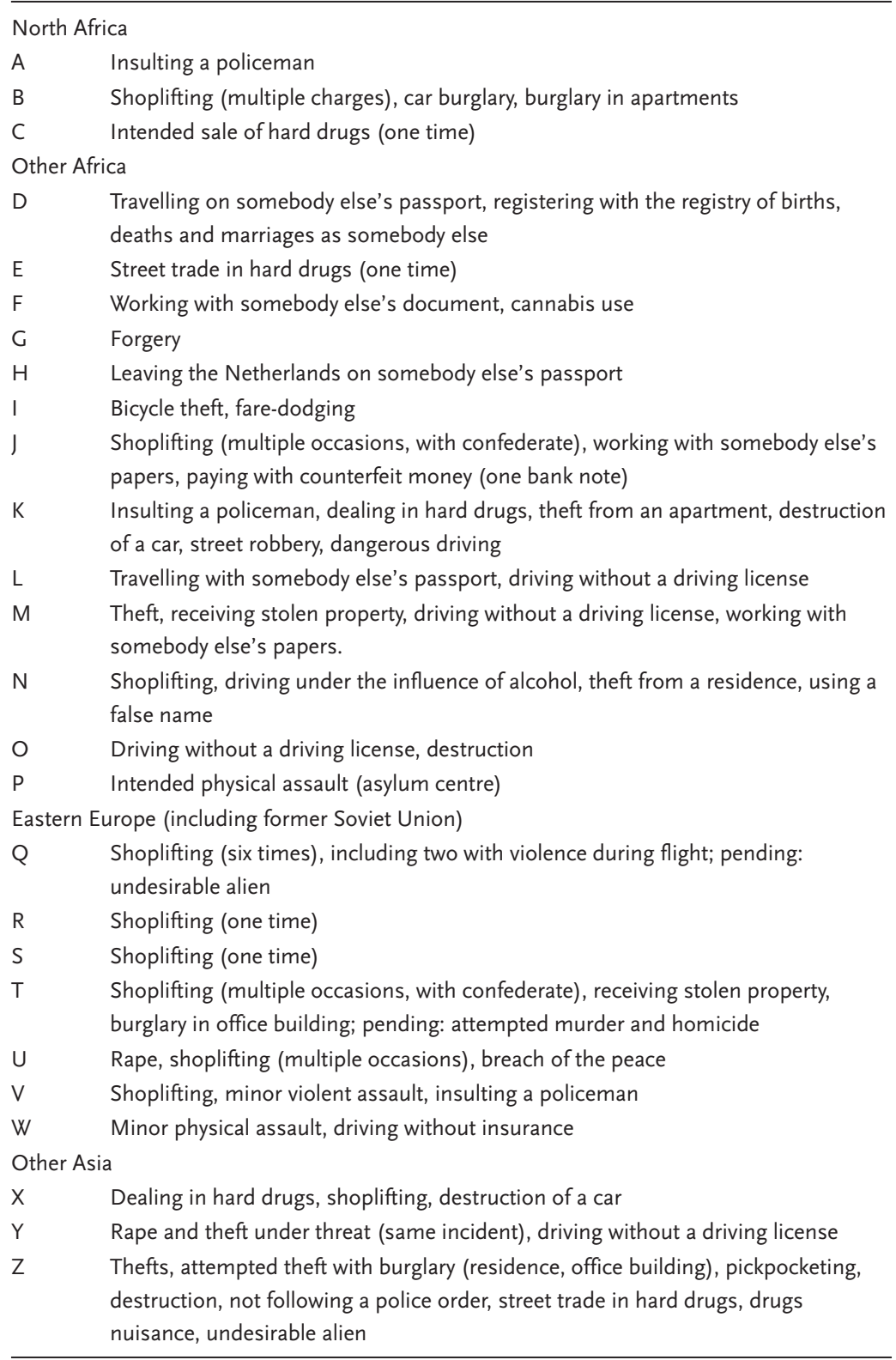

Source: Justitiële Informatie

I tried to neutralise these problems of validity as much as possible, although most are inherent to the research method. Criminal records 
were used as a memory aid. I strove for a confidential atmosphere. With the life-course approach, this was not too difficult to achieve; I asked about the integral development of the respondent as a person, not only about that part of his life which had been important in the asylum procedure or the judicial process. The length of the interviews and my similarity in age to the respondents (I was 3I) also promoted rapport. Leading and suggestive questions were avoided; the interpreters were instructed to omit signs of condemnation. Subjects like criminality and migration motives, which might have made the interviewees feel threatened, were often reserved until the end of the interviews. It is likely that the role of the clergymen promoted trust as well.

\section{Respondent characteristics}

Sixteen of the men were born in Africa, seven were Eastern Europeans and three were from Asia. The average age was 28 (Table 5.I). Most men had been convicted for identity fraud, theft and/or drug-dealing (Table 5.2). All had an asylum background and were considered illegal aliens by the Dutch state at the time of the interview.

I thought at first that each of the men had lived illegally in the Netherlands before they were apprehended and this was true for most of them. They had lived with friends, resided without the knowledge of the authorities in asylum centres or lived on the streets. Some were obligated to report regularly to the aliens police as rejected asylum seekers; such persons are called stampers by the aliens police. Formally they had become illegal migrants who could have been apprehended and detained in order to be expelled every time they reported to the police though most of them were unaware of this. Some stampers had been receiving elementary social support in an asylum centre or from the local authorities even though they were not formally entitled to it; others had been forced to take care of themselves. A few became illegal migrants whilst in prison when their asylum applications were rejected, in some cases, in part, because of convictions.

The transitions between the residence statuses over time were less rigid than I had initially assumed. Most had become illegal migrants after their asylum application was rejected, though four respondents had lived as illegal migrants in several European countries before requesting asylum in the Netherlands. Three respondents had held a temporary residence permit as recognised refugees, which they failed to extend in time because of absence from the Netherlands or personal problems. Some men had been given the status of rejected asylum seeker and illegal migrant, but had managed to re-enter the asylum procedure, at least temporarily. 
In what follows, the emphasis will be on illegal residence without government support. But I suspect the findings are also valid for stampers and asylum seekers, at least to a considerable extent. Under the law these three groups have a particularly marginal social position and other variables which correlate with criminality, such as age and ethnic origin, are comparable too. ${ }^{6}$ This is not to say that having illegal residence status is unimportant. The interviewees tended to commit fewer crimes with the exception of violent crimes - when they had legal residence in the Netherlands than in the periods during which they were illegal migrants. Large-scale quantitative research suggests that the relative number of crime suspects is higher among rejected asylum seekers than among recognised refugees and asylum seekers whose applications are still being processed (De Boom, Engbersen \& Leerkes 2006). The content of many men's criminal records would probably have been different had they had full civil rights in the Netherlands.

\section{Towards a typology of crime among illegal migrants}

Illegal residence status and its consequences strongly contributed to some of the men's crimes. In other cases this status appears to have had little or no influence. In Diagram 5.I, the offences are structured according to their aims and, in connection with that, the influence of their residence status, from strong and relatively direct (residence crime) to very weak and indirect (other crimes). There are two intermediate categories. Subsistence crime and addiction-related crime are committed in response to conditions that are, partly, an indirect consequence of illegal residence status.

I will also address the question of why certain types of crime were rarely committed by the men, if at all. The absence of certain types of crime may be, among other things, an indication of a negative connection between illegal residence status or its consequences and crime.

The diagram's primary purpose is to structure the data. It should not be taken as expressing hard and fast rules. Crimes that are classified in a certain way often have elements in common with crimes that are assigned to another category.

\section{Residence crime}

The aim of residence crime is to obtain residence in the Netherlands or some other Western country. It usually takes place at national borders, and can be aimed at entry and/or departure. These forms of residence crime are associated with what has been called external border control in Chapter I. Besides this, there are variants which occur inside national 
borders; these are related to secondary territorial exclusion as an instrument of internal border control.

Diagram 5.1 A typology of crime among illegal immigrants: convictions and self-reported offences

\section{Residence crime}

- Entering or leaving the Netherlands with false documents, somebody else's documents (borrowed, stolen, bought) or without a document

- Not leaving the Netherlands after having been declared an 'undesirable alien'

- Not being able to identify oneself in the Netherlands or showing a false document/ somebody else's document (borrowed, stolen, bought) (law on identification)

- Recalcitrance during apprehension, ignoring a police order, flight to avoid arrest

- Giving a false name, including registering with the register for births, deaths and marriages with a false name

Subsistence crime

- Working with false papers or somebody else's papers

- Theft (mostly shoplifting)

- Drug dealing (mostly street vendor or drug runner)

- Receiving or resale of stolen goods (mostly clothes, cell phones, bicycles)

- Driving without a driving license and/or car insurance

- Fare-dodging

- Taking the law into one's own hands (violence or destruction following an insult, violence or threat in an attempt to collect a loan, forcing door of a landlord's property)

Addiction-related crime

- Drug dealing (street vendor)

- Shoplifting

- Car burglary

- Burglary in residencies or office buildings

- Street robbery (one convicted respondents denies involvement)

Other crimes

- Sexual violence (sexual assault and rape)

- Violence in connection with mental disturbance (psychoses)

- 'In good faith' (non-Western migrants do not always know what is illegal in the Netherlands)

- Insulting a policeman

- Youth delinquency (experimenting with drugs, driving under the influence/without a driving license, shoplifting)

Since 1994 it has been obligatory in the Netherlands to be able to identify oneself at work, during specific events such as soccer matches, in case of offences or misdemeanours and in case of suspected illegal residence. On I January 2005 a general law on identification came into force, but by then most of my respondents were already in detention. Residence crime inside the Netherlands was rare among these men, since there 
was only a limited identification obligation before 2005. Although no respondent had been convicted of it, some men had identified themselves occasionally with somebody else's driver's license or their old Wdocument (a special ID for asylum seekers), for instance, during traffic checks. It is likely that residence crime inside national borders is now more common.

Many citizens of non-Western countries do not qualify for a residence permit. Even for a tourist visa one must be able to demonstrate 'adequate means of support'. Otherwise one needs to find a guarantor. Many illegal migrants with settled family in the Netherlands formally come as tourists to the Netherlands (Staring 200I). My respondents had lacked that opportunity because they did not have established kin or friends. ${ }^{7}$

Almost all respondents entered the Netherlands in irregular ways though these are not necessarily illegal if the foreigner immediately reports to the police and asks for asylum. Several of the Africans had landed as stowaways in Rotterdam harbour. Most of the Eastern Europeans made use of smugglers who avoided all border controls over land or provided false documents. The North Africans had been shipped to Europe by a smuggler, or formally arrived as tourists at a time when that was easier. The latter group came from regions from which people have migrated to Europe for a considerable time (Sayad 2004). They lived as illegal migrants in Spain, France, Belgium and/or the Netherlands before applying for asylum in the Netherlands, in two of the three cases only after they had been detected by the authorities. Three respondents had flown to Europe; one as a documented tourist, two with false documents.

Later, several of the men tried to leave the Netherlands with invalid documents because they did not see a future for themselves with an illegal residence status in Holland but were unwilling or unable to return to their country of origin. Two of the Africans tried to fly to Canada, a country which, so they believed, is more prepared to receive migrants; one recalled that there were Canadian immigration programmes in Africa in which potential migrants could enrol. Two men had tried to reach Sweden. $\mathrm{S}$ had been arrested in Germany three times; each time he was transferred to the Dutch authorities. On the third occasion the German police fined him for showing a false document. L wanted to fly to Sweden because he could not find work in the Netherlands.

A friend advised me to go to Sweden, to work in construction. Good money, no taxes. I could live with Liberians. It was a question of how to travel. My friend said, 'Hey, there are a lot of junkies in the Red Light district who sell passports.' Eventually I ended up with a Dutch guy who offered me a passport belonging to somebody who looked a bit like me for 200 euros. So I called an African friend. She had 80 
euros. My buddy gave me 50 euros. When I started to beg around like that in Amsterdam I soon had 200, 300 euros. I bought the passport for I50 euros. Then I still had to arrange the journey. I thought, 'I'll try a small airport. Then they won't catch me.' In Rotterdam I got a ticket for 50 euros. At the airport the customs guy said, 'Man, you look stupid! I am sure that's not you!' So he asks, 'Is this your passport?' I say no [gives a somewhat melancholy smile, amused]. So he says, 'Sorry, I have to arrest you for trying to use somebody else's document.' I said, 'Go ahead; I am just trying to live my life.'

L had been counting on a temporary illegal stay in Sweden. He hoped to earn enough money in Sweden to get himself a lawyer in the Netherlands. In the period when he had a temporary residence permit he became a father. Although he no longer has a good relationship with his Dutch ex-wife, he feels tied to the Netherlands because of his daughter. Residence crime clearly touches on subsistence crime in this case. The offence was aimed at residence in a Western country, but behind that aim was the wish to comply with a standard which was thought of as basic by the offender and the social environments in which he participates, participated, or wants to participate - in this case the norm that a father should be able to see his daughter every now and then.

\section{Subsistence crime}

While residence crime is almost inherent in illegal residence, it does not encourage the commission of other crimes to the same degree. Illegal migrants who work in the informal economy are, admittedly, punishable because they do not pay taxes, but they do not have to commit crimes in order to make a living. This also applies to illegal migrants who are supported by family, friends or a partner. It is probably possible to stay alive in the Netherlands without a social network, while still not violating the criminal code. In case of subsistence crime - which should not be interpreted in a economic sense only ${ }^{8}-$ the offender intends to meet social standards that are usually perceived as basic by himself and/or by others who constitute the social networks in which he participates, participated, or wants to participate. Many of the crimes committed were aimed more at prevention or reparation of relative deprivation on account of social comparison, including the situation in the past, than in response to the absolute deprivation of hunger or illness. Illegal residence status had a more indirect influence on these crimes, chiefly for the reason that this status complicates earning a conventional income.

The respondents are not from countries of origin that are the source of sizeable ethnic minorities in the Netherlands, and they had few opportunities to work informally in ethnic niches like takeaway restaurants 
and cleaning services. A few men did succeed in moonlighting somewhat through Dutch contacts. Three men's offences consisted of working in the formal labour market with somebody else's papers.

J had tried to make more of his life, after spending several years alternating between freedom and detention as an illegal migrant. He followed the advice he was given in prison and began looking for a girlfriend. This worked out. Rather quickly the couple decided to live together, out of love according to J, and also because he lacked housing; the Dutch girl still lived with her parents. His girlfriend's pregnancy increased the pressure to earn money: 'My girlfriend said, "Everybody works, why don't you?” ' J arranged an ID from somebody with a work permit and started to work as a garbage collector through a temp agency. He paid 50 euros a week to the supplier of the document until the aliens police intervened.

Many men stole in the Netherlands (Table 5.2). The thefts were mostly surreptitious and unorganised, often shoplifting. Some stole food. N, a physician's son, spoke about the difficult period he went through after his asylum request was rejected. He had to leave his room in the asylum centre and was in danger of going downhill but wanted to limit his degradation. He was keen on distinguishing himself from junkies and vagrants, and did not look for food in litter bins because he found the practice dirty and unhealthy. He tried to take regular showers at the homes of acquaintances. After a while he started feeling extremely ashamed that he had to ask his friends for help so often. He began to 'help himself' and started shoplifting. In this sense, the thefts served to help pay for his marijuana use, which increased sharply in that period. For instance, he stole bras that he was able sell to a couple of Moroccan street boys who had probably seen him begging in the street. However, most thefts were not aimed at buying soft drugs but rather for himself. He was arrested after stealing a sausage. Although he acknowledges that shoplifting gave him a kick in a certain sense (cf. Katz I988), he does not attribute the thefts to a desire for excitement 'My life went wrong and I knew I could get into trouble.'

Most men intended to meet somewhat higher standards with crime than the norm which prescribes that an honourable human being obtains his food from a shop. Nonetheless, these standards are still considered basic. S, who became quite well-off in the car trade after the disintegration of the Soviet Union, stole a leather jacket in the local shopping street. He knew he could sell it to an asylum seeker who was about to marry. On the one hand he hoped to force a final decision about his residence status with this incidental theft ('Are you going to admit me or will you send me away?') since he had been repeatedly advised to submit a new asylum application, even though all his previous requests had been denied. On the other hand he hoped that the sale of the jacket 
would satisfy the appeal from his family to contribute to the funeral costs for his father, who was terminally ill. He regretted his absence from the funeral. Moreover, he believed he had failed as a son because he lacked a good job and offspring: 'My father died without having seen his grandchildren.'

The choice of becoming involved in drug dealing sometimes also qualifies as subsistence crime. An assistant to an Algerian car mechanic, C lived as an illegal migrant in various European countries for years, presumably without committing crimes. He managed to support himself with odd jobs in the informal economy, like re-papering apartments and installing satellite dishes. After reaching a certain age he searched for a wife. Via the internet he met a divorced Algerian woman who lived in Belgium. They got along well, visited her mother and committed themselves to entering into an agreement around Christmastime about how to organise a wedding. But with the access to Europe within reach - by marrying, C hoped to obtain a residence permit - he found that his savings were inadequate for a dowry.

I used to hang around Rotterdam central station when I was out of work. Tourists sometimes asked me if I sold drugs. The police knew me, but left me alone. They knew that I had been released from Aliens' Detention. Six weeks before Christmas, I approached a guy who sells fake brands at the station and inquired about drug dealing. He arranged a contact with an Arab dealer, who advised me to buy drug balls for 450 euros. Later that day, to my surprise, I was apprehended while I was buying a shirt at the V\&D [a department store]. I hadn't had the opportunity to sell one ball! The police said they had mistaken me for somebody else. While I was doing time in prison, many prisoners laughed at me. A dealer should know it is unwise to carry all the balls. [A person who carries a limited number of balls can pretend to be a user, which is not prosecuted in the Netherlands]. The judge was surprised by my criminal activities, because I was illegal for years without committing offences. I told him what I am now telling you. You can inquire about that if you wish.

Three more variants of subsistence crime come to the fore in B's story: receiving and resale of stolen goods, driving without a Dutch driver's license and taking the law into one's own hands. B, who claimed to have been a Mauritian opposition activist, met a Dutch girl, started to live with her and had a daughter with her. The Immigration Services then presented him with a difficult choice. In view of his situation, he could either opt for the asylum procedure, which would mean he could not live with his girlfriend and his daughter, or choose for his relationship and abandon the asylum procedure, perhaps temporarily. B preferred 
the latter option and became an illegal migrant. He expected that he would be able to apply for asylum later; several of his acquaintances had received refugee status at a later stage.

While his relationship lasted, B's involvement in rule violation was limited to driving without a license. He took driving lessons, first informally from a friend, later at a driving school. As an illegal migrant he could not obtain a driver's license. In that light he did not feel that a driver's license was necessary, since he believed he was a good driver. His girlfriend appreciated it when he drove her to places. However, B always complied with all other traffic rules because as an illegal he was uninsured and could be fined if the police were to find out. Besides, he wanted to avoid 'unnecessary' police contacts to minimise the risk of being detained and expelled as an illegal migrant. His record of offences appeared to confirm these claims: it did not mention other traffic infractions.

After a while his girlfriend found a new boyfriend. She wanted to end the relationship, and although she did not insist that he leave the apartment, B took the honourable way out and moved in with an asylum seeker friend a few blocks away. B cried as he said this. He managed to make ends meet by selling African bracelets and other cheap goods to youngsters of various ethnic origins with whom he went out regularly and played street basketball. A friend who was still in the asylum process shared his allowance money with him. Sometimes B bought stolen goods, such as mobile phones. 'You won't let that go if you are illegal. You can trade it or you can use it yourself. That's a little bit bad. But not very.'

B then got into a relationship with a Guinean asylum seeker and moved in with her. Nonetheless, he was increasingly irritated by the limitations of his illegal residence status. His ex-girlfriend allowed him to see his daughter three times a week, but only when she was present. In the street, too, his prestige was diminished now that many people had found out he was illegal. 'They didn't really tell me to take it easy or they'd go to the police. But they'd think less of you. And I could never go too far 'cause I'd think: "Oh, I am illegal, I need to take account." I'm blocked, so to speak.' B applied for asylum once more, in vain. The frustration about his position appears to have been released when he got behind with his rent again.

One time we did not pay. I found myself in front of a locked door. My girlfriend was with acquaintances in France. I called the landlord, left a message on his voice mail; left a letter on the doormat. He didn't react to all those things! I knew him well, I often phoned him and gave him the rent when he came. And my stuff was inside! Clothes, shoes, a bag. Not much, but it was not about the money. These were 
my things and he didn't have the right to change the lock. So then I got angry and forced the door with a friend.

B did not consider contacting the police. Many non-Western newcomers and even Dutchmen are unaware of what the role of Dutch institutions is in such conflicts. In that sense this way of taking the law in one's own hands - based on the principle that a person ought to have control over his possessions - is not specific to illegal migrants. At the same time B noted that he did not have the opportunity to go to the police because he was illegal. Formally he could have done so but risked detention and expulsion.

\section{Addiction-related crimes}

Various researchers have reported on the recent increase in the number of illegal migrants among problematic hard drug users (Braam 2003; Hoogenboezem et al. 2005). Five men came into contact with the police after committing crimes in order to finance their hard drug use. T already took heroin even before emigrating. $U$ was talked into hard drug use in the asylum centre. There is a connection with illegal residence status in three other cases. Z's illegal residence status followed problematic hard drug use; while living in the streets he failed to renew the residence permit he had, and became illegal. The relationship was the reverse in the two other cases, in which substance use was promoted by homelessness, which was in turn, at least in part, caused by the potential implications of the illegal residence status, i.e. illegal migrants' exclusion from the housing and labour market as an instrument of internal border control. In the past the primary risk for the homeless was alcoholism, but nowadays various other addictive stimulants circulate on the streets (Anderson I923). With the latter two respondents, subsistence crime in the form of drug dealing preceded hard drug use. It may be that entrepreneurs with higher positions in the supply chain try to persuade marginalised illegal migrants to become street vendors in the hope of simultaneously recruiting a consumer (hooking, Glaser \& Strauss I97I).

In contrast to subsistence crime, drug-related acquisitive crime is not aimed at fulfilling 'basic' social standards. The drug use is mostly a way of coping with psychological problems. $\mathrm{H}$, son of an Algerian construction foreman, tells how he became addicted to hard drugs in Rotterdam at the age of 30. Some years earlier he had lost contact with his family. After his arrival in Marseille in the South of France, $\mathrm{H}$ lived and worked illegally in Paris for two years, without committing crimes, as an assistant to a Jewish shopkeeper. In I994 he drove to the Netherlands on the chance of finding more opportunities there, and asked for asylum on the recommendation of a travelling companion. 
$\mathrm{H}$ lived for five years without criminal convictions in various refugee centres. In between he left the asylum centre for about a year and was therefore out of the asylum procedure. At the time, he did not have much faith that his claim would actually be recognised, and he started to go around with a group of North Africans who had no permanent homes or addresses. For the most part the men stayed with compatriots who had residence permits. He then got involved in shoplifting. The stolen clothes or electronic goods were, in part, sold for cigarettes, liquor or marijuana. A policeman eventually pointed out to him that he had been issued a temporary residence permit, but that document turned out to have expired. Nonetheless, $\mathrm{H}$ was readmitted to a refugee centre. His convictions stopped for some years. When he had exhausted all legal remedies, he left the refugee centre with 50 euros in his pocket.

It seemed wise to go a big city, but I knew nobody in Rotterdam. Sometimes somebody did me a favour and invited me to stay for the night. Everybody said that it was impossible to get a job without documents in the Netherlands. And I ran into the wrong people once more when I was on the streets. Mostly North African; I hardly spoke Dutch or English. This is when I got into drugs. First dealing only. Then using as well. We sold something, used up the rest. It was not a life I was used to [smiles scornfully]. Sometimes I went to the Salvation Army or St. Paul's church [a Rotterdam church well known for its assistance to marginal social groups] for some food, to shave, for clothing. I started to steal when I couldn't pay for my use by selling drugs. Shoplifting first. But you soon find out that that doesn't yield enough. You use together and learn other things. Breaking into cars for radios or cameras is already better. One day I met an African user. Also illegal. He knew how to break into apartments. He was looking for somebody who could be his lookout. Eventually we got caught. I did a year in prison, then they brought me here.

H's story illustrates once more that the greater part of the men's criminality is incidental or episodic. It is not due to a permanent trait of their personalities that exerts itself irrespective of the circumstances. At the same time, although their behaviour is a response to conditions that can be coupled with illegal residence, it is not inherent to illegal residence.

\section{Other crime}

Certain crimes had little or no connection with the offender's social position under the influence of having illegal residence status an the various forms of border control that go hand in hand with it. The two rape convicts are cases in point. Ironically, they were the only respondents whose 
original partner was in the Netherlands. The Afghan Y attributed the event to his alcohol and soft drug use, as a result of problems with the payment of his allowance money as part of the asylum procedure. The Russian U claimed that the woman, who had exhausted all legal remedies herself, prostituted herself in the asylum centre and had presented the coitus as rape in the hope of getting a residence permit as a victim. (If this allegation is true, her strategy could be classed under the heading of residence crime.) Furthermore, there are indications for a connection between mental disorders and violence (see also Althoff et al. 2006). While in the asylum seeker's centre a Chechen T wounded a Yugoslav with a knife. The offender suffered from hallucinations that started during soft drug use. The man who went on the rampage after the interview turned out to be using psycho-pharmaceuticals, though this was not communicated to me before the interview, and had acted violently a number of times in the course of the asylum procedure as well. One respondent thought he was innocent when a local bicycle thief sold him a bike at the asylum seekers centre. A North African youngster A insulted the policeman who had fined him because his bicycle light was not functioning. Finally, some men who came to the Netherlands as minors were involved in juvenile delinquency. For instance, $\mathrm{N}$ sometimes drove the car of a classmate's father, before he was eighteen. He had learned how to drive on a parking lot behind the local soccer stadium, where he met friends to drink and smoke at weekends.

For the most part, the men committed these other crimes in periods during which they were legally residing in the Netherlands. This does not imply that such crimes do not take place among illegal migrants. ${ }^{9}$ But within this research population, in as far as there is a positive connection between these other crimes and the illegal residence status, illegality followed criminality rather than the other way round. In other words: these men did not become involved in crime as a response to a marginal social position after their asylum requests had been rejected and they had become illegal migrants; it was rather the case that the asylum requests by some of the men were rejected, at least in part, because of their crime convictions during their legal stay in the Netherlands as asylum seekers. Convictions are a counter-indication for obtaining a residence permit and may even be a reason to withdraw a residence permit that has already been granted. In specific cases a migrant can also be declared an undesirable alien (such as Q and Z), in which case continued residence in the Netherlands is not only illegal but becomes punishable as a crime liable to a penalty of six months in prison (see Chapter 6 for more information on what is known in the Netherlands as residence termination). By terminating the legal stay of migrants convicted of crimes, the state deliberately contributes to the number of criminal illegal migrants and, therefore, to a positive connec- 
tion between criminality and illegal residence. This contribution is stronger if such migrants continue to stay in the Netherlands as illegal migrants in spite of the state's assumption that migrants are more inclined to leave if their continued residence is defined as illegal or, in case of undesirable aliens, punishable under criminal law.

Engbersen and Van der Leun (1995) have already pointed out that we should pay attention to such deliberate changing of criminal migrants' residence rights by the state if we want to understand the connection between illegality and criminality. They nonetheless argue that this phenomenon is of limited importance in understanding the relationship between illegality and criminality among non-Western migrants, because during their research period, i.e. the early I990s, the deliberate changing of residence rights mainly pertained to Western European offenders. These constituted a very specific group of mainly EU citizens who were declared undesirable aliens after causing drug-related nuisance in the Netherlands. In spite of European integration, which promotes the free traffic of goods and persons within the EU, citizens from other EU countries can still be declared undesirable aliens and, hence, become illegal migrants if they are convicted of certain crimes. It turns out that the deliberate changing of criminal migrants' residence rights also increasingly involves non-Western offenders. Therefore, to understand the relationship between illegality and criminality among migrants from nonWestern countries - on which this book focuses - it is increasingly relevant to pay attention to such deliberate changing of residence rights. This will be done in the next chapter.

\section{Types of crime not present: external and internal social control}

The men's records of offences rarely mention violent assault and vandalism, particularly in the periods of illegal residence. ${ }^{\text {IO }}$ The relative absence of certain types of crime which could have been committed by men in their position is remarkable. The research group is quite small in this case, but police figures, too, suggest that illegally resident crime suspects are significantly less likely to be involved in violence and vandalism than their legal counterparts with similar ages and country of birth (see Chapter 4; for the low involvement of illegal migrants in violence in the United States see also McDonald (1997) and Wolf (I988); for Belgium see Van Meeteren, Van San \& Engbersen (2008)).

This provides additional evidence for a differential effect of illegal residence status on criminality. Involvement in crime may arise under the influence of illegal residence status, but such involvement usually remains selective. Certain rules are violated, but other rules are observed more closely. B, for instance, drove without a driver's license, but fol- 
lowed other traffic regulations as much as possible. In social traffic too, he was restrained to a greater degree: 'I am blocked, so to speak.'

The low involvement in certain types of crime is, of course, not merely a question of social opportunity and external social control, given illegal residence status, like the deterrence thesis argues (see Chapter I). Social control also comes from inside; it is also internalised by previous socialisation. This is made particularly clear by the observation that the men have consciously and unconsciously avoided crimes of the sort that would have been, on the face of it, opportune and performable variants of subsistence crime. None of the men were, for instance, convicted of robbery. Most respondents found crimes such as bag snatching too immoral - 'Street robbery is an ugly thing to do.' Several respondents never even considered that crimes such as street robbery or hold-ups were an option ('No, never thought about robbing people. No [makes a hissing noise]. Dear me [laughs]. No, that never occurred to me. The car, yes [driving without a driving license].' [laughs] ).

Even the hard drug users recognised internal constraints with regard to their criminal behaviour. $\mathrm{H}$ was the lookout, but could not bring himself to break into apartments. The burglar, too, had no residence permit; apparently he had come to a different decision. The man who became a heroin user in the asylum seeker's centre was only convicted of shoplifting, though for a considerable number of cases. He claimed that he was not a violent person. He also stated that, in his mind, shoplifting is not as immoral as stealing from individual citizens. 'Then I only thought: not against people.'

Most of the men were convicted of victimless or consensual crimes. In the case of victimless crimes there is no clear individual victim; identity fraud primarily impairs state authority. With consensual crimes the victim colludes in the offence, for instance, drug dealing. The men who were convicted of theft mostly limited themselves to shoplifting. Earlier research yielded similar indications. De Haan (I994) counted one illegal migrant among the violent street robbers in the Amsterdam neighbourhood De Bijlmer, although illegal migrants probably represented several per cent of the residents there (Leerkes et al. 2004). German research reaches a similar conclusion (Alt I999: 305):

Die überwältigende Mehrheit von ihnen möchte selbst dann, wenn sie zur Begehung von Straftaten keine Alternative sehen, wenigstens 'so wenig kriminell wie möglich' sein. ('The overwhelming majority of them would like to be "as little criminal as possible", even when they did not see alternatives but to commit crimes'; translation by the author). 
Some of this reluctance to engage in violent street crime may perhaps be associated with the social backgrounds of international migrants. Longdistance migration, in particular, tends to involve people who do not belong to the lowest social strata in their countries of origin (see also Chapter I). ${ }^{\text {II }}$

\section{Criminal antecedents}

I focused on the men's experiences in the Netherlands, but asked whether or not the respondents had committed offences outside of the Netherlands. For most men this does not appear to have been the case. This is indicated by their answers, but also by the nature and timing of the offences for which they were sentenced. People who have had police contacts since childhood tend to commit property crimes as well as violent crimes, often minor offences as well as serious offences (Gottfredson \& Hirschi I990; Beke, Van Wijk \& Ferwerda 2000). It turned out that the men's criminality had usually not started immediately after emigration. Besides this, the crime involvement of many of my respondents had an eposidoc character; after settlement in the Netherlands there was, as a rule, a negative connection between involvement in crime - particularly property crimes and drug trafficking - and conventional opportunities, for example, an income through the asylum procedure, informal work, a temporary residence permit or income via a partner.

Two men reported police contacts because of incidents that would be considered crimes in the Netherlands as well. ${ }^{\mathrm{I} 2} \mathrm{~T}$ had been incarcerated in several Russian prisons. In his case there was not really a question of criminal emigration (Bovenkerk 2002) - he did not come to the Netherlands in order to commit crimes - but he did continue his old behaviour of shoplifting and burglary, both related to hard drug use. Eventually he was involved in a serious violent assault in connection with the decline of his mental health. The man who went on the rampage after the interview had been detained in Georgia once for theft. Six men admitted police contacts in their countries of origin because of political activities, evasion of conscription, desertion, or refusing to carry out an order as a soldier. Furthermore, some men had committed crimes for which they had not been convicted. An African told how he wandered in the bush with some friends after the rebels had driven him out of his village. They sometimes sneaked into farms to steal food. In addition, I spoke to four alleged child soldiers or rebel helpers who claimed to have been forced to participate in looting and, in one case, murder. None of these respondents was involved in crime in the Netherlands to any significant extent; their records of offences show only light property crime or fraud. (Perhaps the term survival crime is more appropriate to describe forced vio- 
lence by child soldiers in Africa then to describe the crime involvement among illegal migrants in Western countries such as the Netherlands.)

In sum, it seems there is no unequivocal connection between criminal antecedents and crime in the Netherlands. The possible trajectories that can be distinguished analytically appear to occur in reality too: I) a clear past history of criminality with a clear continuation thereof, 2) a clear past history of criminality that ends, at least in that form i.e. the child soldiers, 3) no criminal history and little or no criminal behaviour in the Netherlands, for instance one conviction for working with somebody else's documents and 4) no criminal history and several police contacts in the Netherlands. The second, third and fourth variants are most prevalent among the men. Althoff et al. (2006) also conclude that criminal antecedents are not the rule among criminal asylum seekers (see also De Haan \& Althoff 2002).

\section{Theoretical interpretation}

\section{Status dilemmas and crime}

The preceding analyses show that the men were not merely passive bearers of the illegal residence status and the various forms of border control that define it, and nothing else. Their social position was also determined by other social statuses in their status-sets, such as father, son or boyfriend (the notion of the status-set is taken from Merton's (1957), see also Chapter 3). Above all, we must understand the men as migrants: their aspirations resemble traditional familial group values in the country of origin as well as values that are characteristic of the milieus in which they move in the Netherlands. An uncle tries to arrange a good and safe future for his nephew in Europe, a son is expected to contribute to his father's funeral costs, a bridegroom is expected to pay a dowry, a boyfriend wants to chauffeur his Dutch girlfriend around.

Illegal residence status, and the marginal social position that may result from it, may hamper the observance of these basic social standards. Hence, the men were frequently confronted with status dilemmas (Hughes 1994). The social expectations and opportunities that are coupled with the illegal residence status may be at odds with parallel statuses such as that of a father or fiancé. The milieus in which the men move confront them with these status expectations; but they are also imposed on them internally. People who seriously disappoint their internalised status expectations risk tensions with the social environment and within themselves.

Each man has to respond to these institutional contradictions in his own way: 'I am just trying to live my life.' The interviews indicate that a 
certain weighing usually occurs: in order to maintain one standard, concessions are made in other norms, at least temporarily (cf. Matza I964). Accommodation of conflicting behavioural standards takes place in social life continuously, and must take place if social traffic is not to stagnate (Goffman I969, I97Ib). Sometimes this is also the case - to a greater degree - during illegal residence. The men sometimes substituted criminality for conventional behaviour.

When dealing with these phenomena, where individuals identify with conventional ambitions but do not have sufficient resources to realise them in conventional ways, criminologists often refer to Merton (I938: 672-682). His strain theory was primarily related to the American situation where deprived groups aspired to be upwardly mobile. A more modest social dream is also observable among some of these men. The North Africans, in particular, did not leave home because of safety concerns; their coming to Europe, and the residence crime this usually involved, was primarily aimed at upward social mobility. Their subsistence crime appears to have been inspired - at least to a greater degree than among most of the other men - by a desire to get ahead in the world. In most of the other cases criminality appears to have been aimed at preventing or reducing social descent. These offenders did not know beforehand that they would become illegal migrants. They tried to hold on to a standard and identity that had been a guarantee for them in the past: safety or a certain standard of living in the country of origin and/or the Netherlands, as an asylum seeker or recognised refugee (cf. Newman i999).

The respondents tended to sacrifice standards to which they are not so deeply attached, at least in comparison to other options. Legal jobs would have been preferable for many men, compared to black labour; working black is more attractive than crime. Minor offences were preferred to the serious offences that would appear to be a step too far for the men, whose consequent shame and condemnation would be too great, both by their own conscience, and within their social environment. Such crimes would create a strong new tension between their aspirations and their actual identity, even if they might help reduce the initial tension between illegal residence status and the parallel statuses. It seems that these men aimed at a golden mean.

Unlike residence crime and subsistence crime, addiction-related crime does not modify the status dilemma by selectively substituting criminal alternatives for conventional behaviour. Still, the objective of substance abuse may be an apparent resolution of the tensions that status dilemmas cause. This coping behaviour does not seek to manipulate the external causes of such tensions, but to check their emotional consequences. While residence and subsistence crime can be regarded as problem-oriented coping, substance use is seen as evasive emotion-oriented coping (Billings \& Moos I98I). In criminology too, problematic 
drug use tends to be understood as a response to limited opportunities for normal social functioning. The adaptation does not have an innovative character i.e. new ways to old goals, as is often the case with residence and subsistence crime, but amounts to a withdrawal from normal social transactions (compare retreatism in Merton I938).

\section{Status dilemmas and culture}

By interpreting the men's offences as behavioural reactions to status dilemmas I have tried to link the current structure-oriented perspective to a more actor-oriented viewpoint that does justice to aspects of interpretation and socialisation. One of the reasons this is important is that there are similarities as well as dissimilarities in the extent to which given social conditions come to take on the meaning of a status dilemma. This is because a status is a position in the social structure to which certain behavioural expectations, or roles, are attached. These behavioural expectations are not completely inherent to the status, but can vary between cultures and subcultures.

Several of the men, for example, landed in Rotterdam without much in the way of money, family or friends. The Lebanese respondent $\mathrm{X}$ found his inability to pay rent for pension accommodation a sufficiently alarming prospect to become a street trader in hard drugs. The man had spent most of his youth with Italian clergymen in conditions of relative prosperity. As a teenager he was part of a group of alternative Italian youngsters who frequently smoked soft drugs. A respondent from South Sudan who grew up in a poor family and claims to have travelled to Europe with the help of the church, lived for a considerable time in the streets of Rotterdam on just 30 euros, eating bread and sardines and drinking cola, without committing crimes. Eventually a stranger offered him illegal work. The observation that $\mathrm{C}$ was prepared to deal drugs for his wedding suggests that the meaning of a given situation may also differ per group. Although the incapacity to contribute to a wedding would be degrading to most fiancés, the giving of a dowry (the mahr) is a strong cultural prescription in certain Arab countries (Douwes 2003).

Paying attention to such aspects of interpretation and socialisation enhances our understanding of the behavioural reactions of the men, including their criminal strategies (cf. Van Gemert I998; Van San I998; Van San \& Leerkes 200I; Bovenkerk 200I). Their experiences in the country of origin seemed to affect offending in the Netherlands, even though most of the men had probably not come to the attention of the police as a result of criminality. As has been said, the men did not perceive all the possibilities that were within their reach. Neither did they follow all the strategies that they perceived. A good example of a behavioural improvisation for which previous socialisation appears to have 
created the preconditions was given by the Serbian respondent W. He collected broken televisions in local electronics stores and sold them to a repairer. He rewarded the shopkeepers for their kindness with inexpensive supermarket pies. He was familiar with this sort of trading; he used to collect and sell cardboard with his parents and other gypsies in Belgrade. Among the West African respondents, we may observe additional indications of a connection between ethnic origin and behavioural strategies. The men had relationships with Dutch partners with remarkable frequency and often had children with them. Unlike most of the other respondents they could communicate with these women in English, but we also know that polygyny - a man having several partners without necessarily being married to them - is quite common in West Africa (Collins i988: 104).

Although the men were mostly convicted for minor offences, they did not commit precisely the same types of crimes. The Africans were more frequently convicted for fraud. The records of offences of the Eastern Europeans almost exclusively relate to theft. Two of the three North Africans sold hard drugs (Table 5.2). Similar ethnic patterns are observable in the police data on all apprehended illegal migrants (Chapter 4; De Boom et al. 2006).

Previous research suggests that ethnic differences in the forms of criminality are, at least in part, connected to differences in access to opportunity structures, including criminal opportunity structures (also see Chapter 4). Interestingly, the interviews suggest that this diversity may also have been encouraged by differences in perception and evaluation of criminal strategies. The African respondents at least appeared to be relatively accepting of fraud with government documents, including variants in which some other respondents were involved. However, they declared themselves very strongly opposed to drugs. O said: 'I didn't want to do drugs, although I knew people who were dealing.' Some men added that thieves were severely beaten in their places of origin. It appeared that the Eastern Europeans found theft relatively acceptable in the circumstances, especially when large enterprises were the victims. The North Africans who were dealing drugs found involvement in this trade less reprehensible than theft. Ethnic differences in perception and evaluation of criminal strategies may be a cause of ethnic differences in criminal opportunity structures. It can be assumed that legal and illegal migrants will try to produce criminal opportunities they 'value' and are familiar with, at least in comparison to other criminal options.

Such ethnic differences may be connected to social circumstances in the countries of origin. For instance, many African countries are relatively unstable and corrupt by international standards - see for example the Transparency International index - and consequently certain forms of government regulation may have less legitimacy for African migrants 
(cf. Kehla I999). The cultivation of hemp traditionally constitutes an important source of revenue in the Riff Mountains (Van Gemert i998).

\section{Concluding remarks}

Three research questions served as a guideline for this study. These will be answered in this section. A number of remarks on the term survival crime and the representativeness of the findings will close this chapter.

I. This sub-study increases our insight into the preferences of criminal illegal migrants with an asylum background. It turns out that criminality in this group is in part aimed at residence in the Netherlands or other Western countries. Residence crime usually takes the form of identity fraud or illegal border-crossing. It tends to be a response to practices of external border control by the state. Beyond that, many men made certain minimum demands on the quality of their illegal residence, which they could not always satisfy in conventional ways either. I therefore find it useful to make an analytical distinction between residence crime and subsistence crime. The most common forms of subsistence crime are working with somebody else's papers, theft from shops, or street dealing in drugs. A third category was found. Addiction-related crime, which is aimed at the consumption of illegal drugs to cope with psychological problems, also appears to develop from illegal residency in the context of a policy of institutional exclusion as an instrument of internal border. The latter crimes particularly can be more socially disruptive and personally intrusive for the victims, particularly in the case of car and house burglary. Finally, a rather heterogeneous residual category was noted which included sexual violence, violent assault in connection with mental disorders, insulting policemen and the like.

The men did not commit all types of crimes that could have been feasible variants of residence crime, subsistence crime or drug-related crime. They preferred minor and non-violent offences. That preference stems from a combination of external and internal social control. Many men desired to reduce 'unnecessary' police contacts and wanted to limit the chances of deportation, which conforms the deterrence thesis. Simultaneously, they were inclined to sacrifice relatively light social standards. Standards prescribing people not to murder or rob other people, are valued very highly in almost all social environments. On account of their previous socialisation in conventional environments, the men probably committed fewer and less serious crimes than we would expect based on their limited access to formal and informal institutions in the Netherlands. ${ }^{\text {I3 }}$ More research could profitably be done on cultural simi- 
larities and dissimilarities in the perception and valuation of behavioural strategies involving crimes.

2. It appears that aspects of the restrictive immigration policy often played a role in the circumstances that led the men to commit crimes. With residence crime this share was greater and more direct than with subsistence crime and addiction-related crime. In the case of the latter two types of crime, the connection with illegal residence status runs to a greater degree via the outcome of processes of marginalisation in the Netherlands, particularly economic deprivation and homelessness. Illegal residence status hardly contributed to the residual category of other crimes, if at all. It appears that the men mostly, but not exclusively, committed offences of this sort during periods when their residence was legal.

Social capital modifies the relationship between illegality and criminality; social support tends to smooth the edges of social exclusion by the state. In the previous chapter I argued that is true for practices of exclusion by means of external border control. It appears that embedded illegal migrants are relatively likely to be visa overstayers; they do not have to hire a smuggler to enter the country of destination illegally. In this chapter we have seen that social capital in the country of destination tends to decrease the likelihood of involvement in subsistence and addiction-related crime, which is, potentially, the outcome of institutional exclusion as an instrument of internal border control.

However, the interviews also suggest that embeddedness does not necessarily diminish the chances of engaging in criminality, even in the case of conventional social networks. It turns out that social integration often comes at a price - if people want to belong to a group they need to position themselves according to the roles that are expected of them in the social relationship. This is a new insight in this field. If social psychology is right, i.e. if strong social relations increase the chances of problem-oriented coping, while a lack thereof tends to be coupled with emotion-oriented coping or its avoidance (Billings and Moos I980), social embeddedness in conventional milieus will curb drug-related crime, but may sometimes promote residence and subsistence crime, at least in cases where an offender does not have legal sources to maintain his social relationships, for instance because these relationships do not give access to such resources. ${ }^{\mathrm{I}}$ It seems thus that the effects of social embeddedness as such should analytically be distinguished from the effects of social capital.

The men certainly made choices even though their opportunity structures were limited. For that reason, the relationship with the illegal residence status must not be conceived of as entirely deterministic. No doubt some rejected asylum seekers return voluntarily to their country 
of origin, in so far as they receive a laissez passer. It is possible that others who stay in the Netherlands expect less and accept more limiting social conditions like not consuming food from the supermarket and not driving a car. Some men created legal opportunities that other men did not perceive, such as giving pies to shopkeepers in exchange for broken televisions.

3. Although no records of offences have been collected in the countries of origin, it is probable that most men did not have police contacts there because of criminality. This is the impression given by their comments and by the timing and nature of the majority of the crimes for which they have been convicted.

\section{Survival crime?}

The interviews confirm that term 'survival crime', if it is of any value, must be understood in a broad, sociological sense; simply staying alive is usually not at stake (cf. Engbersen 200I). But even then the concept has its drawbacks. The term inevitably evokes associations with survival in a biological sense - particularly outside of the social sciences - and cannot easily be stripped from its normative connotations. In my opinion, it's use implicitly suggests that we should forgive illegal migrants their crimes, 'because they have only committed these in order to survive'. Which is not to say that there cannot be a humanitarian problem in regard to this group, in addition to a crime problem.

The descriptive value of the term is also dubious. Some men tried to be upwardly mobile with the aid of crime. They tended to commit 'development crime' rather than survival crime. Addiction-related crimes are not aimed at preserving the old identity either. Perhaps we should use the more neutral term adaptation crime, or some other term, to denote that offending can be a reaction to the, potentially, very limiting conditions as a result of having illegal residence status, with residence crime, subsistence crime and addiction-related crime as possible particulars thereof. We could use the term adaptation conformism to denote that illegal residence status - in so far as it goes hand in hand with secondary territorial exclusion - may also curb rule-breaking, particularly with more expressive offences that do not help to continue illegal residence with a certain standard of living, such as violence, vandalism, an aggressive driving style or being loud-mouthed.

\section{Representativity}

The findings cannot be generalised with certainty because of the limited size of the research group. Statistical representativity, however, was not 
the main objective of this sub-study. The primary aim was to gain an insight into the qualitative diversity within the phenomenon (Hammersley \& Atkinson I995). Nonetheless, even with these 26 respondents, hardly any new types of offences and motives were encountered as additional respondents were interviewed. This suggests that the diversity in the population is not very great. In that case the men do perhaps constitute a fair reflection of all criminal illegal migrants with an asylum background or in a similar situation. Van Kalmthout and Van Leeuwen (2005) also carried out field work in the Tilburg prison. The overwhelming majority of the 6r illegal migrants they spoke to, only some of whom had an asylum background, had not committed crimes or had been convicted for relatively minor and unorganised crimes. Police figures on all apprehended illegal migrants also indicate that minor and apparently instrumental offences constitute a large majority of the apprehensions for crimes. ${ }^{\text {I5 }}$

It is nonetheless probable that the situation of rejected asylum seekers differs from other groups of illegal migrants in certain respects. In comparison with the informal chain migration that we can observe among ethnic minorities in the Netherlands, asylum seekers will depend to a greater degree on residence crime to establish themselves in the Netherlands. Further, they will be more inclined to continue travelling to try their luck in other Western countries.

The income position of illegal migrants with an asylum background appears to differ less from other groups than expected. Some men still obtained benefit payments or housing, even from local governments, after the rejection of their asylum applications, or shared the allowances of friends who remained in the asylum process. In addition, they managed to partially compensate for the lack of established family by entering into relationships with singles in the Netherlands.

The respondents presumably differ most from the migrants who move to the Netherlands in order to commit crimes and/or to flee prosecution for crimes. An unintended consequence of the relatively open borders after the end of the Cold War and the ongoing expansion of the European Union is that there are now fewer barriers to Eastern European criminals, for instance, coming to commit crimes in Western Europe. Such offenders, a substantial number of whom lack a residence status, are often involved in instrumental crimes as well, including burglary, car theft and circulating counterfeit money (Weenink et al. 2004). But we are not yet in a position to say whether these crimes should also be understood as residence crime, subsistence crime or addiction-related crime, or whether the restrictive immigration policy in the Netherlands contributes to their prevalence. The next chapter, which reports the findings of the fifth and final sub-study, will pay more attention to such forms of criminal migration and cross-border crime. 


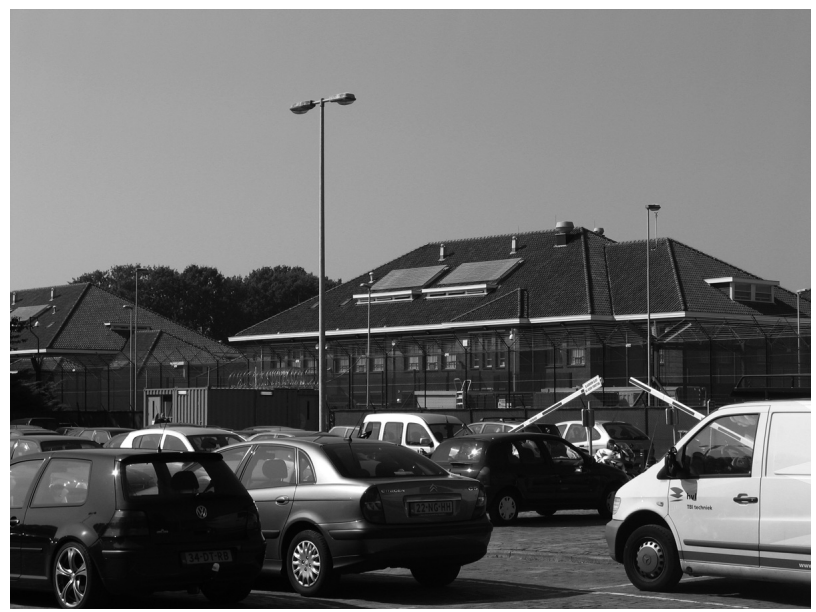

The Aliens' Detention of the Tilburg prison, seen from the car-park

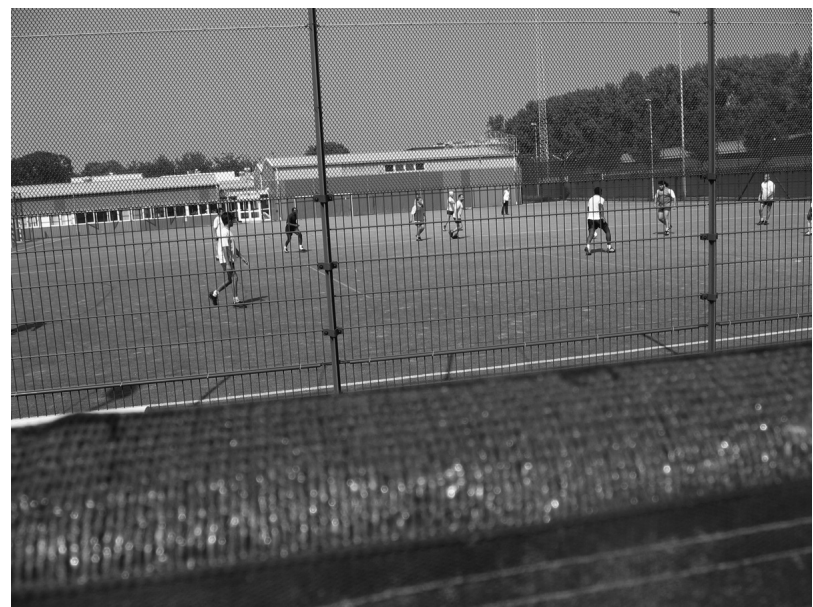

Illegal immigrants playing football in the Aliens' Detention of the Tilburg prison 


\section{The rise in crime}

\section{Introduction}

There are indications that there has been a rise in crime among illegal migrants in the Netherlands. Previous analyses of police data have shown that, while in 1997 3I per cent of apprehensions involving such migrants were related to crime, this share had increased to 38 per cent in 2000 (Engbersen et al. 2002). In 2003 the figure was 45 per cent (Leerkes et al. 2004) and in 2004 it went up to 49 per cent (Boekhoorn et al. 2004). The crimes concerned are mostly theft, identity fraud and involvement in drug dealing. Illegal residence as such does not fall under Criminal Law in the Netherlands (ACVZ 2002) and will thus not be counted as a crime here.

Like in the previous two chapters this sub-study critically examines the marginalisation hypothesis. To what extent can it explain the rise in crime? Specifically, I will try to falsify the marginalisation thesis by taking five important alternative hypotheses into consideration that have never been fully investigated. Three alternative hypotheses have already been discussed in the previous chapters to some extent; two are introduced in this chapter.

Firstly, we have seen that criminal activities may lead to the status of being an illegal migrant instead of the other way around. Legal migrants may loose their residence permits because of offending in the Netherlands. Illegal migrants may be declared undesirable aliens, after which their continued presence is punishable as a crime under Dutch law. Hence, the rise in the number of illegal migrants registered as crime suspects may be due to the changes in the way the state reclassifies migrants under different residence statuses.

Secondly, a part of the illegal population may have migrated to the Netherlands with the intention of committing crimes. In these cases, criminality is not the result of an unforeseen process of marginalisation after settlement in the Netherlands. In the period under study, migration opportunities for nationals from former European colonies were steadily curbed, while border controls with respect to Eastern Europe were eased, 
at least to some extent. As I will explain in the next section, both developments may have contributed to the number of illegal migrants committing crimes upon or shortly after arrival, increasing the total number of illegal migrants suspected of crimes.

There is a third explanation that has not been given much attention in the previous four sub-studies: the rise in crime may also be an effect of developments in crime detection and reporting by the police. Crime as such may increasingly have been detected and/or registered by the Dutch police, or the police may have given higher priority to apprehending and documenting criminal illegal migrants. Special teams in which various branches of government work closely together have been formed for this purpose in all the largest cities and, in particular, in Amsterdam, since 2002. Whereas in the past illegal migrants primarily risked apprehension at work, the national government is increasingly addressing a whole array of social problems including the clandestine infrastructure surrounding them public disorder in mixed neighbourhoods, tracing doss houses and the like.

Fourth, as we saw in Chapter 4, the rise in the crime figures may have been brought about by a simultaneous increase in crime among legal migrants. The chances of illegal migrants engaging in criminal careers in the Netherlands appear to depend, at least in part, on the number of criminal illegal migrants they encounter in their ethnic social networks.

The final alternative hypothesis, which has not figured prominently in the previous chapters, is demographic. The rise in crime may be a sideeffect of demographic changes with regard to the composition or size of the illegal population. It could simply be that the number of young male illegal migrants has increased between 1997 and 2003.

Data on all illegal migrants apprehended in the Netherlands between January I997 and October 2003 were analysed for this sub-study. These police data were linked to administrative data from the Dutch Immigration and Nationalisation Service (IND) on all foreigners who have been declared 'undesirable aliens' between 1997 and 2003, or lost their residence permit in that period in other ways because of criminal activities. These primary data sources were compared with existing police figures and Cruijff and Van der Heiden's (2004) estimates of the size of the illegal population in the Netherlands.

The marginalisation thesis, already explained at some length in the introductory chapter, will not be repeated here. The alternative hypotheses will be described in more detail in the next section. Subsequently, the data sources and research method will be explained and the results presented. This chapter's conclusion summarises the main findings of this final sub-study. 


\section{Specification of the alternative hypotheses}

\section{Reclassification}

The first alternative hypothesis understands the rise in crime as the result of changes in the way the Dutch state classifies certain migrants as 'illegal migrants', while the actual behaviour of migrants may have changed little. For instance, migrants can be declared 'undesirable aliens'. ${ }^{\mathrm{I}}$ For a legal migrant this can be done when he or she has committed a crime for which three or more years of imprisonment can be inflicted. Illegal migrants can be declared undesirable aliens more easily. ${ }^{2}$ Undesirable aliens, once so declared, are not allowed to be in the Netherlands for five years, or ten years in the case of a conviction for drug trafficking or serious violence. If they are found in the country within this term, they are treated as illegal migrants. In addition, being in the Netherlands as an undesired alien constitutes a crime which is punishable with imprisonment up to six months. Furthermore, the residence permit of criminal foreigners may be withdrawn and extensions of the permit refused, if the crimes committed are not serious enough to declare the foreigner an undesirable alien or if the person has a family in the Netherlands. ${ }^{3}$ In this sub-study the term 'status reclassification' will be used as a sociological synonym for the aforementioned forms of changing residence statuses by the state. Status reclassification is an aspect of internal border control that should be distinguished analytically from the institutional exclusion of illegal migrants, on which the marginalisation thesis focuses: an important difference between this third aspect of internal border control and the two aspects that are central in this study, i.e. institutional exclusion and secondary territorial exclusion, is that status reclassification should primarily be understood as a state response to migrant crime; the two main types of internal border control, on the other hand, are analysed as a condition to which migrants adapt in ways that increase or decrease crime and public safety in the country of destination.

The criteria for reclassification were relaxed in July 2002; from then on, legal migrants with less than five years of residence in the Netherlands became at risk of losing their residence permit for less serious crimes (ACVZ 2005). Moreover, the government made more use of status reclassification between 1997 and 2003, and a number of policy projects were implemented in order to promote the ending of residence rights of criminal aliens.

Status reclassification may increase the number of crime suspects with illegal residence status in three ways. First, undesirable aliens may in fact re-enter or remain in the Netherlands. If they are arrested they contribute, per definition, to the total number of crime suspects with 
illegal residence status. Second, we can expect that additional offending will be relatively common among former legal migrants who have been declared undesirable aliens, should they remain. After all, past offending is the best-known predictor of future offending (Gottfredson \& Hirschi I990; Laub \& Sampson 2003; Blokland 2005). Third, legal migrants who have been detained because of crimes may end up as a crime suspect in the apprehension data on illegal migrants after their residence permit is withdrawn. Such offenders may be re-apprehended in prison on the grounds of illegal residence, just before they are transferred to the Aliens Custody where the expulsion procedure starts. The initial apprehension reason (for instance a burglary or murder) may not be erased, as policemen customarily register the most serious apprehension reason in the data on illegal migrants (see next section). In theory, an increase in status reclassification might also reduce the number of crime suspects with illegal residence status, but this effect is probably small. ${ }^{4}$

\section{Criminal migration and cross-border crime}

Crime does not have to be the outcome of processes in the country of destination. Foreign criminals may decide to cross borders in order to smuggle illegal goods, to seize criminal opportunities in the country of destination, or to escape prosecution. Migrants with no further criminal intentions after settlement may also use false documents to cross the border in order to circumvent external border controls (Torpey I999; Kyle \& Siracusa 2005). In the literature the terms 'criminal migration' and 'cross-border crime' are often used to denote such phenomena (Benyon 1996; Van Duyne 1993; Gaylord I999; Vagg 1992). Although there are substantial differences among these various forms of criminal migration and cross-border crime, they can all be contrasted with the marginalisation thesis; in case of criminal migration and cross-border crime, offending is intended beforehand and not related to practices of institutional exclusion.

Criminal migration and cross-border crime are understudied in relation to illegal migration, but there are reasons to believe that various forms of criminal migration and cross-border crime do occur among illegal migrants. Moreover, their prevalence may have increased in the Netherlands in the period that was studied for this sub-study (I9972003).

First, the use of false documents to enter the Netherlands is increasingly common among illegal migrants, particularly among non-Europeans who lack social ties in the European Union and have fewer opportunities to overstay tourist visas (as was argued in Chapter 4). Tourists from poorer countries usually have to prove sufficient financial means or have to find a sponsor in the country of destination (usually a 
family member, friend or partner). A visa can be refused if the issuing embassy fears that the 'tourist' will settle illegally. Since the I980s the list of countries requiring a visa to enter the EU has been expanded (Bigo \& Guild 2005).

Second, external border controls with respect to Eastern Europeans were eased considerably in the I990s because of the fall of the Iron Curtain and the European Union's eastern enlargement. In the early I99os visa requirements for short visits were already dropped for a number of countries such as Poland (an EU member state since 2004), and in 200I the visa requirements for short visits were dropped for Bulgaria and Romania, both EU member states since 2007.

An unintended consequence of the relaxation of external border controls has been an increase in Eastern European offenders committing crimes in Western Europe, such as house burglary and car theft (Bort 2000; Von Lampe 2004; Weenink \& Huisman 2003). A significant proportion of these offenders are reported to be illegal migrants (Weenink et al. 2004). Criminal migration and cross-border crime also appear to occur among non-European migrants. Turkish migrants are found to play an important role in the distribution of heroin in the $\mathrm{EU}$ (Bovenkerk \& Yesilgöz 1998), while cocaine trafficking is run, to a considerable degree, by South American $m$ Haagsemarkt igrants (Zaitch 2002). The relation with illegal immigration, however, is unclear. Zaitch (2002) reported that some Colombian drug traffickers established themselves illegally in the Netherlands simply because they were unable to obtain a residence permit.

\section{Policing}

The rise in the number of illegally residing crime suspects could be a consequence of improved crime detection or crime recording by the Dutch police, due to a general trend in criminal law enforcement and registration. Between 1999 and 2002 the police forces were expanded considerably in the Netherlands..$^{5}$ In addition, Wittebrood and Nieuwbeerta (2006) have demonstrated that in the period under study the Dutch police became more active in recording crimes, in part because of technological advances. Hence, the rise in crime among illegal migrants should be compared to possible increases in the number of documented crime suspects in the population at large.

Furthermore, the increase might be due to the police giving a higher priority to detecting and/or recording offending by illegal migrants, so as to meet public concerns about unwanted immigration and crime or to carry out 'law and order' policy decisions by the national government. During the period of study it became less controversial in Dutch society to argue that immigrant crime is a social problem. Clear indications of 
changing public opinion regarding this theme can be found in the International Social Survey Program (ISSP). As part of the ISSP, two representative surveys on national identities were carried out, in 1995 and 2003, respectively. In 1995, 37 per cent of the Dutch respondents $(\mathrm{N}=\mathrm{I}, 823)$ agreed or agreed strongly that immigrants increase crime rates. In 2003 , this percentage had gone up to $44 \cdot 7$ per cent $(\mathrm{N}=2,089)$. (The survey shows similar trends in most other Western countries for this period.)

In most cases the police target crime suspects regardless of residence status (Van der Leun 2003). They often do not know in advance whether a criminal suspect is living in the country legally or not. However, there are two exceptions to this rule. First, it could be the case that the police have deployed more personnel over time to trace identity fraud by illegal migrants. Another exception occurs when criminal illegal migrants are specifically targeted. In the Amsterdam area in particular - and to a lesser degree in other urban areas - specialised teams have been formed since 2002 to arrest illegal migrants who are heavily involved in criminal activities and to target the criminal organisations surrounding them. Between 1997 and 2003 the Amsterdam police deployed five coordinated actions under the name 'Spirit', in which approximately 400 illegal migrants were arrested in total. Not all these arrestees are criminal illegal migrants because of what the police call 'bycatch': usually a substantial number of non-criminal illegal migrants are apprehended who find themselves in the vicinity of the criminal illegal migrants who the actual targets (for instance in a housing block or café). The first Spirit action took place in September 2002.

Further, it could also be that the residence status of foreign crime suspects is registered more accurately by the police (Boekhoorn et al. 2004). It is unknown to what extent police officers actually began to do this in the period of study, but if they did, crime suspects who were likely to be registered as 'aliens' in the past - without a further specification of their residence status - increasingly have been registered as 'illegal aliens', adding to the rise in crime under study.

It should be noted that the political pressure to reduce illegal residence by increased policing of illegal migrants - adding to practices of secondary territorial exclusion - mostly built up in the period 20022006 , i.e. largely after the period under study here. In 2002-2006 a succession of centre-right cabinets governed the Netherlands. By 2006 this had culminated in the conclusion of a 'performance contract' between the Ministry of Justice and the police regions, in which the police obligated themselves to apprehend I2,000 illegal migrants in 2007. 


\section{Ethnic embeddedness and demographic changes}

In Chapter 4 I showed how involvement in crime among illegal migrants is, to some extent, positively connected with involvement in crime among legal migrants of comparable age and country of origin. It is likely that this association is partly the result of processes of differential association: newcomers without a residence permit may become involved in types of crime they encounter among the more established migrants in their social networks. Ethnic networks in the country of destination - including criminal networks - constitute important resources for newcomers, particularly for illegal migrants (see also Zaitch 2002). Therefore, we should investigate whether the rise in crime among illegal migrants is connected to a simultaneous rise in crime among legal migrants.

Finally, the rise in the number of crime suspects could be a by-product of developments in the composition of the illegal population or its size. Demographic changes may affect crime figures, for involvement in crime correlates with sex, age, ethnicity and the degree of urbanisation (Gottfredson \& Hirschi I990; Junger-Tas, Marshall \& Ribeaud 2003; Thornberry \& Krohn 2003; Van Dijk, Manchin \& Van Kesteren 2007). It could be that the share of young males from certain ethnic groups and/ or the degree of urbanisation has grown between 1997 and 2003. It could also be that the number of crime suspects has merely increased proportionally to an increase in the illegal population.

\section{Data sources, research method and validity}

\section{Data sources}

The data on apprehended illegal migrants have been provided by all 25 Dutch police forces and are taken from the Vreemdelingen Administratie Systeem (VAS), the national database in which all known aliens are documented. Migrants who have been handed over by other government agencies (for instance the Labour Inspectorate) and those who have been apprehended by the police are included in it as well. The entries include information on nationality, sex, age, arrival date in the Netherlands, date of apprehension and the most serious apprehension reason. Between January I997 and October 2003, 107,322 apprehensions were registered. Of these, 93,030 concerned non-EU nationals (including nationals of countries that have become EU member states after 2003). About 70 per cent of these are males aged between twenty and 40.

The reasons for apprehension are usually classified into five categories (cf. Engbersen \& Van der Leun 200I): (I) infringements of the Aliens Act, which are mildly punishable or not at all; (2) common mis- 
demeanours that are usually punished with a fine, such as fare dodging, driving under the influence of alcohol, illegal prostitution and the like; (3) crimes for which a term of imprisonment of up to four years can be imposed, such as shoplifting, car and house burglary ${ }^{6}$, vandalism and staying in the Netherlands as an undesirable alien; (4) crimes for which a term of imprisonment of four or more years can be imposed, including robbery and physical assault; and (5) crimes mentioned in the Opium Law, which range from large-scale drug trafficking to petty dealing or mere drug possession (due to registration practices, such drug crimes cannot be classified in terms of seriousness). The latter three categories are felonies (misdrijven). These are generally considered 'criminal activities' in Dutch society, while illegal residence and misdemeanours are not (see also Van der Leun 2003). In about one-third of the apprehended third nationals living in illegal residence the reason for apprehension was a suspicion of a felony.

Some of the illegal migrants in the database are brought in by the Aliens Police. Some illegal migrants, such as rejected asylum seekers, have resided legally in the Netherlands before becoming illegal migrants. They are required to report to the Aliens Police on a regular basis, where they may eventually be apprehended to be expelled. Others are apprehended by or handed over after border controls, workplace checks, or housing inspections in disadvantaged urban areas. Most illegal migrants are apprehended by the regular police; they are either crime suspects or fall into the hands of the police as 'additional catch' when people are asked to show ID in the course of regular policing activities. As was mentioned, special teams occasionally target criminal illegal migrants, particularly in the Amsterdam area.

The arrival date in the Netherlands is registered in the VAS in about 55 per cent of the cases. Persons who initially stayed legally in the Netherlands have often had previous contacts with the authorities (for instance when arriving at the airport). In these cases the arrival date may have been present in the database before the actual date of apprehension as an illegal migrant. For recidivists, i.e. illegal migrants who are registered more than once in these VAS data as 'illegal aliens', the first apprehension date may have been registered as the arrival date. Sometimes the police rely on statements by the arrestee about the arrival date if these are deemed sufficiently reliable.

The IND, being a special branch of the Ministry of Justice, provided me with information on status reclassification. They listed all persons who have been declared undesirable aliens or who lost a residence permit because of crimes in other ways during the period 1997-2003. These data were linked to the VAS data, using unique 'foreigner numbers'.

In addition, I used other data sources for specific tests: statistics on registered crimes among the Dutch population, in general, and among 
legal (non-EU) migrants. Finally, the demographic hypothesis was examined with the help of Cruyff and Van der Heijden's (2004) estimations of the size of the illegal population, which make use of the capture-recapture method. This method was initially developed by ecologists to estimate the size of animal populations that cannot be observed in their entirety (for a discussion on the validity of this method in the social sciences see Van der Heijden et al. 2003).

\section{Research method}

In this study I focus on apprehensions for crimes. The three criminal categories mentioned in the previous section were re-arranged into four types of crime: 'property crimes', ' 'false documents', 'drugs' and 'other crimes'. The rationale for basing the categories on the content of the crime committed rather than its seriousness is that offending in response to marginalisation usually concerns subsistence crime and crimes to finance drug use (this was been described in the previous chapter). These are usually property crimes, possession of false papers (working in the formal economy with somebody else's papers) and drug possession and trafficking. If there is still a rise in crime after controlling for the alternative hypothesis, it should mainly be visible with respect to these three types of crime in particular, rather than for the category 'other crimes' (mainly violence against persons and goods or being in the Netherlands as an undesirable alien).

For every year since I997 - the first year for which reliable digital data were available - I assessed the number of suspects for each of the four types of crime (the analyses were also done at the apprehension level, yielding similar results). The analysis is limited to illegal migrants from countries that were not, at the time, EU countries, including Poland (EU member since 2004) and Bulgaria (EU member since 2007). The data for the first three quarters of 2003 were extrapolated to 2003 as a whole by multiplying all 2003 figures with $12 / 9$.

The hypotheses explained above primarily serve heuristic ends. Although they sometimes overlap, they draw attention to different mechanisms that may contribute to the number of crime suspects with illegal residence status. In order to put the marginalisation thesis to a critical test, the alternative hypotheses were operationalised, i.e. defined in measurable terms, in ways that put the marginalisation thesis at a disadvantage rather than favouring its corroboration.

The indicator for status reclassification is the sum of all crime suspects in the VAS in the period I997-2003, concerning persons: (I) who have been declared undesirable aliens in these years, (2) who applied in vain for a residence permit and/or lost this permit in the period examined due to criminal activities, but who were not declared undesirable 
aliens, or (3) who have been apprehended as undesirable aliens in these years but were not declared undesirable aliens in this period (but apparently earlier). These are wide-ranging criteria. The indicator includes illegal migrants who have been declared undesirable aliens after having committed subsistence crime or addiction-related crime under the influence of institutional exclusion as an instrument of internal border control. $^{8}$

A suspect was counted as a case of criminal migration or cross-border crime if the crime was committed within three months after the date of entry to the Netherlands, or if the person had committed any other crime within three months. The underlying assumption is that such offenders start offending quite quickly after arrival, while offending in response to marginalisation tends to develop more gradually. The period of three months is, of course, somewhat arbitrary, though immigration policy generally uses this period to distinguish between short and long residence. The analyses were also done using other periods, varying from one to six months, yielding similar results.

When controlling for the reclassification and criminal migration hypotheses, all crime suspects that indicated instances of status reclassification or criminal migration were excluded from the annual totals. The policing, embeddedness and demographic hypotheses were examined by comparing the trends on illegal migrants with general developments in documented crime in the Netherlands.

\section{Validity}

While illegal immigration is an inherently difficult subject for empirical research (Cornelius I982; Rodriguez I987), it has become clear over the years that qualitative fieldwork can yield important results (see for instance Mahler I995; Staring 200I; De Genova 2007). The previous substudy contributed to that qualitative body of research. Yet, as we have seen in Chapters 2 through 4, the VAS data provide valuable additional quantitative insight into illegal residence - especially but not exclusively in relation to crime involvement.

All arrested illegal migrants are fingerprinted in the Netherlands. While illegal migrants may be registered with different aliases, each of them is assigned a unique foreigner number by the Aliens police that will identify them regardless of the stated names. ${ }^{9}$ The VAS database labels individuals with these unique foreigner numbers, increasing the validity of the apprehension data for scientific purposes.

Nonetheless, it has often been noted that police data are problematic for scientific purposes. First, there is an unknown and substantial amount of crime that never appears in police files (Felson I994). Methodologically, this 'dark number' can be reduced by using self-report stu- 
dies, yet for undocumented migrants this is unrealistic. In the vast literature on police data, three main sources of bias are mentioned.

First, the likelihood of the public reporting a crime to the police increases with the visibility of the crime. Hence, police data are more adequate when dealing with communal crimes than with, for example, organised crime, environmental, or white-collar crimes. This implies that I am unable to draw specific conclusions about illegal migrants' involvement the latter crimes on the basis of police data. (But for a number of reasons it is unlikely that illegal migrants are heavily involved in these crimes; if desired see note 5 in the concluding chapter of this book).

Second, the likeliness of being stopped by the police varies across space and time. Police data inevitably mirror patterns of police surveillance. Attention of law enforcers commonly concentrates on strategic sites, such as train stations or crime-ridden areas, increasing the likelihood of being apprehended there. Moreover, suspects frequenting lowerstatus neighbourhoods are likely to run a higher risk of being apprehended than suspects in other parts of cities (Smith I986). As these lower-status neighbourhoods also tend to be where illegal migrants are concentrated, they may have a higher likelihood of being stopped by the police if they engage in crime there.

Third, police apprehensions are often suspected to be selective with respect to migrants. In the UK and the US, questions surrounding 'racial profiling' or 'ethnic profiling' have generated fierce debates over the years (Tyler \& Wakslak 2004; Waddington, Stenson \& Don 2004). Migrants are more often stopped and searched than would be expected on the basis of their share in the population. So far, in the Netherlands, little evidence has been mustered for the proposition that the police differentially arrest by 'foreign appearance' (Aalberts I990; Rovers I999; Boekhoorn et al. 2004). However, it must be noted that recent and sound research is lacking. In any event, the implications are limited in this sub-study, as the data on illegal migrants were compared with police data on comparable legal migrants.

In sum, police data have their drawbacks, but are nonetheless the most suitable data to study patterns of criminal activity among illegal migrants, in particular when possible problems of selectivity and bias are taken into account (cf. Hagan \& Peterson I995; Tonry I997), as I do in the form of the control for the policing hypothesis. The police statistics are then a useful source of information, at least for this sub-study's main purpose: critically examining the marginalisation thesis by analysing trend data.

Two specific limitations of this study should be mentioned. First, the validity of the registered arrival dates could not be tested against other measures. In particular, the self-reporting of arrival dates may be problematic. Some people may have claimed that they had just arrived in the 
Netherlands in the hope of evading punishment, although length of stay makes no difference in this respect. Still, others may have reported extensive residence in the Netherlands in the vain hope of legalisation. Yet in this sub-study we are primarily interested in how rates of criminal migration have developed over time, and there is no reason to assume that biases in self-reported arrival dates have changed during the studied period. Second, the share of criminal migration and cross-border crime for the cases with no registered arrival date is uncertain, though it is unlikely that this share is very high. ${ }^{\circ}$

\section{Testing the alternative hypotheses: results}

Table 6.I starts with an overview of crime suspects between I997 and 2003. In 1997 the police registered 3,I70 crime suspects illegally residing in the Netherlands. In 2003 this figure had risen to 7,337 (2003 index: 23I). The table includes figures for the total number of additional crime suspects with illegal residence status for the years i99 8 up to and including 2003, in comparison to the hypothetical situation in which the number of such suspects would have remained stable. It shows that II,939 additional crime suspects were registered in these six years (See $N$ in Table I: $(3,247-3,171)+\ldots(7,337-3,171))$.

Table 6.I also includes estimations of the annual crime rate among illegal migrants and comparable legal migrants. The crime rate is the percentage of the population registered as a suspect annually. For the figures on the crime rate among illegal migrants the estimations by Cruyff and Van der Heijden (2004) of the total size of the illegal population were used. Note that during the I990s the crime rate among illegal migrants was lower than among legal migrants, which confirms the deterrence thesis. However, by 2003 it had become increasingly equal to, and may even have surpassed, the crime rate among legal migrants, in particular in comparison to the first generation (3.4-5.8 per cent $>3.7$ per cent).

\section{Control 1: Reclassification}

Table 6.2 shows that 5,580 non-EU nationals were declared undesirable aliens between I997 and 2003. An additional I,375 lost their residence permit or saw their applications otherwise refused because they were considered a threat to public order. It is clear that status reclassification has become more common since 1997: compared to 1997, the annual number of cases had almost doubled by 2003 . 


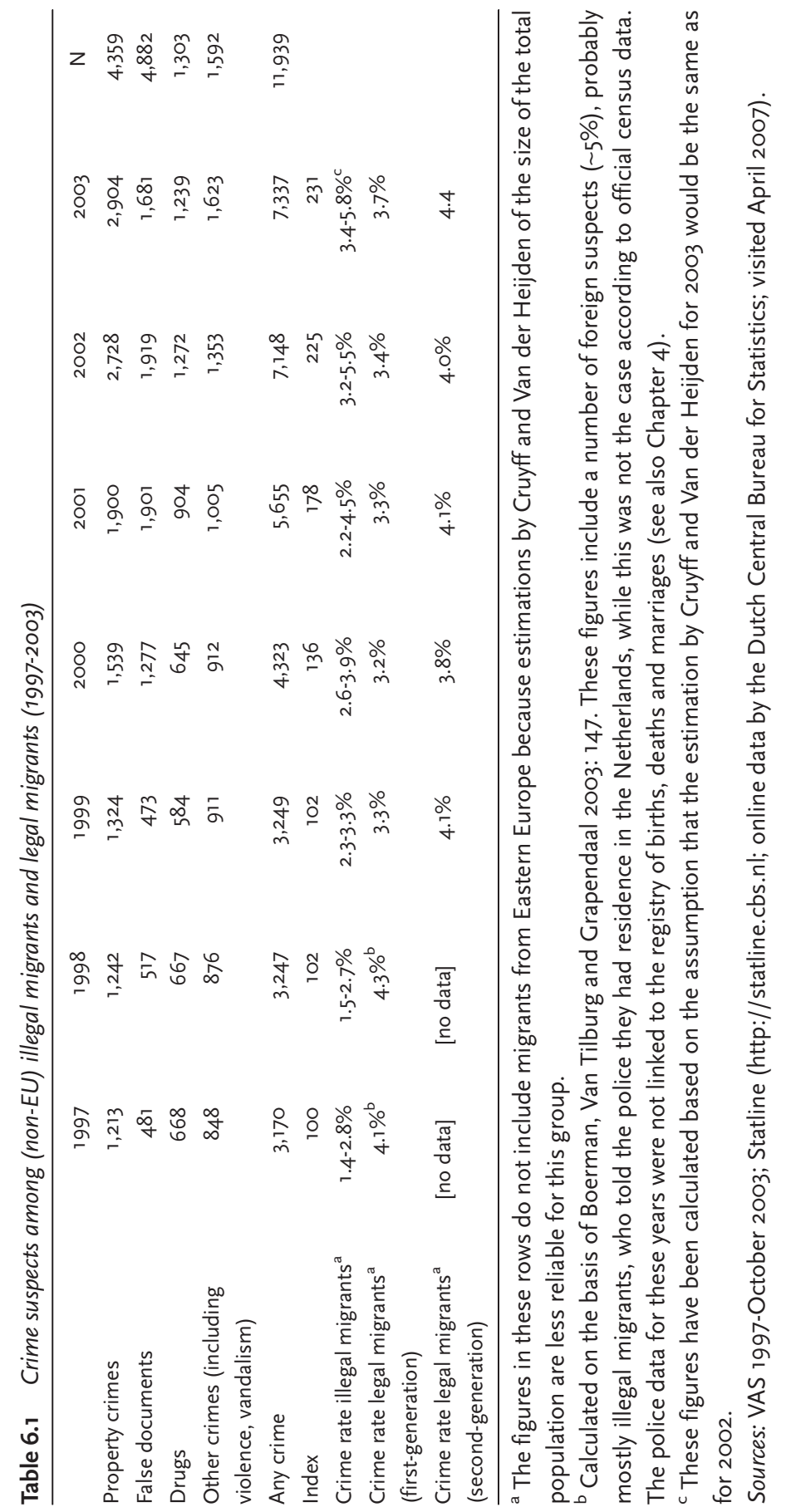


Table 6.2 Undesirable alien resolutions and (other) residence terminations, non-EU nationals (1997-2003)

\begin{tabular}{|c|c|c|c|c|c|c|c|c|}
\hline & $\begin{array}{l}\text { Undesirable } \\
\text { alien }{ }^{\text {b }}\end{array}$ & $\begin{array}{l}\text { Other } \\
\text { residence } \\
\text { termina- } \\
\text { tions }^{c}\end{array}$ & $\begin{array}{l}\text { New } \\
\text { reclassi- } \\
\text { fications } \\
\text { total }\end{array}$ & $\begin{array}{l}\text { In VAS* } \\
\text { (property } \\
\text { crimes) }\end{array}$ & $\begin{array}{l}\text { In VAS } \\
\text { (false } \\
\text { docu- } \\
\text { ments) }\end{array}$ & $\begin{array}{l}\text { In VAS } \\
\text { (drugs) }\end{array}$ & $\begin{array}{l}\text { In VAS } \\
\text { (other } \\
\text { crimes) }\end{array}$ & $\begin{array}{l}\text { In VAS } \\
\text { (any } \\
\text { crime) }\end{array}$ \\
\hline 1997 & 732 & 37 & 769 & 54 & 0 & 10 & $54(21)^{d}$ & 101 \\
\hline 1998 & 709 & 37 & 746 & 65 & 2 & 17 & וך & 132 \\
\hline 1999 & 744 & 29 & 773 & 65 & 2 & 56 & $99(53)^{d}$ & 201 \\
\hline 2000 & 710 & 60 & 770 & 103 & 2 & 167 & $121(57)^{d}$ & 353 \\
\hline 2001 & 657 & 333 & 990 & 115 & 9 & 275 & $187(80)^{d}$ & 557 \\
\hline 2002 & 903 & 449 & 1352 & 215 & 10 & 250 & $340(92)^{d}$ & 705 \\
\hline $2003^{a}$ & 1,125 & 430 & 1555 & 159 & 4 & 68 & $396(63)^{d}$ & 497 \\
\hline Total & 5,580 & 1,375 & 6,955 & 776 & 29 & 843 & $1,268(393)^{d}$ & 2,546 \\
\hline $\begin{array}{l}{ }^{a} \text { VAS } \\
\text { b Som } \\
\text { period } \\
\text { c Only } \\
\text { an unc } \\
\text { severa } \\
\text { d The } f \\
\text { sions } f\end{array}$ & $\begin{array}{l}\text { t such perso } \\
\text { desirable ali } \\
\text { d instances } \\
\text { figures in br } \\
\text { for 'undesira }\end{array}$ & $\begin{array}{l}\text { en in the } \\
\text { are count } \\
\text { ackets con }\end{array}$ & $\begin{array}{l}\text { nly counte } \\
\text { ted that co } \\
\text { same yea } \\
\text { sidence te } \\
\text { cern the } r\end{array}$ & $\begin{array}{l}\text { oncern per } \\
\text { ar; only th } \\
\text { ermination } \\
\text { number of } \\
\text { ounted. }\end{array}$ & $\begin{array}{l}\text { ersons wl } \\
\text { ne first c } \\
\text { ns. } \\
\mathrm{f} \text { cases it }\end{array}$ & case is $c$ & $\begin{array}{l}\text { than once } \\
\text { in the same y } \\
\text { not been de } \\
\text { counted in }\end{array}$ & $\begin{array}{l}\text { in this } \\
\text { year. } \\
\text { eclared } \\
\text { tase of } \\
\text { rehen- }\end{array}$ \\
\hline
\end{tabular}

Sources: Netherlands Immigration and Naturalisation Department; VAS

1997-October 2003

Not all reclassified migrants end up in the VAS data, but a substantial number do: they represent about 2,500 crime suspects. About one-third of these appear to pertain to cases of status reclassification before 1997: these crimes involve suspects apprehended as an undesirable alien between 1997 and 2003 at least once, but who were not reclassified in these years.

In order to control for the effects of status reclassification, all cases in the VAS involving 'reclassified' suspects were excluded from the analyses (Table 6.3, Control I). Developments in status reclassification do indeed appear to explain, to a limited extent, the increase in the rise of crime under study: whereas for all cases the crime index in 2003 was 23I, the crime index for the non-reclassified cases was 223.

As expected, the levelling-off of the rise in crime as a result of this first control mainly occurs for 2001, 2002 and 2003, when status reclassification became more prevalent. The decrease is also most pronounced for the category 'other crimes', which includes arrests for residing in the country as an 'undesirable alien', as well as violence. 
Table 6.3 Crime suspects among (non-EU) illegal migrants after controlling for alternative hypotheses (1997-2003)

\begin{tabular}{|c|c|c|c|c|c|c|c|c|}
\hline & 1997 & 1998 & 1999 & 2000 & 2001 & 2002 & 2003 & $\mathrm{~N}$ \\
\hline \multicolumn{9}{|c|}{ After control 1 (reclassification) } \\
\hline Property crimes & 1,168 & 1,184 & 1,267 & 1,454 & 1,798 & 2,537 & 2,765 & 3,997 \\
\hline False documents & 481 & 515 & 471 & 1,275 & 1,892 & 1,909 & 1,677 & 4,853 \\
\hline Drugs & 658 & 650 & 528 & 478 & 629 & 1,022 & 1,171 & 530 \\
\hline Other crimes & 796 & 811 & 817 & 801 & 823 & 1,058 & 1,295 & 829 \\
\hline Any crime & 3,069 & 3,115 & 3,048 & 3,970 & 5,098 & 6,443 & 6,840 & 10,100 \\
\hline Index & 100 & 101 & 99 & 129 & 166 & 210 & 223 & \\
\hline \multicolumn{9}{|c|}{ After control 2 (migration by foreign criminals) } \\
\hline Property crimes & 936 & 925 & 939 & 1,043 & 1,220 & 1,817 & 2,069 & 2,397 \\
\hline False documents & 311 & 358 & 204 & 495 & 688 & 841 & 715 & 1,435 \\
\hline Drugs & 296 & 339 & 312 & 333 & 320 & 457 & 567 & 552 \\
\hline Other crimes & 734 & 708 & 732 & 668 & 612 & 839 & 1,055 & 210 \\
\hline Any crime & 2,246 & 2,289 & 2,157 & 2,508 & 2,808 & 3,880 & 4,352 & 4,518 \\
\hline Index & 100 & 102 & 96 & 112 & 125 & 173 & 194 & \\
\hline \multicolumn{9}{|c|}{ After control $3^{\text {a }}$ (general policing) } \\
\hline Property crimes & 936 & 925 & 930 & 1,033 & 1,162 & 1,594 & 1,669 & 1,697 \\
\hline False documents & 311 & 358 & 202 & 490 & 655 & 738 & 577 & 1154 \\
\hline Drugs & 296 & 339 & 309 & 330 & 305 & 401 & 457 & 365 \\
\hline Other crimes & 734 & 708 & 725 & 661 & 583 & 736 & 851 & -140 \\
\hline Any crime & 2,246 & 2,289 & 2,136 & 2,483 & 2,674 & 3,404 & 3,510 & 3,020 \\
\hline Index & 100 & 102 & 95 & 111 & 119 & 152 & 156 & \\
\hline \multicolumn{9}{|c|}{ Control $5^{\mathrm{b}}$ (demographic growth) } \\
\hline Property crimes & 936 & 974 & 1,257 & 1,215 & 1,107 & 1,398 & 1,464 & 1,799 \\
\hline False documents & 311 & 377 & 273 & 576 & 624 & 647 & 506 & 1137 \\
\hline Drugs & 296 & 357 & 418 & 388 & 290 & 352 & 401 & 430 \\
\hline Other crimes & 734 & 745 & 980 & 778 & 555 & 646 & 746 & 46 \\
\hline Any crime & 2,246 & 2,409 & 2,886 & 2,921 & 2,547 & 2,986 & 3,079 & 3,352 \\
\hline Index & 100 & 107 & 128 & 130 & 113 & 133 & 137 & \\
\hline
\end{tabular}

${ }^{\text {a }}$ Extrapolated figures are on the basis of data until 1 October.

b These figures have been calculated based on the assumption that the estimation by Cruyff and Van der Heijden for 2003 would be the same as for 2002 .

Sources: VAS 1997-October 2003; Immigration and Naturalisation Service Data; CBS Statline (http://statline.cbs.nl; online data by the Dutch Central Bureau for Statistics; visited April 2007)

\section{Control 2: Criminal migration and cross-border crime}

Of all crime suspects with a registered date of entry in the Netherlands, 37 per cent committed at least one crime within three months of their stay in the Netherlands (Table 6.4) and 33 per cent committed at least one crime within four weeks. The proportion of criminal migration and 
cross-border crime differs considerably according to the type of crime. This diversity is more easily demonstrated if we specify the crimes somewhat further. Three types of criminal migration emerge: drug trafficking (8I per cent), false documents ( 56 per cent) and aggravated property crimes with burglary or violence ( 29 per cent, particularly by Eastern Europeans at a rate of 40 per cent).

Table 6.4 Number of (non-EU) crime suspects with illegal residence status, apprehended at least once for a crime within three months of arrival. 1997-2003 ${ }^{a}$

\begin{tabular}{|c|c|c|c|c|c|c|c|}
\hline & $\begin{array}{l}\text { Property } \\
\text { crimes } \\
\text { with } \\
\text { burglary } \\
\text { and/or } \\
\text { violence }\end{array}$ & $\begin{array}{l}\text { Other } \\
\text { property } \\
\text { crimes }\end{array}$ & $\begin{array}{l}\text { False } \\
\text { documents }\end{array}$ & $\begin{array}{l}\text { Drug } \\
\text { trafficking }\end{array}$ & $\begin{array}{l}\text { Drugs } \\
\text { other }\end{array}$ & $\begin{array}{l}\text { Other } \\
\text { crimes }\end{array}$ & $\begin{array}{l}\text { Any } \\
\text { crime }\end{array}$ \\
\hline 1997 & $136(20)$ & 98 (17) & $170(35)$ & $16(50)$ & $346(54)$ & 77 (9) & $840(26)$ \\
\hline 1998 & $151(23)$ & 112 (19) & $157(30)$ & $19(33)$ & $295(48)$ & 111 (13) & $840(26)$ \\
\hline 1999 & $180(26)$ & $163(24)$ & 269 (57) & $22(48)$ & $224(42)$ & 99 (11) & $943(29)$ \\
\hline 2000 & $220(30)$ & $210(25)$ & 780 (16) & $6(55)$ & $252(40)$ & $153(17)$ & 1,609 (37) \\
\hline 2001 & 338 (35) & $267(28)$ & $1,209(64)$ & $30(58)$ & $498(58)$ & $256(25)$ & $2,578(46)$ \\
\hline 2002 & 437 (31) & $332(24)$ & $1,069(56)$ & $504(90)$ & $238(33)$ & $267(20)$ & $2,816(39)$ \\
\hline $2003^{b}$ & $373(26)$ & $339(22)$ & $964(57)$ & $376(85)$ & $257(32)$ & $272(17)$ & $2,555(35)$ \\
\hline $\begin{array}{l}\text { 1997-2003 } \\
\text { of which: }\end{array}$ & 1,717) & $1,436(24)$ & $4,600(56)$ & $973(81)$ & $2,054(45)$ & $1,213(17)$ & 11,844 (37) \\
\hline $\begin{array}{l}\text { Europe } \\
\text { (non-EU) }\end{array}$ & $1,385(40)$ & $990(32)$ & $1,342(56)$ & $75(75)$ & $303(26)$ & $520(26)$ & $4,616(40)$ \\
\hline Africa & $189(12)$ & $263(14)$ & $1,654(53)$ & $273(74)$ & $679(33)$ & $386(13)$ & $3,333(30)$ \\
\hline $\begin{array}{l}\text { Asia } \\
\text { (including } \\
\text { Turkey) }\end{array}$ & 81 (17) & 126 (19) & 1,099 (57) & 70 (87) & $224(40)$ & $223(15)$ & $1,802(36)$ \\
\hline $\begin{array}{l}\text { Latin } \\
\text { America }\end{array}$ & $60(16)$ & $48(12)$ & $493(67)$ & $524(85)$ & $778(64)$ & $61(12)$ & $1,943(52)$ \\
\hline $\begin{array}{l}\text { North } \\
\text { America/ } \\
\text { Oceania }\end{array}$ & $2(7)$ & 9 (19) & $11(43)$ & 31 (100) & $70(74)$ & $23(30)$ & $146(49)$ \\
\hline
\end{tabular}

${ }^{a}$ Figures between brackets pertain to the percentage of suspects apprehended within three months of stay as a percentage of all crime suspects in this category with illegal residence status.

${ }^{\mathrm{b}}$ Extrapolated figures are on the basis of data until 1 October.

Source: VAS 1997-October 2003

The use of false documents upon entry appears to be quite common among all non-Western third-country nationals. Asians (with the exception of Turkey) and Sub-Saharan Africans are somewhat over-represented. National disparities are more pronounced for drug trafficking and 
aggravated theft, i.e. theft in combination with burglary or violence. Latinos represent about one in ten crime suspects with illegal residence status, though also represent about half of all suspected drug traffickers who committed a crime within three months. Criminal migration involving aggravated property crimes is most prevalent among Central and Eastern Europeans. No less than four-fifths of suspects of aggravated crimes who offended within three months of stay, concern what are, or were at the time, nationals from non-EU countries (mostly Poles, Romanians, Lithuanians and citizens of the former Republic of Yugoslavia). These nationalities constituted about one in three crime suspects with illegal residence status.

These figures clearly demonstrate that the marginalisation hypothesis cannot explain all crimes committed by illegal migrants, because a substantial proportion of illegal migrants start to offend upon arrival or soon after. Moreover, it appears that forms of criminal migration and crossborder crime have increased, particularly after I999. While in the midI990 about a quarter of all crime suspects were suspected of having committed a crime within three months of arrival, by 200I this share had almost doubled. The subsequent fall after 200I may be related to the growing importance of marginalisation effects and status reclassification.

In the second and subsequent controls, all those suspected of committing at least one crime before three months of stay were excluded from the analyses (Table 6.3). As a result, the crime index for 2003 dropped further from 223 to I94. The decrease is most pronounced for 'false documents' and 'other crimes', which include violence. The crime index for 'drugs' is hardly affected because most illegal migrants apprehended for drugs are not apprehended for drug-trafficking but for drug dealing (a form of subsistence crime, as well as a way to finance drug use, see also Table 6.4).

\section{Control 3: Policing}

The possibility that the rise in the number of crime suspects is due to changes in policing strategies and/or crime recording practices should also be taken into consideration. As has been said, general (a) as well as specific (b) developments in policing should be taken into consideration.

(3a) The total number of crime suspects in the regular population increased by 24 per cent between 1997 and 2003 (Table 6.5). Apart from developments in crime tracing and recording, it should also be pointed out that the number of criminals may actually have increased in the legal population, for instance because of population growth (the Dutch population indeed grew by approximately 5 per cent between I997 and 2003). But since we want to put the marginalisation thesis to a critical test, I 
have assumed that the increase in the number of crime suspects illegally residing in the Netherlands is completely due to general improvements in crime detection and recording. Hence, the number of such crime suspects was divided by the crime index in the legal population, i.e. by development in the general police figures. For instance, the number of suspects in I997 was divided by I, the number of suspects in $200 \mathrm{I}$ by I.05 and so on (see the index in Table 6.5). As a result of these adjustments, the 2003 crime index for illegal migrants was reduced from I96 to 156 . Still, the rise in crime suspects with illegal residence status is considerably more pronounced than in the legal population.

Table 6.5 Total number of crime suspects in the Netherlands (1997-2003)

\begin{tabular}{ccccc}
\hline Year & Total population & Crime Suspects & Crime rate (\%) & $\begin{array}{c}\text { Crime index } \\
\text { (suspects) }\end{array}$ \\
1997 & $15,567,107$ & 266,292 & 1.7 & 100 \\
1998 & $15,654,192$ & 266,978 & 1.7 & 100 \\
1999 & $15,760,225$ & 268,717 & 1.7 & 101 \\
2000 & $15,863,950$ & 270,212 & 1.7 & 101 \\
2001 & $15,987,075$ & 280,070 & 1.8 & 105 \\
2002 & $16,105,285$ & 302,895 & 1.9 & 114 \\
2003 & $16,192,572$ & 329,470 & 2.0 & 124 \\
\hline
\end{tabular}

Source: CBS Statline (http://statline.cbs.nl; visited April 2007).

(3b) There are two exceptions to the rule that the police target crime suspects regardless of residence status. First, it could be the case that the police have deployed more personnel over time to trace identity fraud by illegal migrants, although the prevalence of identity fraud may also have actually increased as an adaptation to the law on identification, or as a subsistence crime in an effort to gain fraudulent access to the formal labour market. Another exception occurs when criminal illegal migrants are specifically targeted, as for instance in the Amsterdam area.

For these reasons, I excluded all known cases concerning false papers, not just the cases committed by early offenders, these were already excluded when controlling for criminal migration and cross-border crime. Due to this additional control, the crime index for 2003 dropped only marginally from I56 to I54 (figures not in table). Apparently, increased policing of identity fraud can hardly account for the rise in crime. When the apprehensions that occurred in Amsterdam were also excluded, the crime indexes actually increased somewhat, even for 2002 and 2003 when Spirit was operational. The rise in crime between 1997 and 2003 occurred across the country, not being limited to Amsterdam or other large urban areas (see also control $5 \mathrm{a}$ ). 
Finally, the supposition that the police increasingly check and register the residence status of foreign crime suspects finds no clear support in the data. If this were the case, how are we to account for the observation that the net rise in crime after all controls (see hereafter, after control 4 and 5) is limited to the indicators of subsistence crime and crimes to finance drug use, and does not pertain to 'other crimes'? ${ }^{13}$

\section{Control 4 and 5: Ethnic embeddedness and demographic changes}

The crime rate among non-Western migrants rose slightly between I999 and 2003 (no comparable data were available for I997 and I998). For instance, for the ages twelve to 80 the crime rate among first and second generation migrants from Africa, Asia and Latin-America was 3.7 per cent in I999, 3.6 per cent in 2001 and 4.I per cent in 2003 . For Eastern Europeans these figures were 2.3 per cent, 2.4 per cent and 2.6 per cent. II These increases are not more pronounced than in the population at large (compare Table 6.5), which was already controlled (3a).

The embeddedness hypothesis may, at the most, contain some truth for illegal migrants from a number of Eastern European countries. For instance, the crime rate among migrants from the former Soviet Union (ages I2 to 80) rose from 2.0 per cent in I997 to 3.2 per cent in 2003. This may partly explain why the crime index for 2003 after control 3a is higher for Eastern Europeans (242) than for the other regions of origin (I29; figures not in table). Finally, the rise in the number of crime suspects may also have been caused by developments in (a) the composition of the illegal population, or (b) its size.

(5a) Crime involvement correlates with sex, age, ethnicity and the degree of urbanisation. Unfortunately, Cruyff and Van der Heijden (2004) did not make specific estimations of subgroups within the illegal population apart from a general distinction between Europeans and non-Europeans, which was used for control $5 \mathrm{~b}$. But on the basis of the apprehension data in the VAS, it appears unlikely that the rise in crime has been caused by changes in the composition of the illegal population with regard to age, sex, ethnicity, or the rate of urban residency.

First of all, the average age of all apprehended third nationals living in illegal residence actually rose from 28.8 in I997 to 29.7 in 2003. Furthermore, the share of males has increased only marginally from 79 per cent to $8 \mathrm{I}$ per cent. Besides this, the rise in crime is more pronounced for women (I83 after control 3 b) than for men (I50). A number of notable changes have occurred with regard to the ethnic composition of the illegal population. For instance, the share of Eastern Europeans among non-EU nationals in the VAS increased from 30 per cent to 42 per cent between I997 and 2003, while the share of the North-Africans (a group with a high crime involvement) decreased from 20 per cent to I4 per 
cent. Yet it is unlikely that these changes are responsible for the increase in the number of crime suspects. The rise in crime is not limited to specific nationalities, and it even transpires that the total rise in crime actually became somewhat more pronounced if developments in the ethnic makeup were corrected for. Finally, changes in the degree of urban residence can also not account for the rise in crime. The relative number of apprehensions in the four largest cities actually decreased between I997 and 2003, and the rise in crime is not spatially concentrated within the Netherlands. ${ }^{\text {I2 }}$

(5b) There are two proxies for assessing developments in the size of the illegal population: (I) the annual number of apprehensions in the VAS for crimes, but also for illegal residence and misdemeanours and (2) the estimations by Cruyff and Van der Heijden (2004). Both indicators suggest an initial fall, followed by a rise in the size of the illegal population. The eventual rise is more pronounced according to the apprehensions than according to the estimations. This disparity may point at an increase in the chance of apprehension over time, both as a result of the rise in crime and because of better detection of illegal labour. Cruyff and Van der Heijden's estimations are not sensitive to such developments in the likelihood of apprehension, at least not in theory.

Figure 6.1 Relative developments in the estimated number of illegal migrants from Eastern Europe and other (non-EU) illegal migrants (1997; index=100)

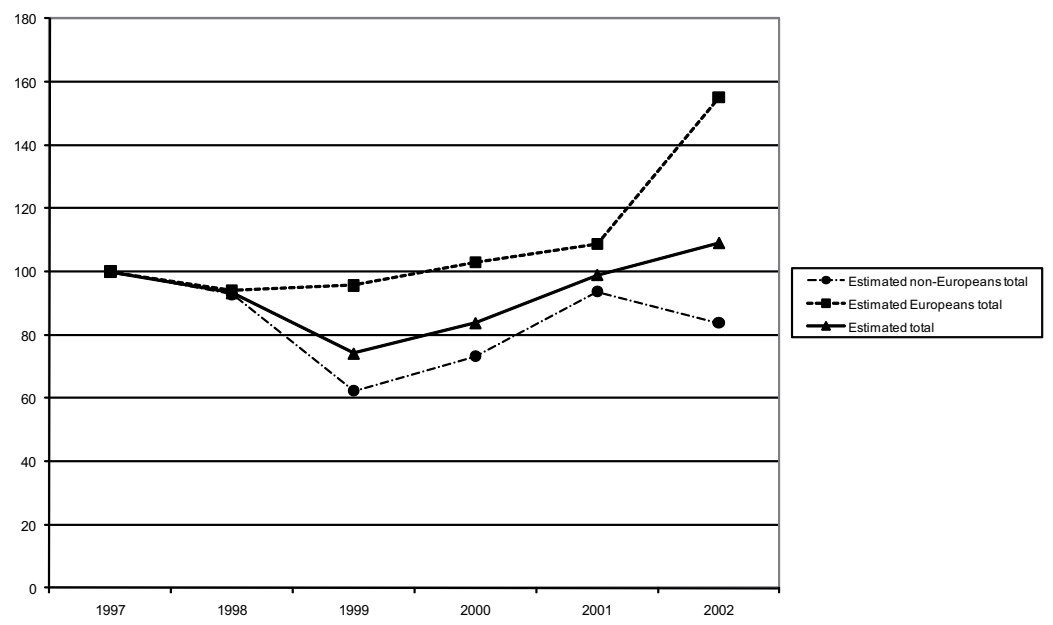

Sources: Vreemdelingen Administratie Systeem 1997-2002; estimations taken from Cruyff and Van der Heijden 2004: 38-39

Figure 6.I shows how the estimated size of the illegal population developed since I997. The number of Eastern Europeans and other non-EU 
nationals have been estimated separately. The estimations for I997 have been set at Ioo, while the year 2003 has been excluded because the estimates by Cruyff and Van der Heijden for that year cannot be compared to the other years; only the first nine months were available at the time and for statistical reasons the estimation cannot simply be extrapolated to the whole year. An important observation is that while the number of Eastern Europeans appears to have risen, the size of other non-EU groups appears to be stable or somewhat diminishing.

Hence, it is unlikely that the rise in crime is completely due to an increase in the size of the illegal population in the Netherlands, for two reasons. First, as we have already seen, the rise in crime is not limited to migrants from Eastern European countries. Second, the increase in the size of the third national illegal population since 200I - i.e. Eastern Europeans and other non-EU nationals combined - is, in any case, much less pronounced than the increase in the number of crime suspects. If the figures in Table 6.3 are adjusted for possible changes in the size of the illegal population, as was done for control za (using the estimations by Cruyff and Van der Heijden for the available years), the crime rate for 2003 drops a little further from ${ }_{5} 6$ to I37. Interestingly, the index for I999 now also mirrors the general trend (see Table 6.3). ${ }^{\mathrm{I3}}$

\section{Concluding remarks}

In this sub-study the marginalisation thesis - which assumes that internal border control in the form of institutional exclusion may push illegal migrants towards crime - was subjected to a critical examination. The rise in apprehensions of illegal migrants for crimes in the Netherlands between 1997 and 2003 was taken as a test case. When controlling for five alternative hypotheses, the marginalisation thesis could not be falsified. It appears that marginalisation explains a substantial part of the rise in crime. Yet the picture is more nuanced, and we can conclude that a combination of factors has contributed to the rise in crime among illegal migrants in the Netherlands. Increased migration by offenders committing crimes upon or soon after arrival - which includes criminal migration and cross-border crime - as well as general developments in policing and police registration practices account for 22 per cent and 29 per cent of the increase respectively, while status reclassification ( 6 per cent) and demographic growth (I5 per cent) were less important. Marginalisation effects appear to be responsible for the remaining part, i.e. 28 per cent of the increase. ${ }^{\mathrm{I}}$ Because the alternative hypotheses were favoured in the analyses, this appears to be a conservative estimate.

To make the effects more tangible, it can be calculated that the intensification of institutional exclusion of illegal migrants in the Netherlands 
appears to have led to a minimum of 3,000 additional crime suspects in the period I998 to 2003, because of the effects of marginalisation (see $N$ after control $5 \mathrm{~b}$ in Table 6.3). Whether or not this is a high number depends partly on the perspective from which it is judged. For illegal migrants who still reside in the Netherlands in spite of heightened institutional exclusion, the increase is significant. For them, their chances of involvement in subsistence crime and/or drug-related acquisitive crime appear to have increased, on average, by at least 37 per cent between 1997 and 2003 (this is not the same as the fact that 28 per cent of the increase appears to be due to marginalisation effects, see note). ${ }^{15}$ Moreover, it could be argued that the total criminogenic effects of institutional exclusion are somewhat stronger, because (I) the alternative hypotheses were operationalised according to broad criteria and (2) illegal migrants were already excluded from the formal labour market in I99I, six years before 1997, the first year for which reliable digital data were available. Yet, in any event, the increase is quite marginal compared to crime problems in general. The additional three thousand crime suspects equal o.I5 per cent of the suspects in the legal population for the researched period (see Table 6.4) and, even without the controls, the number of additional crime suspects $(\mathrm{I} 2,000)$ equals no more than 0.6 per cent of the crime suspects legally residing in the Netherlands in this period, invalidating the myth that illegal migrants are responsible for a large share of all crimes. While illegal migrants have been overrepresented in crime statistics in recent years, their criminal activities still account for only a small proportion of all crimes in the Netherlands. Still, it must be noted that the effects are concentrated in certain urban areas (see Chapter 3) and they have brought about substantial increases in incarceration costs (also see the conclusion of this book). ${ }^{16}$

While this book mainly documents the unintended repercussions of closed internal borders, the analyses in this sub-study also point to the unintended repercussions of open external borders. It appears that open and closed societies generate and facilitate specific forms of crime. In a time in which the free movement of legal goods and certain persons is promoted, it is also much easier for foreign criminals to migrate for shorter or longer periods of time and to commit crimes like drug trafficking or aggravated theft in other countries. The unintended consequences of restrictive or liberal migration management indicate the complexities of dealing with international migration and crime. I will return to this point in this book's final chapter.

Another point that will be discussed in this book's conclusion is to what degree the strict policies on illegal residence discourage unwanted migrants from coming to and residing in the Netherlands. As we have seen in this sub-study, there are no empirical indications that their number has diminished in the Netherlands in response to these policies. Yet 
given the current state of research we cannot rule out the possibility that the tightening of internal border controls has prevented a further increase. Yet it is worth mentioning that Van Meeteren, Van San and Engbersen (2008: I62) have not found a rise in the number of illegal migrants in Belgium for the period 200I-2005 (unfortunately their study does not estimate illegal residence in I997, I998, I999 and 2000). Internal border controls in Belgium have not been increased to the same degree as in the Netherlands in the period of study (I997-2003). 



\section{Conclusions and discussion}

This final chapter reflects on the coherence of the sub-studies in this book and summarises the main findings of the study as a whole. I start with an explanation of this study's theoretical contribution, followed by a number of comments concerning the main limitations of this study, as well as some suggestions for future research. I then continue with a discussion of some implications for policy.

\section{Theoretical conclusions}

This study was intended to contribute to what Merton (I968) called 'theories of the middle range', i.e. theories that aim to bridge the gap between abstract theorising and empirical evidence. In particular, it contributes to substantive theory on the terrain of migration, crime and public safety by critically examining and developing ideas proposed by other researchers in the Netherlands and elsewhere.

This study's primary theoretical contribution is that it adds to the insight that today, in order to understand crime and other forms of rule observance and violation among migrants, researchers should pay due attention to the governmental regulation of international migration and the ways in which these practices interact with semi-autonomous social forces from other segments of society. In other words: in explaining crime and transgressions among migrants we should not only look at, for example, cultural factors or forms of social exclusion in destination countries that tend to be countered by the state, such as racial discrimination on the labour market or educational deprivation among second generation migrants. We should also pay attention to how migrants adapt to formalised practices of social exclusion implemented and legitimised by the state itself.

Various types of border control were distinguished in this study. A distinction was made between external border control and internal border control. The two main variants of internal border control, on which this study focused, were called institutional exclusion and secondary territorial exclusion. 
The first reason for paying attention to various forms of border control is that these are, more or less by definition, coupled with new forms of illegality and migrant crime. Certain types of behaviour have become obligated in order to reach restrictive immigration goals. One case in point, which is related to external border control, is the obligation to enter or leave a country with valid papers. Other examples, which are related to practices of secondary territorial exclusion, are the obligation to show a valid ID in public space and the requirement made of an undesirable alien to leave the country. The violation of such stipulations constitutes what has been coined residence crime in this study: crimes committed with the aim of residing in a jurisdiction, in spite of the external and internal border controls by the state that claims sovereignty there. Other examples of residence crime are crossing the border with a smuggler or showing a false ID.

Second, this study demonstrates that there are significant, albeit complex and more indirect, relations between the intensified regulation of international migration and migrants' involvement in more regular forms of crime, such as theft, drug trafficking and violence. It documents that aspects of migration control may become associated with factors that are known to promote or depress crime and disorder.

Practices of institutional exclusion tend to encourage criminal involvement among illegal migrants who establish themselves in spite of these practices. This is chiefly for the reason that institutional exclusion may trigger the criminological mechanism known as strain. According to strain theories people are more likely to use illegal pathways if the conventional roads to culturally prescribed goals are increasingly closed off to them (Merton 1939; for more recent applications of this theory see Agnew 1992; Young 1999). This approach sees criminality as a behavioural adaptation in response to the strain people may experience between goals they believe to be legitimate and access to the means to realise these ambitions in a conventional way. Hence, the experience of strain in the face of migration control may not only promote certain forms of residence crime such as the use of false IDs, ${ }^{\mathrm{I}}$ but may also, albeit more indirectly, incite certain conventional forms of crime and disorder. We have seen that illegal migrants sometimes resort to crime, particularly those that generate economic resources, in the hope of achieving social standards that they themselves consider elementary and/or are considered as elementary by the milieus of which they are or aspire to be a part. They sometimes perceive no other option than to commit a crime, given their marginal social position after settlement, which was in turn caused or at least reinforced by institutional exclusion as an instrument of internal border controls. Unlike residence crime, offenders place greater demands on the quality of their lives in the case of what is called subsistence crime in this study. Examples of such stan- 
dards are: the desire to consume food from shops, contributing to the funeral costs of a father, paying a dowry, wanting to chauffeur a Dutch girlfriend (in the Netherlands illegal migrants are not entitled to a driver's license). The main variants of subsistence crime that were found are various forms of theft, working with false documents and street trade in drugs.

It appears that the increased institutional exclusion of illegal immigrants may also lead to problematic drug use: in a number of cases problematic drug use emanated from homelessness and/or a career in subsistence crime as a clean drug dealer. Like other marginalised users, such illegal migrants often become dependent on addiction-related crimes such as burglary to finance their substance use. Hence, in the case of subsistence crime and addiction-related crimes, the connection between offending and institutional exclusion appears to run via the outcome of processes of marginalisation in the country of destination, in particular via economic deprivation and homelessness.

Chapter 6 analysed the steep increase in the number of illegal migrants suspected of crimes in the Netherlands. It showed that as practices of institutional exclusion were being intensified in the Netherlands the documented crime rate among illegal migrants grew accordingly to become roughly as high as, or perhaps even higher than among comparable non-Western migrants with legal residence. It appears that the rise has various causes. Yet it is likely that the main explanation lies in the increase in institutional exclusion as an instrument of internal border controls.

Internal border control in the form of secondary territorial exclusion impacts the involvement of migrants in conventional types of crime as well. Usually it does so in the opposite direction of institutional exclusion: the study documents that secondary territorial exclusion increases the social pressure to avoid police contacts, which generally decreases offending, even if it may sometimes encourage specific residence crimes such as using fake IDs for identification purposes or driving away after a traffic accident. Secondary territorial exclusion tends to decrease rule violation because it usually triggers a different criminological factor than strain, to wit social control.

According to the social control approach in criminology, people are more likely to control their criminal impulses if they have something to lose by indulging them (Hirschi I969; Meier \& Johnson I977; Nagin \& Paternoster I994; Weerman I998; Schuyt I995: 136-I55). In addition to the punishments that are aimed at deterring legal residents from crime, illegal migrants risk being held in Aliens' Detention, expulsion, and the loss of social and economic ties in the country of destination, even in the case of minor norm violations that would normally be sanctioned with a fine, alternative punishments, or brief terms of imprisonment. There 
were good reasons why the threat of excommunication and banishment was an important instrument of social control in former times (Morris \& Rothman I998).

The effects of secondary territorial exclusion are more easily overlooked than the effects of institutional exclusion. The fact is that in police data rule transgression catches the eye more easily than rule observance. Nonetheless, this study has found three empirical observations that confirm the deterrence thesis, which asserts that the elevated detention and expulsion risks for illegal migrants tend to depress crime rates among them.

Firstly, it turns out that the crime rate among illegal migrants was substantially lower than among comparable legal migrants in the midI990s, i.e. when the institutional exclusion of illegal migrants was less developed in the Netherlands.

Secondly, the deterrent effects reveal themselves in the low involvement of illegal migrants in expressive or symbolic crimes such as assault and vandalism (see for instance Van San I998; Cohen \& Rotton 2003). It appears that in the case of the instrumental crimes mentioned - residence crime, subsistence crime and addiction-related crime - the social control mechanism is outweighed by the strain mechanism.

Thirdly, this study has found indications that criminal illegal migrants often prefer types of crime that do not require overt contact with the victim (cf. Scott I985, I990). Overt crimes are more likely to lead to police contacts and tend to have higher clear-up rates than covert crimes. Robbery occurring under the influence of institutional exclusion appears to be rare among illegal migrants.

The question may be raised of why the effects of institutional exclusion differ from the effects of secondary territorial exclusion. Is it not the case that both types of border controls involve the state's endeavour to achieve the social exclusion of, in its view, unwanted immigrants? It should be noted that the difference does not lie in the fact that the first type of social exclusion is institutional, while the second is territorial. Rather, the difference lies in the fact that institutional exclusion tends to demonstrate itself to the migrant as an actual state or condition, whereas secondary territorial exclusion tends to demonstrate itself as a feared prospect or repercussion. In these two senses, the state's endeavour to achieve social exclusion appears to trigger different criminological mechanisms. In the first sense immigration control has already brought about a strong measure of social exclusion: access to work and housing may turn out to be limited given practices of internal border control. In the second sense internal border control evokes the fear that additional social exclusion may be awaiting; in the latter case, immigration controls function as a sanction, a threat, a fear of further exclusion. While social exclusion as a condition may trigger the strain mechanism, social exclu- 
sion as a possible prospect and sanction tend to contribute to social control, which usually promotes rule observance.

An additional contribution of this study lies in demonstrating that the increased regulation of international migration may become associated with the involvement of migrants in the committing of felonies, but also in less serious forms of rule transgression such as misdemeanours and violations of unwritten social rules. In that respect the two aspects of internal border control also appear to yield similarly differential effects. It turns out that misdemeanours should likewise often be understood as a response to the strain between legitimate aspirations and limited access to conventional means to fulfil these aspirations, in part as a consequence of having illegal residence status. Cases in point are: living in overpopulated illegal doss houses, not having a permanent address, homelessness and approaching potential marriage partners in the street with an eye to obtaining a residence permit. But the risk of apprehension and expulsion also reveals itself in the case of misdemeanours and violations of unwritten social rules. It turns out, for instance, that some illegal migrants keep their curtains closed during the day in the hope of not being seen. Yet, as a rule, the socially wrought restraint of illegal migrants has a favourable effect on neighbourhood safety and liveability. At least there are indications that illegal migrants are less noisy than legal residents because of expulsion risks, and on the streets they appear to assume less dominant stances as well (Chapter 3).

\section{The interaction with social ties}

The effects of external and internal border controls do not always manifest themselves in the same measure and in the same way for all groups of illegal migrants; if we want to understand that variation we have to realise that there are several interests and beliefs in segments of the differentiated, open-market societies in the West that differ from the beliefs and interests that dominate immigration policies. I have contributed to the insight that both the extent and the way in which aspects of immigration control have consequences for public safety are to a considerable extent determined by the interplay between these state practices and the relatively autonomous, sometimes opposing forces from other parts of society. These conclusions are inspired by sociology, particularly the sociology of law. ${ }^{2}$

By its very nature, a restrictive immigration policy clashes with the interests of migrants who are subjected to it but fail to meet the criteria for legal residence. Therefore it is not very remarkable that some of these migrants try to establish themselves without government consent. This study shows, however, that in countries like the Netherlands there exist, concentrated in certain (shadow) places, more established groups 
whose interests are negatively affected by these policies, who contest the legitimacy of such policies, or who contribute to the opportunity structure of illegal residence because they profit from the weak social position of illegal migrants. This was mainly demonstrated indirectly by analysing the spatial distribution patterns of illegal migrants (Chapter 2). These analyses indicate that there are three social actors who partially undermine restrictive immigration objectives: (I) established non-Western migrant communities, (2) employers, particularly in sectors that depend on the secondary labour market and (3) migrant and native singles with a foreign partner or an interest in obtaining such a partner. Restrictive immigration policies also encounter resistance from within the state itself, from local governments or state professionals for example, as well as from organisations in civil society such as Dutch churches and progressive action groups, but the latter effects were not prominent in this study (for this see Van der Leun 2003, 2004).

These sectional interests and beliefs reduce the effectiveness of attempts at regulation of international migration flows. In addition, precisely because they reduce the degree of social exclusion that is realisable by the state, they also determine in part to what extent and how the potential effects on crime and public safety of the state's endeavour to implement social exclusion become manifest.

As a rule, the likelihood that border control has repercussions for public safety decreases with the extent to which the illegal migrant has social ties with the established population. This finding was already present in the existing research, although attention was mainly directed at the role of established migrant communities and professionals in mitigating the effects of institutional exclusion and it has found additional support in his study. It transpires that illegal migrants from established migrant communities - especially from Turkey, but also for example from China - are apprehended for crimes considerably less often than illegal migrants from groups that have made less headway in the Netherlands, such as Somalis and Iranians (Chapter 4). This is partly because illegal pioneers often depend on residence crime in order to come to the Netherlands; for want of ties with established residents it is more difficult for them to obtain a tourist visa or temporary residence permit. After settlement, pioneers depend to a relatively high degree on subsistence crime and drug-related crimes, especially on variants that are executable by a relatively unorganised offender such as various forms of theft and street trade in drugs. It seems that social ties with the legal population generally reduce the strain between legitimate aspirations and access to conventional means of realising those ambitions.

I also found qualitative indications on the individual level that such social ties may mitigate the criminogenic potential of institutional exclusion by the state. During their stay in the Netherlands, there may be con- 
siderable variation in the degree of connection illegal migrants have to more established inhabitants. My respondents tended to commit fewer crimes in the period during which they found black work or were financially supported by a partner, than for instance in the periods when they lived on the street and/or hung around with other delinquents. With the exception of violence, they were also more often involved in crime when they their residence was illegal than in the periods when they were received as asylum seekers (see also De Boom, Engbersen \& Leerkes 2006). In addition, the men who managed to forge the fewest social ties also appeared to run the highest risk of developing careers as drug users in the urban margin, partly because they lacked social support to cope with their difficult life conditions in other ways.

The likelihood of involvement in misdemeanours and violations of unwritten rules appeared to decrease as well with the bond between the illegal migrant and segments of the legal population. It appears that legal residents rarely see illegal migrants as detrimental to public safety if they live with their families or a partner, or can afford to rent apartments (Chapter 3). By contrast, it turned out that footloose illegal newcomers who have a deviant position in neighbourhoods are sometimes seen as a threat in this sense. The latter groups are more often homeless, live for shorter periods in illegal pensions, or sleep in cars or minivans. Although not all of the latter groups aspire to an established position in the country of destination, the state can keep them out of the legal housing market more successfully because they have limited ties with established residents. Owing to their relative disembeddedness, they are also less acquainted with important neighbourhood rules, such as the times when garbage is collected.

Interestingly, the effects of secondary territorial exclusion also vary with the strength of the social ties between an illegal migrant and social minorities. Here, such ties appear to amplify its tendency to depress migrant crime. The more integrated an illegal migrant, the more he or she has to lose by detention and expulsion from the Netherlands, because such ties do not eliminate the risk of expulsion; strictly speaking, only naturalisation can eliminate that risk. ${ }^{3}$ It turns out in any case that relatively unconnected illegal migrants, like the pendulum migrants from Eastern Europe, are much more overtly visible in neighbourhood life than other groups of illegal migrants, and sometimes display behaviour that is offensive to many residents, particularly to women. ${ }^{4}$

\section{Nature of the social ties}

All that has been said so far about the importance of social embeddedness confirms the tenor of previous research in the Netherlands. At the same time, however, I demonstrated that the role of social ties with the 
legal population is more complex. The interests and beliefs among the three social actors - migrant communities, employers and singles - do not by definition reduce the chances of an migrant violating social rules under the influence of his or her illegal residence status. First, while the degree of social ties is relevant, so is the question of with whom one is connected. Previous research assumed that ethnic embedding enhanced access to formal and informal institutions. Yet it is argued in this study that ethnic embedding sometimes also increases access to criminal circuits (Chapter 4). Furthermore, it was observed in Chapter 5 that illegal migrants who become hard drug users often end up in marginal drug networks in the cities. There they learn forms of crime that help to finance drug use. It should be noted, however, that such ties appear to be weaker and more fragmented than the familial ties of the illegal migrants in the Turkish community that Staring (200I) described (see also Sansone (1992) on the nature of social ties in marginal criminal networks).

Second, it was shown that even ties with 'conventional' milieus can sometimes encourage criminality under the influence of institutional exclusion (Chapter 5). Such social ties may under certain conditions increase the social pressure towards offending. It appears that illegal migrants sometimes commit crimes as a means of complying with demands articulated in their social environments. Strain under the influence of institutional exclusion may be amplified in the case of a conflict between the outcome of having illegal residence status and the expectations associated with the parallel statuses of the migrant, for example, the status of son, father, or husband. As it turns out, the effects of social embeddedness in the form of social capital - which increases behavioural options, including criminal options - should be disentangled from the effects of social embeddedness in the form of social expectations.

For a combination of reasons, however, it is unlikely that refinements such as these are the rule rather than the exception in Dutch society. ${ }^{5}$

\section{The form of rule transgression}

In this book it has been argued that illegal migrants' social ties influence the shape of possible rule transgression under the influence of having illegal residence status. As has been said, an illegal migrant who has a Dutch girlfriend with a car appears to have a higher chance of driving himself, albeit without a driver's license.

Also - and most importantly - there turn out to be significant differences in the nature of crimes committed according to region of origin. Because of their ties with established migrant communities, illegal migrants have an elevated chance of involvement in a type of crime that is relatively common among their countrymen with legal status. 


\section{Other factors}

Crime involvement is not only a matter of exogenic restraint and opportunity given the illegal residence status and social ties in the country of origin; in response to strain migrants appear to choose forms of criminality they find less morally abhorrent in comparison to other perceived criminal alternatives. It appears that the weighing of behaviour alternatives differs to some degree, both between and within ethnic groups. While illegal migrants from Eastern Europe appear to opt for theft in case of criminality under the strain of a marginal position, African migrants have an elevated chance of becoming involved in identity fraud or financial scams, while illegal North Africans relatively often decide to become drug dealers. Thus the form that criminality may take under the influence of having illegal residence status is in large measure socially and culturally determined (cf. Cullen I984).

In sum, illegal migrants' patterns of rule violation and observation should to a considerable degree be understood as the aggregate of individual responses to conditions that are the outcome of different aspects of border control, which interact in complex ways with different degrees and types of social embeddedness in the country of destination as well as cultural factors that are related to the country of origin.

This book's central claim does not imply, of course, that norm violation or observation among illegal migrants is always an adaptation to restrictive immigration policy. The study also shows that some forms of rule violation among illegal migrants, like sexual crimes, are only marginally the outcome of restrictive immigration policies, if at all (Chapter 5). In addition, we have seen that some forms of criminal migration and cross-border crime - where an offender migrates to other countries with the intention to commit crimes such as drug trafficking or burglary occur among illegal migrants in the Netherlands (Chapter 6). It is unlikely that restrictive immigration policy contributed to these forms of offending. On the contrary, certain types of criminal migration and crossborder crime presuppose relatively open borders, as was the case with forms of transnational brigandage from Eastern European countries that were already due to become EU members during the period of study. Furthermore, it was shown that in Holland a significant and increasing number of criminal illegal migrants appear to be former legal migrants who have lost their residence rights and are declared undesirable aliens because of criminal activities. Admittedly, such practices of what has been called status reclassification in this study (Chapter 6) constitute an increasingly significant third element of internal border control. Yet status reclassification should primarily be understood as a state response to migrant crime rather than as a cause or condition of migrant crime and disorder. 
Similarly, I have argued that illegal migrants do not only or even primarily conform to social rules as an adaptation to secondary territorial exclusion, but rather because they have internalised such rules as a result of previous socialisation in the country of origin, and often subscribe to their legitimacy.

\section{Limitations and suggestions for future research}

All in all, this book primarily increases our insight into the unintended effects of restrictive immigration policy for migrant crime and public safety in the country of destination. It demonstrates that not all migrants who are formally excluded do in fact abandon residence in countries like the Netherlands. This is possible in part because such countries are not only closed welfare states, but also differentiated open-market societies. It turns out that this combination of social conditions also influences in several ways the more unintended and unanticipated consequences of immigration control in the context of public safety.

An important limitation of this study is that the intended effects of migration controls have, in a large measure, not been researched. Accordingly, this study does not shed light on the extent to which immigration controls overall and internal border controls, in particular, diminish certain migration flows, as they are intended to do. While there are, as yet, no empirical indications for a decrease in illegal residence in the Netherlands because of increases in internal border controls (Chapter $6)$, I could not rule out the possibility that these increases have prevented a steeper growth of illegal residence in the Netherlands.

Because of this limitation it is not yet clear whether institutional exclusion, while increasing the chances of an illegal migrant becoming involved in crime, has a negative effect on the absolute number of criminal illegal migrants. It could be that fewer criminal illegal migrants remain, insofar as the population at risk would diminish more as a result of institutional exclusion than compensated for by the increase in the risk of crime involvement. In that case, it is possible that fewer illegal migrants more often violate social rules as a consequence of institutional exclusion. $^{6}$ (It could even be that internal border controls, insofar as they reduce immigration substantially, benefit the life chances of the remaining unwanted migrants in some respects. Perhaps the lower the number of remaining illegal migrants the lower their mutual competition for life chances in the country of settlement with respect to work, housing and finding a partner.)

A similar reservation concerns the effects of social embeddedness. I have asserted that the chances of illegal residence status having negative consequences for public safety diminish on average according to the strength of the social ties between the illegal migrant and more estab- 
lished actors in Dutch society. That does not necessarily mean that the magnitude of the safety problems that are coupled with illegal residence is smaller because of such ties, since ties with the legal population also facilitate illegal residence. If they were to disappear, the absolute magnitude of the safety problems that are coupled with illegal residence would perhaps decrease, while the relative magnitude would increase. That is to say, again, fewer illegal migrants would more frequently transgress formal and informal social rules that are relevant for public safety in the country of destination.?

We could learn more about the intended effects of migration control by means of a comparative, international study. Unfortunately such a study is currently lacking. Four additional routes for future research suggest themselves.

Firstly, my analyses could be replicated for other countries. This might provide additional evidence for the mechanisms that have been described in this book. Or it might transpire that aspects of immigration controls yield different outcomes in different countries: unintended consequences should always be understood in relation to the logic of situations' (Popper 1962: 95-97). For instance, it could be hypothesised that in countries with a larger informal economy and a larger private housing market, a shift to informal practices will be more likely as a result of institutional exclusion by the state, rather than a shift towards crime.

Secondly, more research could be done on whether neighbourhood social organisation is weakened as the proportion of people in a given neighbourhood who lack a residence permit reaches a certain threshold, making such areas more attractive for offenders in general (Chapter 3).

A third route to explore is whether this study's findings are also relevant to an understanding of crime and rule trespassing among legal migrants, especially first generation migrants with temporary residence permits. For example, it can be expected on the basis of this study that the risk of losing a residence permit will have a deterrent effect on their criminal involvement. This may provide an additional explanation for the finding that criminal involvement among first-generation migrants is usually lower than among their offspring (De Haen-Marshall I997; Tonry 1997). It may also be useful to account for differences between first- and second-generation migrants in the extent to which they are pressured to comply with unwritten social rules. ${ }^{8}$ My findings may also be relevant in helping to understand aspects of rule trespassing and compliance in other underprivileged and repressed groups such as persons in hiding (cf. Scott I990).

Finally, more research should be conducted on illegal migrants as crime victims, given the greater tendency on their part to shun police contacts in instances of victimisation, and given the observation that they are pressured to settle in high-crime neighbourhoods. 


\section{Implications for policy}

This study indicates the complexities of dealing with international migration, crime and public safety. It demonstrates that closed as well as open borders may trigger specific forms of migrant crime and other forms of rule violation that are important for public safety in countries of destination. If free movement of legal goods and certain persons is promoted, as occurred as part of the EU's eastern enlargements, it also becomes easier to migrate to other countries for shorter or longer periods of time to commit crimes such as drug trafficking or aggravated theft. This is all the more likely if there are large international economic disparities. Nevertheless, selective closure of external borders may generate certain forms of smuggling and trafficking. Likewise, this study has helped to document the fact that practices of institutional exclusion may lead to subsistence crime and drug-related crimes.

Hence, in a globalised world that is simultaneously characterised by large international disparities in wealth and life chances, easy solutions to migrant crime are clearly unavailable. Policymakers who want to limit migrant crime should base their approach on an assessment of the intended and unintended effects of restrictive versus more liberal migration policies. This is clearly beyond the scope of this study.

Yet a number of points can be made on the basis of this study. First, internal border controls by means of institutional exclusion are currently becoming more common in destination countries in Europe and North America (Carrera \& Guild 2007; Jencks 2007; NCSL 2008). In that sense, the Netherlands constituted a strategic site in which to study the effects of such measures. My study suggests that institutional exclusion is not beneficial to public safety in destination countries, as long as the intended effects of such measures - discouraging illegal residence - are indeed limited, as they appear to be in the Netherlands. This is particularly true if repatriation policies are also ineffective. In that case, institutional exclusion merely contributes to the creation or entrenchment of a marginal migrant population. This is not to say, of course, that governments might not have other reasons for opting for the institutional exclusion of unwanted migrants, as a way of preserving the primary labour market for the established population, for instance, or for symbolic reasons, showing their voters that 'something is being done' about illegal immigration.

The second point is that secondary territorial exclusion, at least from the perspective of public safety, appears to be a better way to go than institutional exclusion. Detention and expulsion risks, or at least the belief by migrants that such risks exist, tend to depress rule violation among illegal migrants, particularly if they value continued residence outside of detention. I have shown that this general finding does not al- 
ways hold: illegal migrants' tendency to shun police contacts may endanger public safety indirectly if the number of illegal migrants reaches a certain threshold, since it may then weaken neighbourhood social organisation in concentration areas, making such areas more attractive to offenders. Likewise, it is questionable whether secondary territorial exclusion benefits public safety, insofar as apprehension mainly leads to repeated periods in detention and is not followed by repatriation. ${ }^{9}$ Finally, it should be stressed that there is of course a clear tension between secondary territorial exclusion and the values of civil liberty.

An additional point of relevance to policymakers is the question of whether all immigration controls are actually necessary or at least realistic. This study confirms that in some economic sectors, such as horticulture and the takeaway restaurant trade, the economic situation requires or promotes the use of cheap and flexible labour (Chapter 2). It appears that domestic supply in the Netherlands and other destination countries cannot always meet this demand. The recent opening up of the Dutch labour market to workers from new EU member states such as Poland shows that legal labour migration is certainly possible at the lower end of the labour market as well. This raises the question of why such restrictions were not lifted earlier by means of temporary labour migration programmes. Had that been the case, housing of such workers could also have been planned for, while problems of overcrowding in run-down urban doss houses might have been prevented or at least reduced. It should be mentioned here that temporary labour programmes for nonEU citizens may be necessary in the not too distant future if the labour supply from the new EU member states dries up. Temporary labour migration programmes could also be ideologically justified as a way to stimulate development in poorer countries through remittances, and as a means of creating opportunities for work and mobility that are, after all, very unequally distributed across the planet.

\section{Towards a right to elementary social relieffor illegal migrants?}

I would like to end this book with some comments on the question of what should be done with those illegal migrants who are difficult to repatriate, but who are often not legalised either. More particularly, I will look at the question of whether such migrants should be given a right to elementary social relief. Before turning to this question, it is necessary to explain at some length the birth of 'illegals care' in the Netherlands.

In the I990s, a period when the Dutch welfare state was slimmed down, additional and more informal social safety nets developed in the Netherlands. Illegal migrants, in particular, are now extremely dependent on them. For instance, a 2002 case study in The Hague and Leiden revealed that there was considerable solidarity with illegal migrants at a 
local level (Rusinovic et al. 2002; Van der Leun 2004). A highly varied group of churches, civil initiatives, migrant organisations, left-wing activists and civil servants expressed support for illegal migrants. These institutions and individuals tended to specialise in the support they offered. Some donated meals (see also the rise of food banks in the Netherlands since 200I (Desain et al. 2006)), while others gave legal advice or information about health care, arranged temporary accommodation, or offered language courses.

Interestingly, local governments - faced with the outcomes of restrictive immigration policy in the form of homeless illegal migrants in their streets, some of whom were committing subsistence and drug-related crime - also began to offer relief to specific categories of illegal migrants. For instance, many municipalities subsidise their accommodation or have begun to organise accommodation themselves. According to an inventory by the VNG, an organisation of Dutch municipalities, I70 of the approximately 400 municipalities offered such support in direct or indirect ways, from which more than 2,000 persons benefited (Van der Leun 2004). Such municipal support is largely aimed at asylum seekers whose applications have been turned down.

Yet these local networks are quite loose and unorganised. Each of the individuals and organisations involved tries to take care of a small part of the demand. Moreover, not every applicant can be helped, since resources are limited. The organisations must be selective and are forced to set criteria governing who may or may not be helped; the old distinction between the deserving poor and undeserving poor tends to return under these criteria. Rejected asylum seekers, i.e. refugees, have a greater chance of being helped than other groups of illegal migrants such as 'fortune seekers'. This is the case with municipal support, but also for support by churches. Women and children are helped more often than single men. ${ }^{\mathrm{IO}}$

A growing group of vulnerable illegal migrants is accumulating in the Netherlands, composed of people who cannot find sufficient employment, do not have a family or partner to support them, and are to a great extent excluded from the informal social safety nets. They are increasingly often declared undesirable aliens due to repeated illegal residence, more or less serious criminal activities, or a combination of the two. There may also be a question of problematic drug use (Chapter 5; see also Molenaar 2007). The size of this group is unknown, but in the Netherlands it appears to involve between several hundred and several thousand individuals. They are mostly, but not exclusively, adult males.

A considerable number of the members of this group are difficult to expel, because they manage to keep their identities secret, but also in part because their countries of origin appear to be reluctant to take such marginalised illegal migrants back. ${ }^{\text {II }}$ They are also less likely to be 
granted residence rights under legalisation programmes which tend, in the Netherlands and elsewhere, to exclude migrants who have been convicted of crimes. It appears that detention is becoming the dominant form of 'relief' for this group (see also Wacquant 2006). Their detention often takes place in regular prisons: in the period I994-2006 the number of foreign-born prisoners in the Netherlands almost doubled, from 30 September 1994 when there were 4,370 persons, to 30 September 2006 when there were 9,045. ${ }^{\mathrm{I2}}$ This increase had several causes, such as the increased repression of drug trafficking. However, the number of persons in Aliens' Detention also multiplied by more than a factor of six: on 30 September 1994, 425 persons were in Aliens' Detention, on 30 September 2006, 2,555. Comparable developments appear to have taken place, to varying degrees, in other EU countries (Alt I999; EMN 2007; Van Meeteren, Van San \& Engbersen 2008; Van Kalmthout, HofsteeVan der Meulen \& Dünkel 2007) and in the US (Scalia 2002). In Western Europe as a whole there are now more than 200 detention centres for illegal migrants (Broeders \& Engbersen 2007).

Van Kalmthout and Van Leeuwen (2004) have carried out research in two large Dutch institutions for Aliens' Detention: the Tilburg Penitentiary and Ter Apel Penitentiary. They found that the average length of stay in these institutions has almost doubled in recent years, from 44 days in 1995 to 80 days in 2003 (2004: I3). Furthermore, they found that the percentage of successful expulsions, in spite of increased efforts to expel illegal aliens, remained almost unchanged at just under 50 per cent. ${ }^{13}$ Further, Van Kalmthout and Van Leeuwen reported that before detention, a minimum of 29 per cent of detainees had been presented at an embassy or consulate at least once with an eye to expulsion. ${ }^{\text {I4 }}$

Formally, detention in the Aliens' Detention is primarily a tool for expulsion (ACVZ 2002). The state can put an alien in custody until the country of origin supplies a laissez passer, a document with which the alien can return home. By law, detention may be as long as it is reasonable to expect that such a document may be obtained. Meanwhile, the alien cannot disappear into illegality. If all procedures work out as intended, a stay in the Aliens' Detention usually lasts a number of days or weeks. If expulsion is more problematic or eventually impossible, length of stay can increase to more than a year.

The figures by Van Kalmthout and Van Leeuwen correspond with the supposition that Aliens' Detention increasingly functions as a sort of final relief for strongly marginalised illegal migrants. During my own fieldwork in the penitentiary at Tilburg, I found indications of this as well. Several men to whom I spoke turned out to have been in Aliens' Detention more than once. The clergymen and psychologists working in the institution turned out to know some of them quite well from previous stays. Institution staff members also told me that undesirable 
aliens are sometimes put in detention by the police in the big cities during special festivities in town such as Koninginnedag, the nationwide celebration of the Dutch queen's birthday.

Illegal migrants sometimes appear to contribute to this informal relief function. Staff members claimed that detainees - between themselves they referred to them as aliens - sometimes preferred a stay in Aliens' Detention to life on the streets. Reputedly there were even cases where a detainee who had been released because no laissez passer could be obtained, set up camp in the bushes next to the institution. Although most illegal migrants whom I interviewed found Aliens' Detention a difficult and denigrating experience - especially if they had not been apprehended for crimes - some respondents judged it less negatively. An undesirable alien from Iran, who had for years been part of a group of street drug-users in the Amsterdam neighbourhood De Bijlmer, claimed that he sometimes pleaded guilty to offences he had not committed in order to recover in detention from his life on the streets.

These unintended functions of detention reveal similarities with the poorhouses of the past, particularly the earliest variants such as the houses of correction or workhouses. These institutions were characterised by a strong measure of social control and repression (Poederbach I932; Katz I986; Wagner 2005; Van Leeuwen 2000), and these 'police institutions for the poor' (Poederbach I932: 20) also locked up the unemployed who had committed only light offences. An Amsterdam ordinance from I6I3 defines the target group of the houses of correction as follows:

Great crowds of beggars and vagabonds, very lazy idlers, men as well as women who are found here in the City, who steal the alms from the truly deserving, to the burden of the Municipality and its Citizenry, and who usually set out for idleness, noise, gaming, drunkenness, prostitution and other godlessness, for (as has often been found) Spies, Night Robbers and Thieves may hide among them. (Cited in Poederbach I932: 22; translation by author)

The later workhouses were characterised by a higher degree of voluntary residence, and the poor could submit admission requests themselves. Further, a right to absence was increasingly introduced on condition of good behaviour. Later on, detainees even received an elementary salary, whereas all income from their work had previously gone to the institution. Such poorhouses, which were a Dutch invention, existed in many Western countries from the end of the sixteenth century until well into the second half of the twentieth century (Wagner 2005). The transition between the former and the latter poorhouses occurred around the late eighteenth and early nineteenth centuries. 
There are also differences between current detention practices and the poorhouses of the past, but the primary difference is one of ideology. Whereas illegal migrants are officially not prepared for a return to society, although that often happens in practice, a stay in the poorhouses did serve that particular purpose, even if their return often did not occur in the way the establishment imagined it would. After all, labour was mandatory because it was assumed this would correct the behaviour of the poor and teach them to support themselves in decent ways (Foucault I977). But in part because the latter often did not succeed, the poorhouse gradually developed from a reform institution to counteract pauperism into a relief house for the poor (Wagner 2005). ${ }^{15}$ In Aliens' Detention, labour is not mandatory, though in most detention centres such as the one in Tilburg the detainees were given the opportunity to labour if so desired; wages are 2.56 euros per hour (Van Kalmthout \& Van Leeuwen 2004: 80). ${ }^{\mathrm{IC}}$

In sum, a differentiation of poor relief appears to develop in countries of destination, under the influence of international migration and its regulation, leading among other things to a renaissance of old arrangements, which do of course pertain to migrants who come from much greater distances than before; in that sense there appear to be a question of a progressive regression in history, whereby some aspects repeat themselves on a different scale.

The differentiation of poor relief is twofold. First, the arrangements have developed in the shadow of a national welfare state with its slimmed down but still superior social security. Second, these arrangements are multiform themselves. They include softer and harder variants, which also differ in the extent of formalisation and the local or national scale or level at which they are organised.

These developments raise the question of whether such informal types of illegals care will or should be formalised. It would not be the first time that humanitarian ideas and public order considerations among elites had contributed to the granting of social rights to the poor (cf. De Swaan 1988, 1989, I994, I997). This question is the more pressing because, as was argued in the first sub-study, international migration from poorer to richer countries is likely to continue, possibly even in a larger measure. If the number of migrants who receive state permission to settle does not keep up with the actual social demand, while the effectiveness of expulsion policy does not increase, illegal residence will remain prevalent in the Western world, and the social figure of the illegal migrant will then become a permanent fixture. Most illegal migrants will be capable of supporting themselves; nonetheless a subgroup that is very dependent on care will always stand out, particularly if the regular labour and housing market are closed off to it. 
At this point there is already, in various ways, a form of differentiated citizenship in the Netherlands and countries like it. For instance, aliens with residence permits do not have all the political rights that presentday Dutch nationals have, and although foreigners who are citizens of EU member states are free to settle in the Netherlands, if they apply for welfare benefits they lose their residence rights. Illegal migrants have certain elementary rights as well; in the Netherlands they have a right to basic medical care and legal aid, though the outcome of a legal case may be awaited in the Netherlands only in cases of human trafficking, and children without legal residence have a right to education.

Perhaps it will transpire that the revival of old variants of poor relief is in fact a prelude to a further formal differentiation of citizenship. The generally felt need to support illegal migrants and the desire to control the potential threat they represent could lead to a right to elementary relief for certain categories of illegal migrants, for example, people who cannot be expelled. On the one hand, there are evidently problems attached to a right to poor relief and the increase in citizenship differentiation it implies. One snag is that it brings us closer to the pre-industrial class-based society in which birth rather than achievement determined social position. This drawback could perhaps be diminished by granting specific groups of illegal migrants the opportunity eventually to earn a residence permit in case of good behaviour, just like legal migrants may eventually be allowed to become naturalised and acquire full citizenship (cf. Entzinger \& Van der Meer 2004). A second drawback is that poorhouses for illegal migrants should ideally offer only basic relief, and should preferably be introduced in the EU as a whole if they are not to function as magnets for unexpellable illegal migrants in other EU countries.

On the other hand, a case could certainly be made for such a right to elementary relief, and perhaps the later poorhouses could be used as a model for such a right. A number of detention practices for migrants who commit minor residence, subsistence and drug-related crimes could then perhaps be steered in a more humane direction. This would require us to accept that international inequality in an era of intensified globalisation is bound to promote local differentiation of all kinds, including increased local social stratification, irrespective of efforts by governments to control international migration, and also, in part, precisely because of these efforts. 


\section{Notes}

\section{Chapter 1}

I. The term 'Western countries' is widely used in the social sciences (for an example see Andreas \& Snyder 2000), and usually refers to the affluent, industrialised countries in West Europe and North America, plus Australia and New Zealand. In this study the term 'non-Western countries' is used as a proxy to refer to countries whose citizens tend to be subjected to restrictive migration policies. In the period of study this also included a number of countries in Central Europe that were non-EU countries during the research period or part thereof (1997-2005), such as Poland and Romania. The latter countries are often considered Western countries.

2. While the number of non-European illegal migrants has remained fairly constant, the number of European illegal migrants appears to have decreased somewhat recently, since a growing number of Eastern Europeans have obtained residence rights as EU citizens as a result of the EU's enlargements (for the most recent estimations see Van der Heijden et al. 2006).

3. According to Castles and Miller (2003), there are approximately I.5 million first-generation migrants in Italy with a residence permit and approximately 300,000 illegal migrants. While the number of registered first-generation migrants in the Netherlands (+/- I.6 million) more or less equals the number in Italy, there were, as has been said, approximately I50,000 illegal migrants during my research period (I997-2005).

4. See Van Heek (1936) for a marvellous pioneer study on Chinese migrants in the Netherlands. The post-war taboo primarily concerned research that did not only look for socioeconomic explanations in order to account for ethnic differences in offending (see also Maas-De Waal I99I; Van Gemert 1998). See, for example, Saragin (I980) on the post-war sensitivity with regards to studying race and crime.

5. These are, by the way, not necessarily the groups from whom scientists can learn the most. More research should be done comparing immigrant groups with a high and low involvement in crime so as to reduce 'sampling on the dependent variable'.

6. I suspect that research in many countries lags behind because of the greater reserve internationally with regard to the study of crime among migrants and ethnic minorities. An additional reason is that registration practices in the Netherlands, which is a fairly organised, bureaucratised country, lend themselves to scientific research (although my predecessors, particularly Joanne van der Leun, nonetheless had to do a lot of work to make such research possible). In other countries, residence status is often not well documented in police files (McDonald I997).

7. Sometimes the distinction between minor and serious offences is difficult to make in police data on illegal migrants, because at the time of registration the cases have not 
been prosecuted and judged. An incident that is initially registered as a major crime (for instance house burglary) may eventually be prosecuted and judged as a minor crime (for instance simple theft), and the other way around. For this reason my predecessors classified house burglary as a minor crime because theft is, usually, a minor crime in the Netherlands, even if house burglary can be punished with more than four years of imprisonment, even if this is rarely done in practice.

8. According to CBS Statline (http://statline.cbs.nl; visited August 2007) domestic migration in the Netherlands, i.e. rehousing between municipalities, was 642,089 in 2005 . The official international migration from and to non-Western countries was 59,719 (immigration 36,508 and emigration 23,2II). Hence, the ratio between domestic and the latter types of international migration was approximately II:I.

9. The unskilled labour migration in the I960s from countries around the Mediterranean was in this respect rather exceptional, made possible in part by the active recruitment practices by the countries of destination, in regions that were specifically selected for this purpose by the governments of the countries of departure. The Moroccan government encouraged recruitment among the poor Berber population (Van Gemert I998). Chain migration by poorer migrants is often subsidised by established immigrants.

Io. There are a number of exceptions. For instance, Holland received Jewish refugees from Germany in the I930s, although there was an inclination to admit only the wealthier refugees. Actually, a relatively substantial number of poorer Jewish refugees became 'illegal migrants' in Holland in the years before the Second World War (Van Eijl 2005).

II. Two other reasons are mentioned in the literature: first, the decreasing costs of transportation, which enabled longer journeys for larger and larger segments of the population, even in developing countries. The second reason is decolonisation; for instance, Surinam - a former Dutch colony - became independent in I975.

I2. At present the right to leave a country is a human right, although strangely enough this right is not complemented by the right to enter another country.

I3. At present an asylum request is, for instance, recognised only if there is a demonstrable political threat to the applicant. A general threat to a group is no longer sufficient (Lucassen \& Penninx 1997). Moreover, those who are recognised as refugees increasingly receive temporary residence permits (Doornbos and Groenendijk 200I). They become illegal migrants if they stay in the country after the expiration of the temporary residence permit.

I4. In the Netherlands, a housing permit by the local government is required to be allowed to rent almost all cheap rent-controlled accommodation, except for single rooms with shared kitchen and toilet facilities. Applications for a housing permit are rejected if the applicant lacks a residence permit. After the introduction of the Linking Act it is easy for local governments to verify whether or not an applicant has a residence permit.

I5. Dutch Bureau for Statistics (http://statline.cbs.nl; visited May 2007).

I6. Medical practitioners sometimes put medical ideals before the stipulations of legislators, while teachers who admit talented illegal youngsters to schools sometimes put pedagogical and humanitarian ideals before immigration policy.

I7. Foreigners who stay in the Netherlands for three months or less do not have to add their names to the official register of births, marriages and deaths. The registrations in the VAS, on which this study is in part based, are not dependent on the register of births, marriages and deaths.

I8. A very small minority of illegal migrants were born with this status and thus had no influence over their classification as illegal aliens. However, many illegal migrants initially came to the Netherlands or another Schengen country with a tourist visa and/or initially resided legally in the Netherlands for another reason, while requesting asylum for example. 
I9. Undesirable aliens can be prosecuted and imprisoned for six months each time they are found in the Netherlands within the period laid down (five or ten years). See also Chapter 6.

20. See for instance the pronouncements by Jaap Blokker (one of the owners of Blokker, a Dutch chain of general goods stores): 'Illegalen roven winkels leeg' ('Illegals plunder shops'), which was published in the national newspaper de Volkskrant on 26 July 2003.

2I. In January 2007 the fourth sub-study ('I am just trying to live my life') was presented at the Nieuwspoort press centre in The Hague, together with two other studies on asylum migration and crime (De Boom, Engbersen \& Leerkes 2006; Althoff, De Haan \& Miedema 2006). A number of representatives of national political parties were present.

22. The proper legal term in the Netherlands is 'staandehoudingen'. When the police stop someone, it is a staandehouding. This does not necessarily lead to an arrest, which involves deprivation of liberty. For illegal migrants, however, registered stops will usually end in an arrest. In addition, the distinction between apprehension and arrest is not really reflected in everyday language. Therefore the terms apprehension and arrest are used interchangeably in this study.

\section{Chapter 2}

I. Of all apprehensions, 52 per cent lack a registered residential address. In approximately 20,000 of these cases it is likely that the apprehended immigrants concerned did not yet have residential addresses in the Netherlands because these apprehensions took place at ports, airports, state highways and train stations, were carried out by the military police who control the border, or happened on the registered day of arrival in the Netherlands. If these apprehensions are left out of consideration, the percentage of missing values decreased from 53 to 42 . Police stations have been identified with the help of the Internet. In order to check whether the registered home addresses described the place of apprehension rather than the place of residence, a sample of $\mathrm{I}, 500$ was taken from the data. In 38I cases, the residential address was equal to the place of apprehension. However, these are not necessarily invalid registrations because at least 74 of the 38I cases pertain to centres for asylum seekers, brothels, companies and market gardens. It may well be that the arrested immigrants actually resided where they were apprehended. The analyses in the first part of the chapter, i.e. at the level of municipalities, are based on 28,857 apprehensions. The analyses at the neighbourhood level are based on 23,775 apprehensions.

2. Cruyff and Van der Heijden (2004) reported separate estimates for provinces and police districts of the four biggest cities. These estimates are based on the place of apprehension (and not, as is the case in this chapter, on the registered residential addresses). For the year 2002, we compared their estimates with the number of apprehensions in our database. For nearly all provinces, the number of apprehensions equals between 9 and II per cent of the estimated total number of illegal migrants. Only the province of Utrecht deviates (5 per cent). This suggests that there are no substantial geographical differences in risk of arrest between urban and rural areas. When police regions in the big cities were compared, I found that the risk of arrest appears to be elevated somewhat in Amsterdam (I5 per cent).

3. The Dutch Bureau for Statistics (CBS) uses the following definition of a non-Western immigrant: an immigrant is 'non-Western' if he or she was born in Turkey, Africa, Latin America or Asia with the exception of Indonesia and Japan. An inhabitant is counted as a second-generation immigrant if at least one of the parents is born abroad. In principle, the mother's country of birth determines whether such inhabitants are counted as 'Western' or 'non-Western'. If the mother's country of birth is the Nether- 
lands, than the father's country of birth determines this. Figure 2.3 includes first- and second-generation immigrants from non-Western countries. CBS excludes Indonesia and Japan from the rest of Asia for differing reasons. Indonesia is excluded because a substantial number of older Dutchmen were born there to Dutch parents in colonial times. Japan is excluded for it is considered a highly industrialised country. Of course, the latter raises the question of when China and India are to be excluded (!). All in all, CBS statistics appear to provide ethnic data based on country of origin without directly measuring ethnicity: in a number of recent studies CBS has even published a number of studies on third-generation immigrants because there was a demand by researchers and policy makers to get data on these mostly young people. Direct measurements of ethnicity were abandoned in the I970s for political reasons. It seems that 'objective criteria' such the countries of birth of parents and grandparents are considered less problematic. Personal communication by the CBS confirmed that the organisation tries to approximate 'social categories that are discerned in Dutch society at large'.

4. The measure for the relative concentration of illegal residence shows a rather skewed distribution; ten 'outliers', i.e. neighbourhoods where the relative concentration is more than three standard deviations higher than the average, have therefore been excluded from the analyses. This did not affect the statistical significance of the analyses, as the total number of urban neighbourhoods is more than I,200 (see Table 2.2).

5. Next to the proportion of single persons, two additional neighbourhood characteristics had a significant effect on the concentration of illegal migrants - the average size of families and the percentage of families with children. Both variables are, however, strongly correlated with the other independent variables (particularly with the percentage of non-Western immigrants). For statistical reasons ('collinearity') these variables could not be included in the model. The 'effect' of both variables is probably merely due to the effect of the percentage of non-Western immigrants.

6. It is difficult, however, to isolate the effects of the presence of legal, non-Western immigrants from the effects of the socioeconomic status of the neighbourhoods, for ethnic segregation is, in part, due to ethnic group differences in income (see Farley I99I: 288). The standardised effect of the socioeconomic status of the neighbourhoods diminished from -0.34 , when the concentration of illegal migrants is only predicted with the value of the housing stock and the average income of the residents (not shown in Table 2.2), to - 0.07 when the share of non-Western immigrants was controlled for (see the second model). Furthermore, it is possible that a small number of illegal migrants live in upmarket areas - for instance, domestic workers (see Mahler I995 on this topic for the US). We did not, however, find indications for this in the Dutch police data. In the Netherlands, with its cultural taboos on sharp class divisions, domestic workers do not usually live with their employers. It is also easier to find more suitable accommodation in cheaper areas at an acceptable travel distance from the workplace in the Netherlands since neighbourhoods are smaller and the rate of income segregation is substantially lower than in the US; in Dutch neighbourhoods, cheap and expensive blocks are located much closer to each other than in the US.

7. The standardised effect drops from 0.29 , when the concentration of illegal migrants is predicted only on the basis of the percentage of single residents, to 0.24 when the percentage of legal, non-Western immigrants is added to the model, to 0.20 in the fifth regression model.

8. Additional information was obtained on twelve neighbourhoods for which the model does not accurately predict the number of registered illegal migrants (these neighbourhoods are highlighted in Figure 2.7). It turns out that such anomalies can be quite well explained and do not contradict the theoretical approach. Neighbourhoods with more illegal migrants than predicted are either being used as prostitution areas, or house (or have in their vicinity) centres for asylum seekers or market gardens. No suitable statistical data could be found on these aspects of the first and third dimensions of the 
spatial opportunity structure for illegal migrants, i.e. the presence of compatriots in centres for asylum seekers and the opportunities for illegal labour in prostitution areas. Neighbourhoods with fewer registered illegal migrants than predicted were mainly found in Amsterdam and Rotterdam (where the home addresses of illegal migrants are not very accurately recorded), or were affluent districts with many single people and much private homeownership. If we had had data on the concentration of single people with low incomes and private ownership of inexpensive houses, we would probably have predicted the concentration of illegal migrants for these neighbourhoods more adequately. If the twelve highlighted neighbourhoods are left out of consideration, the model's explanatory power increases from 50 to 60 per cent. The remaining unexplained variance, which is never zero in cases of empirical research, probably points to similar measurement errors, or to unmeasured variables such as the presence of churches, psychiatric clinics and institutions for the homeless. These institutions sometimes house illegal migrants, particularly those who are unemployed and have no supportive network of family and friends (the 'floating population').

\section{Chapter 3}

I. Secondary analyses based on estimates by Cruijff and Van der Heijden in Leerkes et al. (2004) show that the annual risk of arrest for criminal illegal migrants is I3 per cent, against 6 per cent for non-criminal illegal migrants. Because the probability that an address is recorded in the VAS is lower for criminal ( 20 per cent) than for non-criminal (33 per cent) migrants, criminal illegal migrants are on average 30 per cent more likely to enter our neighbourhood measure of illegal residence. This will not greatly bias the estimates, because the majority of the illegal migrant population is not involved in crime (in about half the cases illegal residence is the sole reason for arrest). In addition, criminal and non-criminal illegal migrants tend to live in the same neighbourhoods.

2. The eigenvalue of the factor is I.53. Both variables have factor loadings of .87 on the factor; the correlation between the variables is .53 .

3. These six factors have the following eigenvalues (item factor loadings in parentheses) of 2.18 (factor loadings .66, .73, .57, .54, .77), 2.05 (factor loadings .68, .79, .75, .62), I.7I (factor loadings .7I, .60, .60, .72), 2.54 (factor loadings .62, .74, .73, .76, .70), I.5I (factor loadings .72,.64, .76) and I.8I (factor loadings .74, .61, .68, .60).

\section{Chapter 4}

I. Asylum seekers, for instance, are as a rule not allowed to work and cannot apply for unemployment benefits, but do receive board, lodgings and some 'pocket money'. Labour migrants may, of course, work and as a consequence are entitled to the social arrangements that are linked with it. Foreigners admitted to the Netherlands because of family formation or family reunification usually have the right to work, and have a right to concomitant social arrangements when they loose their jobs or become ill. As a rule, however, they cannot apply for unemployment benefits that are not related to work.

2. Kehla (in Engbersen I999) and Zaitch (2002) had already done some work in this direction.

3. I selected countries from which the total number of legal migrants, aged eighteen to 25, was greater than I,000. 
4. A hypothetical example can illustrate the adjustments made. Suppose Kromhout and Van San had counted a Ioo suspects from a particular country of origin, 80 of them legal migrants and twenty illegal. Kromhout and Van San could not distinguish between them with certainty using HKS. Suppose that out of these twenty illegal migrants, ten told the police they resided in the Netherlands but concealed their precise residential addresses, five told the police they resided in the Netherlands and disclosed their addresses, and the remaining five told the police they did not reside in the Netherlands. In this case, Kromhout and Van San would report 95 'legal' suspects (i.e. Ioo5), data adjustment A would lead to 75 'legal' suspects (twenty illegal migrants would be subtracted from the number of 'legal' immigrants reported by Kromhout and Van San), and adjustment B would lead to 9o 'legal suspects' (only the five illegal migrants who disclosed their residential addresses would be subtracted from the 95 'legal' suspects reported by Kromhout and Van San). In this example, the actual number of legal migrants (80) would be between data adjustment A (75) and data adjustment B (90).

5. Crime involvement varies with age. It tends to rise from twelve up to eighteen or nineteen years, and then slowly declines (cf. Gottfredson \& Hirschi I990). To control for this correlation, age should be held constant (particularly because the share of minors may vary between ethnic groups and between legal and illegal migrants). The alternative would be to present separate figures for legal and illegal migrants aged twelve to eighteen. This would not make sense, however, because few illegal migrants are minors in Holland.

6. This is not the same as the average number of suspects in 1999 and 2000 divided by the average size of the population, multiplied by 100.

7. The data presented by Kromhout and Van San do not allow a specification according to sex and age at the same time. In the relevant age category (eighteen to 25 years of age), they do not present separate data on police registrations of male and female youngsters.

8. Ethnic crime patterns tend to be fairly constant within a time span of a few years (cf. Van San \& Leerkes 200I).

9. This may constitute an underestimation of the actual number of illegal migrants from Morocco. Some illegal migrants from Morocco tell the police they were born in Algeria, because this obstructs their deportation from the Netherlands. Note, however, that this does not necessarily mean that the prevalence of crime among illegal Moroccans was underestimated, for it is a relative measure. It was only underestimated in as far as criminal illegal Moroccans lie about their country of birth more often than non-criminal illegal Moroccans did.

Io. 'Crimes' refers to apprehensions in three categories usually distinguished by Engbersen et al. as 'minor offences', 'serious offences' and 'drugs'. See also Chapter 6.

II. The self-reporting of offences has many drawbacks as well (cf. Junger I990) and it would be nearly impossible to obtain access to criminal illegal migrants without police assistance. Judicial data on convicted offenders may also be biased. For instance, the percentage of suspects who are summoned to court may differ per ethnic group because of group differences in the willingness and/or ability to pay financial settlements (De Leng \& Hille I99I).

I2. Type of crime committed correlates with age (with more vandalism and less violence among minors). See also notes 5 and 17.

I3. This calculation was made for the total number of offences committed by offenders from the eight ethnic groups for which the 'quality' of criminality is specified. Hence, Cramer's V was derived from a $2 \times 9$ cross-tabulation, i.e. residence status by type of offence.

I4. Note that Cramer's V, calculated per ethnic group, correlates negatively with the respective crime rates among legal migrants which were depicted in Table 4.I: from $\mathrm{r}=-0.67$ $(p<0.07)$ with adjusted crime rate A to $\mathrm{r}=-0.8 \mathrm{I}(\mathrm{p}<0.02)$ with the unadjusted crime rate. 
Hence, the chance of illegal migrants' crime involvement being limited to the use of false documents, and not extending to other offences, appears to rise as the crime involvement in the ethnic group as a whole decreases.

I5. Without False Documents the unweighted correlation coefficients in Figure I are 0.53 $(\mathrm{p}<0.09), 0.58(\mathrm{p}<0.06)$ and $0.55(\mathrm{p}<0.08)$ for the initial data and data adjustment A and B. Similarly, without False Documents and without Surinam the unweighted correlation coefficients are 0.79 ( $\mathrm{p}<0.0 \mathrm{I}), 0.77$ ( $\mathrm{p}<0.0 \mathrm{I})$ and 0.78 ( $\mathrm{p}<0.0 \mathrm{I})$. Without False Documents the weighted correlation coefficients are $0.4 \mathrm{I}(\mathrm{p}<0.2 \mathrm{I}), 0.40(\mathrm{p}<0.22)$ and 0.43 (p<0.19). Without False Documents and without Surinam the weighted correlation coefficients are $0.92(\mathrm{p}<0.00), 0.88(\mathrm{p}<0.00)$ and $0.93(\mathrm{p}<0.00)$.

I6. For similar findings about the market for stolen telecom services in Australia see Grabosky and Smith (2001: 30).

I7. As can be seen in Table 4.5, the diminished share of violence cannot be due to the deviant age composition of the illegal population, with fewer adolescents, since similar patterns prevail among illegal offenders aged twelve to eighteen and eighteen to 25 .

I8. In the Netherlands, approximately half of all apprehensions of illegal migrants do not result in deportation. Either non-deported illegal migrants manage to conceal their identity, or their countries of origin decline to cooperate (Engbersen et al. 2002).

I9. Most foreigners from non-Western countries need such an invitation if they want to reside in the Netherlands for more than three months (this is called a Machtiging Voorlopig Verblijf or MVV). The Dutch authorities link several financial responsibilities to such an invitation.

\section{Chapter 5}

I. The actual situation is somewhat more complex. Rejected asylum seekers only become illegal migrants within this term of four weeks if an appeal against the decision is impossible, or if the asylum seeker is given leave to appeal but does not have the right to reside in the Netherlands while awaiting the decision.

2. The state sometimes does not realise the possibility for repatriation immediately. It may also be that the asylum seeker cannot leave because (s)he is stateless or because the country of origin does not furnish a laissez passer, or because (s)he refuses to leave because of a lack of prospects in the country of origin, fear for prosecution in so far as the asylum request has been rejected undeservedly, migration debts, etc. The migrant can also hinder expulsion by keeping silent about his or her true identity.

3. The heightened involvement of North Africans in this street trade can partly be explained by the increasing unemployment rate among former guest workers, chain migrants and their offspring. Unemployed Moroccans will have become well informed about Dutch street life. The wholesale business is more often conducted by Turks, Latin Americans and Dutch nationals (Bovenkerk 200I). North Africans have limited access to hard drugs in their region of origin.

4. The clergymen estimate that 80 per cent of the detainees attend the services. Religion supports many detainees during detention. Others attend the services as an outing. The services were probably a good place to recruit respondents because they are a space that the men can appropriate to a certain degree. They can express a shared cultural/spiritual identity which helps to put the earthly detention regime into perspective, and experience a certain collective power vis-à-vis the institution. The guards kept a certain distance; some detainees read out loud from the Bible.

5. The interpreters were: a female Russian interpreter for Russian, a male MoroccanDutch interpreter for French-Arabic and a female Dutch interpreter for Serbo-Croatian. On two occasions a telephone interpreter was used via the Ministry of Justice. One 
respondent's Dutch language skills were lower than expected and with another respondent the interpreter was ill during an interview. The Serbo-Croatian interpreter was found through the internet, the remaining interpreters via my personal network.

6. Applicants for asylum are allowed to remain in Holland, but may not travel freely between countries. In addition, they do not have a right to a Dutch driver's license for scooters or automobiles. Unlike illegal migrants, asylum seekers receive housing and allowances for food and clothing (for some rejected asylum seekers this was also true in some cases). However, these allowances amount to no more than 40 euros per week. Asylum seekers are allowed to work, but no more than twelve weeks a year. In addition, it is probable that differences in deprivation according to residence status are partly cancelled out by differences in punishment. Illegal migrants risk detention in Alien's Custody (sometimes for more than a year at a time) and expulsion, whereas criminal asylum seekers tend to get a fine, alternative sentences or a prison sentence.

7. In addition, a visa application requires time and contact with government bodies. These requirements may be particularly problematic for refugees - and almost all the men (23 out of 26) considered themselves as such.

8. For this reason I used the term 'bestaanscriminaliteit' in the original Dutch version of this text. It translates as 'existence crime'. 'Livelihood crime' might also be an appropriate term here.

9. Staring (200I: I84), for instance, reported that the Turkish illegal migrants he interviewed had mostly been detained for violence (the interviews were not about crime). Violence is also relatively common among legally resident Turkish migrants, for instance in connection with honour vengeance (see Chapter 4).

Io. Two men destroyed property during fits of anger as a result of taking the law into their own hands (K and $\mathrm{M})$. The other case in which goods were destroyed $(\mathrm{X})$ was a failed car burglary (drug-related crime).

II. The social class background of the long distance 'illegal pioneers' who were interviewed for this sub-study was certainly not low. This may be, in part, a consequence of the regulations governing migration which, though privileging higher income groups when granting tourist visas, primarily raise migration costs for people who do not meet the official criteria and are not helped by established residents to settle clandestinely, for instance, with tourist visas. See Chapter I.

I2. The Afghan respondent stated that he used to distil liquor, which was punishable under the Taliban administration. He claimed he was detained for it, but escaped when he was sentenced to an Islamic re-education camp.

I3. The hysteresis effect (Bourdieu I977), in which systems - in this case the habitus - do not immediately react to forces that are exerted on them, may help us understand why serious crime problems usually do not occur among poor migrants, but rather among their children (Tonry 1997).

I4. It also seems that relational embeddedness does not necessarily imply social capital.

I5. In 2003 I2 per cent of the apprehensions because of crime concerned a serious offence, i.e. an offence with a maximum punishment of at least four years in prison (undesirable aliens are not counted in this figure, see Leerkes et al. 2004: 27). These offences are usually violent crimes. Furthermore, a significant proportion of illegal migrants who are recorded as having committed violent crimes are legal migrants who were declared illegal migrants because of criminal activities (as undesirable aliens or because of the application of the sliding scale, see Chapter 6). 


\section{Chapter 6}

I. Section 67 Aliens Act 2000 and Section 197 Criminal Law.

2. For illegal migrants it is sufficient if the person resides illegally in the Netherlands and has repeatedly violated a stipulation in the Aliens Act that is punishable as a misdemeanour (for instance not leaving the Netherlands after admission has been refused), or if the person is believed to be a threat to public order or national security (in which case no conviction for a crime is necessary).

3. According to Article 8 of the European Convention on Human Rights (Rome, 4 November 1950), migrants legally residing in a country have a right to maintain a family life there, which obviously clashes with the implications of a being an undesirable alien. Such migrants may still make short visits to the Netherlands, even if continued settlement is regarded as illegal residence.

4. Some 'undesirable aliens' are criminally active illegal migrants who never had a legal status. In theory it is possible that the chances of such illegal migrants leaving the country increase because of being turned into 'undesired aliens'. However, there is no empirical evidence for such an effect. If they stay, they can be imprisoned for six months in case of re-apprehension. But many illegal migrants spend long periods in Aliens' Detention anyhow, officially with an eye to repatriation. Furthermore, it is probable that such migrants constitute a minority of the undesirable aliens (see note 8 of this chapter).

5. Between 1999 and 2002 the total number of police officers increased from 40,000 to about 47,000 (Ministry of Justice 2005: 127).

6. See note 7 in Chapter I. Formally, house burglary is not a minor crime, but my predecessors had good reasons to classify it as a minor crime nonetheless.

7. The category 'property crimes' is taken as an indicator for subsistence crime and addiction-related crime and is therefore defined in a broad sense; it includes property crimes with a violent component (although the latter are relatively rare among illegal migrants). It entails: 'theft', 'theft with burglary', 'theft with violence', 'conning', 'extortion', 'receiving', 'counterfeiting' and 'embezzlement'. Theft and theft with burglary make up the large majority of the cases in this category (about 80 per cent).

8. The IND data did not lend themselves to a neat distinction between undesirable aliens who were illegal migrants to begin with and undesirable aliens who initially had a residence permit. Nonetheless, it is probable that former legal migrants constitute a majority of the cases. In only I 45 of the cases do the IND entries mention 'illegal residence' among the reasons for declaring a person an undesirable alien between 1997 and 2003, mostly in addition to convictions for crimes. This may be an underestimation of the actual number of reclassified illegal migrants, as only the most serious reasons (i.e. felonies) for declaring a person an undesirable alien may have been registered. The IND system allows for the registration of three reasons. However, it is not likely that illegal migrants constitute the majority of the persons who become undesirable aliens. Legal migrants outnumber illegal migrants in the total Dutch population by a ratio of Io:I (also see Chapter I).

9. According to the police, this principle was somewhat less strictly adhered to in the I990 than it is today. However, this possible bias does not weaken the argument. On the contrary, it makes the argument stronger. Assume that in the first years of the research period (I997-2000) a higher number of illegal migrants were registered in the VAS under more than one name and foreigner number than in the later years of the research period (200I-2003). In that case, this study overestimates the number of crime suspects with illegal residence status in a higher measure for the first years under study than for the later years because of double counts. This would mask the real rise in crime between 1997 and 2003. Moreover, similar results were obtained when the analyses were done on the level of the apprehension. 
IO. If a person is arrested at the border, the arrival date is self-evident. If, on the contrary, an illegal migrant had been living in the Netherlands for some time before the apprehension, the police will depend more often on what the arrestee is willing to tell them about the date of entry. In such cases it is more likely that no date of entry will be registered, because the arrestee may not report it or the conveyed information is deemed unreliable. Finally, analysis of the missing values revealed that such apprehensions are connected to somewhat different types of crimes than what turns out to be characteristic for criminal migration.

II. CBS Statline (statline.cbs.nl). These figures include first- and second-generation migrants.

I2. The contribution of the four largest cities (Amsterdam, Rotterdam, Utrecht and The Hague) to the total number of apprehensions in the VAS, for crimes and other reasons, dropped from 45 per cent in I997 to 4I per cent in 2003. After control 3a, the crime index for 2003 for the four cities was 150 , for the other regions 164 .

I3. While the crime index for 2003 decreases as a result of this final control, $\mathrm{N}$ increases; the total number of additional crime suspects would have been somewhat higher because of marginalisation effects than has actually been the case, if the size of the illegal population had not dropped and then risen, but had remained constant since 1997.

I4. The relative increase between 1997 and 2003 is I3I (23I-I00). Of this, status reclassification appears to explain 8 (23I-223), criminal migration 29 (223-194), general developments in crime finding and registration 38 (I94-156) and demographic growth I9 (I56I37). The size of these contributions should be taken as approximations, also because the order of the controls influenced the outcomes to some extent.

15. The increase is 37 per cent (I37 vs. IOO) if it is assumed that all crime suspects remaining after control $5 \mathrm{~b}$ can be explained by the marginalization thesis. The increase is higher if it is assumed that these remaining crimes have, in part, other backgrounds that are unconnected to state policies (such as 'honour violence'). For instance, the increase is 48 per cent if it is assumed that in every year 500 crime suspects offended because of such reasons $((3079-500) /(2246-500)=1.48)$.

I6. In the period 1994-2006 the number of foreign-born prisoners almost doubled in the Netherlands: on 30 September 1994 there were 4,370 persons, whereas on 30 September 2006 this has risen to 9,045.2I. The increase has several causes, such as the heightened repression of drug trafficking in general. However, the number of persons in Aliens Custody multiplied by more than a factor of six in this period: on 30 September I994, 425 persons were in Aliens Custody; on 30 September 2006, 2,555 (Statline (http://statline.cbs.nl), online data by the Dutch Bureau for Statistics; visited June 2007).

\section{Chapter 7}

I. The strain mechanism provides an explanation for only a part of residence crimes, such as making use of a people smuggler or using false IDs: in these cases the offender adapts his or her behaviour in the face of strain. These forms of residence crime can be contrasted with 'nominal' residence crimes such as staying in the country as an undesirable alien. In the latter case rule violation is not an adaptation to strain, but becomes merely defined as a rule violation.

2. My principle source of inspiration has been Griffith and Weyers' approach (2005), which goes back to a considerable extent to an article by Moore (I973). Furthermore, I am indebted to Hannerz's ideas (I992) about cultural complexity and globalisation. According to Hannerz the outcomes of globalisation differ from place to place because 
global trends (which translate here as governmental migration regimes) are in constant interplay with local conditions (read: social ties).

3. One of Sayad's (2004) Algerian respondents, who had a temporary residence permit in France, phrased it poetically: 'naturalisation is a vaccine against deportation'.

4. It is not the case, by the way, that all illegal migrants aspire to an integrated position; some come only with the expectation of a temporary stay (see Chapter 3 ). In addition, illegal migrants without social ties can also become attached to residence in the Netherlands. In that case the tie is more of a psychological nature than sociological. Hirschi's (1969) social control theory relates to both types of ties.

5. (I) A tie with the established society seems to produces stronger status expectations as well as to provide the conventional means to live up to these expectations. If this were not the case, we would have no good explanation for the low crime rate among Turkish and Chinese illegal migrants. (2) In some migrant groups crime is quite prevalent, particularly among young men (see Van San and Leerkes 200I). However, among adults a relatively small minority is involved in crime with any frequency. Annually, approximately 2 per cent of the registered population is recorded as a crime suspect (Chapter 6). Illegal migrants discovered committing crimes have an average age of 30 years (Engbersen et al. 2002). (3) Illegal residence status constitutes a major handicap to criminal cooperation. In criminality as well, illegal migrants tend towards a marginal position. After all, even if there is no evidence that could lead to conviction, the first police contact can lead to detention and expulsion because of illegal residence or to status reclassification as an undesirable alien. In addition, illegal migrants cannot start a company that can serve as a front for criminal activities such as wholesale drug trade (Zaitch 2002).

6. A simple numerical example can clarify this. Assume that approximately 8 per cent of the 150,000 illegal migrants commit crimes (the number of registered suspects is probably an underestimation of the real number). On the one hand, the number of delinquent illegal migrants would remain the same if a more lenient policy with respect to illegal residence doubled the number of illegal migrants to 300,000 , while the crime rate halved to 4 per cent. On the other hand, the number of criminal illegal migrants could increase in spite of the more lenient policy with respect to illegal residence, if the crime rate decreased by less than 50 per cent, for example, because the conventional life chances for illegal migrants also decreased under the influence of their increasing numbers.

7. While a number of illegal migrants who now come to the Netherlands 'under direction' (Staring 200I) would try to migrate on their own initiative, others would abandon migration. Furthermore, it is possible that some illegal migrants lose their ties - which apparently were not very strong, in that case - while residing in the Netherlands, for instance because a relationship with a partner ends. Nothing is known about the magnitude of such effects.

8. For instance, Bovernkerk (I978: I47) reports that, according to the Amsterdam police, first generation Moroccan migrants - most had temporary residence permits at the time - were characterised by their docile behaviour when dealing with the police. Now, 30 years later, urban sociologists describe second-generation street youths of Moroccan origin - most have Dutch citizenship or permanent resident permits - as very assertive and provocative (De Jong 2007).

9. Repeated detentions may be a risk factor for crime involvement, because it promotes differential association with other offenders and may lead to deviance amplification.

Io. These observations are based in part on information from a key informant who works at the foundation Landelijk Ongedocumenteerden Steunpunt ('National Support Point for the Undocumented').

II. According to VAS data, for the period 1997 to October 2003, one out of every five apprehensions of an undesirable alien led to an expulsion. In cases of illegal aliens 
apprehended for illegal residence, about 42 per cent resulted in an effective expulsion. In cases of serious offences it was 33 per cent and for minor offences, 39 per cent. For drug offences the percentage was relatively high (47 per cent), probably because these often involve apprehensions at Schiphol Airport, where there is less uncertainty about the country of origin. The figures mentioned are indicative. In approximately one-third of cases there is no information on possible expulsion. It may also be, incidentally, that delinquent aliens obstruct expulsion more effectively by using aliases.

I2. CBS Statline (http://statline.cbs.nl), visited August 2007. The number of detainees who were born in the Netherlands, including second generation migrants, also increased in the period mentioned. As a consequence the percentage of foreign-born detainees did not increase as sharply as the absolute numbers, but rose from 50 per cent to 56 per cent.

I3. For 2003 the percentage of expulsions from the Penitentiaries at Tilburg and Ter Apel via Schiphol Airport was 33 per cent. A further 2 per cent of the detainees in that year were transferred to foreign authorities in surrounding countries. In 2002 these figures were 42 per cent and 3 per cent, respectively, and in 199544 per cent and 2 per cent (Van Kalmthout \& Van Leeuwen 2004: I3, 24).

I4. Van Kalmthout and Van Leeuwen (2004: 60). The authors base this on the checklist used by the government to record information about the alien, filled in by the local aliens police. Out of 329 respondents who were researched by Van Kalmthout and Van Leeuwen, 95 respondents (29 per cent) had been previously presented, thirteen respondents (4 per cent) had not and there were no data available for 22I respondents ( 67 per cent).

15. The least productive workers remained dependent on the poorhouse much longer than the more productive ones, who often found work elsewhere if economic conditions improved. In addition, many of the poor seem to have availed themselves of the opportunities offered by the institution in strategic ways, for example, by using it as temporary relief centre in winter.

I6. One reason why labour is not mandatory is that it is rather costly to organise working facilities in detention centres. In the Aliens' Detention in Tilburg there was a work facility for illegal migrants. The unit closed down in 2007 when a number of alternative locations for Aliens' Detention became available in the West of the Netherlands, i.e. closer to the embassies in The Hague, including a remarkable number of detention boats. The use of boats may also be meant to symbolise the government's wish that the migrants who are detained there leave the Netherlands. 


\section{References}

Aalberts, M. (I990), Politie tussen discretie en discriminatie [Policing between Discretion and Discrimination]. Arnhem: Gouda Quint.

Advies Commissie Vreemdelingen Zaken (ACVZ) (2002), Vreemdelingen in bewaring [Aliens in Detention]. The Hague: ACVZ.

Advies Commissie Vreemdelingen Zaken (ACVZ) (2005), Openbare orde en verbl fsbeëindiging: Advies over het vreemdelingrechtel $k$ openbare orde-beleid en de toepassing van de 'gl dende schaal' als maatstaf voor het intrekken van de verbl fsvergunning van in Nederland verbl vende vreemdelingen [Public Order and Residence Termination: Advice on the Public Order Policy and the Use of the 'Sliding Scale' as a Criterion for the Withdrawal of the Residence Permit of Aliens in the Netherlands]. The Hague: ACVZ.

Agnew, R. (I992), 'Foundation for a General Strain Theory of Crime and Delinquency', Criminology 30 (I): $47-87$.

Alt, J. (I999), Illegal in Deutschland. Forschungsproject zur Lebenssituation 'illegaler' Migranten in Leipzig [Illegal in Germany. Research Project on the Life Situation of 'Illegal' Migrants in Leipzig]. Kalsruhe: Von-Loeper Literaturverlag.

Alt, J. (2003), Leben in der Schattenwelt: Problemkomplex Illegale Migration [Life in the Shadow World: Problems of Illegal Migration]. Karlsruhe: Von Loeper.

Althoff, M., W. De Haan and S. Miedema (2006), Criminaliteitspatronen en carrières van asielzoekers [Crime Patterns and Careers among Asylum Seekers]. Apeldoorn: Police and Science.

Anderson, B. (2000), Doing the Dirty Work? The Global Politics of Domestic Labour. London: Zed Books.

Anderson, E. (I999), Code of the Street: Decency, Violence, and the Moral Life of the Inner City. New York: Norton.

Anderson, N. (I967 (I923)), The Hobo: The Sociology of the Homeless Man. Chicago: The University of Chicago Press.

Andreas, P. and T. Snyder (eds.) (2000), The Wall around the West: State Borders and Immigration Controls in North America and Europe. Lanham: Rowman \& Littlefield Publishers.

Angel-Ajani, A. (2003), 'A Question of Dangerous Races?’, Punishment Q Society 5: 433-448.

Anthias, F. (I990), 'Race and Class Revisited. Conceptualising Race and Racisms', Sociological Review 38: 19-42.

Bade, J. (2003), Legal and Illegal Immigration into Europe: Experiences and Challenges. Wassenaar: NIAS.

Bade, J. (2004), 'Legal and Illegal Immigration into Europe: Experiences and Challenges'. European Review I2: 339-375.

Bauman, Z. (2003), Liquid Love: On the Frailty of Human Bonds, Cambridge: Polity.

Bauman, Z. (2004), Wasted Lives: Modernity and its Outcasts, Cambridge: Polity.

Beck, U. and E. Beck-Gernsheim (2002), Individualization: Institutionalized Individualism and its Social and Political Consequences, London: Sage. 
Beke, B., H. Van Wijk and H. Ferwerda (2000), Jeugdcriminaliteit in groepsverband ontrafeld: tussen rondhangen en bendevorming [Groupwise Youth Delinquency Analysed: Between Hanging Around and Gang Formation], Amsterdam: SWP.

Bellair, P. (I997), 'Social Interaction and Community Crime: Examining the Importance of Neighbor Networks', Criminology 35: 677-703.

Benoit-Smullyan, E. (I944), 'Status, Status Types, and Status Interrelations', American Sociological Review 9: I5I-I6I.

Benyon, J. (I996), 'The Politics of Police Co-operation in the European Union', International Journal of Sociology of Law 24: 253-279.

Bernasco, W. and F. Luykx (2003), 'Effects of Attractiveness, Opportunity and Accessibility to Burglars on Residential Burglary Rates of Urban Neighborhoods', Criminology 4I: 98I-IOO2.

Berreman, G. (I960), 'Caste in India and the United States', American Journal of Sociology 66: I20-127.

Bigo, D. and E. Guild (2005), Controlling Frontiers: Free Movement into and within Europe. Aldershot: Ashgate.

Billings, A. and R. Moos (I98I), 'The Role of Coping Responses and Social Resources in Attenuating the Stress of Life Events', Journal of Behavioral Medicine 4 (2): I39-I57.

Black, D. (I978), Dispute Settlement by the Police, New Haven: Yale University Press.

Blok, A. (200I), Honour and Violence, Cambridge: Polity Press.

Blok, H., Botman, S., Van Kempen, R. et al. (2000), Comparative Statistical Analyses at National, Metropolitan, Local and Neighbourhood Level - The Netherlands: Amsterdam and Rotterdam. Amsterdam: Urbex.

Blokland, A. 2005. Crime over the Life Span - Trajectories of Criminal Behavior in Dutch Offenders, Leiden: NSCR.

Blom, M., J. Oudhof, R. Bijl, and B. Bakker (2005), Verdacht van criminaliteit: Allochtonen en autochtonen nader bekeken [Suspected of Crime: Allochtones and Autochtones Further Examined], Voorburg, The Hague: CBS / WODC.

Boekhoorn, P., T. Speller and F. Kruijssen (2004), Operationeel toezicht vreemdelingen; Evaluatie van de bevoegdheden in de Vreemdelingenwet 2000 voor het vreemdelingentoezicht door de politie [Operational Supervision of Aliens: Assessment of Alien Law 2000 for the Supervision of Aliens by the Police], The Hague: Boom Juridische Uitgevers.

Boerman, F., W. Van Tilburg and M. Grapendaal (2003), Landelijke criminaliteitskaart 20002001. Aangifte- en verdachtenanalyse op basis van HKS gegevens [National Crime Map 2000-200I. Reporting and Suspect Analysis on the Basis of HKS Data], Zoetermeer: KLPD.

Bolt, G. and R. Van Kempen (2002), 'Moving up or Moving Down? Housing Careers of Turks and Moroccans in Utrecht, the Netherlands', Housing Studies I7(3): 40I-422.

Bonacich, E. (I973), 'A Theory of Middleman Minorities', American Sociological Review 38: 585-594.

Bonacich, E. and R. Appelbaum (2000), From Behind the Label: Inequality in the Los Angeles Apparel Industry. Berkeley: University of California Press.

Bort, E. (2000), Illegal Migration and Cross-Border Crime: Challenges at the Eastern Frontier of the European Union. San Domenico: European University Institute.

Boswell, C. (2003), 'The "External Dimension" of EU Immigration and Asylum Policy', International Affairs 79 (3): 619-638.

Botman, S. and R. Van Kempen (200I), The Spatial Dimensions of Urban Social Exclusion and Integration: The Case of Rotterdam, the Netherlands. Amsterdam: Amsterdam Study Centre for the Metropolitan Environment.

Bourdieu, P. (I977), Outline of a Theory of Practice. Cambridge: Cambridge University Press.

Bourdieu, P. (I983), 'The Forms of Social Capital', in J. Richardson (ed.), Handbook of Theory and Research for the Sociology of Education, 24I-258. New York: Greenwood Press. 
Bourdieu, P. (1990), The Logic of Practice. Stanford: Stanford University Press.

Bourdieu, P. and L. Waquant (I992), An Invitation to Reflexive Sociology. Chicago: University of Chicago Press.

Bovenkerk, F. (ed.) (1978), Omdat zij anders zijn: Patronen van rasdiscriminatie in Nederland [Because They are Different: Patterns of Racial Discrimination in the Netherlands]. Meppel: Boom.

Bovenkerk, F. (I994), 'Over de oorzaken van de criminaliteit van allochtone jongeren' [On the Causes of the Criminality of Allochthone Youth], in Ministy of Justice, Aanpak jeugdcriminaliteit: Met de neus op de feiten [Tackling Youth Delinquency: Facing the Facts], 5I-65. The Hague: Ministy of Justitie.

Bovenkerk, F. (200I), Misdaadprofielen [Crime Profiles]. Amsterdam: Meulenhoff.

Bovenkerk, F. (2002), 'Essay over de oorzaken van allochtone misdaad' [Essay on the Causes of Allochthone Crime], in J. Lucassen and A. de Ruijter (eds.), Nederland multicultureel en pluriform? Een aantal conceptuele studies [Is the Netherlands Multicultural and Diverse? A Number of Conceptual Studies], 200-245. Amsterdam: Aksant.

Bovenkerk, F. and J. Junger-Tas (2000), De oorzaken van criminaliteit onder etnische minderheden: Twee invalshoeken [The Causes of Crime among Ethnic Minorities: Two Perspectives]. The Hague: NWO.

Bovenkerk, F. and Y. Yeşilgöz (1998), De maffia van Turkije [The Turkish Mafia]. Amsterdam: Meulenhoff 1998.

Bovenkerk, F., K. Bruin, L. Brunt and H. Wouters (1985), Vreemd Volk, Gemengde Gevoelens: Etnische Verhoudingen in een Grote Stad [Strange People, Mixed Feelings: Ethnic Relations in a Big City], Amsterdam: Boom.

Bovenkerk, F., W. De Haan and Y. Yeşilgöz (I99I), 'Over selectiviteit gesproken! (Non)discriminatie in opsporingspraktijken van de politie in Nederland' [Speaking about selectivity! (Non-)discrimination in policing in the Netherlands], Tijdschrift voor Criminologie 2: 309-32I.

Braam, S. (I994). De Blinde Vlek van Nederland: Reportages over de Onderkant van de Arbeidsmarkt [The Blind Spot of the Netherlands: Reports on the Bottom of the Labour Market]. Amsterdam: Van Gennep.

Braam, S. (2003), Tussen gekken a gajes: Avonturen in de undercoverjournalistiek [Between Madmen and scum: Adventures in Undercover Journalism]. Amsterdam: Singel Pockets.

Broeders, D. and G. Engbersen (2007), 'The Fight against illegal Migration. Identification Policies and Immigrants' Counter Strategies', American Behavioral Scientist 50 (I2): I592-I609.

Brown, M. (I988), Working the Street: Police Discretion and the Dilemmas of Reform. New York: Russell Sage Foundation.

Buikhuizen, W. and H. Timmermans (I97I), 'Criminaliteit onder Ambonezen' [Crime among Ambonese Immigrants], Nederlands tijdschrift voor criminologie 13: 73-83.

Burgers, J. (I996), 'Natte vingers en vuile handen; over het schatten van het aantal illegale vreemdelingen. Een reactie op Böcker en Groenendijk' [Wet Fingers and Dirty Hands; Estimating the Number of Illegal Immigrants. A reply to Böcker and Groenendijk], Migrantenstudies I2 (I): I4-26.

Burgers, J. (I998), 'In the Margin of the Welfare State: Labour Market Position and Housing Conditions of Undocumented Immigrants in Rotterdam', Urban Studies 35(10): I855-1568.

Burgers, J. and G. Engbersen (eds.) (I999), Illegale Vreemdelingen in Rotterdam [Illegal Immigrants in Rotterdam]. Amsterdam: Boom.

Bursik, R. and H. Grasmick (I993), 'Economic Deprivation and Neighborhood Crime Rates, I960-1980'. Law \& Society Review 27: 263-284. 
Carling, J. (2002), 'Migration in the Age of Involuntary Immobility: Theoretical Reflections and Cape Verdean Experiences', Journal of Ethnic and Migration Studies 28 (I): 5-42.

Carrera, S. and E. Guild. (2007), An EU Framework on Sanctions against Employers of Irregular Immigrants. Some Reflections on the Scope, Features and Added Value. Brussels: Centre for European Policy Studies.

Carter, D. and H. Merrill (2007), 'Bordering Humanism: Life and Death on the Margins of Europe', Geopolitics I2 (2): 248-264.

Castles, S. and M. Miller (2003), The Age of Migration. International Population Movements in the Modern World. Basingstoke / London: Macmillan.

Chavez, L. (1992), Shadowed Lives: Undocumented Immigrants in American Society, Fort Worth: Harcourt Brace College Publishers.

Chiricos, T., M. Hogan and M. Gertz (1997), 'Racial Composition of Neighborhood and Fear of Crime', Criminology 35: 107-I3I.

Clay, G. (I973), Close-up: How to Read the American City, New York: Praeger.

Cloward, R. and L. Ohlin (I960), Delinquency and Opportunity Structures: A Theory of Delinquent Gangs. New York: The Free Press.

Cohn, E. and J. Rotton (2003), 'Even Criminals take a Holiday: Instrumental and Expressive Crimes on Major and Minor Holidays', Journal of Criminal Justice 3I (4): 35I-60.

Coleman, S. (I990), Foundations of Social Theory. Cambridge: The Belknap Press of Harvard University Press.

Collins, R. (1988), Sociology of Marriage and the Family: Gender, Love and Property. Chicago: Nelson-Hall.

Collins, R. (2008), Violence. A Micro-Sociological Theory. Princeton / Oxford: Princeton University Press.

Cornelius, W. (200I), 'Death at the Border: Efficacy and Unintended Consequences of US Immigration Control Policy', Population and Development Review 27 (4): 66I-685.

Cornelius, W. (2005), 'Controlling 'Unwanted' Immigration: Lessons from the United States, I993-2004', Journal of Ethnic and Migration Studies 3I (4): 775-794.

Cornelius, W., T. Tsuda, P. Martin and J. Hollifield (eds.) (2004), Controlling Immigration: A Global Perspective. Stanford: Stanford University Press.

Covington, J. and R. Taylor (I99I), 'Fear of Crime In Urban Residential Neighborhoods: Implications of Between- and Within-Neighborhood Sources for Current Models', The Sociological Quarterly 32 (2): 23I-249.

Cruyff, M. and P. van der Heijden (2004), 'Een raming van het aantal illegalen in Nederland' [An Estimation of the Number of Illegals in the Netherlands], Chapter 2 in A. Leerkes, M. Van San, G. Engbersen et al. Wijken voor Illegalen: Over Ruimtelijke Spreiding, Huisvesting en Leefbaarheid [Neighbourhoods for Illegals: On Spatial Dispersion, Housing and Liveability], 3I-4I. The Hague: Sdu Uitgevers.

Cullen, F. (I984), Rethinking Crime and Deviance Theory: The Emergence of a Structuring Tradition. Totowa: Rowman \& Allanheld.

Davies, P, P. Francis and V. Jupp (2003), Victimisation: Theory, Research and Policy. Basingstoke: Palgrave Macmillan.

De Bakker, E. (200I), De cynische verkleuring van legitimiteit en acceptatie: Een rechtssociologische studie naar de regulering van seizoensarbeid in de aspergeteelt van Zuidoost-Nederland [The Cynical Fading of Legitimicy and Acceptation: A Sociological Study on the Regulation of Seasonal Labour in the Asparagus Cultivation in the South-East of the Netherlands]. Amsterdam: Aksant.

De Boom, J., G. Engbersen and A. Leerkes (2006), Asielmigratie en criminaliteit [Asylum Migration and Crime]. Apeldoorn: Police and Science.

De Botton, A. (2004), Status Anxiety. London: Hamish Hamilton.

De Genova, N. (2007), Working the boundaries: Race, space and 'illegality' in Mexican Chicago. Durham / London: Duke University Press. 
De Haan, W. (I993), Beroving van voorbijgangers: Rapport van onderzoek naar straatroof in 1991 in Amsterdam en Utrecht [Robbing Passers-by: Report on Street Robbery in I99I in Amsterdam and Utrecht]. The Hague: Ministry of Domestic Affairs.

De Haan, W. (I994), 'Berovers in de Bijlmer' [Robbers in the Bijlmer Neighbourhood], Tijdschrift voor Criminologie 36 (3): I68-183.

De Haan, W. and M. Althoff (2002), Vreemd en verdacht: Een verkennend onderzoek naar criminaliteit in en om asielzoekerscentra: Een samenvatting van de recent verschenen publicatie [Strange and Suspect: An Exploratory Research into Crime in and around Asylum Seekers' Centres: A Summary of the Recently Published Publication]. Groningen: University of Groningen.

De Haan, W. and F. Bovenkerk (I993), 'Moedwil en Misverstand. Overschatting en onderschatting van allochtone criminaliteit in Nederland' [Wilfulness and Misunderstanding. Overrating and Underrating of Allochthone Crime], Tijdschrift voor criminologie 35 (3): 277-300.

De Haen-Marshall, I. (ed.) (I997), Minorities, Migrants and Crime: Diversity and Similarity across Europe and the United States. Thousand Oaks: Sage Publications.

De Jong, J. (2007), Kapot moeil k: Een etnografisch onderzoek naar opvallend delinquent groepsgedrag van 'Marokkaanse' jongen [Being Difficult: An Ethnographic Research on Conspicious Delinquent Group Behaviour of Morrocan Youth]. Amsterdam: Aksant.

De Leng, A. and H. Hille (I99I), 'Een onderzoek naar de selectiviteit in de afdoening van winkeldiefstalzaken' [A Research into the Selectivity of the Prosecution of Shop Theft], Tijdschrift voor Criminologie 2: I74-I9I.

De Regt, A. (1984), Arbeidersgezinnen en Beschavingsarbeid. Ontwikkelingen in Nederland 1870-1940: Een Historisch-sociologische Studie [Worker Families and Civilisation Work. Developments in the Netherlands I870-I940: A Historical and Sociological Study], Meppel: Boom.

Desain, L., M. Van Gent, P. Kroon, J. Stouten and B. Van Waveren (2006), 'De voedselbank en hun klanten' [The Foodbank and its Custumers], Sociaal bestek 4: 8-II.

De Swaan, A. (1988), In Care of the State: Health Care, Education and Welfare in Europe and the USA in the Modern Era. New York: Oxford University Press.

De Swaan, A. (1989), 'Perspectives for Transnational Social Policy', Government and Opposition 27 (I): 33-5I.

De Swaan, A. (ed.) (I994), Social Policy beyond Borders: The Social Question in Transnational Perspective. Amsterdam: Amsterdam University Press.

De Swaan, A. (I997), 'The Receding Prospects for Transnational Social Policy', Theory and Society 26 (4): 56I-575.

Ditton, J. and S. Farrall (eds.) (2000), The Fear of Crime. Aldershot: Ashgate.

Doomernik, J. (200I), 'Tussen daar en hier; Van werving tot smokkel' [Between There and Here; From Recruitment to Smuggling], Tijdschrift voor Criminologie 43 (4): 33I-340.

Doomernik, J. and D. Kyle (eds.) (2004), Organized Migrant Smuggling and State Control: Conceptual and Policy Challenges, Special issue of Journal of International Migration and Integration, 5 (3).

Doornbos, N. and K. Groenendijk (200I), 'Uitkomsten van asielprocedures: een cohortonderzoek' [Outcomes of Asylum Procedures: A Cohort Research], Nederlandsch Juristenblad $76(6)$ : 245-253.

Douwes, D. (2003), De islam in een notendop. Wat iedereen over de islam moet weten [Islam in Summary. What Everybody Should Know about Islam]. Amsterdam: Prometheus.

Düvell, F. (ed.) (2006), Illegal Immigration in Europe. Beyond Control?. Houndsmills, Basingstoke Hampshire: Palgrave Macmillan.

Duyvendak, J. and M. Hurenkamp (eds.) (2004), Kiezen voor de kudde: Lichte gemeenschappen en de nieuwe meerderheid [Opting for the Herd: Light Communities and the New Majority]. Amsterdam: Van Gennep. 
Ehrenreich, B. (2002), Global Woman: Nannies, Maids, and Sex Workers in the New Economy. New York: Metropolitan Books.

Elias, N. (1939), Über den Prozess der Zivilisation: Soziogenetische und psychogenetische Untersuchungen [The Civilizing Process: Sociogenetic and Psychogenetic Investigations]. Basel: Haus zum Falken.

Elias, N. (1978), What is Sociology? London: Hutchinson.

Elias, N. and J. Scotson (1965), The Established and the Outsiders: A Sociological Enquiry into Community Problems. London: Cass.

Engbersen, G. (I996), 'The Unknown City', Berkeley Journal of Sociology 40: 87-II2.

Engbersen, G. (1997), In de schaduw van morgen: Stedel ke marginaliteit in Nederland [In the Shadow of Tomorrow: Urban Marginality in the Netherlands]. Amsterdam: Boom.

Engbersen, G. (200I), 'The Unanticipated Consequences of Panopticon Europe: Residence Strategies of Illegal Immigrants', in V. Guiraudon and C. Joppke (eds.), Controlling a New Migration World, 222-246. London: Routledge.

Engbersen, G. (2003), 'The Wall around the Welfare State in Europe: International Migration and Social Exclusion', The Indian Journal of Labour Economics 46 (3): 479-495.

Engbersen, G. and J. Van der Leun (I995), 'Illegale vreemdelingen en criminaliteit: De differentiële kansenstructuur van illegalen [Illegal Immigrants and Crime: The Differential Opportunity Structure of Illegals], Tijdschrift voor Criminologie 37 (3): 238-256.

Engbersen, G. and J. Van der Leun (1998), 'Illegality and Criminality. The Differential Opportunity Structure of Illegal immigrants', in K. Koser and H. Lutz, Eds. The New Migration in Europe. Social Constructions and Social Reality. 199-223, London: Macmillan Press.

Engbersen, G. and J. Van der Leun (200I), 'The Social Construction of Illegality and Criminality', European Journal on Criminal Policy and Research 9 (I): 5I-70.

Engbersen, G., J. Van der Leun and P. Willems (I995), Over de verwevenheid van illegaliteit en criminaliteit [On the Interweaving between Illegality and Criminality]. Utrecht: Utrecht University.

Engbersen, G., J. Van der Leun, R. Staring and J. Kehla (I999), Inbedding en uitsluiting van illegale vreemdelingen [Incorporation and Exclusion of Illegal Immigrants]. Amsterdam: Boom.

Engbersen, G., R. Staring, J. van der Leun, J. de Boom, P. van der Heijden and M. Cruijff (2002), Illegale vreemdelingen in Nederland. Omvang, overkomst, verblijf en uitzetting [Illegal Immigrants in the Netherlands: Size, Migration, Residence and Expulsion], Rotterdam: Erasmus University Rotterdam / Risbo.

Engbersen, G., M. Van San and A. Leerkes (2006), 'A Room with a View. Illegal Immigrants in the Legal Capital of the World', Ethnography 7: 209-242.

Engbersen, G., J. van der Leun and J. de Boom (2007), The Fragmentation of Migration and Crime. Crime and Justice. A Review of Research, 389-452 (Special issue on Crime and Justice in the Netherlands, Editors M. Tonry and C. Bijleveld). Chicago: Chicago University Press Crime and Justice Series.

Espenshade, T. (1995), 'Unauthorized Immigration to the United States', Annual Review of Sociology 2I: 195-2I6.

European Migration Network (EMN) (2007), Illegally Resident Third Country Nationals in EU Member States: State Approaches towards Them, Their Profile and Social Situation. Berlin: EMN.

Faist, T. (2000), The Volume and Dynamics of International Migration and Transnational Social Spaces.Oxford: Clarendon Press.

Farley, R. (I99I), 'Residential Segregation of Social and Economic Groups and Blacks: I970-80', in C. Jencks and P. Peterson (eds.), The Urban Underclass, 274-298. Washington, D.C.: The Brookings Institution Press. 
Felson, M. (I994), Crime and Everyday Life; Insights and Implications for Society. Thousand Oaks: Pine Forge Press.

Fischer, P., R. Martin and T. Straubhaar (I997), 'Should I Stay or Should I Go?', in T. Hammar et al. (ed.), International Migration, Immobility and Development, 49-90. Oxford: Berg Press.

Fortuyn, P. (200I), De islamisering van onze cultuur: Nederlandse identiteit als fundament [The Islamisation of our Culture: Dutch Identity as a Fundament]. Uithoorn: Karakter Uitgevers.

Foucault, M. (I977), Discipline and Punish: The Birth of the Prison, New York: Pantheon Books.

Gans, H. (I982 (I962)), Urban Villagers: Group and Class in the Life of Italian-Americans. New York: The Free Press of Glencoe.

Gans, G. (I995), The War against the Poor: The Underclass and Antipoverty Policy. New York: BasicBooks.

Garland, D. (200I), The Culture of Control: Crime and Social Order in Contemporary Society. Oxford: Oxford University Press.

Gaylord, M. (I999), 'Cross-Border Crime and Legal Jurisdiction in Post-Colonial Hong Kong', Crime, Law \& Social Change 3I: 3I-48.

Giele, J. and G. Elder (I998), Methods of Life Course Research. Quantitative and Qualitative Approaches. Thousand Oaks: Sage Publications.

Glaser, B. and A. Strauss (I97I), Status Passage. London: Routledge.

Goffman, E. (1963), Behavior in Public Places: Notes on the Social Organization of Gatherings. London: The Free Press of Glencoe.

Goffman, E. (1969), Strategic Interaction. Philadelphia: University of Pennsylvania.

Goffman, E. (I971a), Relations in Public: Microstudies of the Public Order. New York: Basic Books.

Goffman, E. (I97Ib), The Presentation of Self in Everyday Life. Harmondsworth: Penguin.

Goodey, J. (2003), 'Migration, Crime and Victimhood. Responses to Sex Trafficking in the EU', Punishment Q Society 5 (4): 4I5-43I.

Gottfredson, M. and T. Hirschi (I990), A General Theory of Crime. Stanford: Stanford University Press.

Goudriaan, H. (2006), Reporting Crime. Effects of Social Context on the Decision of Victims to Notify the Police. PhD thesis, University of Leiden.

Goudriaan, H., K. Wittebrood and P. Nieuwbeerta (2006), 'Neighbourhood Characteristics and Reporting crime: Effects of Social Cohesion, Confidence in Police Effectiveness, and Socio-Economic Disadvantage, British Journal of Criminology 46: 719-742.

Grabosky, P. and R. Smith (200I), 'Telecommunication Fraud in the Digital Age', in D. Wall (ed.), Crime and the Internet, 29-43. London: Routledge

Griffith, J. and H. Weyers (eds.) (2005), De sociale werking van recht: een kennismaking met de rechtssociologie en rechtsantropologie [The Social Operation of Law: an Introduction to the Sociology and Anthropology of the Law]. Nijmegen: Ars Aequi Libri.

Guiraudon, V. and G. Lahav (2007), Immigration Policy in Europe. The Politics of Control. London: Routledge.

Gzymala-Kazlowska, A. (2005), 'From Ethnic Cooperation to In-Group Competition: Undocumented Polish Workers in Brussels', Journal of Ethnic and Migration Studies (4): 675697.

Hagan, J. and R. Peterson (eds.) (I995), Crime and Inequality. Stanford: Stanford University Press.

Hale, C. (I996), 'Fear of Crime: A Review of the Literature', International Review of Victimology 4: 79-I50. 
Hamilton, D. and T. Trolier (1986), 'Stereotypes and Stereotyping: an Overview of the Cognitive Approach', in J. Dovidio and S. Gaertner (eds.), Prejudice, Discrimination and Racism, I27-I63. Orlando: Academic Press.

Hammersley, M. and P. Atkinson (I995), Ethnography: Principles in Practice. London: Routledge.

Hannerz, U. (1992), Cultural Complexity: Studies in the Social Organization of Meaning. New York: Columbia University Press.

Hirschi, T. (1969), Causes of Delinquency. Berkeley: University of California Press.

Hoogenboezem, G. and E. Bransen (2005), Problematisch harddruggebruik door illegalen, asielzoekers en vluchtelingen. Een verkenning met behulp van 'Rapid Assessment and Response' [Problematic Hard Drugs Use by Illegals, Asylum Seekers and Refugees. An Exploration with the 'Rapid Assessment and Response']. Utrecht: Trimbos Instituut.

Hooghiemstra, B. (2003), Trouwen over de grens: Achtergronden van partnerkeuze van Turken en Marokkanen in Nederland [Marrying across the Border: Backgrounds of the Partner Choice of Turks and Moroccans in the Netherlands]. The Hague: SCP.

Hoogteijling, E. (2002), Raming van het aantal niet in de GBA geregistreerden [Estimation of the Number of Unregistered Residents in the Netherlands]. Voorburg: CBS.

Hughes, E. (I945), 'Dilemmas and Contradictions of Status'. American Journal of Sociology 50: $353-359$.

Hughes, E. (I994 (I95I)), 'Bastard institutions', reprinted in L. Coser (ed.), Everett C. Hughes: On Work, Race, and the Sociological Imagination, I92-199. Chicago: University of Chicago Press.

Instituut voor Sociologisch Economisch Onderzoek (ISEO) (2002), Integratiemonitor 2002 [Integration Monitor 2002]. Rotterdam: ISEO

Jargowsky, P. (I997), Poverty and Place: Ghettos, Barrios, and the American City. New York: Russell Sage.

Johansson, S. (1987), 'Status Anxiety and Demographic Contraction of Privileged Populations', Population and Development Review I3 (3): 439-470.

Junger, M. (I990), Delinquency and ethnicity. An investigation on social factors relating to delinquency among Morrocan, Turkish, Surinamese and Dutch boys. Deventer / Boston: Kluwer.

Junger-Tas, J., I. Haen Marshall and D. Ribeaud (2003), Delinquency in an International Perspective - The International Self-Report Delinquency Study. Monsey: Criminal Justice Press.

Katz, J. (1988), Seductions of Crime: Moral and Sensual Attractions in Doing Evil. New York: Basic Books.

Katz, M. (1986), In the Shadow of the Poorhouse: A Social History of Welfare in America. New York: Basic Books.

Kehla, J. (I999), 'Schaduwnetwerken in de informele ruimte: Legale en illegale Afrikaanse migranten in de Bijlmer' [Shadow Networks in the Informal Space: Legal and Illegal African Migrants in the Bijlmer Neighbourhood], in G. Engbersen (ed.), Inbedding en uitsluiting van illegale vreemdelingen [Embeddedness and Exclusion of Illegal Aliens], I56-Igo. Amsterdam: Boom.

Kelling, G. and J. Wilson (I992), 'Broken Windows: The Police and Neighborhood Safety', The Atlantic Monthly, March.

Killias, M. (I990), 'Vulnerability: Towards a Better Understanding of a Key Variable in the Genesis of Fear of Crime', Violence and Victims 5: 97-108.

Klaver, J. and E. Visser (I999), Evaluatie Wet Arbeid Vreemdelingen. Eindrapport [Evaluation of the Law on Labour by Aliens. Final Report]. The Hague: Ministry of Social Affairs and Employment. 
Kleemans, E. (I996), Strategische misdaadanalyse en stedelijke criminaliteit: Een toepassing van de rationele keuzebenadering op stedelijke criminaliteitspatronen en het gedrag van daders, toegespitst op het delict woninginbraak [Strategic Crime Analysis and Urban Crime: The Use of Rational Choice Perspective for Urban Crime Patterns and Behaviour by Offenders, in Particular for Burglary]. Enschede: PhD thesis University of Twente.

Kloosterman, R., J. Van der Leun and J. Rath (I998), 'Across the Border: Immigrants' Economic Opportunities, Social Capital and Informal Business Activities', Journal of Ethnic and Migration Studies 24(2): 249-268.

Kloosterman, R. and J. Rath (200I), 'Immigrant Entrepreneurs in Advanced Economies: Mixed Embeddedness Further Explored', Journal of Ethnic and Migration Studies 27(2): I89-20I.

Kroese, G. and R. Staring (I993), Prestige, professie en wanhoop. Een onderzoek onder gedetineerde overvallers [Prestige, Profession and Dispair. A Research among Detained Robbers], Arnhem: Gouda Quint.

Kromhout, M. and M. Van San (2003), Schimmige werelden; Nieuwe etnische groepen en jeugdcriminaliteit [Shadowy Worlds: New Ethnic Groups and Youth Delinquency], The Hague, Ministery of Justice.

Kyle, D. and R. Koslowski (eds.) (200I), Global Human Smuggling. Comparative Perspectives. Baltimore and London: The Johns Hopkins University Press.

Kyle, D. and C. Siracusa (2005), 'Seeing the State Like a Migrant. Why So Many Non-criminals Break Immigration Laws', in W. van Schendel and I. Abraham (eds.), Illicit Flows and Criminal Things: States, Borders, and the Other Side of Globalization, I53-I76. Bloomington: Indiana University Press.

Laub, J. and R. Sampson (2003), Shared Beginnings, Divergent Lives - Delinquent Boys to Age 70. Cambridge: Harvard University Press.

Lahav, G. and V. Guiraudon (2000), 'Comparative Perspectives on Border Control: Away from the Border and Outside the State', in P. Andreas and T. Snyder (eds.), The Wall around the West. State Borders and Immigration Controls in North America and Europe, 5577. Lanham: Rowman \& Littlefield Publishers.

Leerkes, A. (2006), 'Ik probeer alleen maar mijn leven te leven'; Uitgeprocedeerde asielzoekers en criminaliteit ['I am Just Trying to Live My Life'; Rejected Asylum Seekers and Crime]. Amsterdam: Elsevier.

Leerkes, A., M. Van San, G. Engbersen, M. Cruijff and P. van der Heijden (2004), Wijken voor illegalen. Over ruimtelijke spreiding, huisvesting en leefbaarheid [Neighbourhoods for Illegals. On Spatial Spreading, Housing and Liveability]. The Hague: SdU.

Lenski, G. (I990 (I966)), 'A Theory of Inequality', in R. Collins (ed.), Four Sociological Traditions, Selected Readings, 8I-I08. New York: Oxford University Press.

Levitas, R. and W. Guy (eds.) (I996), Interpreting Official Statistics. London: Routledge.

Lewis, D. and G. Salem (1986), Fear of Crime: Incivility and the Production of a Social Problem. New Brunswick: Transaction.

Lofland, J. and L. Lofland (I995), Analyzing Social Settings: A Guide to Qualitative Observation and Analysis. Belmont: Wadsworth.

Lofland, L. (I973), A World of Strangers: Order and Action in Urban Public Space, New York: Basic Books.

Lofland, L. (I998), The Public Realm: Exploring the City's Quintessential Social Territory. New York: Aldine de Gruyter.

Lucassen, J. and R. Penninx (I997), Newcomers: Immigrants and their Descendants in the Netherlands 1550-1995. Amsterdam: Het Spinhuis.

Maas-De Waal, C. (I99I), 'Wetenschappelijk onderzoek naar criminaliteit van allochtonen; een taboe doorbroken?’ [Scientific Research on criminality Among Allochtones; a Taboo Broken?], Tijdschrift voor Criminologie 2: 87-100. 
Mahler, S. (1995), American Dreaming: Immigrant Life on the Margins. Princeton: Princeton University Press.

Markowitz, F., P. Bellair, A. Liska and J. Liu (200I), 'Extending Social Disorganization Theory: Modeling the Relationship Between Cohesion, Disorder, and Fear', Criminology 39: 293-320.

Martin, P. (I993), Trade and Migration: NAFTA and Agriculture. Washington, D.C.: Institute for International Economics.

Martin, P. (2004), 'The United States: The Continuing Immigration Debate', in W. Cornelius et al. Controlling Immigration: A Global Perspective, 5I-85. Stanford: Stanford University Press.

Martin P. and J. Taylor (200I), 'Managing Migration: The Role of International Policies', in R. Zolberg and P. Benda (eds.), Global Migrants, Global Perspectives: Problems and Solutions, 95-120. New York: Berghahn Books.

Massey, D., J. Arango, G. Hugo, A. Kouaouci, A. Pellegrino and J. Edward Taylor (2005), Worlds in motion: Understanding International Migration at the End of the Millennium. Oxford: Clarendon Press.

Massey, D. and N. Denton (1993), American Apartheid: Segregation and the Making of the Underclass. Cambridge: Harvard University Press.

Matza, D. (1964), Delinquency and Drift. New York: Wiley.

McDonald, W. (1997), 'Illegal Immigration: Crime, Ramifications and Control (The American Experience)', in W. McDonald (ed.), Crime and Law Enforcement in the Global Village, 65-86. Cincinnati: Anderson Publishing Company.

Meier, R. and W. Johnson (1977), 'Deterrence as Social Control: the Legal and Extra-legal Production of Conformity', American Sociological Review 42: 292-304.

Merton, R. (1936), 'The Unanticipated Consequences of Purposeful Social Action', American Sociological Review I: 894-904.

Merton, R. (1938), 'Social Structure and Anomie', American Sociological Review 3: 672-682.

Merton, R. (I948), 'The Bearing of Sociological Theory on Empirical Research', American Sociological Review I3: 505-515

Merton, R. (I957), 'The Role-set: Problems in Sociological Theory', British Journal of Sociology 8: 106-I20.

Merton, R. (I968), Social Theory and Social Structure (enlarged ed.). New York: The Free Press.

Mesch, G. (2000), 'Perceptions of Risk, Lifestyle Activities, and Fear of Crime', Deviant Behavior 21: 47-62.

Miceli, R., M. Roccato and R. Rosato (2004), 'Fear of Crime in Italy: Spread and Determinants', Environment and Behavior 36: 776-789.

Milanovic, B. (2005), Worlds Apart. Measuring Global and International Inequality. Princeton: Princeton University Press.

Miller, M. (1995), 'Illegal Migration', in R. Cohen (ed.), The Cambridge Survey of World Migration, 537-540. Cambridge: Cambridge University Press.

Minderhoud, P. (2004), 'Coping with Irregular Migration: the Dutch Experience', in B. Bogusz (ed.), Irregular Migration and Human Righys: Theoretical, European and International Perspectives, 387-406. Leiden: Martinus Nijhoff Publishers.

Molenaar, T. (2007), Verslaafde vreemdelingen. De rol van harddruggebruik bij criminaliteit door illegale vreemdelingen in de Bijlmer [Addicted aliens. The Role of Harddrug Use in Criminality by Illegal Aliens in the Bijlmer Neighborhood]. MA student thesis, Leiden University.

Molho, I. (1995), 'Migrant Inertia, Accessibility and Local Unemployment', Economica, New Series 62 (245): I23-I32.

Moore, S. (I973), 'Law and Social Change: The Semi-autonomous Social Field as an Appropriate Subject of Study', Law and Society Review 7: 719-746. 
Moore, S. and J. Shepherd (2006), 'The Cost of Fear: Shadow Pricing the Intangible Costs of Crime', Applied Economics 38: 293-300.

Moravcsik, A. (I993), 'Preferences and Power in the European Community: A Liberal Intergovernmentalist Approach', Journal of Common Market Studies 3I (4): 473-524.

Morris, N. and D. Rothman (eds.) (I998), The Oxford History of the Prison: The Practice of Punishment in Western Society. Oxford: Oxford University Press.

Musterd, S. (2004), 'Etnische segregatie in Europees perspectief' [Ethnic Segregation in European Perspective], Stedebouw a Ruimtelijke Ordening 85 (5): 28-3I.

Musterd, S. and R. Deurloo (2002), 'Unstable Immigrant Concentrations in Amsterdam: Spatial Segregation and Integration of Newcomers', Housing Studies I7 (3): 487-504.

Musterd, S. and R. Van Kempen (2000), The Spatial Dimensions of Urban Social Exclusion and Integration: a European Comparison. Comparative framework based on analysis at national and metropolitan level: Amsterdam, Antwerp, Berlin, Birmingham, Brussels, Hamburg, London, Milan, Naples, Paris and Rotterdam. Amsterdam: Amsterdam Study Centre for the Metropolitan Environment.

Musterd, S., W. Ostendorf and M. Breebaart (I998), Multi-Ethnic Metropolis: Patterns and Policies. Dordrecht: Kluwer Academic Publishers.

National Conference of State Legislatures (NCSL) (2008), 2007 Enacted State Legislation Related to Immigrants and Immigration. Revised 3I January 2008. Washington, D.C.: NCLS.

Nagin, S. and R. Paternostern (I994), 'Personal Capital and Social Control: the Detterence Implications of a Theory of Individual Differences in Criminal Offending', Criminology $32(4): 59 \mathrm{I}-606$.

Neckerman, K. and F. Torche (2007), 'Inequality: Causes and Consequences', Annual Review of Sociology 33: 335-357.

Newman, K. (I999), Falling from Grace: Downward Mobility in the Age of Affluence. Berkeley: University of California Press.

O'Loughlin, J. and J. Friedrichs (I996), 'Polarization in Post-industrial Societies: Social and Economic Roots and Consequences', in J. O'Loughlin and J. Friedrichs (eds.), Social Polarization in Post-industrial Metropolises, I-I8. Berlin: Walter de Gruyter.

Organisation for Economic Co-operation and Development (OECD) (2005), Trends in International Migration: Annual Report 2005. Paris: OECD.

Organisation for Economic Co-operation and Development (OECD) (2006), International Migration Outlook: Annual Report 2006. Paris: OECD.

Pain, R. and P. Francis (2004), 'Living with Crime: Spaces of Risk for Homeless Young People', Children's Geographies 2 (I): 95-Iıо.

Park, R., E. Burgess and R. McKenzie (I925), The City. Chicago: University of Chicago Press.

Piore, M. (I979), Birds of Passage: Migrant Labor and Industrial Societies. Cambridge: Cambridge University Press.

Poederbach, J. (I932), Het werkhuis en het armenhuis der stad Amsterdam 1782-1932 [The Workhouse and the Poorhouse of the City of Amsterdam I782-I932]. Amsterdam: Stadsdrukkerij.

Polanyi, K. (I944), The Great Transformation. New York: Rinehart.

Popper, K. (I962), The Open Society and its Enemies. 2. Hegel and Marx. Princeton: Princeton University Press.

Portes, A. (I998), 'Social Capital. Its Origins and Applications in Modern Sociology', Annual Review of Sociology 24: I-24.

Portes, A. (ed.) (I995). The Economic Sociology of Immigration: Essays on Networks, Ethnicity, and Entrepreneurship. New York: Russell Sage Foundation. 
Portes, A. (I999), 'Conclusion: Towards a New World - The Origins and Effects of Transnational Activities', Ethnic and Racial Studies 22 (2): 463-477, Special issue on Transnational Communities.

Quillian, L. and D. Pager (200I), 'Black Neighbors, Higher Crime? The Role of Racial Stereotypes in Evaluations of Neighborhood Crime', American Journal of Sociology I07 (3): $717-767$.

Raad voor het openbaar bestuur (ROB) (I998), Illegale blijvers [Illegal Stayers]. The Hague: ROB.

Radcliffe-Brown, A. (1952), Structure and Function in Primitive Society. New York: The Free Press.

Romaniszyn, K. (1996), 'The Invisible community: Undocumented Polish Workers in Athens', New Community 22(2): 321-334.

Rovers, B. 1999. Klassenjustitie: een overzicht van onderzoek naar selectiviteit in de Nederlandse strafrechtsketen. [Class Justice: an Overview of Research on Selectivity in the Criminal Justice System in the Netherlands]. Rotterdam: Erasmus University.

Rusinovic, K., J. Van der Leun, T. Chessa, A. Weltevrede, G. Engbersen and J. Vos (2002), Nieuwe vangnetten in de samenleving. Over problemen en dilemma's in de opvang van kwetsbare groepen [New Safety Nets in Society. On Problems and Dilemmas in the Sheltering of Vulnerable Groups]. Rotterdam: Erasmus University / RISBO.

Sampson, R. and W. Groves (1989), 'Community Structure and Crime: Testing Social Disorganization Theory', American Journal of Sociology 94: 774-802.

Sampson, R. and J. Laub (1993), Crime in the Making: Pathways and Turning Points Through Life, Cambridge: Harvard University Press.

Sampson, R. and J. Laub (2005), Developmental Criminology and its Contents: Trajectories of Crime from Childhood to Old Age. Thousand Oaks: Sage.

Sampson, R., S. Raudenbush and F. Earls (1997), 'Neighborhoods and Violent Crime: A Multilevel Study of Collective Efficacy', Science 277: 918-924.

Sansone, L. (I992), Schitteren in de schaduw: Overlevingsstrategieën, subcultuur en etniciteit van Creoolse jongeren uit de lagere klasse in Amsterdam 1981-1990 [Glittering in the Shadow: Survival Strategies, Subculture and Ethnicity of Creole Youth from the Lower Class in Amsterdam I98I-I990]. Amsterdam: Het Spinhuis.

Saragin, E. (ed.) (I980), Taboos in Criminology. Beverly Hills: Sage Publications.

Sassen, S. (199I), The Global City: New York, London, Tokyo. Princeton: Princeton University Press.

Sassen, S. (1999), Guests and Aliens. New York: The New Press.

Sayad, A. (2004), The Suffering of the Immigrant. Cambridge: Polity.

Scalia, J. (1996), Noncitizens in the Federal Criminal Justice System, 1984-1994. Washington, D.C.: US Department of Justice, Bureau of Justice Statistics.

Scalia, J. (2002), Immigration Offenders in the Federal Criminal Justice System, 2000. Washington, D.C.: US Department of Justice, Bureau of Justice Statistics

Schloenhardt, A. (200I), 'Trafficking in Migrants: Illegal Migration and Organized Crime in Australia and the Asia Pacific Region', International Journal of the Sociology of Law 29: 33I-378.

Schoen, E., P. Defize and M. Bakker (2000), Methodologische evaluatie van de Politiemonitor Bevolking [Methodological Evaluation of the Police Monitor Population]. Delft: TNO.

Schuster, L. (2000), 'A Comparative Analysis of the Asylum Policy of Seven European Governments', Journal of Refugee Studies I3 (I): II8-I32.

Schuyt, C. (I995), Tegendraadse werkingen: Sociologische opstellen over de onvoorziene gevolgen van verzorging en verzekering [Unforeseen Mechanisms: Sociological Essays about Unanticipated Effects of Care and Insurance]. Amsterdam: Amsterdam University Press. 
Schwartz, B. (I967), 'The Social Psychology of the Gift', The American Journal of Sociology 73: I-II.

Sciortino, G. (2004), 'Between Phantoms and Necessary Evils: Some Critical Points in the Study of Irregular Migrations to Western Europe', IMIS-Beitrage 24: I7-43.

Scott, J. (I985), Weapons of the Weak: Everyday Forms of Peasant Resistance. London: Yale University Press.

Scott, J. (I990), Domination and the Arts of Resistance: Hidden Transcripts. New Haven: Yale University Press.

Scott, J. (1998), Seeing like a State: How Certain Schemes to Improve the Human Condition Have Failed. New Haven: Yale University Press.

Shaw, R. and H. McKay (eds.) (I942), Juvenile Delinquency and Urban Areas: A Study of Rates of Delinquency in Relation to Differential Characteristics of Local Communities in American Cities. Chicago: University of Chicago Press.

Shibutani, T. and K. Kwan (I972), Ethnic Stratification. A Comparative Approach. New York: The Macmillan Company.

Shorter, E. (I975), The Making of the Modern Family. New York: Basic Books.

Snel, E., J. de Boom, J. Burgers and G. Engbersen (2000), Migratie, integratie en criminaliteit [Migration, Integration and Crime]. Rotterdam: RISBO.

Snel, E., J. de Boom, J. Burgers and G. Engbersen (2005), Migration, Immigrants and Policy in the Netherlands: Report for the Continuous Reporting System on Migration (SOPEMI) of the Organisation for Economic Co-operation and Development (OECD). Rotterdam: RISBO, Erasmus University Rotterdam.

Snel, E., G. Engbersen and A. Leerkes (2006), 'Transnational Involvement and Social Integration', Global Networks 6 (3): 285-308.

Spierenburg, P. (I995), 'The Body and the state: Early Modern Europe', in N. Morris and D. Rothman (eds.), The Oxford History of the Prison, 48-77. Oxford: Oxford University Press.

Staring, R. (200I), Reizen onder regie: Het migratieproces van illegale Turken in Nederland [Staged Travelling: The Process of Migration of Illegal Turks in the Netherlands]. Amsterdam: Het Spinhuis.

Staring, R. and G. Engbersen (200I), 'The Moral Economy of Low-income Groups: Poverty and Informality', Focaal European Journal of Anthropology 38: 83-101.

Stark, O. (I995), 'The Sharing and Distribution of the Returns to Migration in Developing Countries', in J. Ong, K. Chan and S.Chew (eds.), Crossing Borders. Transmigration in Asia Pacific, IoI-Io6. Singapore: Prentice Hall.

Stepick, A. (I989), 'Miami's Two Informal Sectors', in A. Portes, M. Castells and L. Benton (eds.), The Informal Economy: Studies in Advanced and Less Developed Countries, III-I3I. Baltimore: The Johns Hopkins University Press.

Stepick, A., G. Grenier, M. Castro and M. Dunn (2003), This Land Is Our Land: Immigrants and Power in Miami. Miami: University of California Press.

Sutherland, E. and D. Cressy (I937), Principles of Criminology (third, revised edition). Chicago: Lippincott.

Taylor, J. (I999), 'The New Economics of Labour Migration and the Role of Remittances in the Migration Process', International Migration 37(I): 63-86.

Taylor, R. and M. Hale (I986), 'Testing Alternative Models of Fear of Crime', Journal of Criminal Law and Criminology 77: I5I-189.

Thomas, W. and F. Znaniecki (I9I8), The Polish Peasant in Europe and America: Monograph of an Immigrant Group. Boston: Badger

Thornberry, T. and M. Krohn (2003), Taking Stock of Delinquency - An Overview of Findings from Contemporary Longitudinal Studies. New York: Kluwer Academic Publishers.

Thorns, D. (2002), The Transformation of Cities: Urban Theory and Urban Life. Basingstoke: Palgrave Macmillan. 
Tonry, M. (ed.) (1997), Ethnicity, Crime and Immigration: Comparative and Cross-National Perspectives. Chicago: University of Chicago Press.

Torpey, J. (1999), The Invention of the Passport: Surveillance, Citizenship and the State. Cambridge: Cambridge University Press

Turner, B. (2007), 'The Enclave Society: Towards a Sociology of Immobility', European Journal of Social Theory io (2): 287-304.

Tyler, T. and C. Wakslak (2004), 'Profiling and the Legitimacy of the Police', Criminology 42: I3-42.

Vagg, J. (1992), 'The Borders of Crime: Hong Kong-China Cross-Border Criminal Activity', British Journal of Criminology 32 (3): 310-328.

Van Amersfoort, J. and W. Biervliet (1977), Criminaliteit van minderheden: De bedreigde burger [Criminality among Minorities: The Threatened Citizen]. Utrecht: Spectrum.

Van der Heijden, P., M. Cruyff and H. van Houwelingen (2003), 'Estimating the Size of a Criminal Population from Police Records Using the Truncated Poisson Regression Model', Statistica Neerlandica 57 (3): 289-304.

Van der Heijden, P., G. Van Gils, M. Cruijff and D. Hessen (2006), Een schatting van het aantal in Nederland verblijvende illegale vreemdelingen in 2005 [An Estimation of the Number of Illegally Residing Aliens in the Netherlands in 2005]. Utrecht: University of Utrecht.

Van Kempen, R and M. Idamir (2003), 'Housing Allocation of Ethnic Minority Groups: The effects of Different Housing Allocation Models on Moroccan Households in Two Dutch cities', Journal of Housing and the Built Environment I8(3): 257-268.

Van der Leun, J. (2002), 'Dilemma's binnen de poorten: De Koppelingswet en uitsluiting van illegale migranten van publieke voorzieningen' [Conundrums inside the Gates: The Linking Act and the Exclusion of Illegal Immigrants], Sociologische gids 49 (I): 4558.

Van der Leun (2003), Looking for Loopholes: Processes of Incorporation of Illegal Immigrants in the Netherlands. Amsterdam: Amsterdam University Press.

Van der Leun, J. (2004), 'Lokale solidariteit met illegale migranten' [Local Solidarity with Illegal Immigrants], in H. Entzinger and J. Van der Meer (eds.), Grenzeloze solidariteit. Naar een migratiebestendige verzorgingsstaat [Solidarity without Borders. To a MigrationProof Welfare State], 73-85. Amsterdam: De Balie.

Van der Leun, J. (2006), 'Excluding Illegal immigrants in the Netherlands; Between National Policies and Local Implementation', in V. Guiraudon and G. Lahav (eds.), Immigration Policy in Europe. London: Routledge.

Van der Leun, J., G. Engbersen and P. van der Heijden (I998), Illegaliteit en criminaliteit: Schattingen, aanhoudingen en uitzettingen [Illegal Residence and Crime: Estimations, Apprehensions and Expulsions]. Rotterdam: Faculty of Social Science/Sociology, Erasmus University Rotterdam.

Van der Leun, J. and Kloosterman, R. (2006), 'Going Underground. The Labour Market Position of Undocumented Immigrants in the Netherlands', Tijdschrift voor Economische en Sociale Geografie 97(I): 59-68.

Van der Leun, J. and L. Vervoorn (2004), Slavernij-achtige uitbuiting in Nederland. Een inventariserende literatuurstudie in het kader van de uitbreiding van de strafbaarstelling van mensenhandel [Slavery-like Exploitation in the Netherlands. An Inventory of the Literature with an Eye to the Extension of the Punishability of People Trafficking]. The Hague: Boom Juridische Uitgevers.

Van der Wouden, R., and E. Bruijne (200I), De stad in de omtrek: Problemen en perspectieven van de vier grootstedelijke gebieden in de Randstad [The City in Circumference: Problems and Perspectives for the Four Metropolitan Areas in the West of the Netherlands]. The Hague: Social and Cultural Planning Bureau. 
Van Dijk, J., R. Manchin and J. Van Kesteren. 2007. The Burden of Crime in the EU - A Comparative Analysis of the European Survey of Crime and Safety (EUICS) 2005. Brussels: Gallup-Europe.

Van Duyne, P. (I993), 'Implications of Cross border Crime Risks in an open Europe', Crime, Law Q Social Change 20 (2): 99-III.

Van Eijl, C. (2005), Al te goed is buurmans gek: Het Nederlandse vreemdelingenbeleid 1840-1940 [To be Too Good is to be the Neighbour's Idiot: The Dutch Aliens Policy I840-I940]. Amsterdam: Aksant.

Van Gemert, F. (1998), Ieder voor zich: Kansen, cultuur en criminaliteit van Marokkaanse jongens [Everyone for Himself: Chances, Culture and Crime of Moroccan Youth]. Amsterdam: Het Spinhuis.

Van Gestel, B. (2006), Nieuws, beleid en criminaliteit. Over de wisselwerking tussen lokale media en criminaliteitsbestrijders [News, Policy and Crime. On the Interaction between Local Media and Crime Fighters]. Amsterdam: Aksant.

Van Heek, F. (1936), Chineesche immigranten in Nederland [Chinese Immigrants in the Netherlands]. Amsterdam: N.V. J. Emmering's Uitgevers.

Van Kalmthout, A. and K. Van Leeuwen (2004), Terugkeermogel kheden van vreemdelingen in vreemdelingenbewaring. Deel 2: Evaluatie terugkeerprojecten. [Return Opportunities of Aliens in Alien Custody. Part 2: Evaluation of Return Projects]. N megen: Wolf Legal Publishers.

Van Kalmthout, A. and K. Van Leeuwen (2005), Terugkeermogel kheden van vreemdelingen in vreemdelingenbewaring. Deel 3: Het vergeten gelaat van de vreemdeling [Return Opportunities of Aliens in Alien Custody. Part 3: The Forgotten Face of the Alien]. N megen: Wolf Legal Publishers.

Van Kalmthout, A., F. Hofstee-Van der Meulen and F. Dünkel. (2007) Foreigners in European Prisons. Nijmegen: Wolf Legal Publishers.

Van Leeuwen, M. (2000), De rijke Republiek: Gilden, assuradeurs en armenzorg 1500-1800 [The Rich Republic: Guilds, Insurers, and Poor Relief]. The Hague / Amsterdam: Verbond van Verzekeraars / NEHA.

Van Liempt, I. (2007), Navigating Borders: Inside Perspectives on the Process of Human Smuggling into the Netherlands, IMISCOE-AUP Dissertations Series. Amsterdam: Amsterdam University Press.

Van Meeteren, M., M. Van San and G. Engbersen (2008), 'Zonder papieren': Over de positie van irreguliere migranten en de rol van het vreemdelingenbeleid in Belgie ['Without Papers': On the Position of Irregular Migrants and the Role of the Aliens Policy in Belgium]. Leuven: Acco.

Van San, M. (I998), Stelen en steken: Delinquent gedrag van Curaçaose jongens in Nederland [Stealing and Stabbing: Delinquency by Curaçaoan Youths in the Netherlands]. Amsterdam: Het Spinhuis.

Van San, M. (2002), 'Caring Mothers and Their 'Innocent' Sons: On Justifying the Criminal Behavior of Curaçaoan Youths in the Netherlands', Netherlands' Journal of Social Sciences 38 (3): 212-238.

Van San, M. and A. Leerkes (200I), Criminaliteit en criminalisering. Allochtone jongeren in België [Crime and Criminalisation. Allochthone Youth in Belgium]. Amsterdam: Amsterdam University Press.

Van San, M., E. Snel and R. Boers (2002), Woninginbrekers en zware jongens: Daders uit het voormalig Joegoslavië in beeld [Burglars and Tough Guys: A Portrait of Offenders from the Former Yugoslavia]. Zeist: Kerckebosch.

Van Tilburg, W. and J. Lammers (2004), Landelijke criminaliteitskaart 2003. Een analyse van geregistreerde misdrijven en verdachten op basis van HKS-gegevens [National Crime Map 2003. An Analysis of Documented Crimes and Suspects on the Basis of Police (HKS) Data]. Zoetermeer: KLPD-NRI. 
Van Tillaart, H. (200I), Monitor Etnisch Ondernemerschap 2000: Zelfstandig ondernemerschap van Etnische Minderheden in Nederland in de Periode 1990-2000 [Monitor Ethnic Entrepreneurship 2000: Entrepreneurship Among Ethnic Minorities in the Netherlands I990-2000]. Nijmegen: ITS.

Van Wilsem, J., K. Wittebrood and N. De Graaf (2006), 'Socioeconomic Dynamics of Neighborhoods and the Risk of Crime Victimization: A Multilevel Study of Improving, Declining, and Stable Areas in the Netherlands', Social Problems 53: 226-247.

Vanderveen, G. (2006), Interpreting Fear, Crime, Risk and Unsafety. Rotterdam: PhD thesis Erasmus University Rotterdam.

Veléz, M. (200I), 'The Role of Public Social Control in Urban Neighborhoods: A multilevel Analysis of Victimization Risk', Criminology 39: 937-864.

Visser, J. and R. Van Zevensbergen (200I), Illegale tewerkstelling verkend. Eindrapport [Illegal Labour Explored. Final Report]. The Hague: Ministry of Social Affairs and Employment.

Von Lampe, K. (2004), 'Making the Second Step Before the First: Assessing Organized Crime', Crime, Law \& Social Change 42: 227-259.

Wacquant, L. (200I), 'The Penalisation of Poverty and the Rise of Neo-Liberalism', European Journal on Criminal Policy and Research 9 (4): 40I-4I2.

Wacquant, L. (2006), Straf de armen: Het nieuwe beleid van de sociale onzekerheid [Punish the Poor: The New Policy of Social Insecurity]. Berchem: EPO.

Waddington, J., K. Stenson and D. Don (2004), 'In Proportion: Race, and Police Stops and Search', The British Journal of Criminology 44: 889-9I4.

Wagner, D. (2005), The Poorhouse: America's Forgotten Institution. Lanham: Rowman \& Littlefield Publishers.

Warner, W. (1936), 'American Caste and Class', American Journal of Sociology 42: 234-237.

Waters, T. (I999), Crime and Immigrant Youth. Thousand Oaks: Sage Publications.

Weber, M. (I947), Politics as a Vocation, Translated by H. Gerth and C. Wright Mills. New York: Oxford University Press.

Weenink, A. and S. Huisman (2003), 'Poolse bendes in Nederland; voorlopige bevindingen' [Polish Gangs in the Netherlands; Preliminary Results], Justitiële verkenningen 29 (4): 8I-9I.

Weenink, A., S. Huisman and F. Van der Laan (2004), Misdaad zonder grenzen: Criminaliteitsbeeld Centraal en Oost-Europa 2002-2003 [Crime without Borders: Crime Portrait Central and Eastern Europe 2002-2003]. Driebergen: KLPD.

Weerman, F. (I998), Het belang van bindingen: De bindingstheorie als verklaring van verschillen en veranderingen in delinquent gedrag [The Importance of Ties: The Social Control Theory as an Explanation for Differences and Changes in Delinquency]. Groningen: PhD thesis University of Groningen.

Weerman, F. (200I), Samenplegen: Over criminele samenwerking en groepsvorming [Co-offending: About Criminal Cooperation and Group Formation]. Nijmegen: Ars Aequi Libri.

Wei, E., A. Hipwell, D. Pardini, J. Beyers and R. Loeber (2005), 'Block Observations of Neighbourhood Physical Disorder are Associated with Neighbourhood Crime, Firearm Injuries and Deaths, and Teen Births', Journal of Epidemiology and Community Health 59: 904-908.

Werdmölder, H. (I997), A Generation Adrift: An Ethnography of a Criminal Moroccan Gang in the Netherlands. London / The Hague: Kluwer Law International.

Westerink, H. (2005), Wetenschap \& Beleid - 'Wetenschappers in dienst van het beleid tegen "illegalen"' [Science \& Policy - Scientists in Service of the Policy Against 'Illegals'], Agora: Ontmoetingsplatform voor wetenschap en samenleving op het gebied van de ruimtel ke ordening 2I (I): 20-23. 
Wittebrood, K. and P. Nieuwbeerta (2006), 'Een kwart eeuw stijging in geregistreerde criminaliteit' [A Rise in Documented Crime During a Quarter of a Century], Tijdschrift voor Criminologie 48 (3): 227-242.

Wolf, D. (I988), Undocumented Aliens and Crime: The Case of San Diego County. San Diego: University of California, Center for U.S.-Mexican Studies.

World Bank (2006), Global Economic Prospect. Economic Implications of Remittances and Migration. New York: World Bank.

Wray, H. (2006), 'The Aliens Act I905 and the Immigration Dilemma', Journal of Law and Society $33(2): 302-323$.

Wuertz, K. (I990), 'Verdwaald in eigen buurt: Onveiligheidsgevoelens in buurten en de rol van medebewoners' [Lost in the Neighborhood: Unsafe Feelings in Neighbourhoods and the Role of Co-residents], in F. Winkel and A. Van der Wurff, Angst voor criminaliteit. Theorie, onderzoek, interventie [Fear of Crime. Theory, Research, Intervention], 24926I. Amsterdam: Swets \& Zeitlinger.

Xu, Y., M. Fiedler and K. Flaming (2005), 'Discovering the Impact of Community Policing: The Broken Windows Thesis, Collective Efficacy, and Citizens' Judgment', Journal of Research in Crime and Delinquency 42: I47-I86.

Young, J. (I999), The Exclusive Society: Social Exclusion, Crime and Difference in Late Modernity. London: Sage.

Zaitch, D. (2002), Trafficking Cocaine: Colombian Drug Entrepreneurs in the Netherlands. The Hague: Kluwer Law International.

Zolberg, A. (2003), 'Guarding the Gates', online paper available at www.newschool.edu/ icmec/guardingthegates.html.

Zorbaugh, H. (1929), The Gold Coast and the Slum: A Sociological Study of Chicago's Near North Side. Chicago: University of Chicago Press.

Zuidam, M. and D. Grijpstra (2004), Over de Grens: Een onderzoek naar illegale activiteiten op het gebied van uitzendarbeid [Over the Border: A Research on Illegal Activities of Temporary Agencies]. Leiden: Research voor Beleid. 



\section{Summary}

\section{Research problem}

Western countries like the Netherlands pursue restrictive immigration policies in relation to people from non-Western countries. Policies aimed at making illegal residence unattractive are increasingly part of this. The Dutch 'illegals policy' is marked by an emphasis on institution exclusion of illegal migrants. These migrants are systematically excluded from social institutions such as the formal labour market, the housing market, social security benefits, education (except for minors) and most medical care.

In spite of, and indeed owing to, the restrictive immigration policy of which the illegals policy is only a part - illegal migrants represent a substantial segment of the population, particularly in certain urban neighbourhoods. It is estimated that I50,000 illegal migrants, or approximately I per cent of the total population, were living in the Netherlands in the period under study (I997-2005). In some urban neighbourhoods illegal migrants probably constituted 6 to 8 per cent of the residents. Illegal residence is prevalent in other Western countries as well.

The central question of this study is to what extent, and under which conditions, the residence and migration of illegal migrants impact public safety in the Netherlands, and to what extent aspects of immigration policy contribute to that.

The study focuses on illegal residence but also pays attention to the migration processes that precede it. It examines the extent to which the possible involvement of illegal migrants in crimes can be explained by the illegality of their residence and its potential consequences. Attention is also paid to more subjective aspects of safety and liveability. With an eye to that, the study examines the connection between illegal residence and rule observance and transgression in neighbourhood life, including the violation of unwritten social rules.

There are two main reasons for researching the relationship between illegal residence and public safety. First, practices of institutional exclusion may pressure the affected migrants into involvement in alternative 
and illegal means of migration and subsistence. Second, the risk of expulsion that is inherent in illegal residence is likely to impede rule violation among illegal migrants, as such migrants often try to minimise their chances of police contacts, as these may lead to expulsion.

As illegal residence is concentrated in a relatively limited number of deprived urban neighbourhoods it might be expected that the answer to the primary research question would differ according to the specific place or neighbourhood. Moreover, many perpetrators of crimes are particularly active in the vicinity of where they live. Subjective aspects of safety and liveability are also connected with the neighbourhood to a considerable extent. In addition, research on the spatial spreading of illegal residents could illuminate the social ties between illegal migrants and more established groups in society (see below for some of the reasons why such ties are important for understanding illegal residence in relation to public safety). This implies a second question: To what extent, and in what way, is illegal residence spatially concentrated within the Netherlands, how can patterns of spatial concentration and incorporation be explained, and what are the consequences of the spatial concentration of illegal residence for neighbourhood safety?

\section{Previous research and the contribution of the study}

This study builds on previous research into the social position of illegal migrants, both in the Netherlands and in other Western countries. In the Netherlands, in particular, a number of publications have focused on the relationship between illegality and criminality. A new element in this study is that a sizeable number of criminal illegal migrants were interviewed. An additional innovative aspect is that systematic comparisons were made with crime patterns among comparable migrant groups who have legal residence. Furthermore, theoretical insights from existing research on crime among legal migrants were also employed in greater measure; more attention was paid to cultural aspects in offending, and to the involvement of illegal migrants in criminal migration and crossborder crime, where offending is a migration motive. Some attention is also paid to the deliberate changing of immigration statuses by the state if a migrant is convicted of certain crimes in the country of destination. Legal migrants may be turned into illegal migrants for this reason, potentially adding to the total number of criminal illegal migrants.

Nationally and internationally there have been several studies that provide indications of the crucial factors in spatial settlement patterns of illegal migrants. These settlement patterns were researched systematically for the first time in this study. Finally, the effects of the concentrated presence of illegal migrants in certain residential areas for objective and subjective neighbourhood safety and liveability were examined 
for the first time. For this reason some attention is also paid to the relationship between illegal residence and patterns of transgression of (or compliance with) unwritten social rules in public space.

\section{Data sources}

Various types of data were used, mostly collected during two contract studies. One was financed by the Dutch Ministry of Housing. The other was commissioned by the independent research programme Police and Science, subsidised by the Ministry of Home Affairs. The Amsterdam School for Social Science Research made the writing of this PhD thesis possible.

The quantitative data consisted of police data on all illegal migrants who were apprehended in the Netherlands between January I997 and October 2003. Additionally, data files giving figures on social economic neighbourhood characteristics and aspects of neighbourhood safety and liveability. The Immigration and Naturalisation Service (IND) provided data on all foreigners who were declared undesirable aliens or who lost their residence permits between 1997 and 2003 because of criminal activities.

The qualitative data were twofold. First, fieldwork was carried out between 2003 and early 2006 in two neighbourhoods where illegal residence is relatively common, one in Rotterdam and one in The Hague. In total, twenty professionals, 70 illegal migrants, 45 landlords and IOI residents were interviewed. Second, in 2005, I interviewed 26 male illegal migrants with an asylum history and a record of offences. The latter interviews took place in the Aliens' Detention of the Tilburg Prison.

\section{Five sub-studies}

The data were used in five sub-studies, reports of which are collected in this book and constitute Chapters 2 through 6 . The chapters build on each other, but can nevertheless be read separately in combination with the introductory chapter.

- In the first sub-study, the patterns of spatial concentration and incorporation of illegal migrants in the Netherlands were described and explained by combining quantitative data with qualitative data from the two selected neighbourhoods.

- In the second sub-study, the connections between illegal residence and neighbourhood safety and liveability were analyzed. This was also done by methodological triangulation: quantitative results were compared with the findings of the fieldwork in Rotterdam and The Hague. 
- Using police data, the involvement in crime among illegal migrants aged twelve up to and including 24 from eleven countries of origin was compared to the patterns of crime among legal migrants of comparable age and country of origin.

- The fourth sub-study examined the choices made by criminal illegal migrants in interaction with the social conditions they were confronted with, partly as a result of their illegal residence status. Also, a typology of crime among illegal migrants is given.

- The number of crime suspects with illegal residence status rose substantially in the Netherlands from the middle of the I990s. In the fifth sub-study, six possible explanations for this rise are examined, using various quantitative data.

The chapters mentioned are preceded by an introductory chapter and rounded off by a concluding chapter that describes the main findings and discusses a number of implications for policy. The introduction describes the study's research problem in the light of previous research in this field. Dutch immigration policy is also discussed, as well as a number of other characteristics of Dutch society that are required for a good understanding of this study. It also goes into a number of ethical aspects of this study. Finally, it explains the relevance of the study for other Western countries.

\section{Central findings}

The study shows that some aspects of the patterns of rule violation and observation among illegal migrants, which are relevant for public safety, must be understood as a response to social conditions to which the Dutch restrictive immigration policy contributes. This is true for possible involvement in crimes, as well as for misdemeanours and transgressions of more informal social rules. Hence, this book's central claim: to understand rule violation by migrants today researchers should pay due attention to the governmental regulation of international migration and the ways in which these practices interact with semi-autonomous social forces from other segments of society.

The first reason for paying attention to these state practices is that the intensified regulation of international migration flows is, more or less by definition, coupled with new forms of illegality. Examples in point are entering or leaving a country without valid papers, not being able to show a valid ID after settlement, or not reporting to the aliens police after arrival. Second, there appear to be significant links between the institutional exclusion of illegal migrants and their involvement in more regular forms of rule violations such as theft, violence and drug traffick- 
ing. Yet, the latter relationships are complex: it turns out that a restrictive immigration policy does not have unambiguous consequences for public safety. Some aspects of public safety can be harmed under the influence of this policy, while other aspects benefit in comparison to the effects of legal residence. The study shows that in order to understand this complexity it is useful to make a distinction between various aspects of migration control, particularly between external border control and two main aspects of internal border control: institutional exclusion and secondary territorial exclusion.

On the one hand, the state's endeavour towards social exclusion promotes rule violation via the social mechanism of strain. People are more inclined to opt for illegal pathways according to the degree to which conventional means for fulfilling their aspirations are closed off. This holds true for illegal migrants as well. For instance, there is often a question of residence crime among such migrants. The aim of residence crime is to reside in the Netherlands or another Western country despite restrictive policies. Examples include travelling to or leaving the Netherlands with a false document, or endeavouring to evade controls by using someone else's ID. Furthermore, illegal migrants sometimes become involved in subsistence crime to satisfy social standards that are regarded as elementary by them and/or the social milieus they are, were, or want to be a part of. This is the more likely if illegal migrants are excluded from formal institutions in society that provide legal life chances such as the labour market and social housing. The principal variants of subsistence crime are: working with false documents, theft and dealing drugs in the streets. Strain that occurs under the influence of illegal residence status may also promote problematic drug use and incite forms of addiction-related crime, particularly in case of homelessness.

On the other hand, a restrictive immigration policy strengthens social control, since as long as the foreigner does not have legal residence status, he or she runs a constant risk that the social position in the country of settlement, even if this position is sometimes very marginal, will be forfeited. In line with social control theory, this second tendency of the state's endeavour towards the social exclusion of particular categories of migrants - secondary territorial exclusion - favours rule observance.

The latter tendency expresses itself in the observation that the documented crime rate among illegal migrants used to be substantially lower than among comparable legal migrants, before the institutional exclusion of illegal migrants took on its present shape. Further, it emerges from the low involvement of illegal migrants in expressive or symbolic crimes. In comparison to instrumental offences, in which the offence is primarily a means to a particular end, such as identity fraud, expressive crimes are more often an end in themselves, by which perpetrators express themselves, so to speak. Examples of crimes that are relatively rare 
among illegal migrants are violence against persons and goods. Besides this, there are indications that criminal illegal migrants are relatively likely to commit instrumental crimes that can be carried out surreptitiously and do not require contact with the victim.

It turns out that illegal residence has comparable differential effects on neighbourhood life; illegal migrants sometimes approach strangers in the street in the hope of finding a partner, since this would help them obtain a residence permit, while on the other hand the illegal residence status usually pressures them to observe formal and informal neighbourhood rules, such as the abatement of noise nuisance.

Western societies are increasingly characterised by ethnic, economic, and cultural diversity. This study makes it plausible that there are - concentrated in some neighbourhoods - several groups in the Netherlands who contest the legitimacy of the restrictive immigration policy, are negatively affected by it and/or have an interest in the weak social position of illegal migrants: (I) established non-Western migrant communities, (2) employers who depend on the secondary labour market and (3) singles with a foreign partner or an interest in such a partner. These three social actors, with whom many illegal migrants have or obtain social ties, lessen the success of the strict regulation of migration flows. Simultaneously, they influence the degree to which, and the way in which, illegal residence affects public safety.

As a rule, social ties weaken the first effect of the state's endeavour towards social exclusion, while they strengthen the second, that of social control, since it turns out that such ties often increase the degree of access to regular means of migration, such as travelling with a tourist visa, and subsistence, such as working in the informal economy, living with family, or finding a marriage partner via social networks instead of on the street. Therefore, they often decrease the degree of strain between migrants' aspirations and conventional opportunities. The risk of expulsion, on the other hand, appears to be of greater importance in the case of strong social ties, since an illegal migrant risks loosing these ties and the resources they give access to along with residence in the Netherlands.

Yet the social ties mentioned do not necessarily have a favourable effect on public safety. It turns out that illegal migrants and established inhabitants sometimes cooperate in crime. In addition, social ties that do not lend access to conventional means of subsistence sometimes increase the pressure to violate rules. With the help of crimes illegal migrants sometimes try to satisfy expectations connected to their parallel statuses, such as the status of father, son, or fiancé.

Social ties also influence the form that possible rule violation takes. Because of their embeddedness in established migrant communities, criminal illegal migrants have an elevated chance of involvement in 
types of crime that are relatively common among established countrymen. Moreover, migrants appear to develop forms of crime that they do not morally reject to any great extent, in comparison to other behavioural options. The weighing of behavioural alternatives appears to some degree to differ between and within groups of origin; illegal migrants partly decide for themselves which social ties they will enter into and which ties they would rather not develop.

Rule violation and/or rule observance among illegal migrants is not always an adaption to external and internal border controls. At the same time, this study shows that some crimes, such as sexual crimes or forms of criminal migration, are barely connected to the restrictive immigration policy, if at all. Some types of criminal migration turn out to presuppose relatively open borders. Similarly, while illegal migrants observe social rules because of the risk of expulsion, they have also internalised these rules as a result of previous socialisation in conventional social environments, and thus acknowledge their legitimacy.

The concluding chapter reflects on the theoretical outcomes of this study as a whole, and discusses a number of implications for policy. It ends by looking at the question of whether illegal migrants will or should be given a right to elementary social relief. 



\section{Samenvatting (summary in Dutch)}

\section{Probleemstelling}

Westerse landen zoals Nederland voeren een restrictief immigratiebeleid voor mensen uit niet-westerse landen. Beleid om illegaal verblijf onaantrekkelijk te maken maakt daarvan in toenemende mate deel uit. Het Nederlandse 'illegalenbeleid' kenmerkt zich door een nadruk op de institutionele uitsluiting van illegale migranten. Deze migranten worden systematisch uitgesloten van van maatschappelijke instituties zoals de formele arbeidsmarkt, de woningmarkt, het uitkeringenstelsel en het onderwijs (met uitzondering van minderjarigen) en de meeste medische zorg.

Ondanks en dankzij het restrictieve immigratiebeleid - waarvan het illegalenbeleid slechts een aspect is - vormen illegale migranten een substantieel deel van de bevolking, vooral in bepaalde stadsbuurten. In de onderzoeksperiode (I997-2005) woonden er naar schatting I50.000 illegale migranten in Nederland, of circa een procent van de totale bevolking. In sommige stadsbuurten liep dat percentage vermoedelijk op tot zes á acht procent. Illegaal verblijf komt ook in andere westerse landen op substantiële schaal voor.

De eerste hoofdvraag van deze studie is in hoeverre en onder welke omstandigheden het verblijf en de migratie van illegale migranten gevolgen heeft voor de openbare veiligheid in Nederland en in hoeverre de restrictieve immigratiepolitiek ten aanzien van deze groep daaraan bijdraagt.

De studie richt zich voornamelijk op illegaal verblijf en in mindere mate op het migratieproces dat er aan vooraf is gegaan. Er is in de eerste plaats nagegaan in hoeverre de eventuele betrokkenheid van illegale migranten bij misdrijven verklaard kan worden vanuit de onrechtmatigheid van het verblijf en de potentiële consequenties daarvan voor de migrant. Daarnaast is er aandacht voor meer subjectieve aspecten van veiligheid en leefbaarheid in de ontvangende samenleving. De studie gaat in dat verband tevens in op de relatie tussen illegaliteit en overtre- 
dingen in het buurtleven, waaronder overtredingen van ongeschreven sociale regels.

Er waren twee hoofdredenen om de relatie tussen illegaal verblijf en de openbare veiligheid te onderzoeken. Ten eerste kunnen praktijken van institutionele uitsluiting de 'getroffen' migranten aansporen tot betrokkenheid bij alternatieve en illegale middelen van migratie en bestaan. Ten tweede is het aannemelijk dat het risico op uitzetting dat inherent is aan illegaal verblijf juist een belemmering vormt voor regelovertreding. Dergelijke migranten zullen de kans op politiecontacten en uitzetting wellicht willen minimaliseren.

Aangezien illegaal verblijf geconcentreerd is in een relatief beperkt aantal stedelijke achterstandswijken kon verwacht worden dat het antwoord op de hoofdvraag zou verschillen per woonplaats en daarbinnen per buurt. Veel plegers van criminaliteit zijn namelijk vooral actief in de nabijheid van de eigen woning. Ook subjectieve aspecten van veiligheid en leefbaarheid zijn vaak buurtgebonden. Daarbij geeft onderzoek naar de ruimtelijke spreiding van illegaal verblijf zicht op de sociale bindingen tussen illegale migranten en meer gevestigde groepen in de samenleving (zie hierna over het belang daarvan voor een goed begrip van illegaal verblijf in relatie tot openbare veiligheid). Dit impliceerde een tweede hoofdvraag: In hoeverre en hoe is illegaal verblijf ruimtelijk geconcentreerd in Nederland, hoe kunnen de patronen van ruimtelijke concentratie en incorporatie worden verklaard en wat zijn gevolgen van de ruimtelijke concentratie van illegaal verblijf voor buurtveiligheid?

\section{Eerder onderzoek en bijdrage van deze studie}

In de studie is voortgebouwd op eerder onderzoek in binnen- en buitenland naar de maatschappelijke positie van illegale migranten. Zo waren er vooral in Nederland enkele publicaties verschenen over illegaliteit en criminaliteit. Nieuw is dat voor het eerst uitgebreid is gesproken met een groep delinquente illegale migranten. Daarnaast zijn voor het eerst systematische vergelijkingen gemaakt met de criminaliteitspatronen bij vergelijkbare migrantengroepen met rechtmatig verblijf. Ook is er in sterkere mate gebruik gemaakt van theoretische inzichten uit het onderzoek naar criminaliteit bij reguliere migranten. Zo is er meer aandacht voor culturele aspecten van criminaliteit en voor betrokkenheid van illegale migranten bij criminele migratie, waarbij het plegen van misdrijven over de grens een migratiemotief is. Daarnaast is er enige aandacht voor het bewust wijzigen van verblijfstitels door de staat ingeval een migrant is veroordeeld voor bepaalde misdrijven in het ontvangende land. Legale migranten kunnen om die redenen worden geherclassificeerd als illegale migranten, wat potentieel kan leiden tot een toename van het aantal criminele illegale migranten. 
Er waren nationaal en internationaal diverse studies met aanwijzingen over de ruimtelijke concentratie van illegale migranten en de determinanten daarvan. Daarnaar is in deze studie echter voor het eerst systematisch onderzoek gedaan. Ten slotte is voor het eerst onderzocht wat de effecten zijn van de geconcentreerde aanwezigheid van illegale migranten voor de lokale buurtveiligheid en -leefbaarheid.

\section{Gegevensbronnen}

Voor de studie is gebruik gemaakt van diverse gegevens, die merendeels verzameld werden bij twee opdrachtonderzoeken. Een onderzoek werd gefinancierd door het Ministerie van VROM. Het andere onderzoek was voor het onafhankelijke onderzoeksprogramma Politie en Wetenschap, dat gesubsidieerd wordt door het Ministerie van Binnenlandse Zaken. De Amsterdamse School voor Sociaal-Wetenschappelijk Onderzoek maakte het schrijven van dit proefschrift mogelijk.

De kwantitatieve gegevens betreffen politiegegevens over alle illegale migranten die in Nederland zijn aangehouden tussen januari I997 en oktober 2003. Voorts zijn databestanden verzameld met gegevens over sociaaleconomische buurtkenmerken en aspecten van (buurt)veiligheid en leefbaarheid. De Immigratie en Naturalisatiedienst (IND) stelde gegevens beschikbaar over alle vreemdelingen die vanaf 1997 tot en met 2003 ongewenst zijn verklaard of een verblijfsvergunning hebben verloren vanwege criminele activiteiten.

De kwalitatieve bronnen zijn tweeërlei. Ten eerste heeft er tussen 2003 en begin 2006 veldwerk plaatsgevonden in een Rotterdamse en Haagse buurt waar illegaal verblijf vrij veel voorkomt. Er werden in totaal 20 professionals, 70 illegale migranten, 45 huisbazen en Ior buurtbewoners geïnterviewd. Ten tweede heb ik in 2005 uitgebreid gesproken met 26 (mannelijke) illegale migranten met een asielachtergrond en een strafblad. De laatstgenoemde interviews hebben plaatsgevonden in de Vreemdelingenbewaring van de PI Tilburg.

\section{Vijf deelstudies}

Met de gegevens zijn vijf deelstudies verricht. De onderzoeksverslagen zijn in dit boek gebundeld en vormen de hoofdstukken twee tot en met zes. De hoofdstukken bouwen op elkaar voort, maar zijn zelfstandig leesbaar in combinatie met het inleidende hoofdstuk.

- In de eerste deelstudie zijn de patronen van ruimtelijke concentratie en incorporatie van illegale migranten in Nederland beschreven en verklaard door kwantitatieve gegevens te combineren met kwalitatieve gegevens uit de twee onderzoeksbuurten. 
- In de tweede deelstudie zijn de relaties tussen illegaal verblijf en buurtveiligheid en -leefbaarheid geanalyseerd. Dit is eveneens gebeurd door methodologische triangulatie waarin kwantitatieve gegevensbronnen werden vergeleken met de bevindingen uit het veldwerk in Rotterdam en Den Haag.

- In de derde deelstudie is op basis van politiegegevens de aard en omvang van de criminaliteit onder illegale migranten vergeleken met de patronen van criminaliteit onder vergelijkbare migranten met rechtmatig verblijf. Het betreft migranten uit elf herkomstlanden in de leeftijd van twaalf tot en met 24 jaar

- In de vierde deelstudie is op basis van de interviews in de Vreemdelingenbewaring onderzocht welke keuzes delinquente illegale mannen maakten in de maatschappelijke omstandigheden waarmee ze (mede) door de illegale verblijfsstatus werden geconfronteerd. Voorts wordt een aanzet gegeven voor een typologie van misdaad bij illegale migranten.

- In de vijfde deelstudie zijn op basis van diverse kwantitatieve gegevensbronnen zes mogelijke verklaringen getoetst voor de sterke toename van het aantal criminaliteitsverdachten met een illegale verblijfsstatus sinds het midden van de jaren negentig.

Deze vijf hoofdstukken worden voorafgegaan door een inleidend hoofdstuk en afgesloten met een hoofdstuk dat de centrale bevindingen beschrijft en daarnaast ingaat op een aantal beleidsimplicaties van deze studie. Het inleidende hoofdstuk geeft een nadere omschrijving van de probleemstelling van de studie in het licht van het eerdere onderzoek op dit terrein. Daarnaast wordt het Nederlandse immigratiebeleid besproken, evenals enkele overige kenmerken van de Nederlandse samenleving die voor een goed begrip van deze studie vereist zijn. Voorts wordt ingegaan op enkele ethische aspecten van deze studie. Tot slot wordt ingegaan op de relevantie van deze studie voor andere Westerse landen.

\section{Belangrijkste bevindingen}

De studie laat zien dat de patronen van regelovertreding en -naleving onder illegale migranten, voor zover die relevant zijn voor de openbare veiligheid, voor een substantieel deel begrepen moeten worden als een reactie op omstandigheden waarin de Nederlandse restrictieve immigratiepolitiek een aandeel heeft. Dit geldt voor de eventuele betrokkenheid bij misdrijven en overtredingen evenals voor de patronen van naleving en overtreding van meer informele sociale regels. De studie laat daarmee zien dat het voor een goed begrip van regelovertreding bij migranten nodig is om oog te hebben voor de wijze waarop overheden in bes- 
temmingslanden internationale migratiestromen reguleren, en de wijze waarop die praktijken in wisselwerking staan met sociale krachten vanuit andere, relatief autonome maatschappelijke segmenten.

De eerste reden om aandacht te hebben voor deze overheidspraktijken is dat de regulering van internationale migratie nieuwe vormen van illegaliteit met zich meebrengt. Voorbeelden daarvan zijn het inreizen or verlaten van een land zonder geldige papieren, het zich niet kunnen identificeren, of het niet melden bij de Vreemdelingenpolitie na vestiging. Ten tweede blijken er relaties te bestaan tussen deze praktijken en meer commune vormen van regelovertreding zoals diefstal, geweld en drugshandel. De laatstgenoemde relaties zijn echter complex. Het restrictieve immigratiebeleid blijkt geen eenduidige gevolgen te hebben voor de openbare veiligheid. Sommige aspecten ervan kunnen onder invloed van deze politiek onder druk komen te staan, terwijl andere aspecten er juist door worden begunstigd in vergelijking met rechtmatig verblijf. Deze studie leert dat het zinvol is om een onderscheid te maken tussen afzonderlijke aspecten van migratiecontrole, in het bijzonder tussen externe grenscontrole en twee hoofdtypen van interne grenscontrole: 'institutionele uitsluiting' en 'secondaire territoriale uitsluiting' noem.

Enerzijds stimuleert het statelijke streven naar sociale uitsluiting regelovertreding via het zogenoemde strainmechanisme. Mensen zijn sterker geneigd om illegale paden te betreden naarmate de reguliere wegen tot de doelen die zij voor ogen hebben, zijn afgesloten. Dit geldt eveneens voor illegale migranten. Zo is er onder hen vaak sprake van verblijfscriminaliteit. Dit zijn misdrijven die erop zijn gericht om in een rechtsgebied te verblijven ondanks het restrictieve beleid. Voorbeelden daarvan zijn Nederland in- of uitreizen met een vervalst reisdocument of het zich legitimeren met een document van een ander. Daarnaast proberen illegale migranten soms met bestaanscriminaliteit te voldoen aan sociale standaarden die door henzelf en/of de milieus waaraan ze deel (willen) hebben of hadden als elementair worden beschouwd. De kans daarop neemt toe naarmate illegale migranten zijn uitgesloten van formele instituties in de samenleving die legale levenskansen verschaffen zoals de arbeidsmarkt en het systeem van sociale huisvesting. De voornaamste varianten van bestaanscriminaliteit zijn werken met valse papieren, diefstal en straathandel in drugs. Voorts komt het voor dat strain onder invloed van een illegale verblijfsstatus problematisch druggebruik stimuleert en zodoende verslavingsgerelateerde criminaliteit in de hand werkt.

Anderzijds versterkt de restrictieve immigratiepolitiek externe sociale controle. Zolang de vreemdeling geen verblijfsrecht heeft, bestaat immers het risico dat de verworven maatschappelijke positie in het vestigingsland, ook al is die soms zeer marginaal, moet worden prijsgegeven. 
Zoals op grond van de sociale controle theorie te verwachten is, stimuleert die tweede tendentie van het statelijke streven naar sociale uitsluiting ('secondaire territoriale uitsluiting') doorgaans regelnaleving.

Die tendentie komt ten eerste tot uitdrukking in de waarneming dat de geregistreerde criminaliteit bij illegale migranten aanvankelijk lager was dan onder vergelijkbare legale migranten, toen de institutionele uitsluiting van illegale migranten nog minder vorm had gekregen. Daarnaast toont deze tendentie zich in de relatief lage betrokkenheid van illegale migranten bij zogeheten expressieve misdrijven, waarin de dader zichzelf als het ware uit. Dit in tegenstelling tot meer instrumentele misdrijven waarin het delict in sterkere mate een middel is tot een doel dat buiten het misdrijf zelf is gelegen. Voorbeelden van misdrijftypen die onder illegale migranten beperkt voorkomen zijn geweld tegen personen en goederen. Daarnaast zijn er aanwijzingen dat criminele illegale migranten een relatief grote kans hebben om betrokken zijn bij misdrijftypen die heimelijk uitgevoerd kunnen worden en geen contact met het slachtoffer vereisen.

Het restrictieve immigratiebeleid blijkt soortgelijke differentiële effecten te sorteren in het buurleven. Enerzijds spreken illegale migranten op straat soms ongevraagd onbekenden aan om een partner te vinden voor een verblijfsvergunning. Anderzijds dringt de illegale verblijfsstatus meestal tot een sterke mate van naleving van formele en informele buurtregels, bijvoorbeeld op het gebied van geluidsoverlast.

Westerse samenlevingen kenmerken zich in toenemende mate door etnische, economische en culturele diversiteit. De studie maakt aannemelijk dat er in Nederland diverse groepen zijn die de legitimiteit van het restrictieve immigratiebeleid betwisten, door deze politiek in hun belangen worden getroffen en/of baat hebben bij een zwakke maatschappelijke positie van illegale migranten. Het betreft: (I) gevestigde niet-westerse migrantengemeenschappen, (2) werkgevers, vooral als zij aangewezen zijn op de secondaire arbeidsmarkt en (3) singles met een buitenlandse partner of belangstelling daarvoor. Deze drie sociale actoren, waarmee veel illegale migranten in meer of mindere mate sociale bindingen hebben of verwerven, verminderen de mate waarin de overheidsregulering van migratiestromen succesvol is. Tegelijkertijd bepalen ze mede in hoeverre en hoe die politiek gevolgen heeft voor de openbare veiligheid.

Als regel verzwakken de genoemde sociale bindingen de potentiële criminogene effecten van het statelijke streven naar sociale uitsluiting, terwijl ze de tendentie tot regelnaleving die ervan uitgaat, juist versterken. Dergelijke bindingen geven vaak indirect toegang tot reguliere middelen van migratie (zoals reizen met een toeristenvisum) en bestaan (zoals werken in de informele economie, inwonen bij familie, het via via vinden van een huwelijkspartner in plaats van op straat). Zo verminde- 
ren ze doorgaans de strain tussen legale gedragsmogelijkheden en gedragsdoelen. Het risico van uitzetting lijkt door deze bindingen juist van grotere betekenis te zijn, aangezien een illegale vreemdeling riskeert om naast het verblijf ook deze sociale bindingen te verliezen.

Sociale bindingen met gevestigden blijken niet per definitie een gunstig effect te hebben voor de openbare veiligheid. Soms is er tussen illegale migranten en gevestigde inwoners sprake van criminele samenwerking. Bovendien blijken sociale bindingen de druk tot regelovertreding te kunnen vergroten, althans indien ze geen toegang geven tot conventionele bestaansmiddelen. Het komt voor dat illegale migranten met misdrijven proberen te voldoen aan de verwachtingen die verbonden zijn met hun 'nevenstatussen', zoals de status van vader, zoon of verloofde.

De genoemde sociale bindingen beïnvloeden tevens de vorm die eventuele regelovertreding aanneemt. Door hun inbedding in gevestigde migranten-gemeenschappen hebben delinquente illegale migranten bijvoorbeeld een verhoogde kans op betrokkenheid bij een misdrijfsoort die relatief gangbaar is onder gevestigde landgenoten. Daarbij komt dat migranten in reactie op strain juist die vormen van delinquent gedrag lijken te ontwikkelen die zij moreel beperkt afwijzen in vergelijking met overige waargenomen gedragsalternatieven. De weging van gedragsalternatieven lijkt tussen en binnen herkomstgroepen deels te verschillen. Zo bepalen illegale migranten zelf mede welke sociale bindingen zij aangaan, en welke liever niet.

Regelovertreding en -naleving onder illegale migranten is niet altijd een aanpassing aan externe en interne grenscontrole. De studie laat tegelijkertijd zien dat bepaalde misdrijven, zoals seksuele misdrijven of vormen van criminele migratie, waarin een dader migreert om misdrijven te plegen, niet of nauwelijks verband houden met het restrictieve immigratiebeleid. Bepaalde vormen van criminele migratie blijken juist relatief open grenzen te veronderstellen. Evenzo houden illegale migranten zich niet primair vanwege het risico op uitzetting aan sociale regels die openbare veiligheid helpen waarborgen. Ze hebben deze regels door eerdere socialisatie in conventionele kringen veelal verinnerlijkt en onderschrijven vaak de legitimiteit ervan.

Het afsluitende hoofdstuk beschrijft de voornaamste theoretische conclusies van de studie als geheel en gaat daarnaast in op een aantal belangrijke beleidsimplicaties ervan. Het boek wordt afgesloten met een discussie over de vraag in hoeverre illegale migranten een recht op elementaire opvang zullen of zouden moeten krijgen. 



\section{Other IMISCOE titles}

\section{IMISCOE Research}

Rinus Penninx, Maria Berger, Karen Kraal, Eds.

The Dynamics of International Migration and Settlement in Europe:

A State of the Art

2006 (ISBN 9789053568668 )

(originally appearing in IMISCOE Joint Studies)

Leo Lucassen, David Feldman, Jochen Oltmer, Eds.

Paths of Integration: Migrants in Western Europe (1880-2004)

2006 (ISBN 978905356883 5)

Rainer Bauböck, Eva Ersbøll, Kees Groenendijk, Harald Waldrauch, Eds. Acquisition and Loss of Nationality: Policies and Trends in 15 European Countries, Volume 1: Comparative Analyses 2006 (ISBN 978905356920 7)

Rainer Bauböck, Eva Ersbøll, Kees Groenendijk, Harald Waldrauch, Eds. Acquisition and Loss of Nationality: Policies and Trends in 15 European Countries, Volume 2: Country Analyses 2006 (ISBN 978905356 921 4)

Rainer Bauböck, Bernhard Perchinig, Wiebke Sievers, Eds.

Citizenship Policies in the New Europe

2007 (ISBN 978905356922 I)

Veit Bader

Secularism or Democracy? Associational Governance of Religious Diversity 2007 (ISBN 9789053569993 ) 
Holger Kolb \& Henrik Egbert, Eds.

Migrants and Markets: Perspectives from Economics and the Other Social Sciences 2008 (ISNB 9789053566848 )

Ralph Grillo, Ed.

The Family in Question: Immigrant and Ethnic Minorities in Multicultural Europe 2008 (ISBN 9789053568699 )

Corrado Bonifazi, Marek Okólski, Jeannette Schoorl, Patrick Simon, Eds. International Migration in Europe: New Trends and New Methods of Analysis 2008 (ISBN 978905356894 I)

Maurice Crul, Liesbeth Heering, Eds.

The Position of the Turkish and Moroccan Second Generation in Amsterdam and Rotterdam: The TIES Study in the Netherlands 2008 (ISBN 978908964 06I I)

Marlou Schrover, Joanne van der Leun, Leo Lucassen, Chris Quispel, Eds.

Illegal Migration and Gender in a Global and Historical Perspective 2008 (ISBN 978908964047 5)

Gianluca P. Parolin

Citizenship in the Arab World: Kin, Religion and Nation-State 2009 (ISBN 978908964045 I)

Rainer Bauböck, Bernhard Perchinig, Wiebke Sievers, Eds. Citizenship Policies in the New Europe: Expanded and Updated Edition 2009 (ISBN 978908964 I08 3)

\section{IMISCOE Reports}

Rainer Bauböck, Ed.

Migration and Citizenship: Legal Status, Rights and Political Participation 2006 (ISBN 978905356888 o)

Michael Jandl, Ed.

Innovative Concepts for Alternative Migration Policies:

Ten Innovative Approaches to the Challenges of Migration in the 21st Century 2007 (ISBN 978905356990 0) 
Jeroen Doomernik, Michael Jandl, Eds.

Modes of Migration Regulation and Control in Europe

2008 (ISBN 9789053566893 )

Michael Jandl, Christina Hollomey, Sandra Gendera, Anna Stepien,

Veronika Bilger

Migration and Irregular Work In Austria: A Case Study of the Structure and Dynamics of Irregular Foreign Employment in Europe at the Beginning of the $21^{\text {st }}$ Century

2008 (ISBN 9789089640536 )

Heinz Fassmann, Ursula Reeger, Wiebke Sievers, Eds.

Statistics and Reality: Concepts and Measurements of Migration in Europe 2009 (ISBN 9789089640529 )

Karen Kraal, Judith Roosblad, John Wrench, Eds.

Equal Opportunities and Ethnic Inequality in European Labour Markets:

Discrimination, Gender and Policies of Diversity

2009 (ISBN 978908964 I26 7)

\section{IMISCOE Dissertations}

Panos Arion Hatziprokopiou

Globalisation, Migration and Socio-Economic Change in Contemporary

Greece: Processes of Social Incorporation of Balkan Immigrants in

Thessaloniki

2006 (ISBN 9789053568736 )

Floris Vermeulen

The Immigrant Organising Process: Turkish Organisations in Amsterdam and Berlin and Surinamese Organisations in Amsterdam, 1960-2000 2006 (ISBN 978905356875 ㅇ)

Anastasia Christou

Narratives of Place, Culture and Identity:

Second-Generation Greek-Americans Return 'Home'

2006 (ISBN 978905356878 I)

Katja Rušinović

Dynamic Entrepreneurship: First and Second-Generation Immigrant

Entrepreneurs in Dutch Cities

2006 (ISBN 9789053569726 ) 
Ilse van Liempt

Navigating Borders: Inside Perspectives on the Process of Human Smuggling into the Netherlands

2007 (ISBN 9789053569306 )

Myriam Cherti

Paradoxes of Social Capital: A Multi-Generational Study of Moroccans in London

2008 (ISBN 978905356032 7)

Marc Helbling

Practising Citizenship and Heterogeneous Nationhood: Naturalisations in Swiss Municipalities

2008 (ISBN 978908964034 5)

Inge Van Nieuwenhuyze

Getting by in Europe's Urban Labour Markets: Senegambian Migrants'

Strategies for Survival, Documentation and Mobility

2009 (ISBN 9789089640505 )

Nayla Moukarbel

Sri Lankan Housemaids in Lebanon: A Case of 'Symbolic Violence' and 'Every Day Forms of Resistance'

2009 (ISBN 978908964 051 2)

Jérôme Jamin

L'imaginaire du complot: Discours d'extrême droite en France et aux

Etats-Unis

2009 (ISBN 978908964048 2)

John Davies

'My Name Is Not Natasha': How Albanian Women in France Use

Trafficking to Overcome Social Exclusion (1998-2001)

2009 (ISBN 978905356707 4)

João Sardinha

Immigrant Associations, Integration and Identity: Angolan, Brazilian and Eastern European Communities in Portugal

2009 (ISBN 9789089640369 )

Dennis Broeders

Breaking Down Anonymity: Digital Surveillance of Irregular Migrants in Germany and the Netherlands 2009 (ISBN 978908964 I59 5) 
Jennifer Leigh McGarrigle

Understanding Processes of Ethnic Concentration and Dispersal: South Asian Residential Preferences in Glasgow

2009 (ISBN 978905356 67I 8) 
